U. S. DEPARTMENT OF COMMERCE

W. AVERELL HARRIMAN, Secretary

NATIONAL BÚREAU OF STANDARDS

E. U. CONDON, Director

NATIONAL BUREAU OF STANDARDS MISCELLANEOUS PUBLICATION M177

\title{
TESTS OF INSTRUMENTS FOR THE DETERMINATION, INDICATION, OR RECORDING OF THE SPECIFIC GRAVITIES OF GASES
}

By

FRANCIS A. SMITH, JOHN H. EISEMAN, AND E. CARROLL CREITZ

Issued January 20, 1947

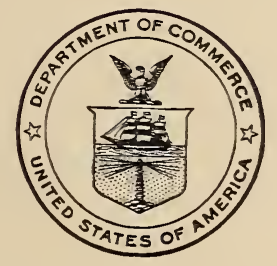

UNITED STATES

GOVERNMENT PRINTING OFFICE

WASHINGTON : 1947

For sale by the Superintendent of Documents, U. S. Government Printing Office Washington 25, D. C. - Price $\$ 1.00$ 


\section{PREFACE}

At the request of the American Society for Testing Materials, a critical study was made of the commercial instruments for the determination of the specific gravities of gases. Eleven different instruments were studied with the use of 15 test gases of known specific gravities. Determinations were made of the accuracy and reproducibility, of the effects of changes of temperature, relative humidity and water content of the surrounding air, and of sources of error and applicable corrections. It is believed that the results herein presented will be of considerable value to those requiring accurate data on the specific gravities of gases.

E. U. Condon, Director. 


\title{
TESTS OF INSTRUMENTS FOR THE DETERMINATION, INDICATION, OR RECORDING OF THE SPECIFIC GRAVITIES OF GASES
}

\author{
By Francis A. Smith, John H. Eiseman, and E. Carroll Creitz
}

\section{ABSTRACT}

At the request of the American Society for Testing Materials, the National Bureau of Standards completed in 1941 a critical study of instruments available to industry for the determination, indication, or recording of the specific gravities of gases. Instruments were submitted for test by all interested manufacturer:s.

The study of 11 instruments, with 15 test gases of known specific gravities, comprised determinations of accuracy and reproducibility, of the effects of changes of temperature, relative humidity and water content of the surrounding air, and of sources of error and applicable corrections. The test gases ranged in specific gravity from helium $(0.15)$, in steps of approximately 0.15 , to butane (2.06). The probable errors in the ralues of the specific gravities of the test gases and mixtures used as standards of reference averaged \pm 0.00004 , which made it possible to fix the errors of the instruments to 0.0001 specific gravity unit.

No attempt was made to evaluate the instruments (which differ markedly in type and applicability) relative to one another, but the error of each instrument with each test gas, with and without the application of corrections, is presented in tables and graphs. With the aid of these, the prospective user may determine from the characteristics exhibited the instrument best aclapted to his specific purpose.

Suggestions for the improvement of the instruments made to the manufacturers may indicate to the reader the direction in which improvement may be anticipated when restrictions imposed by the war are removed.

CONTENTS

Page

Preface

I. Introduction

1. History of the project

2. Definitions

II. Equipment_.....

1. Laboratory facilities

(a) Storage of the test gases

(b) Air-conditioned laboratory $\ldots$

(c) Reference air

2. Test gases

(a) Preparation 8

(b) Accurate determination of reference specific gravity - - 8

(c) Apparatus employed and its accuracy

(d) Constant-temperature bath

(e) Specific gravities of test gases

3. Instruments studied

III. Plan of the tests

1. Methods

(a) Treatment of the results 13 
III. Plan of the tests-Continued

2. Corrections applicable and their evaluation

Page

and their evaluation

(a) Reference air

(b) Adjustment of observations for humidity and carbon dioxide

(c) Pressure corrections

(d) Correction for deviation from ideal gas

(e) Chart corrections

IV. Results of tests of individual instruments 1. Pressure balances

(a) Construction and operation

(1) Edwards gas density balance.

(A) Description

(B) Modifications for testing

(C) Method of operation

(2) Ac-Me balances

(A) Description

(B) Modifications for testing

(C) Method of operation

(b) Results of observations

(c) Sources of error

(1) Temperature coefficients

(2) Variations of temperature

(3) Material tested

(4) Measurement of absolute pressure

(5) Balancing the beam

(A) Edwards balance

(B) Ac-Me Junior balance No. $4041 .--$

(C) Ac-Me balance No. 3511

(6) Leveling ..........

(d) Suggestions for improvement of instruments

(1) Edwards balance

(2) Ac-Me Junior balance No. 4041

(3) Ac-Me balance No. 3511

2. Anubis portable gas balance...

(a) Description

47

(b) Method of operation

(c) Reference air ..... 50

(d) Numerical results _... 52

(e) Mechanical action of the Anubis balance...... 52

(f) Leveling the balance

(g) Temperature coefficient

(h) Other probable sources of error

(1) Air-check correction

(2) Calibration $\ldots \ldots$

(3) Purity of material tested

(4) Determination of balance point of beam _... 59

(5) Pressure determinations . . . . _........ 60

(6) Temperature determinations

(7) Gas-law corrections _................ 61

(i) Comments on operation and some suggestions for improvement

3. Ac-Me recording gravitometer No. 271

(a) Description

(b) Modifications for purposes of tests

(c) Method of operation

(d) Correction for effect of relative humidity on chart

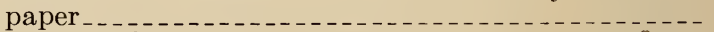

(e) Reference air.

(f) Correction for water vapor and carbon dioxide in ref-

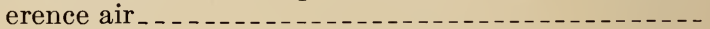

(g) Sources of error

(1) Temperature coefficient

(2) Humidity coefficient

(3) Accuracy of readings............

(4) Material tested 
IV. Results of tests of individual instruments - Continued

3. Ac-Me recording gravitometer No. 271-Continued

(g) Sources of error-Continued

(5) Sealing liquid .

(6) Volume of float..... 73

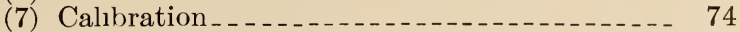

(8) Temperature changes

(9) Temperature and pressure compensator..... 74

(10) Mechanical effects_................ 75

(h) Comments on operation and some suggestions for im-

4. Anubis recording gas gravitometer

(a) Description

(b) Modifications for purposes of tests

(c) Method of operation

(d) Sources of error

(1) Accuracy of reading

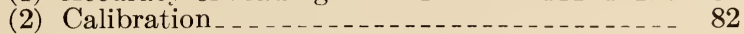

(3) Effects of gravitational forces which change with the position of the mechanism

(4) Gas column

(5) Leveling of instrument.

(6) Weight of ink in pen

(7) Temperature coefficient

(8) Temperature lag

(9) Properties and changes of the sealing oil _... 89

(10) Humidity coefficient .............. 90

(11) Effect of relative humidity on chart_..... 92

(12) Barometric pressure $\ldots \ldots$

(13) Reference air

(e) Comments on operation and suggestions for improvement

5. Sigma recorder No. 7 for specific gravity

(b) Modifications for testing

(c) Method of operation

(d) Correction for composition of reference air

(e) Correction for effect of humidity on chart $\ldots \ldots \ldots$

(f) Temperature coefficient_._.

(g) Humidity coefficient _._.

(h) Other sources of erro

(1) Accuracy of readings

(2) Position of chart $\ldots$

(3) Material tested $\ldots \ldots$

(4) Effect of flame

(5) Height of gas column $\ldots$

(6) Rate of sampling .

(7) Temperature lag

(8) The test weight

(9) Sealing oil _... 105

(10) Oil level $\ldots$

(11) Immersion error $\ldots$

(12) Pendulum weight

(13) Oil in pneumatic compensator........ 106

(i) Comments on operation and suggestions for improvement . .

6. Metric indicating gravitometer

(a) Description

(b) Modifications for testing

(c) Method of operation 109

(d) Correction for composition of reference air...... 110

(e) Temperature coefficient $\ldots$

(f) Humidity coefficient 
IV. Results of tests of individual instruments-Continued

6. Metric indicating gravitometer-Continued Page

(g) Other sources of error

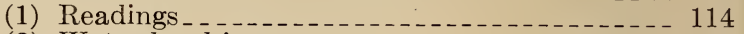

(2) Water level in manometers

(3) Material tested

(h) Comments on operation and suggestions for improvement _. .

7. Ranarex specific gravity recorder No. A2360 and portable specific gravity indicator No. P1284__._.

(a) Description

(b) Modifications for testing

(c) Method of operation

(d) Sources of error

(1) Temperature coefficient.

(2) Pressure differences ...................... 127

(3) Purging

(4) Leaks

(5) Calibration

(6) Viscosity

(7) Readings .

(8) Effect of relative humidity on the chart

(e) Comments on operation and suggestions for improvement

8. Fisher densimeter (experimental model)

(a) Introduction

(b) Description

(c) Method of operation

(d) Sources of error

(1) Temperature coefficient

(2) Pressure changes

(3) Absolute pressure

(4) Changes of water temperature

(5) Material tested

(6) Errors in timing

(7) Errors of the observer

(e) Comments on the operation and some suggestions for improvement.

V. Discussion

1. Interpretation of the results of tests

\section{INTRODUCTION}

\section{HISTORY OF THE PROJECT}

At the request of the American Society for Testing Materials, the National Bureau of Standards undertook a study of instruments available to industry for the determination, indication, or recording of the specific gravity of gases. E. F. Schmidt, chairman of the ASTM Subcommittee D-3-IV (on specific gravity of gaseous fuels), negotiated the loan of instruments to be tested, and the National Bureau of Standards furnished the equipment and personnel and conducted the tests.

Announcement of the proposed tests was made in the Technical News Bulletin of the, National Bureau of Standards in November 1938, inviting all interested manufacturers to submit instruments for the tests. This was done to avoid the possibility of excluding any interested manufacturer from participation and to secure as complete a collection of representative instruments as possible. 
After all preparations had been made for the testing, but before the tests were actually started, each manufacturer was invited to send a representative to inspect the installation and testing program and to offer suggestions particularly, of course, regarding his own instrument. Three of the seven availed themselves of this opportunity.

A copy of the report on the instrument or instruments submitted by him was sent to each of the cooperating manufacturels on October 18,1941 , with the request that he indicate any errors which he found in the report. Replies were received from the manufacturers of all the instruments except the Sigma.

A complete report of 240 typewritten pages was made on February 2, 1942, to ASTM Committee D-3 on Gaseous Fuels. This report, although accurate and complete, was somewhat hastily compiled from the seven separate reports previously made to manufacturers, and was full of repetitions and otherwise unsuitable for printing. In the meantime, the authors of the report had become fully engaged in war work and were unable to spare the time for a satisfactory revision until recently.

Although the experimental work was completed in August 1941, it is doubted that much has been done on the further development of the instruments by their manufacturers, who also have had other things to do. The information is probably not seriously out of date for this reason.

Numerous suggestions were made to the manufacturers in the reports sent to them individually in 1941, and almost without exception, they indicated that the recommendations would be accepted. Although the changes suggested should considerably improve convenience and minimize minor random errors in nearly all instruments, they probably will not result in important changes in the accuracy generally attainable, except in the case of the Anubis instruments, balance and recorder, in both of which the changes are expected to eliminate the sources of relatively large systematic errors in otherwise excellent instruments.

\section{DEFINITIONS}

For the purposes of this report, the following definitions are used: Density is the mass per unit volume of the substance considered (gas or air).

Gas is the material to be tested, as sampled, without change of composition by drying, or otherwise.

Specific gravity of a gas is the ratio of the density of the gas, under observed conditions of temperature and pressure, to the density of air (dried and freed from carbon dioxide) at the same temperature and pressure (usually $1 \mathrm{~atm}$ ) as the gas.

In this report, unless otherwise stated, no corrections are made for deviations from the temperature and pressure relations of ideal gases; hence, the specific gravity of a gas at one temperature and pressure is considered to be the same as at any other temperature and pressure.

For purposes of convenience in maintaining a test mixture of constant specific gravity and in determining that specific gravity by the independent method described later, (section II, 2) the test gases were all dry. In actual practice, the gas to be tested may contain 
more or less water vapor as distributed and used. The specific gravity of such gases should be determined without drying the gas. Or, if drying is necessary to avoid condensation, the water content should be determined and the specific gravity of the dried gas corrected by computation to the value it would have had if the gas had not been dried. (It is impracticable to determine the specific gravity of any gas at a temperature below the temperature of saturation of any of its vapor constitutents. In general, therefore, before entering the testing apparatus a fuel gas from either a manufacturing plant or a natural source must be exposed to a lower temperature or higher pressure, or both, than will exist in the testing equipment. It may be necessary to filter out fog at the condenser.)

In order to provide a reproducible and unchanging standard of reference by which all specific-gravity data may be placed on a common basis for comparison, whatever their source, the specific gravity of each test gas was determined with reference to air that is dry and free from carbon dioxide.

\section{EQUIPMENT}

\section{LABORATORY FACILITIES}

(a) STORAGE OF THE TEST GASES

All the test gases were stored in a steel tank of approximately 35 -cu-ft capacity, tested to $500 \mathrm{lb} / \mathrm{in.}^{2}$, and withdrawn as needed

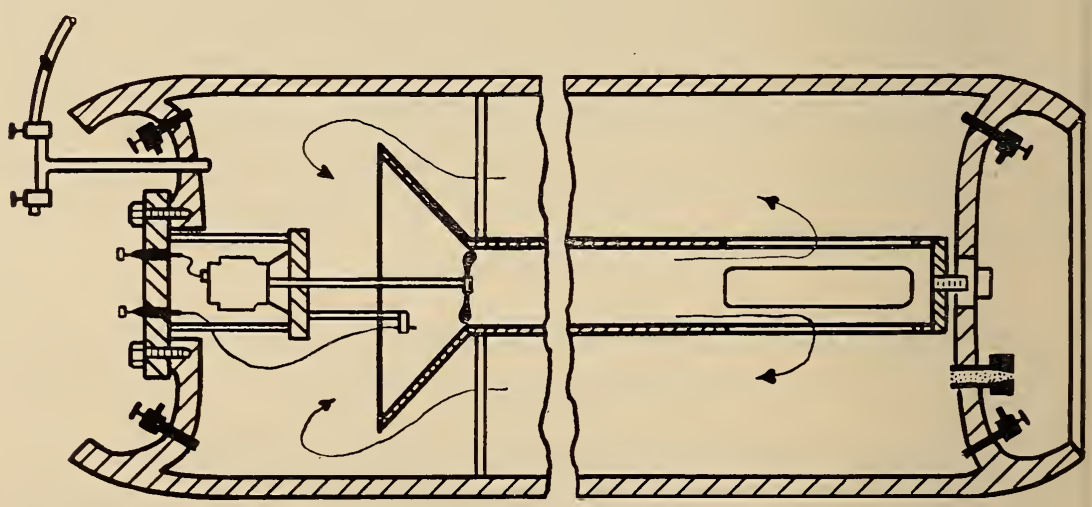

FIgURE 1.-Diagram of mixing and storage tank.

(fig. 1). A motor and fan within the tank provided good circulation well directed by a 6 -in. pipe arranged as a "wind tunnel." Four thermocouples in parallel were distributed in the air stream between the rim of the funnel and the fan to measure the temperature of the gas. Spark plugs with long center terminals conducted the electric leads to the motor and thermocouples through the cover plate. The tank was mounted horizontally, and needle valves were located at the top and bottom of each end, from which to sample the mixture for analysis by a gas interferometer (Zeiss $1 \mathrm{~m}$ ) to determine when mixing was complete. 
Gas was introduced and withdrawn through a single opening in the end of the tank above the cover plate. This opening was fitted with a tee connected to two diaphragm packless valves, one for discharging the discarded residue of a mixture and the other connected to the line to the laboratory.

All connections for the evacuation of the tank and for drying, introducing, and withdrawing gases and distributing them to testing equipment and individual specific-gravity instruments were of copper tubing with soldered fittings and "packless" diaphragm valves or needle valves with vacuum-tight packing, except that instruments equipped by their manufacturers with hose-nipple inlets were connected to the system with minimum lengths of heavy rubber tubing.

After the tank and lines had been tested to establish freedom from leaks, they were repeatedly evacuated and filled with air dried over calcium chloride until the tank was thoroughly dry. The tank was then evacuated. The gases used in making the test mixtures were as pure as could be obtained without undue expense, and were introduced from cylinders at one of the manifold connections. As the gases were introduced they were dried, to avoid the possible condensation of water in the storage tank, by passing them through a dehydrator containing $1.13 \mathrm{lb}$ of freshly activated alumina, at a rate not in excess of $10 \mathrm{cu} \mathrm{ft} / \mathrm{hr}$. Before samples were withdrawn from the tank for the tests, the alumina was removed from the line to avoid any change of composition that might have resulted from selective absorption of any constituent of the mixtures.

\section{(b) AIR-CONDITIONED LABORATORY}

In order to avoid variations of possible importance during testing and to determine the effects of both temperature and humidity on the specific-gravity measurements, the laboratory was air conditioned. In order to place the results obtained over an extended period of time on a common basis, all the instruments were tested at $25^{\circ} \mathrm{C}\left(77^{\circ} \mathrm{F}\right)$, and those affected by the water content of the laboratory air were tested with the air containing 1.1 percent of water vapor, corresponding to a relative humidity of 35 percent at $77^{\circ} \mathrm{F}$. Other temperatures and humidities were employed when some of the test gases were used to establish the effect of the changes. In all cases, ample time was allowed for the temperature and water content of the air of the laboratory to become steady and for the instruments to reach equilibrium with them before testing was started.

(c) REFERENCE AIR

Several of the instruments used the air surrounding them as a standard of reference, and several discharged the gas sample into the surrounding air. It was therefore necessary to prevent the contamination of the air in the laboratory by gas discharged from the instruments. For this purpose an exhaust fan was provided, with ducts arranged to pick up the gas at the point of discharge from the instruments involved. No direct connections to the instruments were made, and dampers in the ducts were adjusted to provide ample flow without affecting the indications of the instruments. For instru- 
ments purged by evacuation, the gas was discharged from a vacuum pump located in the adjoining laboratory, and the reference air was drawn through a copper tube from the outside, on the (normally) windward side of the building.

\section{TEST GASES \\ (a) PREPARATION}

The test gases, which consisted of more than one constituent, were prepared as follows: The constituents were successively passed through the dryer and into the tank to predetermined pressures and thoroughly mixed. Completeness of mixing was checked after each addition by interferometer readings of gas from the four sampling points. The temperature and pressure of the gas in the tank were then observed and used to make one calculation of the composition of the mixture. Interferometer readings, usually in comparison with carbon dioxide, of each constituent and of the mixture in the tank before and after its addition provided independent data for computing the composition of each successive mixture. An evacuated cylinder was filled from the final mixture and reserved for chemical analysis. The three methods of analysis usually checked reasonably satisfactorily.

\section{(b) ACCURATE DETERMINATION OF REFERENCE SPECIFIC GRAVITIES}

The specific gravity of the mixture from the tank was determined by differential weighing in glass globes of about 1-liter capacity, the method and equipment described below being used.

Two glass bulbs of very nearly equal weight and volume were filled, one with air and the other with the gas under consideration, at the same temperature and pressure, and their difference in weight determined by placing one on each pan of a sensitive balance. The bulbs were again evacuated and filled; the bulb that previously contained air was filled with gas and vice versa. The difference in weight was again determined.

The above procedure offered the following advantages: The difference in weight, which is a measure of specific gravity, was doubled, enabling a higher degree of accuracy to be attained; corrections for buoyancy effects on the bulbs were eliminated; the weights of the bulbs became of secondary importance; and temperature and pressure effects were minimized. The results were computed as follows: Let

$B_{1}=$ weight of bulb 1

$B_{2}==$ weight of bulb 2

$V_{1}=$ volume of gas in bulb 1 at $760 \mathrm{~mm}$ of mercury and the temperature of the bath

$V_{2}=$ volume of gas in bulb 2 at $760 \mathrm{~mm}$ of mercury and the temperature of the bath

$D_{a}=$ density of 'air at $760 \mathrm{~mm}$ of mercury and the temperature of the bath

$D_{g}=$ density of the gas at $760 \mathrm{~mm}$ of mercury and the temperature of the bath. 
The same bulb was always weighed on the same balance pan, regardless of its contents.

In general, it was necessary to add weights to one pan or the other to produce a balance. Let

$\left(W_{r}\right)_{1}=$ weight on right pan

$\left(W_{l}\right)_{1}=$ weight on left pan.

The gas and air were then interchanged in the bulbs and

$\left(W_{r}\right)_{1}=$ weight on right pan

$\left(W_{l}\right)_{2}=$ weight on left pan.

At the prevailing barometric pressure, $P$, and the constant temperature of the bath, the quantity of gas in bulb 1 (reduced to units of volume at $760 \mathrm{~mm}$ ) was $(P / 760) V_{1}$, and the quantity in bulb 2 was $(P / 760) V_{2}$. Assume bulb 1 to contain gas and bulb 2 to contain air, both at a pressure of $P_{1} \mathrm{~mm}$ of mercury. The weight of gas in bulb 1 is $\left(P_{1} / 760\right) V_{1} D_{g}$. Likewise, the weight of the air in bulb 2 is $\left(P_{1} / 760\right) V_{2} D_{a}$. Assume also that bulb 1 is placed on the left balance pan and bulb 2 is placed on the right. When a weight equilibrium has been established, the following is true:

$$
B_{1}+\frac{P_{1}}{760} V_{1} D_{g}+\left(W_{l}\right)_{1}=B_{2}+\frac{P_{1}}{760} V_{2} D_{a}+\left(W_{\tau}\right)_{1} .
$$

The gas and air are interchanged in the bulbs, the temperature of the bath remaining constant, while the atmospheric pressure may have changed so that both bulbs are now at a pressure $P_{2}$. As before, with bulb 1 on the left pan and bulb 2 on the right pan, an equilibrium is established.

$$
B_{1}+\frac{P_{2}}{760} V_{1} D_{a}+\left(W_{l}\right)_{2}=B_{2}+\frac{P_{2}}{760} V_{2} D_{s}+\left(W_{r}\right)_{2} .
$$

Subtracting eq 2 from eq 1 and solving for $D_{g} / D_{a}$,

$$
\text { sp gr }=\frac{D_{k}}{D_{a}}=\frac{P_{2} V_{1}+P_{1} V_{2}}{P_{1} V_{1}+P_{2} V_{2}}+\frac{\left(W_{r}-W_{l}\right)_{1}+\left(W_{l}-W_{r}\right)_{2}}{P_{1} V_{1}+P_{2} V_{2}} \times \frac{760}{D_{a}} .
$$

Two assumptions are involved in this derivation: (1) The temperature remains constant, and (2) it is permissible to make a linear extrapolation from prevailing barrometric pressure to $760 \mathrm{~mm}$ of mercury with both air and gas.

\section{(c) APPARATUS EMPLOYED AND ITS ACCURACY}

Six 1-liter ring-neck, round-bottom, mold-blown flasks of approximately equal weight were selected from stock. The necks were removed and 7-mm (inside diameter) glass tubing substituted. The fiasks were then adjusted to approximately the same volume by softening the glass and expanding or shrinking the bulb near the neck. Final adjustment was made by weighing into each bulb the same weight of water and, after adjustment to a previously selected temperature, marking the position of the meniscus in the tubular neck.

Stopcocks were similarly treated. The same measured volume of 
water was introduced into one lead of each cock (the plug being in the "off" position) and the position of the meniscus marked. The stopcock lead and the tubular neck of each corresponding flask were then cut off at the marks, and the cock was joined to the flask in such a way that no appreciable change in volume occurred at the joint. Standard-taper ground-glass connectors to fit the filling apparatus were cut to the proper length for sealing. Excess tubing was removed from the stopcocks, and flasks and connectors weighed. Glass rod was added to the lighter bulbs at the point where the connector was sealed to the cock until all flasks were of equal weight.

The weights and volumes of the six bulbs, as finally adjusted, are shown below.

\begin{tabular}{|c|c|c|}
\hline Bulb number & Weight & Volume at $25^{\circ} \mathrm{C}$ \\
\hline 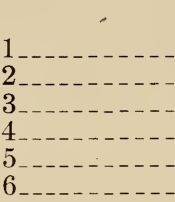 & $\begin{array}{l}\text { 238. } 08^{g} \pm 0.004 \\
238.02 \pm 0.004 \\
238.12 \pm 0.004 \\
\text { 238. } 10 \pm 0.004 \\
\text { 238. } 02 \pm 0.004 \\
238.00 \pm 0.004\end{array}$ & $\begin{array}{l}{ }^{m l} \\
\text { 1082. } 22 \pm 0.04 \\
1081.84 \pm 0.04 \\
1082.30 \pm 0.04 \\
1082.28 \pm 0.04 \\
1082.24 \pm 0.04 \\
1082.15 \pm 0.04\end{array}$ \\
\hline
\end{tabular}

(d) CONSTANT-TEMPERATURE BATH

A well-insulated water bath, in which both bulbs were immersed at the same time, was controlled by a system capable of maintaining a temperature constant to about $0.002 \mathrm{deg}$. C over an extended period, as measured with a resistance thermometer and Mueller bridge accurate to $0.001 \mathrm{deg}$. C. No differences between parts of the bath were found when it was explored with a differential thermocouple capable of indicating, a difference of $0.005 \mathrm{deg}$. C. An uncertainty of 0.002 deg. $\mathrm{C}$ is reflected as an uncertainty of 0.00001 in the density of air.

A permanent glass manifold to which the bulbs were attached while in the thermostat permitted either bulb to be evacuated or filled with either gas (the gas to be measured and purified outdoor air) or to be connected to the atmosphere through a guard tube that could also be flushed with either gas and which prevented the diffusion of room air into the flask when the connection was open. Each flask connected to the manifold was evacuated and filled with the gas to be weighed in it three times, again evacuated, filled to slightly more than atmospheric pressure, and given time to reach the temperature of the bath. Both bulbs were then opened to the air through their guard tubes long enough to establish equality of pressure and closed.

Atmospheric pressures were read with a barometer capable of measuring pressures to $0.05 \mathrm{~mm}$. When the gas in question has a specific gravity near 1.0, errors in pressure of this magnitude are entirely insignificant. When the gas has a specific gravity as far 
removed from 1.0 as that of hydrogen, an uncertainty of $\pm 0.05 \mathrm{~mm}$ of mercury appears in the specific gravity as \pm 0.00002 .

Temperature and barometric pressure were read as promptly as possible after the bulbs were closed. They were then removed from the bath. washed with pumice soap, wiped with damp and dry towels, and the lubricant was removed from the ground-glass connectors. It was found that during periods of extremely low humidity the bulbs acquired a static charge. To eliminate errors from this source, the bulbs, after being cleaned, were held in the steam from boiling distilled water until a light film of condensate had collected. This apparently reduced the charges to negligibility. The bulbs were hung in the balance case for an hour before weighing.

Without doubt, some changes in the weight of the bulbs must have occurred during all this handling. The magnitude of the changes added to rariations in the process of weighing itself were determined by putting the bulbs through 10 cycles as abore described but without turning the stopcocks. There was thus no change in quantity or composition of the inclosed gas, and the reproducibility of results was that of the entire cleaning and weighing process. "The results of the weighings were as shown in table 1 .

TABLE 1.-Reproducibility of the process of cleaning and weighing the bulbs

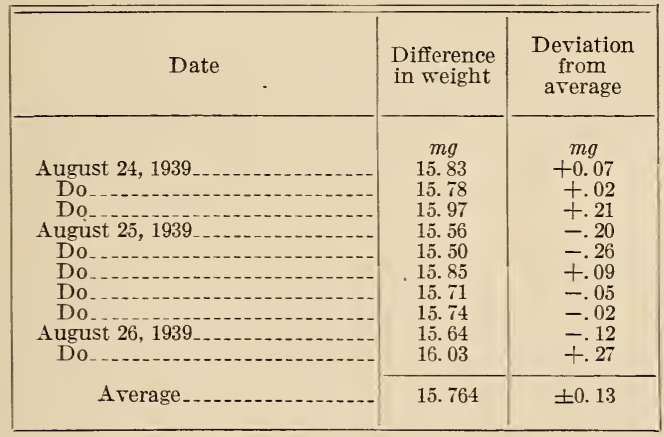

The probable error of a single determination was $\pm 0.11 \mathrm{mg}$. This represents a probable error of \pm 0.00004 in the calculated specific gravity.

If the errors discussed in this section are all of the same sign, a reproducibility of \pm 0.00007 can still be expected.

\section{(e) SPECIFIC GRAVITIES OF TEST GASES}

The approximate composition of the test gases and their specific gravities, determined by 10 weighings of each, are shown in table 2 . The probable errors listed are those computed in the usual manner from the agreement among the observations on an individual gas. The gases are listed in the table in the order of their specific gravities. They are numbered in the order in which they were prepared and used. 
TABLE 2.-Compositions of the test gases, and their specific gravities, as determined by weighing

\begin{tabular}{|c|c|c|c|c|}
\hline $\begin{array}{l}\text { Mixture } \\
\text { number }\end{array}$ & Test gas & Approximate composition & $\begin{array}{l}\text { Specific } \\
\text { gravity }\end{array}$ & $\begin{array}{l}\text { Probable } \\
\text { error }\end{array}$ \\
\hline & & Percent & & \\
\hline & Helium & $\mathrm{He}, 98.3 ; \mathrm{N}_{2}, 1.7$ & 0.15262 & \pm 0.00006 \\
\hline & Helium-nitrogen & $\mathrm{He}, 80.0 ; \mathrm{N}_{2}, 20.0$ & .30480 & \pm .00004 \\
\hline & ..... do & $\mathrm{He}, 65.9 ; \mathrm{N}_{2}, 34.1$ & $.4222_{6}$ & 土. 00003 \\
\hline 6. & 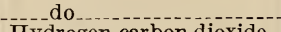 & $\mathrm{He}, 44.5 ; \mathrm{N}_{2}, 55.5$ & .60070 & 士. 00007 \\
\hline & Hydrogen-carbon dioxide & $\mathrm{H}_{2}, 63.1 ; \mathrm{CO}_{2}, 36.9$ & .60805 & \pm .00009 \\
\hline & $\begin{array}{l}\text { Synthetic typical manu- } \\
\text { factured gas. }\end{array}$ & $\begin{array}{l}\mathrm{CH}_{4}, 9.11 ; \mathrm{CO}, 29.96 ; \mathrm{H}_{2}, 34.59 ; \mathrm{O}_{2} \text {, } \\
\quad 0.55 ; \mathrm{N}_{2}, 5.74 ; \mathrm{CO}_{2}, 4.44 ; \mathrm{C}_{2} \mathrm{H}_{6}, 2.64 ; \\
\mathrm{C}_{2} \mathrm{H}_{4}, 12.96 .\end{array}$ & a. $6475_{0}$ & \pm .00007 \\
\hline & Synthetic typical natural & $\mathrm{CH}_{4}, 79.4 ; \mathrm{C}_{2} \mathrm{H}_{6}, 14.7 ; \mathrm{C}_{3} \mathrm{H}_{8}, 2.9 ; \mathrm{N}_{2}$, & .68200 & 土. 00005 \\
\hline & Helium-nitrogen & $\mathrm{He}, 21.1 ; \mathrm{N}_{2}, 78.9$ & $.7962_{6}$ & \pm .00001 \\
\hline & Nitrogen & Atmospheric, fractionated, & $.9666_{4}$ & 土. 00001 \\
\hline & Nitrogen-carbon dioxide... & $\mathrm{N}_{2}, 76.4 ; \mathrm{CO}_{2}, 23.6$ & 1. 09820 & 土. 00002 \\
\hline & - & $\mathrm{N}_{2}, 44.1 ; \mathrm{CO}_{2}, 55.9$ & 1. 27915 & \pm .00005 \\
\hline 12 & - do do & $\mathrm{N}_{2}, 22.9 ; \mathrm{CO}_{2}, 77.1 \ldots$ & 1. 39839 & 土. 00003 \\
\hline 13 & Carbon dioxide... & Commercial & 1.52680 & \pm .00002 \\
\hline 14 & Propane & Phillips, cp, reputed 100 & 1. $5460_{9}$ & \pm .00003 \\
\hline 15 & n-Butane----.--- & $\begin{array}{c}\text { Phillips, cp, reputed } \\
\text { to be. }\end{array}$ & 2. $0644_{4}$ & \pm .00007 \\
\hline
\end{tabular}

a Mixture 1 was used in the determination of temperature and relative-humidity coefficients and consequently was stored for more than 3 months. Its specific gravity was therefore redetermined at the end of that period. The other mixtures were stored for very much shorter periods, and their specific gravities were not redetermined. The value determined for mixture 1 on January 17,1940 , was 0.64750 . On April 26 the redetermination gave $0.6472_{8} \pm 0.00007$. Assuming the change to be uniform and continuous, reference values for intervening dates were determined by interpolation.

\section{INSTRUMENTS STUDIED}

Seven manufacturers provided 11 instruments for the tests. It is believed that all types of instruments in common use are represented. The list of manufacturers and the instruments supplied by them follows:

\section{Company}

\section{Instrument}

American Meter Co., Metric Metal|Metric Indicating Gravitometer.

Works, Erie, Pa.

American Recording Chart Co., 3113 East Eleventh Street, Los Angeles, Calif.

Fisher Scientific Co., 711-23 Forbes Street, Pittsburgh, Pa.

The Permutit Co., 330 West FortySecond Street, New York, N. Y.

The Refinery Supply Co., 621 East Fourth Street, Tulsa, Okla.

Sigma Instrument Co., Letchworth, Herts, England.

Arthur H. Thomas Co., West Washington Square, Philadelphia, $\mathrm{Pa}$.
Anubis Portable Gas Balance No. 115. Anubis Recolding Gas Gravitometer.

Fisher Densimeter (experimental model).

Ranarex Portable Specific Gravity Indicator No. P 1284. Ranarex Specific Gravity Recorder No. A 2360 .

Ac-Me Recording Gravitometer No. 271. Ac-Me Gravity Balance No. 3511. Ac-Me Jr. Gravity Balance No. 4041. Sigma Recorder No. 7 for Specific Gravity.

Edwards Gas Density Balance No. 763.

\section{PLAN OF THE TESTS}

\section{METHODS}

Each instrument was tested with each of the test gases that fell within its range of specific gravity, at the "normal" temperature of $77^{\circ} \mathrm{F}\left(25^{\circ} \mathrm{C}\right)$ and, where applicable, in air having the "normal" water content of 1.1 percent. 
Test gases 1 and 2 also were used to test the instruments at lower and at higher temperatures than $77^{\circ} \mathrm{F}$, in order to determine their temperature coefficients. Similarly, these gases also were used to test the instruments in air having a lower and a higher water content than 1.1 percent in order to determine experimentally their humidity coefficients. Test gases 1 and 2 were used for these purposes because they were typical fuel gases with specific gravities between 0.6 and 0.7, the range most commonly encountered.

The possibility that the results obtained with two of the instruments might be dependent to some extent on the viscosity of the gas, as well as its specific gravity, was investigated.

Test gas 8 was prepared to have a specific gravity very close to that of test gas 6 but a considerably different viscosity, so that a comparison of results obtained with the two gases would indicate the effects of viscosity on the readings of the instruments.

A satisfactory technic was worked out for each instrument in preliminary tests, and the same procedure was followed throughout the entire series of tests with a given instrument. The few cases in which circumstances necessitated deviations from the "standard" procedure are noted in the discussion of the individual instrument to which they apply.

Each test of an instrument consisted of 10 determinations of specific gravity, of which five determinations were made by one observer and five by another, in order to minimize any effects of the personal equation. In every case an effort was made to determine the best performance of which the instrument was capable, after carefully considering all factors which might influence the results.

\section{(a) TREATMENT OF THE RESULTS}

In making a test of an instrument under a given set of conditions, and with a given test gas, the 10 determinations with their mean were treated by the method of least squares to determine the probable error of the mean and that of a single determination. As these figures represent the variability, or uncertainty, of the results obtained with the instrument when using a test gas of constant specific gravity under substantially constant conditions of operation, they serve as a measure of the reproducibility, or "precision," of the instrument.

The mean of the 10 determinations has been compared with the known specific gravity of the test gas to obtain the "error" of the instrument under the conditions of the test, the error serving as a measure of accuracy.

The following data obtained with the Edwards gas density balance, using test mixture 1 at an average temperature of $77.7^{\circ} \mathrm{F}$, are used to illustrate the method of computation of probable error by means of the formula (from Merriman, Method of Least Squares, p. 72):

$$
\text { Probable error of mean } \sqrt{\frac{\Sigma V^{2}}{n(n-1)}} \times 0.6745 \text {. }
$$

Probable error of a single determination $\sqrt{\frac{\Sigma V^{2}}{n(n-1)}} 0.6745 \sqrt{r_{\nu}}$, 
where $V$ is the deviation of a single determination from the mean, and $n$ is the number of determinations.

\begin{tabular}{|c|c|c|c|}
\hline Determination No. & $\begin{array}{l}\text { Observed specific } \\
\text { gravity }\end{array}$ & $\begin{array}{l}\text { Deviation from } \\
\text { mean, } V\end{array}$ & $\begin{array}{c}\text { Square of deviation, } \\
V^{2}\end{array}$ \\
\hline $\begin{array}{r}1 \\
2 \\
3 \\
4 \\
5 \\
6 \\
7 \\
8 \\
9 \\
10\end{array}$ & $\begin{array}{r}0.6433 \\
.6496 \\
.6486 \\
.6475 \\
.6532 \\
.6418 \\
.6489 \\
.6452 \\
.6451 \\
.6447\end{array}$ & $\begin{array}{r}0.0035 \\
.0028 \\
.0018 \\
.0007 \\
.0064 \\
.0050 \\
.0021 \\
.0016 \\
.0017 \\
.0021\end{array}$ & $\begin{array}{r}0.0001225 \\
784 \\
324 \\
49 \\
4096 \\
2500 \\
441 \\
256 \\
289 \\
441\end{array}$ \\
\hline Mean__.... & 0.6468 & & $\begin{array}{r}\text { 0. } 00010405= \\
\Sigma V^{2}\left(\text { sum of } V^{2}\right)\end{array}$ \\
\hline
\end{tabular}

$\frac{\Sigma V^{2}}{n(n-1)}=\frac{0.00010405}{10(10-1)}=0.000001156$

$\sqrt{\frac{\Sigma V^{2}}{n(n-1)}} 0.6745=0.001075 \times 0.6745=0.000725$, probable error of mean.

$\sqrt{\frac{\Sigma V^{2}}{n(n-1)}} 0.6745 \sqrt{10}=0.000725 \times 3.162=0.00229$, probable error of a single determination.

"Observed" specific gravity, mean_---_------ 0.6468.

Specific gravity of text mixture 1_-_----- $0.6474^{1}$

Uncorrected error of instrument_-_-_-_-_-_-0.0006

Uncorrected error, percentage of standard

specific gravity --_-

${ }^{1}$ See footnote of table 2.

The "uncorrected" results of the observations were next "corrected" to take account of certain conditions involved in testing, the effects of which were known quantatively. Some of these corrections were common to more than one of the instruments and will be discussed in the next section. Others applied to only one instrument and will be described in connection with it.

After the "corrections" had been made there still remained certain "sources of error", the effects of which were not known, independently of the observations themselves, definitely enough to justify the application of numerical corrections for them. The observed and "corrected" specific gravities for each of the gases used in the investigation are tabulated for each instrument. The "corrected" results are also plotted, as are other data relating to the sources of error, from which it may be possible, in some cases, to apply additional corrections to the observed results. 


\section{CORRECTIONS APPLICABLE AND THEIR EVALUATION}

(a) REFERENCE AIR

The composition of outdoor air unmodified by products of combustion from nearby furnaces or other apparent sources of probable contamination is so constant with respect to all constituents except water vapor that its density when dried does not change within the limits of accuracy with which we are concerned in this investigation. However, contamination of laboratory air by products of combustion or by air exhaled by the occupants of the laboratory is so insidious a source of error that it is safest to base the most accurate determinations of specific gravity on air from which both carbon dioxide and water vapor have been removed. In the routine operation of specific-gravity apparatus, particularly of the recording type, it may be impracticable to make the comparison with carbon dioxide-free air. Specific gravities measured with respect to dry air of normal carbon dioxide content may be converted to specific gravities of dry air free from carbon dioxide by multiplying by the factor 1.00016 , in the case of such instruments as the Metric portable gravitometer, the two Ac-Me balances and the Edwards balance.

\section{(b) ADJUSTMENT OF OBSERVATIONS FOR HUMIDITY AND CARBON DIOXIDE}

The following applies to such instruments as the Fisher densimeter, the Metric portable gravitometer, and the Ac-Me and Edwards balances.

The conditions of humidity of gas or air existing at the time observations of density or specific gravity are made are not always the conditions under which it is desired to know the results. For example, in the use of the effusion method of determining specific gravity, both gas and air are usually confined over water and are saturated with water vapor at the temperature which happens to exist in the apparatus when the test is made. The square of the ratio of the times required for efflux of gas and air is the ratio of the density of saturated gas to the density of saturated air at the temperature of observation. We are less likely to be interested in this ratio than in the specific gravity (ratio to dry air) of the dry gas or the gas as sampled, or even the gas when saturated at a "standard" temperature. Similarly, in the use of an Edwards balance or other apparatus depending on the same principle, it may be inconvenient to change the humidity of either gas or air, and the ratio found by direct observation may be that of gas of one humidity to air of another, in neither of which are we immediately interested.

The formulas that follow are easily derived by expressing the densities of gas and air under each condition of humidity in terms of their densities when dry, the density of water vapor, and the partial pressure of each component of the mixtures. They permit the ready calculation of the relative densities of gas and air for any conditions of either from observations made under any other conditions. (These corrections do not apply, however, to types of instruments such as the Anubis balance and the Sigma, Anubis, and Acme recorders, which are discussed later.)

The symbols used are:

$R=$ ratio of density of gas to density of air under any definite conditions of humidity in each. 
$R_{s}=$ the particular value of $R$ when both gas and air are saturated.

$S=$ the specific gravity of dry gas; that is, it is the particular value of $R$ when both gas and air are free from water vapor.

$S_{\mathrm{g}}=$ the specific gravity of gas containing a partial pressure, $g$, of water vapor: that is, it is the value of $R$ when the air is dry and the gas is not.

$a=$ the partial pressure of water vapor in the air.

$g=$ the partial pressure of water vapor in the gas.

$w=$ the pressure of water vapor at saturation. (When air is saturated, $a=w$; when the gas is saturated, $g=w)$.

$b=$ the barometric pressure.

$h=$ the average head of water during a determination, in millimeters of mercury.

$p=$ the total pressure at which gas or air is saturated $(b+h)$.

0.622 is the specific gravity of water vapor, that is, it is the ratio of the density of pure water vapor to the density of dry air at the same temperature and pressure.

The specific gravity, $S$, of a dry gas in terms of the ratio, $R$, of the density of gas containing a partial pressure, $g$, of water vapor to the density of air containing a partial pressure, $a$, of water vapor is

$$
S=R\left(\frac{p-a}{p-g}\right)+\frac{0.622(R(1-g)}{p-g} .
$$

The specific gravity, $S$, of a dry gas in terms of the ratio, $R_{s}$, of the density of saturated gas to that of saturated air is

$$
S=R_{s}+\frac{0.622 w\left(R_{s}-1\right)}{p-w}
$$

This is a special case of equation 3 .

The specific gravity, $S_{\mathrm{g}}$, of gas containing a partial pressure of water vapor, $g$, in terms of the specific gravity, $S$, of the dry gas is

$$
S_{g}=S \frac{p-g}{p}+\frac{0.622 g}{p}
$$

For the special case of gas under the conventional "standard" conditions for expressing the heating value of fuel gases in the publicutility industry, $p$ is 30 in. of mercury, and $g$ is the vapor pressure of water at $60^{\circ} \mathrm{F}$. In this case

$$
S_{g}=0.9826 S+0.0108 \text {. }
$$

Under the standard conditions of gas measurement of the American Society of Mechanical Engineers, $p$, is $760 \mathrm{~mm}$ of mercury, and $g$ is the vapor pressure of water at $68^{\circ} \mathrm{F}$. In this case

$$
S_{g}=0.9769 S+0.0144 \text {. }
$$

The ratio $R$ of density of gas to that of air containing a partial pressure, $a$, of water vapor, in terms of the specific gravity, $S_{g}$, of the gas, is

$$
R=S_{g} \frac{p}{p-a(1-0.622)}=S_{g} \frac{p}{p-0.378 a} .
$$


To facilitate the evaluation of these corrections, curves were plotted from which the corrections could be read off when the relative humidity was known (for the water vapor) and when the percentage of carbon dioxide was known. These curves are presented for the convenience of the manufacturers and users to whose instruments they are applicable.

The corrections for water vapor and carbon dioxide that are applicable to the results obtained with the Ac-Me recording gravitometer, the Anubis recording gravitometer, and the Sigma specific gravity recorder may be evaluated by means discussed in the reports on those instruments.

The relative humidity having been determined with any suitable psychrometer, the corresponding percentage of water vapor at the existing dry bulb temperature may be read off from the family of curves presented in figure 2 .

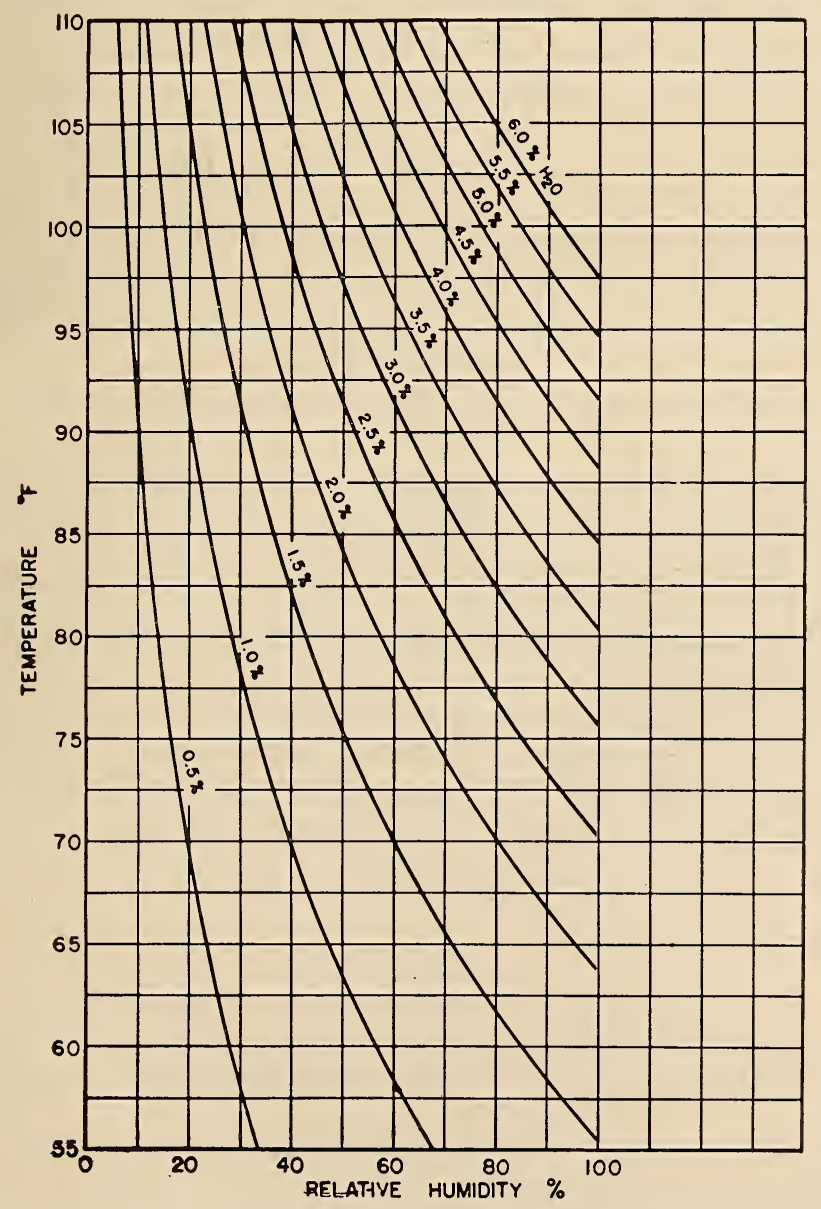

Figure 2.-Percentage of water vapor from percentage of relative humidity at existing dry-bulb temperature. 
Corrections for water vapor applicable to the results obtained with the Metric portable gravitometer may be obtained from the family of curves presented in figure 3 . Corrections applicable to the results obtained with the Fisher densimeter, in which both gas and air are saturated, are discussed in the report on that instrument.

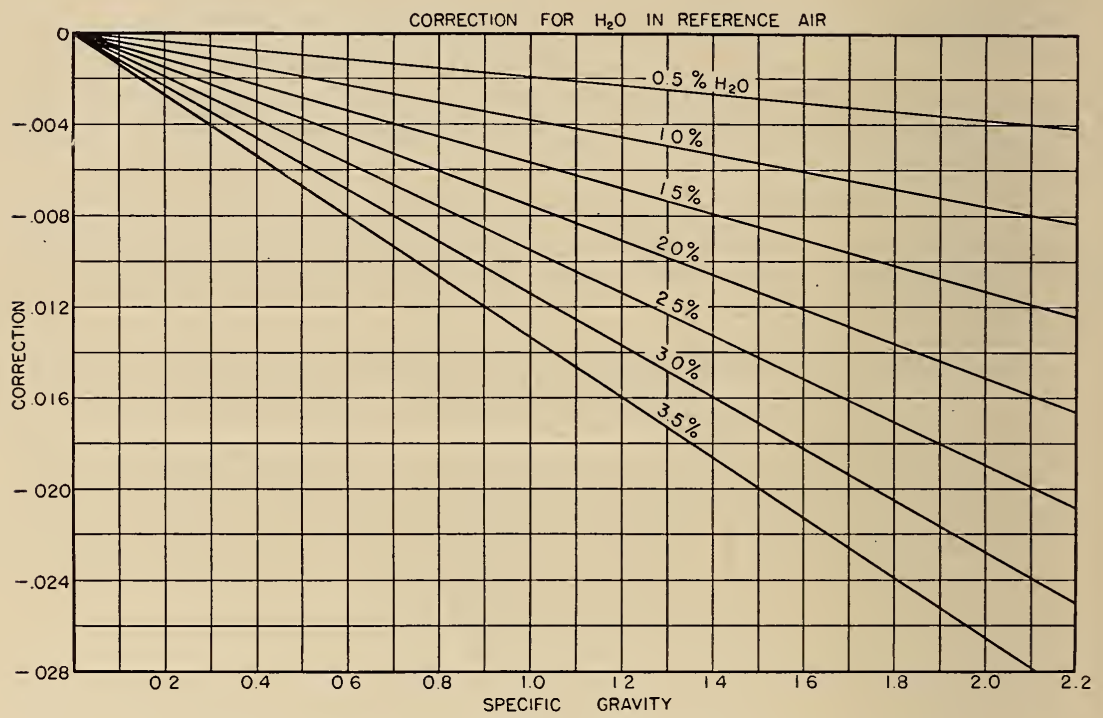

Figure 3.-Correction for water vapor in the reference air.

Corrections applicable to the results obtained with the Anubis portable gas balance (if the carbon dioxide is not removed as well as the water) are discussed in the report on that instrument.

On account of the method of calibration, and since both gas and air are saturated, no corrections for water vapor or carbon dioxide are applicable to the results obtained with the Ranarex recorder or Ranarex portable indicator.

Corrections for carbon dioxide applicable to the results obtained with the Metric portable gravitometer, the two Ac-Me balances, and the Edwards balance may be obtained from the family of curves presented in figure 4 , which were derived from the equation

$$
S=R\left(1.529\left[\mathrm{CO}_{2}\right]+1-\left[\mathrm{CO}_{2}\right]\right),
$$

where

$S=$ specific gravity with respect to dry air free from carbon dioxide

$R=$ observed value uncorrected for carbon dioxide in the reference air

$\left[\mathrm{CO}_{2}\right]=$ concentration of $\mathrm{CO}_{2}$ in reference air expressed as a fraction of the total

$1.5290=$ specific gravity of $\mathrm{CO}_{2}$. 


\section{(c) PRESSURE CORRECTIONS}

For the Edwards and Ac-Me balances a correction of the pressure is applicable at temperatures other than $32^{\circ} \mathrm{F}\left(0^{\circ} \mathrm{C}\right)$ to take account of the expansion of mercury.

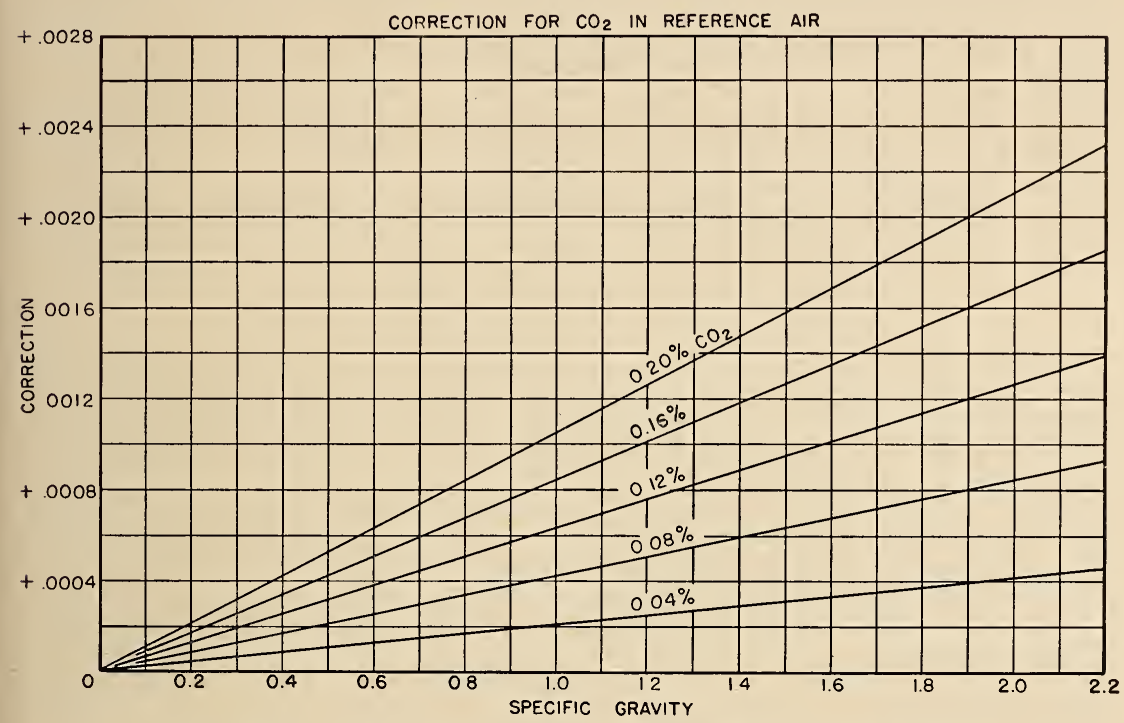

Figure 4.-Correction for carbon dioxide in the reference air.

In making a determination of the absolute pressure at which the beam balances, the difference in pressure between inside and outside of the balance case is read on the scale of a manometer containing mercury at the existing temperature. This difference in pressure is added (algebraically) to the existing barometric pressure to obtain the absolute pressure. The barometeric pressure reading usually is, and during these tests always has been, corrected to a mercury temperature of $32^{\circ} \mathrm{F}\left(0^{\circ} \mathrm{C}\right)$. In order to obtain a correct value for the absolute pressure, the pressure difference should also be corrected to the value it would have if the mercury in the manometer were at $32^{\circ} \mathrm{F}\left(0^{\circ} \mathrm{C}\right)$. At first glance this correction would appear to have a negligible effect on the specific gravity, but the correction increases with the temperature and with the pressure difference involved. As the correction is applied to the observed pressure difference, it must be applied each time the beam is balanced, and the corrected specific gravity computed from the corrected absolute pressures.

For the Edwards balance, the linear temperature coefficient of the maple scale, parallel to the grain, is approximately $0.000005 \mathrm{~mm}$ per $\mathrm{mm}$ per deg C. This amounts to about one-fortieth of the linear coefficient of mercury and is negligible by comparison.

For the Ac-Me balances, the scales are made of aluminum or an aluminum alloy. The linear temperature coefficient of aluminum is 
$0.00002313 \mathrm{~mm}$ per mm per $\operatorname{deg} \mathrm{C}$, which may or may not have been very nearly that of the scale. This amounts to about one-eighth of the coefficient $(0.00018186)$ of mercury, and may be neglected without appreciable error. The corrections, therefore, have been computed from the expansion of the mercury alone.

The pressure differences involved in the tests with these balances have been corrected by means of the formula

where

$$
C=\alpha R t
$$

$C=$ the correction in millimeters of mercury

$\alpha=0.00018 \mathrm{~mm}$ per $\mathrm{mm}$ per $\operatorname{deg} \mathrm{C}$

$R=$ the pressure difference in millimeters of mercury

$t=$ the temperature in $\operatorname{deg} \mathrm{C}$.

(d) CORRECTION FOR DEVIATION FROM IDEAL GAS

As is well known, deviations from ideality of the material tested may be a source of error. By the usual definition, specific gravity is the ratio of the density of gas to the density of air at the same temperature and pressure. If the density of the gas does not have the same coefficients of temperature and pressure as air, the specific gravity according to this definition is a function of those conditions of measurement. When balances of the Edwards and Ac-Me types are used, it is customary to assume ideality in both air and gas by using the above relation in the form: specific gravity is the ratio of the absolute pressure of air to the absolute pressure of gas, when they are made to have the same density at the same temperature. Balancing the beam in each brings the densities to equality.

From the results obtained in this study it appears that the gases up to and including carbon dioxide do not depart from ideality enough to affect their measurement significantly. The densities of propane and butane, however, increase so much more rapidly than their pressures that their specific gravities are significantly dependent on the absolute pressures at which the beam is balanced in them.

If the specific gravity is desired at an absolute pressure of $760 \mathrm{~mm}$, as it was in the present case, for comparison with the specific gravity determined for the test gas at that pressure, it may be possible to make a sufficiently accurate determination by balancing the beam in the gas at two different pressures (by adjusting counterweight or rider) preferably one above and one-below $760 \mathrm{~mm}$. The two values of specific gravity, after correction, are plotted against the absolute pressures, a straight line drawn through the two points and the desired specific gravity read off at the absolute pressure of $760 \mathrm{~mm}$.

\section{(e) CHART CORRECTIONS}

For recording instruments, a correction is applicable for changes in the dimensions of the paper with changing relative humidity. The effects of an 80-percent change of relative humidity on charts for each instrument were measured by the Paper Section of the Bureau and ranged from 0.60 to 0.72 percent in the "machine direction" of the paper and 1.43 to 1.66 percent in the "cross direction." All the circular charts are printed with the 6-o'clock diameter in the machine 
direction, and to minimize the effects of humidity, all tests were made with the pen close to that diameter. All readings were also corrected to a relative humidity of 35 percent by multiplying the difference between 35 and the observed relative humidity by the distance from the pen to the center and by the predetermined change of dimensions per unit change of relative humidity. A typical numerical example follows.

The chart of the Ac-Me gravitometer was found to expand 0.62 percent for an increase of relative humidity of 80 percent. With mixture 2 and a relative humidity of 37.8 percent, the chart reading was 0.6900 . The distance from the center of the chart to the pen was $65.5 \mathrm{~mm}$. If the relative humidity were reduced to the standard of 35 percent, the paper would move inward under the pen (in the direction of a higher specific gravity).

$$
\frac{0.0062 \times(37.8-35.0) \times 65.5}{80}=0.0142 \mathrm{~mm}
$$

which is equivalent to 0.00008 specific gravity. This is the number to be added to the original reading to correct to 35 percent relative humidity.

Readings of the instrument are subject to correction on account of the effect of relative humidity on the chart under all conditions except that in which the instrument is calibrated, and the record is made with the chart exposed to air of the same relative humidity as that existing at the time the chart was printed. At any other relative humidity the circles on the chart are no longer circles, and their radii are different in different directions. A change of relative humidity of 47.4 percent (which is not excessive) from that at calibration resulted in a correction of 0.0014 on the 6-o'clock axis. A correction of approximately 0.0037 would have been required on the 12-o'clock axis with this gas, and one of 0.0065 with a gas of 1.0 specific gravity. There would have been an additional uncertainty in the reading unless the relative humidity at calibration was known to be the same as that at printing.

\section{RESULTS OF TESTS OF INDIVIDUAL INSTRUMENTS}

To facilitate the presentation of the data, the instruments have been arranged in groups based on the type of instrument and the types of corrections that are applicable to them.

Three balances, the Edwards, Ac-Me Junior No. 4041, and Ac-Me No. 3511, are identical in principle. In each of them, a beam carrying a bulb is brought to balance in the same position, successively in air and in gas, by adjusting the pressure within the balance case; the absolute pressures are determined by means of a barometer and a mercury-filled manometer, and the specific gravity is computed from their ratio. The instruments differ in size, method of supporting the balance beam, sealing the balance case, and other minor details of construction, but they are subject to corrections and error's of the same kinds though not necessarily of the same magnitude.

Four instruments, the Anubis balance, Anubis recording gravitometer, Ac-Me recording gravitometer, and Sigma recorder, in princi- 
ple, balance the weight of a given volume of gas at atmospheric pressure by a displacement of the center of gravity of a balance beam, and the amount of this displacement, or "deflection," subject to corrections, measures the specific gravity. This group of instruments includes much greater differences than the first in construction, methods of compensating for changes of atmospheric conditions, etc., and does not permit as much generalization with regard to corrections and sources of error.

Three instruments, the Metric indicating gravitometer, the Ranarex recorder, and the Ranarex indicator, depend on the pressure developed in stopping the movement of the gas that has been set in motion by a rotary blower. Very different constructions are employed by the two manufacturers represented.

One instrument, the Fisher densimeter, depends on a comparison of the rates of efflux of air and gas through an orifice.

\section{PRESSURE BALANCES}

\section{(a) CONSTRUCTION AND OPERATION}

(1) Edwards Gas Density Balance. (A) Description.-The Edwards balance is approximately $91 / 2 \mathrm{in}$. long, $4 \mathrm{in}$. wide, and $51 / 2 \mathrm{in}$. high (Fig. 5). The manometer, mounted on a tripod stand, is $38 \mathrm{in}$. high. The instrument is supplied in a wooden case $393 / 4$ by 12 by $53 / 4$ in. with a handle for carrying it. The total weight, including the case, is $36 \mathrm{lb}$.

This instrument (described briefly in Technological Service Bulletin 5980, of the Arthur H. Thomas Co., Philadelphia, Pa.) consists of a balance beam, one end of which is cemented into a glass tube sealed in a cylindrical glass bulb, and the other end, threaded, carries a counterweight, which consists of two knurled nuts locked together and on its tip a circular target bearing two adjacent horizontal lines on a white background. At its center of balance, the beam is clamped between two cross bars, through which are screwed two steel points, one on either side of the beam. These-points are the pivots on which the beam balances, and are seated, one in a cone and the other in a groove (at right angles to the beam) in an agate support mounted on a metal part that fits snugly inside a cylindrical gastight chamber. This chamber, or balance case, has a glass window at each end, is inclosed in a water jacket, and is fitted with a needle valve at each end for connection to the sample and to vacuum and has a connection to a mercury-filled manometer to measure the pressure difference between the inside and outside of the balance case. The case is fitted with a base consisting of a single foot at the rear and a cross bar at the front carrying two leveling screws, one at each side, but no spirit level, either longitudinal or transverse. On the cross bar at the front is mounted an arm supporting a lens with which to observe the position of the target on the balance beam with respect to a single horizontal black line on a small circular glass window mounted on the end of the beam support inside the window of the balance case. On the under side of the cross bar of the beam is a pendulum screw and nut with which to make fine adjustments of the height of the center of gravity of the beam with respect to its points of support. 
In operation, the balance case and manometer connections are filled with dry air and the pressure is gradually reduced until the beam is balanced. The pressure indicated by the manometer is noted, and the balance is evacuated and filled with gas, the beam balanced as before, and the pressure noted. The specific gravity of the gas is the

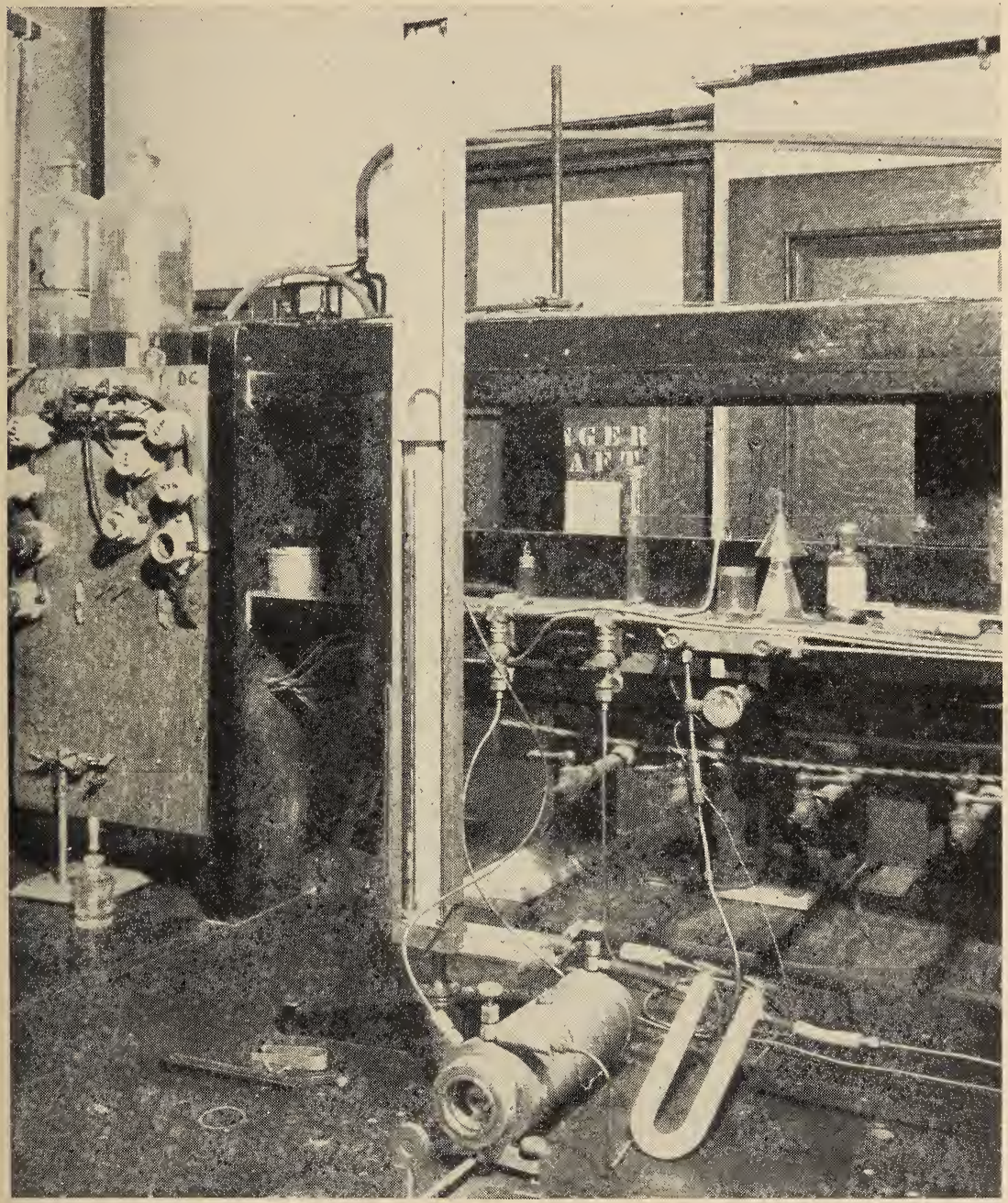

Figure 5.-Edduards gas density balance No. $₹ 63$.

ratio of the absolute pressure required to balance the beam in air to the absolute pressure required to balance it in gas.

(B) Modifications for Testing.-A leak at the ball joint of the manometer connection on the balance case, caused by imperfections in the surface of the ball, was stopped by coating the ball with beeswaxrosin cement. 
The balance case, beam support, and beam were carefully freed of dust. The steel points appeared to be in good condition, as were the cone and slot in the agate bearing. The nut for adjusting sensitivity was very loose and to make it more secure, as well as to increase sensitivity, it was turned as high as possible against the end of the thread. With the nut near the center of the screw, the period of swing was only 7.7 seconds. The period could not be increased beyond 8.0 seconds without changing the adjustment of the needle bearings. As the directions for use stated, "The beam has already been adjusted for high sensitivity and should not be changed unnecessarily," no other change of sensitivity was made.

In order to use the balance over as wide a range of specific gravity as possible with the least possible disturbance of the balance beam by adjusting the counter weight to make it balance at different pressures, the beam was adjusted to balance in dry air at $1475 \mathrm{~mm}$ absolute. An accessory rider was made of aluminum sheet, which, when slipped into the groove in the counterweight, caused the beam to balance in dry air at $388 \mathrm{~mm}$ absolute. The beam could thus be made to balance above or below atmospheric pressure, for use with gases lighter or heavier than air, merely by opening the case and placing or removing the rider, and a return to approximately the original balancing pressure was assured without the necessity of hunting for the proper location of the counterweight on each occasion.

A small hole was bored in the wing of the plug to the water jacket for the insertion of a thermocouple to measure the temperature of the instrument.

An intermittent leak having been traced to the rear needle valve, it was opened and a smeared brass chip was removed from the needle point and cone. The needle and seat were cleaned, and the valve then held satisfactorily.

Air was found to leak into the evacuated balance through the packing in the rear needle valve while filling the balance with gas, unless the gas pressure on the needle valve was kept above atmospheric pressure. A diaphragm pressure regulator was installed in the main gas line and set at $20 \mathrm{lb}$ so that all the lines to the various instruments could be maintained at that pressure and the flow controlled by the valve on the balance.

(C) Method of Operation.-The directions for use of the Edwards gas density balance, No. 5980, supplied with the instrument, were followed with various extensions during the testing with 14 of the gas mixtures of known specific gravity.

In purging the instrument in preparation for a determination of the pressure at which the beam balanced, the balance case was evacuated to an absolute pressure of about $40 \mathrm{~mm}$, then filled to atmospheric pressure with air taken through copper tubing from outside on the windward side of the building, and dried over calcium chloride just before entering the balance. Evacuation and filling was repeated a second and a third time. The needle valve was then opened slightly to the vacuum, and the pressure reduced until the beam balanced.

If the residual pressure after each evacuation were always exactly $40 \mathrm{~mm}$, the specimen would contain 5.3 percent of the previous contents after one evacuation and filling, 0.28 percent after the second, 
and 0.015 percent after the third. Contamination to this extent would result in an error of 0.00013 for helium at one extreme and of 0.00016 for butane at the other. As these errors would be only about twice the uncertainty involved in the "standard" specific gravities of the test gases, and very minor fractions of the errors actually found, they were considered sufficiently small for the purpose of these tests. As in any case, the direction and amount of error from failure to purge completely can be determined after a specific-gravity test, a correction can and should be made if it is large enough to be significant. In this case, the "errors" given above should be subtracted from the observed density of helium and adided to that of butane, but they cannot be considered significant.

A test for leaks was always made before each series of determinations of specific gravity.

The directions do not state clearly whether the "balance" of the beam shall be observed while it is oscillating or stationary. However, the character of the target and lines is unfavorable for accurately estimating the amplitude of oscillation on the two sides of a balance point, damping is rapid, and the precision with which the pressure may be controlled by means of the needle valve makes it possible to adjust the position of the beam gradually and with practically no oscillation. Previous knowledge indicated also that a static balance has generally been used with this instrument, and this method was followed throughout the tests. The means for evacuating the balance is not provided with it. If a hand pump had to be used, adjusting the beam to a stationary balance might present more difficulty.

The beam was brought to balance by removing gas or air from the balance until the beam started to oscillate, slowing down the flow as the swings damped out, until by the time the reference mark reached one of the two parallel marks on the target, no oscillation was perceptible and the beam moved continuously and slowly to a position where the reference mark was between the two marks of the target, and an equal width of white showed on either side of the reference mark between it and the adjacent target mark. The valve was then closed, the manometer tapped alternately twice on each side at the meniscus, and the position of the meniscus read to an estimated $0.1 \mathrm{~mm}$. The beam was then again observed to verify the balance point. If any change had occurred while the manometer was being read, the beam was rebalanced.

While changing the short rubber-hose connection to the gas and air lines, care was taken to hold the balance firmly against the stone bench top by resting the left wrist and fingers on the front and rear needle-valve knobs, respectively, and to avoid any slightest jar to the balance during a series of determinations.

Occasional small permanent (for the time) shifts in the balance point have been traced to such disturbances or to tapping the balance case. Contact with the balance case itself was avoided to prevent disturbance of its temperature.

In making a single determination of specific gravity, the beam was balanced in air after purging three times, then in gas after purging three times, and then in air again after purging three times. Each time the beam was balanced, the manometer readings, the tempera. 
ture of the instrument, the corrected barometric pressure, and the time were recorded. If the instrument temperature changed in such a way that the mean of the temperature at the two balance points in air was not the same as the temperature at the intermediate balance point in gas, the resulting value for the specific gravity was corrected by multiplying it by the ratio of absolute temperatures required to bring the average of the air temperatures to the gas temperature.

(2) Ac-Me Balances. (A) Description.-The two Ac-Me gravity balances, Junior No. 4041, and 3511, differ in size, method of suspending the balance beam, and minor details of construction. Both balances are mounted on wooden bases, 14 by 6 in. and 22 by $71 / 2$ in., respectively, and are about 8 and 11 in. high (fig. 6). The bases are provided with leveling screws and circular levels, and may be supported either on a table or on a tripod stand 37 in. high. A manometer, provided for attachment to the stands, brings the total height to $631 / 2$ in. With the needed accessories, tripod, manometer, air dryer, pump, and hose connections, the Junior No. 4041 balarce weighs 50 lb. and No. 3511, $76 \mathrm{lb}$.

In both balances the beams are suspended from frames attached to face plates. The frames slide into cylinders, to the open ends of which the face plates are attached by cap screws. Rubber gaskets serve to make the cases gastight when assembled. Plastic windows in the face plates permit the observation of scales attached to the beams and of thermometers attached to the frames inside the cases.

Connections are made from the balance cases through needle valves and heavy rubber tubing with metal union fittings to the source of gas or air to the pump in both balances. The connection to the manometer is also through a needle valve on balance No. 3511, and a fourth needle valve permits the controlled discharge of excess pressure to the outside without disconnecting the balance from the pump or gas supply. These two valves are missing on the Junior balance (No. 4041).

A hand pump of the reciprocating plunger type is provided with each balance. It is fitted with check valves to permit operation as the plunger moves in either direction and serves for either pressure or vacuum.

The mercury manometer supplied has tubes of 3.5- to $4.0-\mathrm{mm}$ bore mounted in a channel 2 in. wide made of cast aluminum alloy, with a removable sliding cover and metal plugs to prevent spilling mercury during transit. A millimeter scale with the zero at the center is stamped on an adjustable strip of thin metal mounted between the glass tubes and overlaps both a little.

The air dryer uses calcium chloride and is fitted with brass plug cocks for connection to the metal hose fittings.

In each balance, the balance beam is a metal rod with a bulb at one end and large and small adjustable counterweights with lock nuts at the other. On the tip of the balance beam is a scale which is observed through the window in the face.

A cross arm at the center of gravity has screw clamps for attaching metal suspension strips and a short vertical rod threaded for a weight with which to adjust the sensitivity. Four thin metal suspension strips, two at each end of the cross arm, are used in each balance, 
but their arrangements are different. Viewed from the side, the pair of suspensions in the Junior balance form a narrow $\mathrm{V}$. In balance No. 3511, they form a narrow-topped $\mathrm{X}$, a true Cardan suspension, though one of rather extreme form. In the Junior balance. the

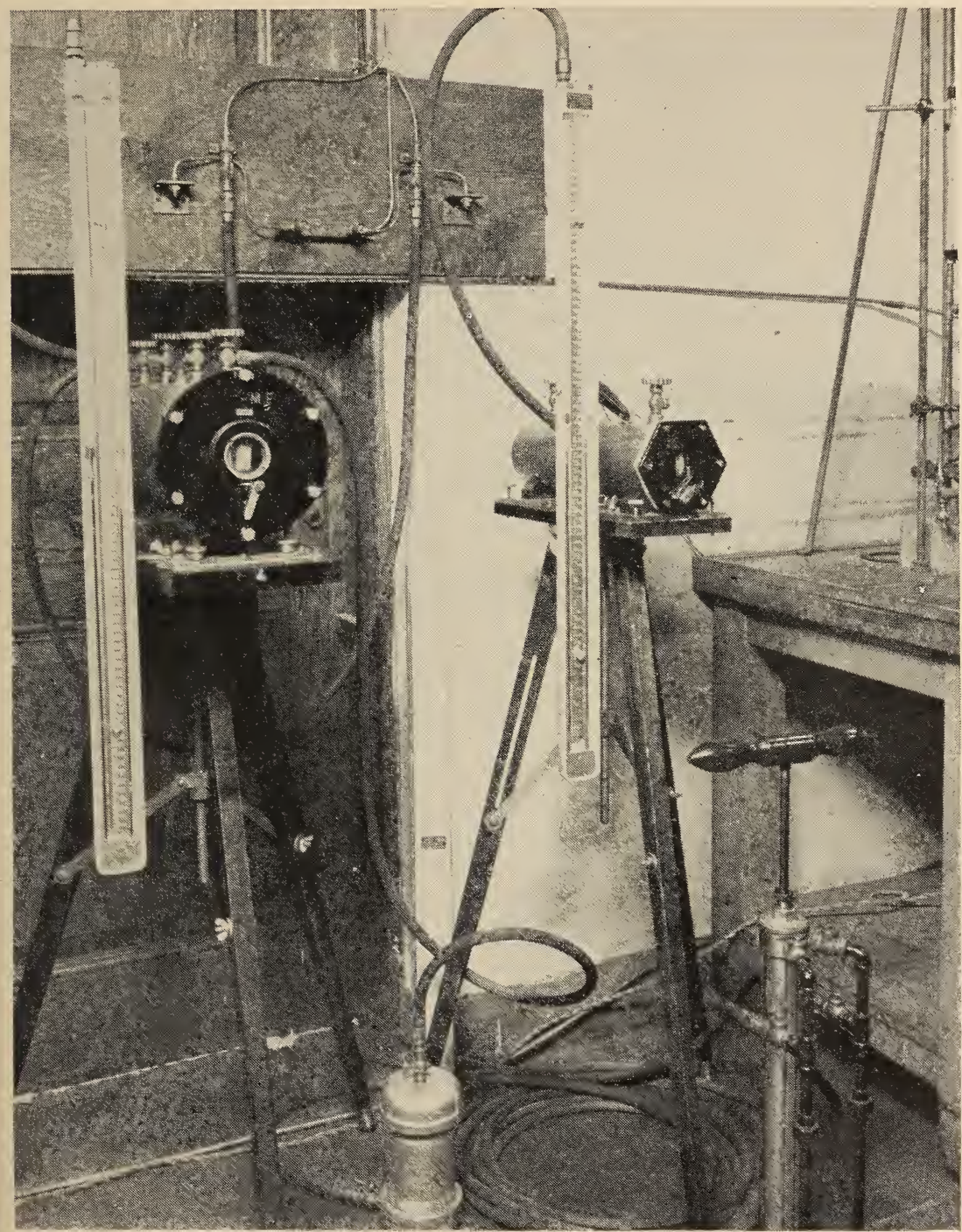

Figure (i.-Ac-Me gravity balance No. 3511 (left) ; Ac-Me Junior gravity balance No. 4041 (right).

springs are of steel $0.001 \mathrm{in}$. thick and one-sixteenth in. wide. Phosphor bronze springs 0.001 in. thick and one-eighth in. wide are used in balance No. 3511. The suspension in the Ac-Me Junior balance does not entirely prevent lateral motion that may be caused by the 
manipulation of valves. The suspension of the Ac-Me No. 3511 balance does prevent lateral motion. In each balance, the weight of the beam can be lifted from the suspensions and locked rigidly in position for transportation by a cam on a shaft running through a packing in the face plate to a handle.

(B) Modifications For Testing.-An aluminum clip to serve as a holder for a rider was attached to the beam of each balance by clamping it between the small counterweight and its locknut. The counterweights were adjusted to balance in air, with the clip in place, at absolute pressures of about $1,500 \mathrm{~mm}$. Riders, made of Nichrome wire, cause the beams to balance in air at about $400 \mathrm{~mm}$ when placed on the holders. The use of these riders permitted the quick adjustment of the balances for use with air above or below atmospheric pressure, with a minimum of disturbance of the mechanism.

The hand pump was used only for the introduction of air at pressures above atmospheric. Evacuation was accomplished by means of a motor-driven rotary pump.

The supply of test gas was delivered through the diaphragm pressure regulator set to deliver $20 \mathrm{lb} / \mathrm{in}^{2}{ }^{2}$ so that the flow of gas could be controlled by the needle valve on the balance case. Leakage of air into the evacuated balance through valve packings and hose connections was thus prevented with certainty.

(C) Method of Operation.-The directions for use supplied with the instruments were followed, with various extensions, during the testing with 14 of the gas mixtures of known specific gravity with both balances.

During purging, the balance was evacuated to an absolute pressure of about $82 \mathrm{~mm}$, then filled with dry air from outside the building. This was done three times. The same procedure was followed in the case of gas. Purging three times was found to reduce the previous content of the gas to a negligible fraction of the sample.

A test for leaks was always made before each series of determinations of specific gravity. No leakage into or out of balance No. 3511 was detected during more than 2 years of use, but some trouble was encountered from leakage where the rods pass through the plastic window of the Junior balance when the pressure was above atmospheric, but not when it was below. Tests for leakage were thereafter made with the balance under both pressure and vacuum.

The level of the balances was verified each time before balancing the beam, but no adjustment of the level of balance No. 3511 was found necessary after the initial adjustment made before starting the tests. In both balances it was found that the balancing pressure was affected a little by the amplitude of oscillation of the balance beam, and if the amplitude was too great the decrements were irregular, particularly with the Junior balance. The decrements were small and fairly uniform if the beam oscillated only about one scale division. For these reasons, the final balancing pressure was always determined with oscillations of about this magnitude. With practice, it was possible to control the oscillation of the beam by timing small changes of pressure while approaching the balance point.

The distance between the cross hair on the window and the scale on the balance beam and the curvature of the scale introduced uncer- 
tainties into the readings until a single light bulb was placed several feet behind and to the right of the observer to throw a shadow of the cross hair onto the scale. The use of the shadow instead of the cross hair as an index completely eliminated parallax.

Following an adjustment of pressure to balance the beam, the manometer was tapped and read to the nearest quarter millimeter.

In making a single determination of specific gravity, the same sequence of repeated observations with gas and air was employed as with the Edwards balance. Similar data were recorded, and computations and corrections for changes of temperature were made in the same way.

\section{(b) RESULTS OF OBSERVATIONS}

In conducting a test of each instrument at a given temperature, with a given test gas, two observers each made a series of five determinations by balancing the beam alternately six times in air and five times in gas, beginning and ending with air. The absolute pressures for air, before and after each absolute pressure for gas were averaged and used with that for the intermediate gas for the computation of the five values of the specific gravity.

The 10 determinations of specific gravity obtained by the 2 observers were then averaged for the test. The temperature reported with each test is the average of all the observations of instrument temperature recorded during the test, and was used to correct the absolute pressures in the manner described in section III, 2 (c). The corrected specific gravities were computed from the corrected absolute pressures, and averaged. For test mixture 1 in the Edwards balance, the average temperature was $7 \tau .7^{\circ} \mathrm{F}$.

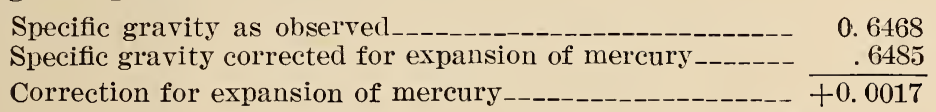

As may be seen, the correction, even with pressure differences under $350 \mathrm{~mm}$, is not negligible. Had greater differences of pressure been involved, the correction would have been greater.

In the tests with pressure balances, the air for reference was dried as it entered the balance. The concentration of carbon dioxide in the air from outside the building was probably about 0.04 percent. ${ }^{2}$ This would cause the specific gravity indicated by the balance to be low by 0.00014 . See section III, $2,(b)$.

Summarizing the observations and corrections for test mixture 1:

Correction for expansion of mercury in manometer above

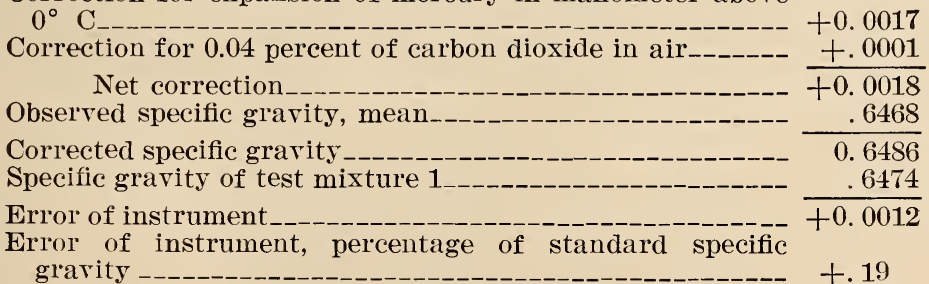

${ }^{2}$ The correct figure is 0.03 percent of $\mathrm{CO}_{2}$ in most locations. The difference is purely of academic interest, since it would alter the correction by only 0.0001 in the most extreme case, that of butane. 
Each instrument was operated with different types of gases of different specific gravities, at different temperatures, and with the beam balanced in air both below (mixtures 1 to 9 ) and above (mixtures 10 to 15) atmospheric pressure. The data have been treated in the manner described above in each case, and summaries of the numerical results are presented in tables 3,4 , and 5 .

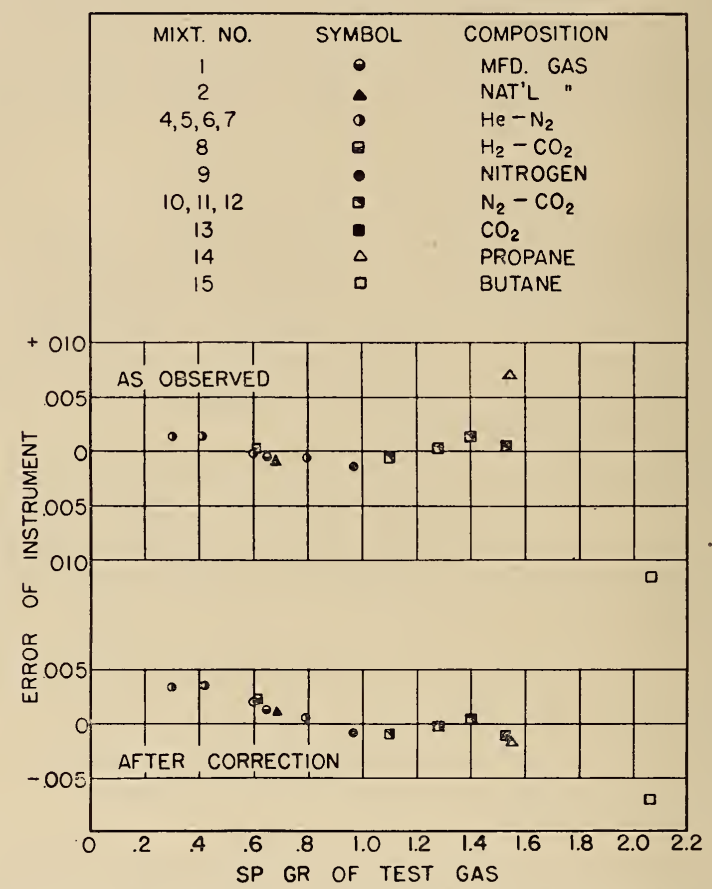

Figuke 7.-Error of the Edwards gas density balance determined with each test gas, as observed and after the application of corrections for the temperature of the mercury in the manometer and for carbon dioxide in the reference air.

The errors of the instruments, uncorrected and after corrections for the temperature of the mercury in the manometer and for carbon dioxide in the reference air were applied, have been plotted for each test gas in figures 7,8 , and 9 .

For test mixtures 14 and 15 (propane and butane, respectively) the instruments were tested with the beam balanced in gas both above and below atmospheric pressure, and the errors for these gases given 
Specific Gravities of Gases

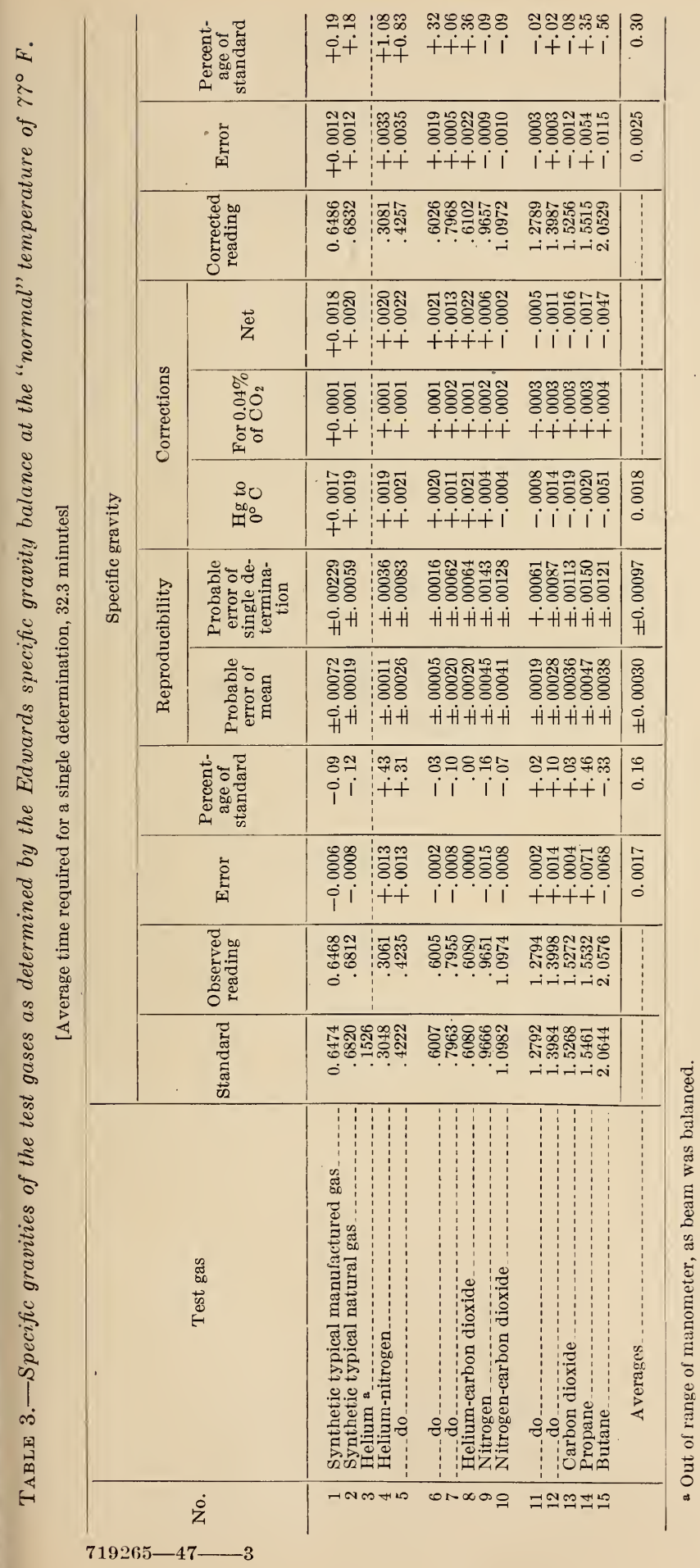




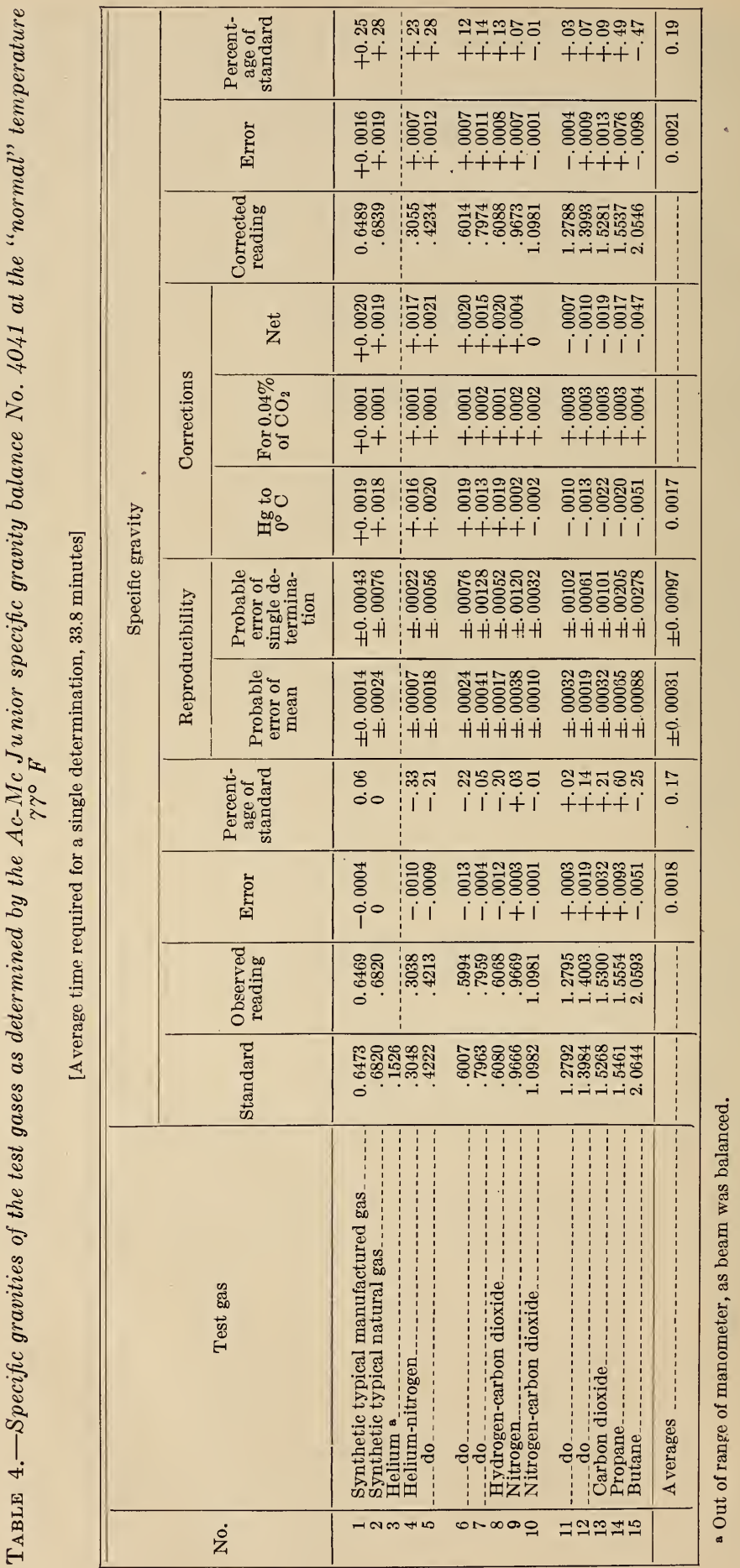


Specific Gravities of Gases

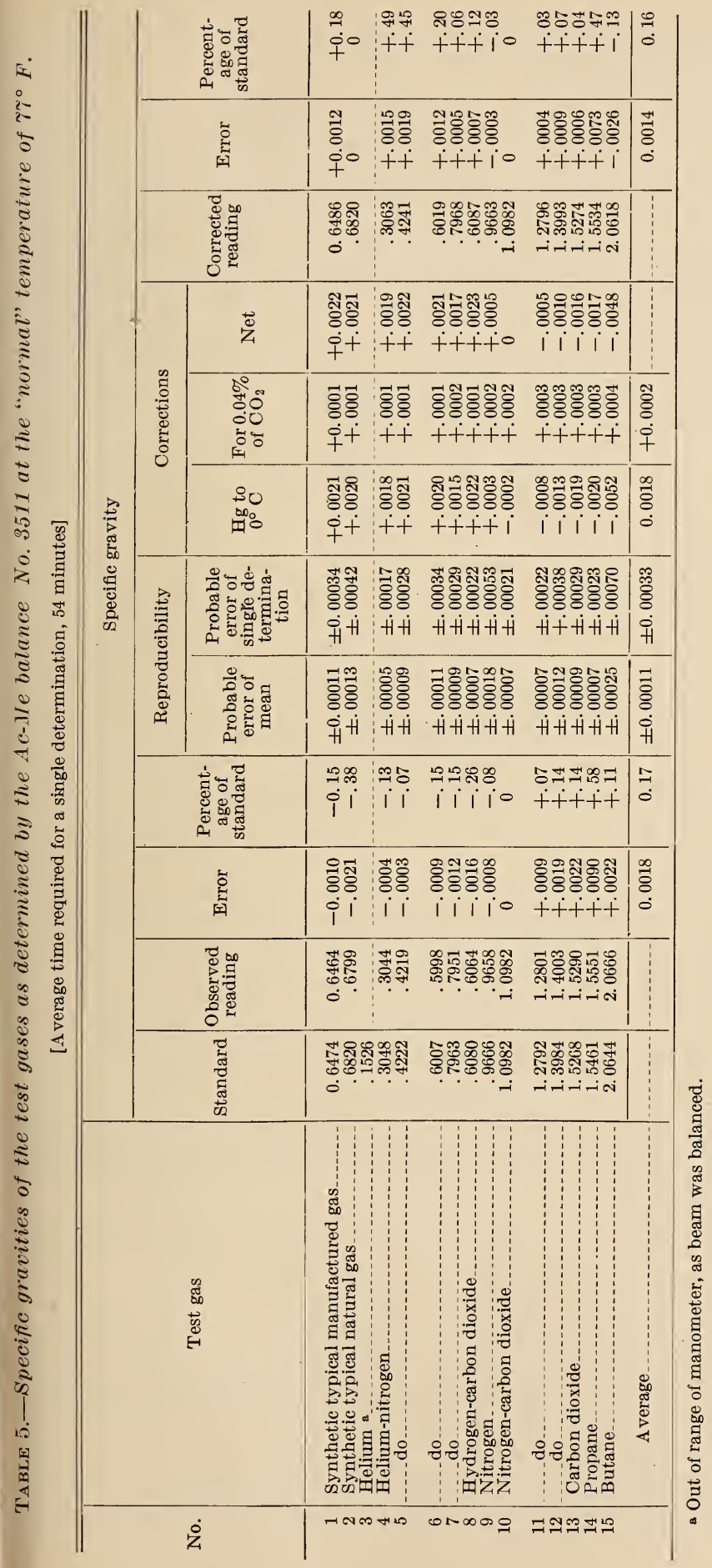


in the tables and plotted in the figures are "as observed" at the following a verage absolute pressures :
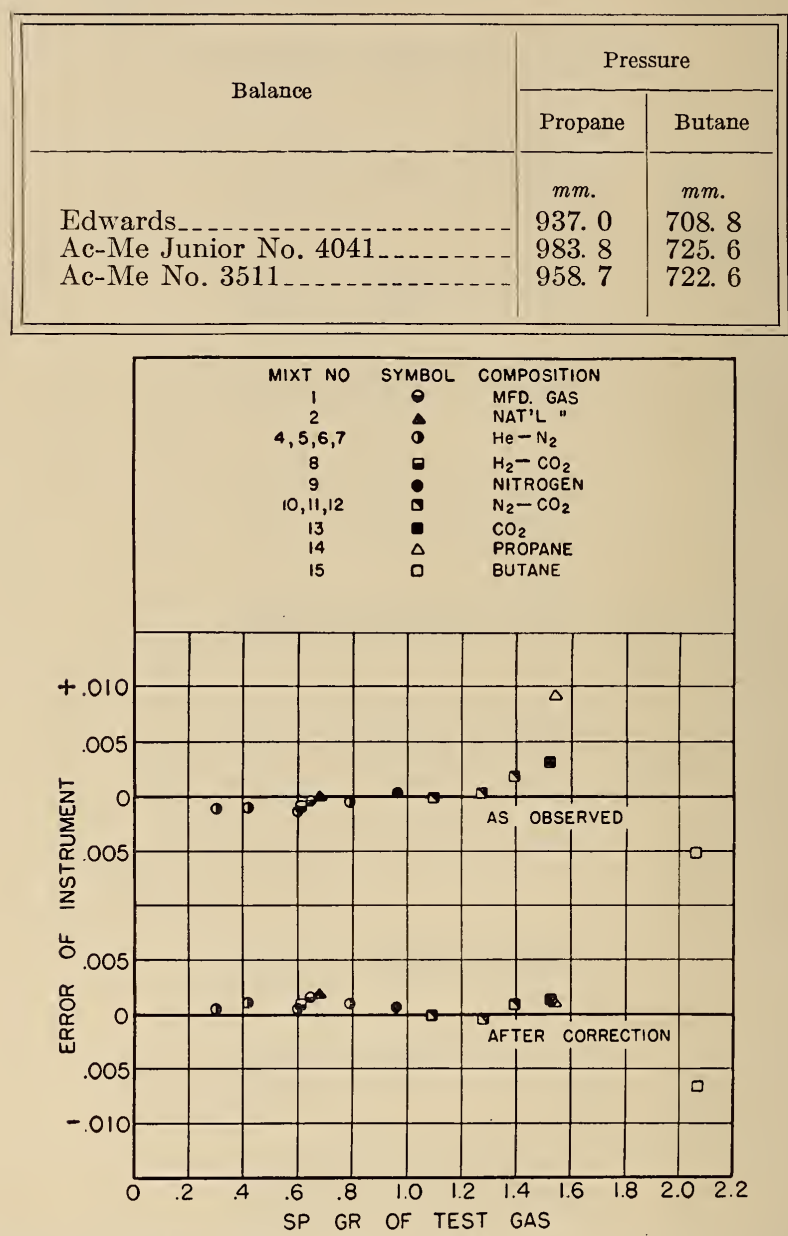

Figure 8.-Error of the Ac-Me Junior specific gravity balance No. 4041 determined with each test gas, as observed and after the application of corrections for the temperature of the mercury in the manometer and for carbon dioxide in the reference air.

'The errors, after correction, given in the tables are for the same pressures, but the errors, after correction, plotted in the figures for these gases were determined after interpolating between (or extrapolating from) the values for specific gravity obtained at the above absolute pressures and those obtained at absolute pressures below atmospheric in order to arrive at a value of specific gravity at an absolute pressure of $760 \mathrm{~mm}$, the pressure, at which the standard specific gravities of the test gases were determined.

In the case of propane, the error of each instrument was reduced in the manner just described to a value comparable with those ob- 


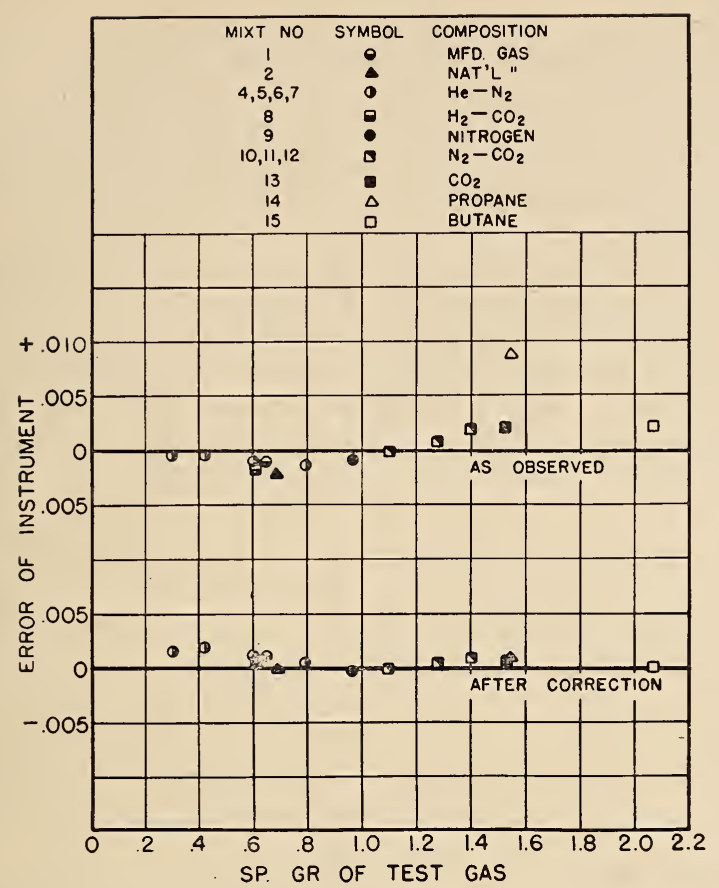

FIGURE 9.-Error of the Ac-Me specific gravity balance No. 3511 determined with each test gas, as observed and after the application of corrections for the temperature of the mercury in the manometer and for carbon dioxide in the reference air.

tained with the gases whose supercompressibilities (above that of air) were of negligible effect. The method was not so effective with butane except in the larger Ac-Me balance (No. 3511). The failure of the method in the case of the Ac-Me Junior (No. 4041) is believed to be attributable to the contamination of the reference air with butane that had been absorbed by the rubber hose and gasket, an effect that will be discussed later. IVhy the specific gravity remained low after the correction of the observations with the Edwards balance has not been satisfactorily explained. If the range of the manometer is sufficient to accommodate the air pressure required, it would be desirable in the routine measurement of the more compressible gases to adjust the counterweight on the beam so that the gas tested will balance the beam at just about normal pressure.

\section{(c) SOURCES OF ERROR}

(1) Temperature Coefficients.-Except for differences between the thermal expansions at constant pressure of the gases themselves and that of air and the effect of temperature on the manometer, there is no apparent reason why the measurements made with specific gravity balances of this group should be affected by temperature. The first of the two effects mentioned is known to be very small in the case of the usual gases, and corrections have already been made for the second. 
It was, therefore, to be expected that no appreciable effect of temperature on the corrected specific gravity would be found. To make sure of this, however, tests, consisting of 10 determinations of specific gravity of the same test gas (mixture 1), were made after adjusting and maintaining the temperature of the room to give instrument temperatures 10 or $12 \mathrm{deg}$ on each side of the temperature at the time of the original test.

The results, as observed and after correction for the temperature of the mercury in the manometer and for carbon dioxide in the air, have been plotted against temperature in figures 10,11, and 12. Straight lines, determined by the method of least squares, have been passed through the three points of each plot, and the slopes of the lines, constituting the temperature coefficients, have been indicated thereon.

The radius of the circle around each observed point is equal to the

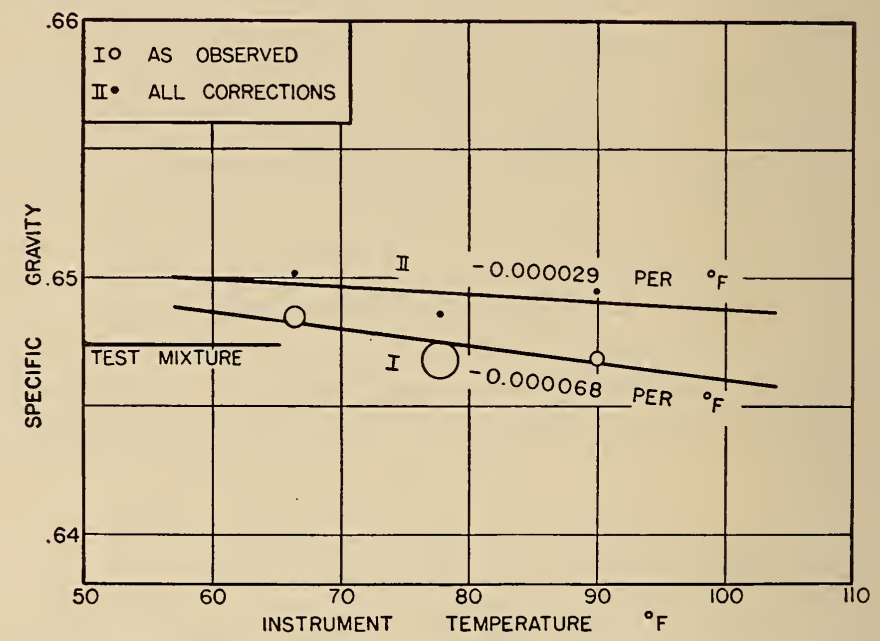

FIGURE 10.-Temperature coefficient of the Edwards gas density balance determined with text mixture 1, as observed and after the application of corrections for the temperature of the mercury in the manometer and for carbon dioxide in the reference air.

probable error of the mean of the 10 determinations which that point represents.

It may be noted that after corrections have been made for the temperature of the manometer, no residual temperature effects are greater than can be accounted for by random errors in the observations equal to the probable error of the series.

(2) Variations of Temperature.-If the temperature of the balance changes irregularly, so that the mean of the two air temperatures is not the same (within a few tenths of a $\operatorname{deg} \mathrm{F}$ ) as the intermediate gas temperature, correction of the specific gravity by an appropriate ratio of the absolute temperatures to bring the mean air temperature to the gas temperature is required. The variation to be permitted without correction is determined by the allowable error in the specific gravity. A difference of $0.1 \mathrm{deg} \mathrm{F}$ between the mean of the air 


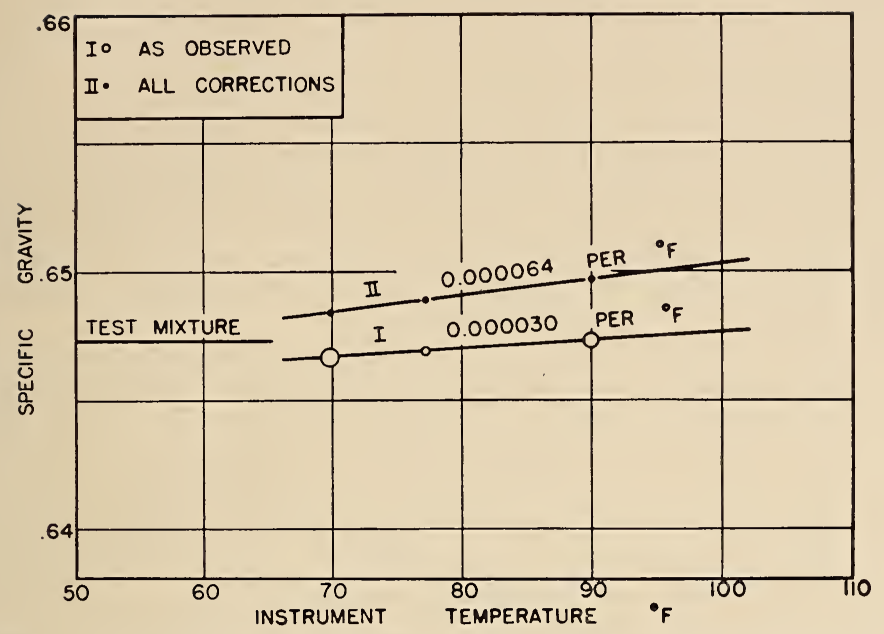

FIGURE 11.-Temperature coefficient of the Ac-IIe Junior specific gravity balance No. 40.11 determined with test mixture 1 , as observed and after the application of corrections for the temperature of the mercury in the manometer and for carbon dioxide in the reference air.

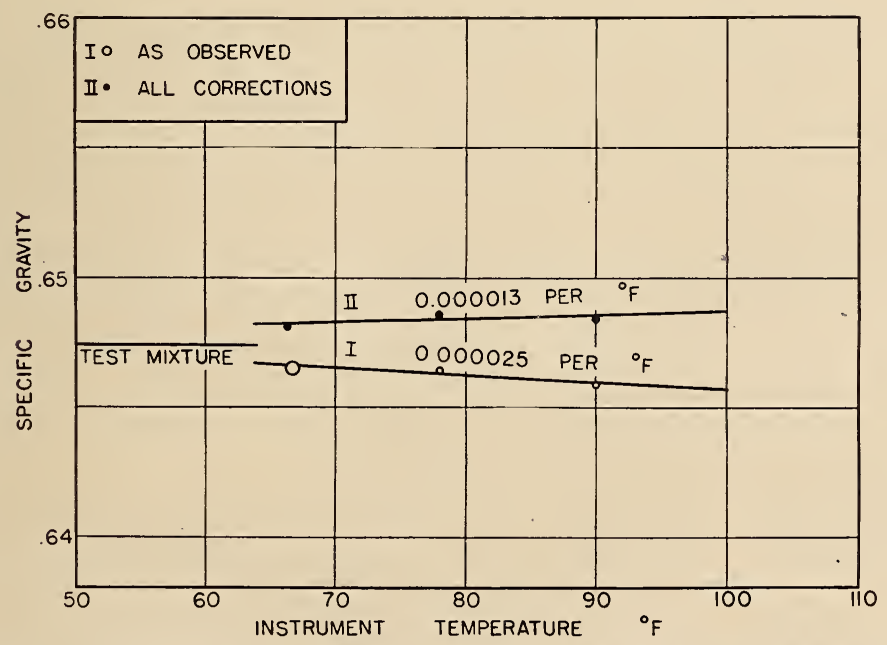

FIGURE 12.-Temperature coefficient of the Ac-Me specific gravity balance No. 3511 determined with test mixture 1 , as observed and after the application of corrections for the temperature of the mercury in the manometer and for carbon dioxide in the reference air. 
temperatures and the gas temperature changes by 0.0001 the specific gravity of a gas of 0.6475 specific gravity. Handling of the balance case causes such changes, and even changes in radiation from the operator or nearby electric lights, etc. may nullify careful control of the room temperature.

(3) Material Tested.-The possible effects of deviations of the gas tested from the ideal gas laws has been well illustrated by the errors in the "observed" specific gravities of propane and butane and their correction. The errors were of considerable magnitude, although the absolute pressures differed from atmospheric by not more than $224 \mathrm{~mm}$ for propane and $-51.2 \mathrm{~mm}$ for butane.

An uncertainty of the composition of the material tested, as a result of incomplete purging, may be a source of error. If the beam is balanced after purging three times by evacuation to $40 \mathrm{~mm}$ or less and filling to $760 \mathrm{~mm}$ or more (absolute), as was done with the Edwards balance, the error in the case of helium would amount to 0.00013 or less. If the beam is balanced after purging three times by evacuation to $110 \mathrm{~mm}$ or less and filling to $1,410 \mathrm{~mm}$ or more (absolute), as recommended by the manufacturer of the Ac-Me balances, the error for helium, assuming complete mixing, would amount to 0.0005 and for butane to 0.0015 , which may or may not be considered negligible. In the case of gases with specific gravities nearer air, the error would be correspondingly less.

If the pressure in the gas line connected to the needle valve is not kept above atmospheric, air may enter through the valve packing or any other possible leak in the line between the source of supply and the valve seat. It will then enter the balance case when the valve is opened for purging and filling.

A leak anywhere in the balance case would, of course, be a source of error through contamination of the gas sample with air while the pressure in the balance case is less than atmospheric. It was found necessary to replace the rubber gasket sealing the front cover of the Ac-Me Junior balance, and on four occasions leaks were found where the plastic window is penetrated to permit attachment of the mechanism to the front cover. Detection was by soap solution applied to the face of the balance, with the container above atmospheric pressure. Three of the leaks were evidenced by bubbles at the edges of the openings in the metal face. One appeared where the body of the packing gland for the locking device is screwed through the face. The recommendation of the manufacturer to make a test for leaks before using the instrument should not be disregarded.

A nearly, but incompletely, sealed dead space in communication with the inside of the balance case may be a source of error through contamination of the sample by slow interchange during and following changes of pressure. If the space in question is a part of or is the entire bulb on the beam, an error may also arise through a change in the weight of the bulb. The Edwards balance is fitted with a glass bulb which, in the absence of pin holes, it is probably easier to make permanently tight than a bulb of another material. On the other hand, the glass bulb is attached to the beam by inserting the end of the beam into a glass tube sealed into one end of the bulb and fastening it in place with cement. Needless to say, the space 
between the beam and the tube should be either sealed completely and permanently, or be made to communicate freely and completely with the interior of the balance case so that they can be purged together.

The composition of the sample, especially that of the reference air, may be uncertain because rubber absorbs gases while in contact with them, and then gives them up again to contaminate a different gas which has displaced the first. Especially is this true of water vapor, carbon dioxide, and the hydrocarbons. Of the gases used in this study, butane is absorbed more rapidly and in larger quantities than the others. It is also given off again rapidly when displaced by air.

The Ac-Me balances as furnished by the manufacturer are connected to the manometer with $30 \mathrm{in}$. of rubber hose and to the supply of gas and air by another hose $67 \mathrm{in}$. long. To determine whether butane absorbed by the rubber hose and the rubber gasket which seals the face to the container was contaminating the air when the balance was filled with air, the rubber hose of the Ac-Me Junior was replaced by copper tubing. Five determinations of the specific gravity of butane were then made at an average absolute gas pressure of 715.4 $\mathrm{mm}$ and five determinations at $204.9 \mathrm{~mm}$. When plotted and extrapolated to a pressure of $760 \mathrm{~mm}$, the error was only -0.0013 as compared to -0.0065 when the rubber tubing was used. It is possible that it might have been still smaller if the quantity of gasket rubber exposed to the gas had also bcen reduced to a minimum.

A similar replacement of the rubber hose of the Ac-Me No. 3511 balance with copper did not produce a corresponding reduction in the error of the tests. The results of three tests when copper tubing was used were all within the spread of the values obtained in the regular testing, and their average was slightly lower. If there had been any contamination of the reference air by butane from the hose, the values obtained when the copper tubing was used should have been higher.

In the tests with propane and butane, the purging of both $\mathrm{Ac}-\mathrm{Me}$ balances had been increased. In purging with gas, the balance was evacuated and filled four times to atmospheric pressure, instead of filling it three times to considerably more than atmospheric pressure. When purging with air, the balance was evacuated and filled to a pressure of about $700 \mathrm{~mm}$ above atmospheric pressure each time. This resulted in passing about $450 \mathrm{cu}$ in. of air through the hose in purging the Junior and $1,500 \mathrm{cu}$ in. in purging the No. 3511 balance. It seems probable that the effect of replacing the hose with metal on the readings of the Junior balance and the absence of any such effect in the No. 3511 balance resulted from the threefold difference in purging. If so, the fact that the tests with the Junior balance remained low after correcting for the effect of compressibility, while the larger balance gave excellent agreement with the standard, is also accounted for by absorption and release of butane from the rubber.

(4) Measurement of Absolute Pressure.-Uncertainties in the value of the absolute pressure at which the beam has been balanced may arise from uncertainty as to either the barometric pressure or the pressure difference.

Uncertainties in the barometric pressure arising from lack of necessary corrections, or from scale errors, or errors in reading may cause 
errors in the specific gravity. Corrections for temperature of a mercurial barometer often amount to $2 \mathrm{~mm}$ or more. Assuming everything else correct, failure to make such a correction (of $2 \mathrm{~mm}$ ) in the case of initial air, gas, and final air pressure readings of one of the determinations made with mixture 1 would result in the numerical value being higher by 0.0011 than it should have been. Such an error of course becomes larger as the absolute pressure involved becomes smaller.

Uncertainties in the pressure difference may arise in a number of ways. Probably the most frequent and perhaps the largest error is the result of failure to correct the observed pressure difference to that of mercury at $0^{\circ} \mathrm{C}$. In the determination of the specific gravity of mixture 1 , referred to in the preceding paragraph, the correction amounted to $1.6 \mathrm{~mm}$ for the air and $0.6 \mathrm{~mm}$ for the gas, and changed the specific gravity by 0.0014 . This error, of course, becomes larger with higher temperatures and larger pressure differences. If neither the barometer nor the pressure difference are corrected to their readings at $0^{\circ} \mathrm{C}$, the error resulting may be smaller. In the present illustration the specific gravity obtained without correction of barometer or pressure difference would be too low by 0.0002 . The correction to the barometer will not change very markedly if the temperature is nearly the same at all times, but the correction to the pressure difference, depending on the magnitude of that difference, varies greatly with different gases, and, while the two corrections may cancel in some circumstances, the only certain way to avoid the errors involved is to apply the corrections to both at all times.

In the case of the pressure difference, still other errors may be involved. The scale of the manometer supplied with the Edwards balance is made of rood, and wood expands and contracts with changes in relative humidity. The reference mark on the slide may not be accurately parallel to the horizontal marks on the scale. In the case of this instrument, there was a difference of about $0.2 \mathrm{~mm}$ from one side to the other. The slide is set out in front of both scale and manometer, with nothing to guide the observer in avoiding errors of parallax.

The scales of the Ac-Me instruments are etched on metal tapes which lie between the arms of the manometer but not even with the centers of the meniscus. The readings therefore involve a mental extrapolation of the end of one of the lines on the scale to the top of the meniscus in addition to front-and-back parallax. Although the background is dull white, it is difficult to illuminate the meniscus so that it stands out sharply, which makes it still harder to obtain accurate readings.

It is, of course, desirable to conserve weight and expense in construction, and the small bore of the manometer tubes is probably the result of efforts in this direction. In tubes less than 8-mm bore, differences in capillarity between one meniscus and the other, especially where one is open to the outer air and the other is not, may lead to errors of several tenths of a millimeter even though the tubes are tapped before reading. Even an apparently clean mercury surface in an apparently clean glass tube wets the surface of the glass to an extent that varies markedly from one position to another in the tube. The errors of 
parallax will probably be nearly random and may have opposite signs on the two sides of the manometer, thus doubling the effect.

(5) Balancing the Beam.-Variations in the pressure at which the beam is judged to be balanced involves errors of two kinds: (1) uncertainty as to when the positions of the beam are identical in successive tests with air and gas, and (2) mechanical effects which result in the beam assuming the same position under different forces. The magnitudes of both types of error depend mainly on peculiarities of construction of the individual balance; it is therefore necessary to discuss the three balances separately.

(A) Edwards Balance.-The beam of the Edwards balance carries a small "target" ruled with two closely spaced horizontal lines and is viewed, with the aid of a lens, through a window ruled with a single horizontal line, the "reference mark." If the beam is balanced with the reference mark opposite the upper mark on the target and then balanced with the reference mark opposite the lower mark on the target, the difference between the respective pressures amounts to about $8 \mathrm{~mm}$. If the operator succeeds in balancing the beam in the same position to one-tenth the distance between the lines on the beam target, he still has an uncertainty in the corresponding pressure of $\pm 0.8 \mathrm{~mm}$ from this source alone (and this difference may be in opposite directions during the measurements of gas and air).

Variations in the pressure difference required to produce apparently identical settings may result from slight and often unnoticed mechanical disturbances. When the beam had been brought to balance by a steady drift without oscillation, a tap with the finger on top of the front needle valve caused a slight oscillation. After oscillation ceased, the beam was found balanced at a different position than before, with no change of pressure. ${ }^{3}$

Although the presence of dust or moisture on the bearing surfaces or on the parts of the beam assembly, or imperfections in the agate bearings or on the points are recognized causes of such irregular behavior, thorough cleaning and examination with a glass disclosed no cause of this kind. The behavior continued with no other indication than a sudden change in the pressure at which the beam balanced. The change sometimes persisted for several determinations and involved both gas and air. Nothing was found loose on the beam assembly. The greatest care was taken to avoid the slightest jar and to prevent dust from entering the balance. Nevertheless, such changes, amounting to several millimeters of pressure, sometimes occurred two or three times in the course of the 10 successive determinations that constituted a "test" with one gas. When such changes were known to have occurred, the pressure measurement involved was discarded and the testing continued on the new basis until another such shift in the balance point of the beam occurred. Shifts undoubtedly occur which involve changes too small to be definitely ascribed to this cause, and which therefore enter as a variability in the results of the tests. In the illustration given of the treatment of the data, the 10 determinations of specific gravity involved balancing the beam 12 times in air. There was no known variation in the air,

3 To restore as closely as possible the original position of the balanced beam required a change of pressure as great as $4 \mathrm{~mm}$. 
but the extreme values of the absolute pressures involved were $9 \mathrm{~mm}$ apart. This variability is reflected in the high value of \pm 0.0023 for the probable error of a single determination.

If the beam is balanced repeatedly in air, the balance point being approached alternately from opposite directions without displacing it far enough to touch the stop in either direction, no significant difference in the balance point results. In normal use, however, purging the balance involves displacing the beam until it comes in contact with the stop. If care is taken that this contact is very gentle, the balancing pressures are usually reproducible. If the pressure is changed too rapidly or if the beam rebounds appreciably from contact with the stop, the balancing pressures are much more valiable. Undoubtedly this result and the shifts in the balancing pressures discussed above are caused by small shifts in the position of the points on the bearings and as these are not plane surfaces, the slope of the bearing surface changes with position. Changing the slope of the surface on which the bearing points rest might be expected to change the pressure at which the beam balances.

(B) Ac-Me Junior Balance No. 4041.-The elimination of errors of parallax in reading the position of the cross hair on the beam scale is essential. This may be accomplished by using a light in a fixed position and reading the position of the shadow of the cross hair on the scale as previously described.

The position of the shadow can be estimated to about one-tenth of a division on the scale; the divisions are about $1 \mathrm{~mm}$ apart. To avoid error's resulting from failure to secure exact balance, the sensibility of the balance was determined. The pressure was set to balance the beam with the cross hair near one end of the scale. Starting with a swing five or more divisions up and down, readings on the scale were taken each time the direction of swing reversed, while the amplitude decreased to less than one division up and down. Choosing a group of readings where the decrements were uniform, the mean reading of the cross hair was determined as in the case of the pointer of an analytical balance. This process was repeated at a series of pressures. The differences between successive absolute pressures were then divided by the corresponding differences between the readings on the scale to determine the number of millimeters corresponding to one division on the scale attached to the beam. The intention was to bring the beam to an approximate balance, determine the reading on the scale and on the manometer, and then correct the latter, using the sensibility, to what it would have been had the reading on the beam scale been exactly zero. It was found, however, that the values for sensibility were quite variable. For air at absolute pressures from 322 to $382 \mathrm{~mm}$, the sensibility varied from $10.5 \mathrm{~mm}$ per division to $7.25 \mathrm{~mm}$ per division, and averaged $8.9 \mathrm{~mm}$ per division. In the case of mixture 1 at absolute pressures from 505 to $626 \mathrm{~mm}$, the sensibility varied from $11.4 \mathrm{~mm}$ per division to $13.1 \mathrm{~mm}$ per division, but the $13.1 \mathrm{oc}-$ curred in the middle of the range, the average being 12.3. During this work it was also observed that when the reading on the beam scale was near zero, the mean reading was different when the amplitude was two or three divisions than when it was one division, although the pressure remained the same. 
It was noticed early in the testing that as the pressure was reduced to approach the balance point with the beam swinging with small amplitude, the beam could be balanced at a particular pressure. Then, if the amplitude of the swing were increased by vibration incident to closing the valve so that the reading of the cross hair reached several divisions below the zero, or if the vibration occurred while the reading was several divisions below zero, the beam would oscillate on either side of a reading which was about two-tenths of a division below zero instead of zero, thus causing the beam to balance at zero at a higher pressure than before the vibration occurred. The suspension was suspected and new springs installed, with the same result. The mechanism was checked and everything found tight. The action of each spring was observed with a lens while the beam was moved repeatedly from one extreme position to the other, but all appeared perfectly flat, and bending was smooth and without any perceptible twist or kink. Care was taken during testing to see that the beam was balanced on the same side of this "hump." Failure to recognize and guard against such behavior may result in errors or variations of several millimeters in the balancing pressures.

It would appear that a determination of sensibility would be a good test of proper functioning of the suspension. It would also appear that 9 to $12 \mathrm{~mm}$ per division is a rather large value, for considerable variations in the absolute pressure might be expected as a result of failure to secure exact balance at zero on the beam scale by the means provided by the manufacturer, as was indeed the case. Such variations are reflected in the variations observed in the series of ten determinations which constitute a test.

During the testing with mixture 6 (in December 1940), a tendency was noticed for the absolute pressure at the balance point to increase slightly during the series of ten determinations, which required a full day, although there was no corresponding drift of temperature to account for it. This tendency was noted from time to time, and with the heavier gases it became more pronounced. Mixtures 1 to 9 , inclusive, were all balanced below atmospheric pressure, so the effect, corresponding to a gradual increase in the weight of the bulb, could not be accounted for on the basis of gas entering the bulb through a leak or by deformation of the bulb in such a way as to lengthen the lever arm of the beam on that end. For butane, the effect had become so pronounced that increases in the absolute pressure at successive air balances amounting to several millimeters occurred several times during the series of determinations. Condensation of butane on the bulb was unlikely, because the pressure was never above 880 $\mathrm{mm}$ absolute, and its reevaporation into the air would have caused the balance in the contaminated air to occur at a lower instead of at a higher pressure. The effect of such behavior on the resulting specific gravity is probably not very great. An adequate explanation for this behavior has not been found.

(C) AC-Me BaLaxce No. 3511.-The elimination of parallax in reading the scale on the beam of this instrument was as necessary as for the smaller Ac-Me balance and was accomplished in the same way, by suspending a light in front of the balance and reading the position on the scale of the shadow of the cross hair. 
Scale divisions are of about the same length, $1 \mathrm{~mm}$, as in the Ac-Me Junior balance and can likewise be read to about one-tenth division. The sensibility of the balance was again tested at different parts of the scale with different amplitudes of vibration and with both air and mixture 1 in the balance. For air at absolute pressures from 381 to $406 \mathrm{~mm}$, the values of the sensibility were 1.26, 1.81, 2.35, 1.82, and $1.24 \mathrm{~mm}$ per division. Although these values are quite symmetrical, the value 2.35 was found at $2.2 \mathrm{~mm}$ below the zero of the scale. With test mixture 1 at absolute pressures from 586 to $627 \mathrm{~mm}$, the sensibilities were $2.02,2.84,3.39$, and $3.96 \mathrm{~mm}$ per division, increasing continuously from six divisions above to eight divisions below the zero of the scale. The average values, 1.7 and 3.0, in the two cases are, however, of a size likely to insure good reproducibility.

(6) Leveling.-If the level of the balance changes during a determination of specific gravity, the result may be in error. The Edwards balance does not carry a level and, as has already been stated is subject to the effects of comparatively slight shocks, which make necessary the checking of the air reading before and after balancing with gas. If the check readings are the same, it is probably safe to assume that the observed specific gravity has not been affected by a change of level.

The Ac-Me Junior balance was removed from the tripod and leveled up on a bench. The beam was then balanced in air at $1448.3 \mathrm{~mm}$ absolute. The front of the balance was then lowered by turning the two front leveling screws one complete turn, which tilted the balance through an angle of 10.1 minutes of arc. The beam then balanced at $1445.05 \mathrm{~mm}$ absolute. The change in balancing pressure was thus $3.25 \mathrm{~mm}$ for 10.1 minutes of arc. Successive determinations of the balancing pressure during the tests with test gases sometimes varied by $3.25 \mathrm{~mm}$ or more with the balance level. The intentional tilt was sufficient to move the bubble of the spirit level from the center until its edge nearly reached the reference circle; hence, errors from inaccurate leveling should not be significant in comparison with other uncertainties unless the tilt is easily noticeable on the spirit level.

During the application of similar tests to the larger Ac-Me balance, tilting the balance from the level position through 10.1 minutes of arc (by one turn of the leveling screw) changed the manometer reading by $4.25 \mathrm{~mm}$, from $1491.75 \mathrm{~mm}$ absolute to $1496.0 \mathrm{~mm}$ absolute, when the beam was balanced in air. Variations of successive determinations of the balancing pressure during the tests with test gases did not average much more than one-tenth of $4.25 \mathrm{~mm}$. One turn of the leveling screws caused the bubble in the spirit level to move from the center until its rim nearly reached the reference circle, but one-tenth of a turn produced only a barely perceptible change in the position of the bubble. A careful verification of the level is therefore desirable before each determination of the balancing pressure if the highest accuracy of which the balance is capable is to be obtained.

\section{(d) SUGGESTIONS FOR IMPROVEMENT OF INSTRUMENTS}

As one result of the investigation, certain suggestions for the improvement of each instrument were made to its manufacturer. In some cases these can be incorporated by the user of an instrument. 
These suggestions have been given careful consideration by the manufacturers, and some of them have since been adopted, as have other improvements originated by the manufacturers. The suggestions made for each instrument are stated below, but it should be recognized that after an instrument has been in use for a period of years, it is difficult to suggest improvements that may not already have been tried and discarded. In any case, improvements in performance and convenience must be balanced against increased complexity and cost.

(1) Edwards Balance.-(1) In view of the apparent susceptibility of the instrument to changes of balance point with slight mechanical disturbance, it might be desirable to eliminate the most frequent source of such disturbances, the changing of a rubber-hose connection at the rear needle valve when changing from air to gas and the reverse. Separate needle valves for gas and air might be used. Metal unions, cone and cylinder rather than ball and socket, would probably give less trouble than rubber-tube connections. Connections could then be made to both gas and air and left undisturbed for as long as desired.

(2) Some provision for anchoring the balance firmly to a solid foundation, free enough from vibration to avoid migration of the points on the supporting surfaces, and massive enough to resist movement by accidental contact, would probably result in a marked improvement in reproducibility.

(3) It might also be desirable to include in the directions some warningn of the effect of changing the pressure too rapidly, while purging, on the reproducibility.

(4) It might be desirable to provide some sort of reflecting surface behind the manometer tubes, and to bring the glass slide closer to the tubes and scale so that the operator could more easily avoid errors of parallax in reading the position of the meniscus, and at the same time make it easier to see the meniscus.

(5) If the nut for adjusting sensitivity is intended to be moved to different positions on its screw and left there, some means of keeping it in the desired position should be provided. The effect on the period of swing of moving the nut the full length of the screw is very small. Perhaps a heavier nut could be used, so that any reasonable changes of sensitivity might be made without the necessity of changing the position of the points. An 8-second period seems rather short, and the fact that changing the point of balance from one line to the other on the target involves a pressure change of $8 \mathrm{~mm}$, would seem to indicate that increasing the sensitivity might decrease the variability, and probable error of single determinations.

(6) As the effect on the specific gravity of correcting the pressure difference to $0^{\circ} \mathrm{C}$ to correspond with most barometer readings is not negligible, it would be advisable to call attention to this in the directions for use. It might also be helpful to state in the directions what period of swing is considered suitable for ordinary work, and what period is suitable for high sensitivity capable of yielding results concordant to \pm 0.0005 .

(7) It might be a convenience to operators who use the balance to test gases of widely different specific gravities to provide some means, such as a set of calibrated riders, which might be attached to 
the counterweight or other suitable holder in such a way as to be kept from moving while the balance is in use, but which would permit them to be interchanged conveniently to eliminate the necessity of adjusting the counterweight between tests. The range of the instrument might be changed in such a way, in three or four steps, so that it would accommodate all gases within the range of the manometer. Correspondence with the manufacturer indicates that most of the suggestions made can and will be incorporated in future models.

(2) Ac-Me Junior Balance No. 4041.-(1) Some means of casting a shadow of the cross-hair on the beam scale might be incorporated to advantage. An adjustable mirror mounted on the base might be a possible solution for use in the field, provided it did not reflect direct sunlight into the case and cause trouble from temperature changes.

(2) A wider tongue on the open end of the case would not tend to cut the rubber gasket as readily and might decrease the chance of leaks at this point.

(3) A window separated from the attachments of the mechanism to the face and reducing to a minimum the number of openings through the face would reduce the opportunities for leaks.

(4) A sensibility nearer 2- or 3 -mm pressure per scale division would improve the reproducibility of the results. This could probably only be accomplished by increasing the sensitivity and period of swing (if the size of the bulb and case are not increased), and this may cause other difficulties.

(5) Some means of leveling other than by adjusting the clamps on the legs of the tripod would be an added convenience.

(6) The end of the manometer that is open to the outer air might be equipped with a dust cap, which would help keep the mercury clean and still permit flow of air.

(7) The manometer tubes might be of larger and certainly should be of more uniform bore to decrease errors of capillarity and permit the measurement of $760 \mathrm{~mm}$ above and below atmospheric pressure without adjustment of the quantity of mercury. The whole mercury column is $45 \mathrm{~mm}$ shorter when most of it is in the closed side than when in the open side. With the present tubes, the slots in the scale are not long enough to accommodate the difference in bore.

(8) It might be well, in the instructions, to direct the user to tap the manometer on both sides before reading either meniscus.

(9) The hand pump does not work well on vacuum, and pumps effectively only on the down stroke on pressure. This may be the fault of this individual pump.

(10) Same as suggestion (7) on Edwards balance.

(11) A filter of some sort over the calcium chloride in the air dryer would be desirable to prevent dust from being blown into the balance case. A wad of absorbent cotton was used during these tests. Evidences of calcium chloride having been in the case were found before starting the tests.

(12) It would be desirable, if the balance is to be used with the hydrocarbon gases, to eliminate the rubber hose and minimize the exposure to gas of the rubber gasket.

(3) Ac-Me Balance No. 3511.-Suggestions (1) and (6 to 11) for 
the Ac-Me Junior No. 4041 balance apply equally to the larger balance and rere repeated for it. It was also stated that "some means for" determining the temperature (and temperature changes) of the gas in the container more accurately than can be done with the present thermometer might be desirable, although perhaps not practicable" in the case of this balance.

\section{ANUBIS PORTABLE GAS BALANCE}

(a) DESCRIPTION

The Anubis portable gas balance No. 115 (fig. 13) is described in Care and Operation Bulletin No. 106 of the American Recording Chart Co. The balance consists essentially of a gas chamber, within which a spherical bulb of spun brass is mounted on an invar beam provided with a cross head, in the under side of which are set two specially finished and very hard chrome-steel balls. These balls (used instead of the knife edges of an ordinary balance) rest on the highly polished and

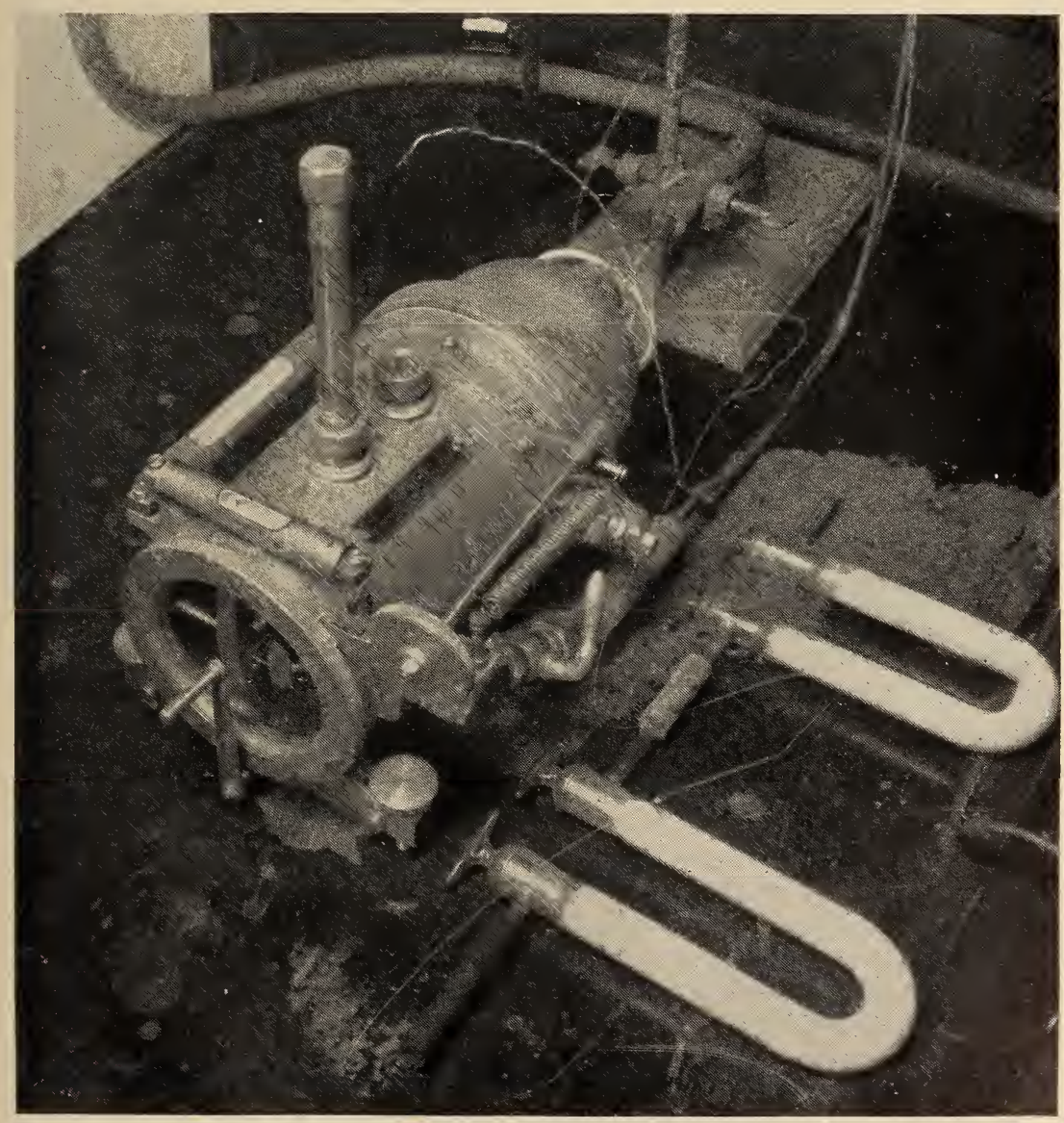

Figure 13.-Anubis portable gas balance No. 115. 
optically plane surfaces of two sapphires. The bulb is counterbalanced by a weight near the opposite end of the beam, and a small calibrating weight is directly below the center of gravity of the beam assembly. The front of the gas chamber is closed by a disk of plate glass, through which the oscillations of the beam are observed. The back head of the gas chamber is hemispherical, incloses the bulb, and is fitted with a purge valve consisting of a cap sealed with a sheet rubber gasket. The chamber is supported by a single ball-shaped foot under the back and by a cross bar at the front with two leveling screws. Two large transit levels, one longitudinal and the other transverse, are mounted rigidly on the chamber, and a thermometer in a metal sheath is mounted on top of the chamber with its bulb projecting through to the inside. A lever is fastened to the end of a shaft that projects through the transverse mounting of the chamber at the front, extends through a special rubber "torsion-tube" packing, and operates a toggle mechanism that raises two lifter forks. These forks engage the cross head of the beam on either side and lift the beam assembly and lock it against a locking pin which projects downward from the top of the chamber against the center of the cross head. A fixed scale, graduated in tenths from 0.5 to 1.5 , is mounted inside the front window at one side, and a movable index scale is mounted on the end of a movable arm at the other side. The movable arm is bent at right angles and passes through another special rubber "torsion-tube" packing in the side of the chamber near the back to form a shaft on which is mounted, outside the chamber, a toothed sector in mesh with a worm. The worm is rotated by a micrometer wheel at the front of the gas chamber and serves to raise or lower the movable index scale until, during a measurement, the beam pointer oscillates equally above and below the center of the scale. The micrometer wheel is divided into 100 equal parts for interpolation between the tenths on the fixed scale. It is possible to estimate tenths of a division on the wheel, so the specific gravity may be read to the third and estimated to the fourth decimal place. The gas chamber is provided with a fitting to which a manometer may be attached for use at pressures other than atmospheric, but this is not usually necessary and no manometer was furnished with the instrument tested. When used at atmospheric pressure, problems of leakage are eliminated. The sample is introduced through a plug cock mounted on the gas chamber near the front and provided with a fitting for rubber hose.

The beam assembly is calibrated by the manufacturer by adjusting the center of gravity with respect to the point of support to produce a fixed sensibility. This sensibility is such that the segment of arc subtended by the movable index scale when the micrometer wheel is lotated a given number of units on the specific-gravity scale corresponds to the same number of specific-gravity units between air and a gas of known specific gravity. It is thus calibrated to a deflection of arc that is directly proportional to the density of the gas. The conversion of density to specific gravity is made by correcting the observed reading of the instrument to the temperature and pressure at calibration, which was $30 \mathrm{in}$. and $60^{\circ} \mathrm{F}$, by application of the gas laws. The correction factors may be read from a chart supplied with the instrument. 


\section{(b) METHOD OF OPERATION}

The directions and illustrations in Instruction Bulletin No. 106, supplied with the balance, are good and are clearly presented. They were followed, with a few minor modifications and extensions, during the testing with nine of the gases of known specific gravity. 'The other gases used in the study were outside the range of the instrument.

Each test of the instrument with a test gas was preceded by an "air check," which involved purging the instrument with room air dried over calcium chloride for 5 minutes, making a reading, and repeating the purge and reading until no further drift in the readings was apparent. When the variations in the readings had become random, the instrument was then alternately purged and read as before, five times by each of two observers. The temperature and corrected barometric pressure at the time the balance was closed for each reading were recorded, and the level of the instrument checked or adjusted. The reading that should have been obtained with air is the reciprocal of the "correction factor" for the same temperature and pressure read from the chart supplied with the instrument. The difference between this "correct" value for air and the reading actually obtained is one value of the "air-check correction." The data for the first such air-check correction will show how all of them. were obtained.

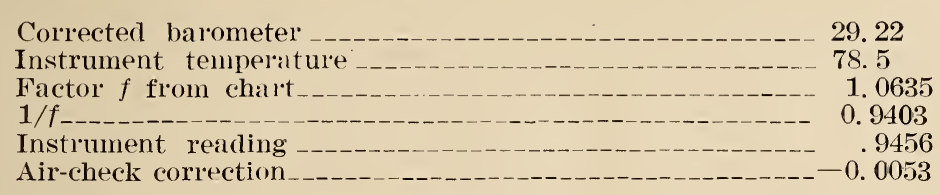

Ten independent settings of the scale were made for air before introducing a test gas and the 10 corresponding values of the aircheck correction were averaged. As this instrument does not measure the ratio of the density of the gas to that of the reference air but measures the difference between them, the average air-check correction was added (algebraically) to each of the readings obtained with the test gas.

The air check and the determination of the air-check correction were made just before each test with gas because the correction had been found to drift by a significant amount over a period as short as 2 weeks. When the correction had reached -0.0087 , the balance-adjusting rod was shifted, bringing the correction to +0.0038 . This effect will be discussed further in the section on sources of error.

Each test of the instrument with a test gas involved purging the instrument for one-half hour or more if the rate of flow approximated that used with air, or for 5 or 10 minutes if higher rates, sufficient to be felt by a moistened finger at the purge valve, were used. A reading was then taken, and the balance was alternately purged for 10 to 15 minutes and read until variations in the reading became random, as in the case of the air check. The balance was then left closed, and the temperature and pressure recorded for the reading last taken were considered to be the temperature and pressure during a series of five readings by each of two observers. The average air-check correction, previously determined, was applied to each 
of the 10 readings on gas, and the resulting value was then multiplied by the pressure and temperature correction factor taken from the chart, to give 10 values for the specific gravity. These 10 values of specific gravity obtained by the two observers were then averaged for the test.

Disregarding the changes of temperature and barometric pressure that may occur during the series of 10 readings is justified for these tests for the following reasons: The values of temperature and pressure used were those existing at the time the balance case was closed, at atmospheric pressure. The series of 10 readings required less than one-half hour. Barometric changes during this time are usually small, and could not produce any significant leak in a balance case tight enough to be used at pressures other than atmospheric. The temperature of the room was automatically controlled, and observed variations in the temperature of the balance rarely exceeded $0.5 \mathrm{deg} \mathrm{F}$ in a period of 2 hours. Except for leakage, the only possible error from changes of pressure or temperature during the observations is that caused by a change in the relative volumes of the balance case and the bulb. As both are made of brass, they should expand alike if subject to equal changes of temperature. If the case were $1 \mathrm{deg} \mathrm{F}$ warmer than the bulb, the apparent specific gravity would be diminished by 0.003 percent. As the bulb is very thin, a difference of even 1 deg between its temperature and that of the surrounding case could not occur except with a very rapidly changing temperature.

In making a reading, the beam was lowered gently to the jewels and released entirely when the beam pointer reached the lower edge of the movable index. The micrometer wheel having been turned counterclockwise somewhat below the anticipated reading, it was turned only clockwise during the approach to the balance reading. Because the balance point usually tends to shift toward a higher reading as the amplitude of swing decreases, the reading was always taken at the point at which the beam pointer having swung four divisions up then swung four divisions down. The reading of the pointer on the movable-index scale was noted at the top of the swing and again at the bottom of the swing, when, if not equal, an adjustment of the micrometer wheel was made immediately. If not equal by the time the swing had decreased to four up and four down, the beam was raised from the jewels and restarted without readjusting the micrometer wheel unless the reading had been overshot.

When testing was started with mixtures having specific gravities greater than 1.0, and with the movable index in approximately the right position, it was found that the pointer could not be lowered to the bottom of the movable index with the beam release lever. A swing of satisfactory amplitude was produced by lowering the pointer with the release lever to a suitable point (determined by experiment in the case of each gas) and then releasing the beam while in motion.

\section{(c) REFERENCE AIR}

The air used for reference with the Anubis balance was dried as it entered the balance, but only in later determinations was carbon dioxide removed. The concentration of carbon dioxide in the air of 
the room was found to average about 0.10 percent, as the room was not large, was not well ventilated, and contained two and sometimes three observers.

To take account of the error introduced by the presence of carbon dioxicle in the air with which the air check was determined and to indicate how corrections for it may be applied if and when circumstances require it, the results as observed have been corrected for 0.1 percent of carbon dioxide in the reference air in those cases in which it was not remored by Ascarite. The correction cannot be applied to the mean observed value of the specific gravity in the same way in which it was done for the instruments that measure the ratio of the density of the gas to that of the reference air, because this instrument measures the difference between them. The correction must be applied by including it in the air-check correction. The reading that the balance should give with air free from water vapor and carbon dioxide at the observed temperature and pressure (the reciprocal of the factor taken from the chart) was corrected to what it would have been had the chart been computed with air containing the quantity of carbon dioxide found in the reference air, by means of the equation

where

$$
S=R\left(1.5290\left[\mathrm{CO}_{2}\right]+1-\left[\mathrm{CO}_{2}\right]\right),
$$

$S=$ the reading which the balance should give with pure air at the observed temperature and pressure.

$S=(1 / f$, where $f$ is the factor from the chart. $)$

$R=$ the reading that the balance should give with air containing the observed concentration.

$\left[\mathrm{CO}_{2}\right]=0.0010$ by rolume: the observed concentration and $1.5290=$ the specific gravity of carbon dioxide.

The data previously used to illustrate the determination of the aircheck correction will be used to illustrate the evaluation of an aircheck correction that takes account of 0.1 percent of carbon dioxide in the reference air. The ralue of $1 / f$ previously used, 0.9403 , was substituted for $S$ in the above equation, which was then solved for $R$.

$$
0.940 .3=R(1.5290 \times 0.0010+0.9990)
$$

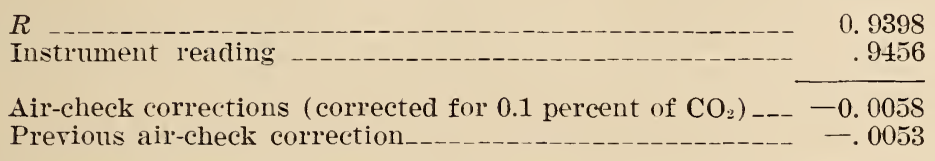

Difference in applied correction because of 0.1 percent

of $\mathrm{CO}_{2}$

The correction for carbon dioxide was applied by subtracting 0.0005 from each "air check" made with room air. The value -0.0005 applies only to the temperature $78.5^{\circ} \mathrm{F}$ and barometric pressure 29.22 , for it depends on the value of $f$ from the chart corresponding to these conditions. At appreciably different temperatures and pressures, it may have a different value.

The specific gravity of test gas 1 , corrected for 0.1 percent of carbon 
dioxide in the air, was determined as follows from the data obtained during the first of the 10 readings on gas:

\begin{tabular}{|c|c|}
\hline ected bar & \\
\hline Instrument temperature -- & 78. 2 \\
\hline [nstrument reading & 0.6124 \\
\hline air-check & -.0057 \\
\hline rrected for air & 0. \\
\hline $\mathrm{rt}_{-}$ & 1. 0574 \\
\hline $6067 \times 10574)$ & $0.6 \pm 15$ \\
\hline
\end{tabular}

Each of the other nine instrument readings on test gas 1 was treated in the same manner, and when averaged gave a value of specific gravity (corrected for 0.1 percent of carbon dioxide) of 0.6422 .

The observed results of the tests with mixtures 1,2 , and 6 have been corrected as indicated above. In all the other tests the carbon dioxide was removed by Ascarite before drying the air, and consequently no correction for carbon dioxide was applicable.

The error of the instrument with test gas 1 was computer as follows:

Specific gravity, corrected for $\mathrm{CO}_{2}$ in air-_-_-_- 0.6422

Specific gravity of test mixture 1

Error of instrument_-_- 0.0052

Error, percentage of standard_..

The data for each of the nine test gases and for the first test gas. at three different temperatures have been treated in the same way.

(d) NUMERICAL RESULTS

A summary of the numerical results obtained from the tests of the balance with the series of test gases employed in the investigation (except the tests made for determining a temperature coefficient) is given in table 6 , and in figure 14 the instrumental errors are plotted with respect to the specific gravities of the test gases. It is quite evident that the errors are not primarily dependent on the chemical makeup of the gas or the order in which they were measured, but that they tend to approximate some continuous function of the specific gravity. At specific gravities of 0.56 and 1.00 , which represent calibration points, there are no appreciable errors, but at other densities the error's are too systematic and far too great to be considered the result of random causes. A consideration of the mechanics of the balanced system provided an adequate explanation.

\section{(e) MECHANICAL ACTION OF THE ANUBis BALANCE}

In the following discussion, the true specific gravity of gas in the balance case is represented by $S$ and the scale reading obtained when the beam is balanced by $R$. S-R is the error of the reading, of course. The forces acting on the balance beam (including everything attached to it) may be resolved into a supporting force exerted by the agate plane and the "apparent" weight, $m$, of the beam (the weight in vacuum minus the buoyant force exerted by the gas in the balance case). When the beam is in equilibrium, these forces are equal in magnitude and act in opposite directions in the same vertical line. If the buoyant force is changed, one end of the beam is affected much 


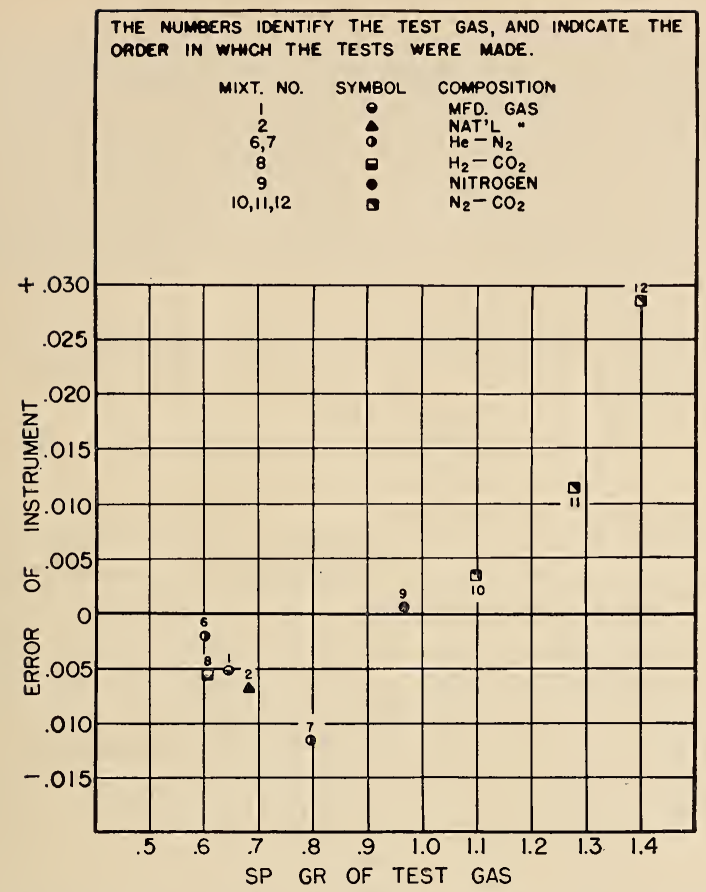

Figure 14.-Error of the Anubis portable gas balance No. 115 determined with each test gats after correction for carbon dioxide in the reference air.

TABLE 6.-Specific gravities of test gases as determined by the Anubis portable gas balance No. 115 at the "normal" temperature of $77^{\circ} \mathrm{F}$.

[A verage time required for a single determination, 4.2 minutes]

\begin{tabular}{|c|c|c|c|c|c|c|c|}
\hline \multirow[b]{3}{*}{ No. } & \multirow[b]{3}{*}{ Test gas } & \multicolumn{6}{|c|}{ Specific gravity } \\
\hline & & \multirow[b]{2}{*}{$\begin{array}{l}\text { Stand- } \\
\text { ard }\end{array}$} & \multirow[b]{2}{*}{$\begin{array}{l}\text { Cor- } \\
\text { rected } \\
\text { reading }\end{array}$} & \multirow[b]{2}{*}{ Error } & \multirow[b]{2}{*}{$\begin{array}{l}\text { Per- } \\
\text { cent- } \\
\text { age of } \\
\text { stand- } \\
\text { ard }\end{array}$} & \multicolumn{2}{|c|}{ Reproducibility } \\
\hline & & & & & & $\begin{array}{l}\text { Probable } \\
\text { error of } \\
\text { mean }\end{array}$ & $\begin{array}{l}\text { Probable } \\
\text { error } \\
\text { of single } \\
\text { determina- } \\
\text { tion }\end{array}$ \\
\hline 1 & $\begin{array}{l}\text { Synthetic typical manufactured } \\
\text { gas }\end{array}$ & \multirow{4}{*}{$\begin{array}{r}0.6474 \\
.6820 \\
.1526 \\
.3048 \\
.4222\end{array}$} & \multirow{2}{*}{$\begin{array}{r}0.6422 \\
.6751\end{array}$} & \multirow{2}{*}{$\begin{array}{r}-0.0052 \\
-.0069\end{array}$} & \multirow{2}{*}{$\begin{array}{l}-0.80 \\
-1.01\end{array}$} & \multirow{2}{*}{$\begin{array}{r} \pm 0.00014 \\
\pm .00007\end{array}$} & \multirow{2}{*}{$\begin{array}{r} \pm 0.00045 \\
\pm .00022\end{array}$} \\
\hline 2 & $\begin{array}{l}\text { Synthetic typical natural gas } \\
\text { Helinm a }\end{array}$ & & & & & & \\
\hline 4 & Helium-nitrogen a & & & - & (n) & --- & - \\
\hline 5 & 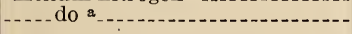 & & & & & & \\
\hline 6 & _.... do & .6007 & .5986 & -.0021 & -0.35 & \pm .00025 & \pm .00079 \\
\hline 7 & do & .7963 & .7849 & -.0114 & -1.43 & \pm .00029 & \pm .00092 \\
\hline 8 & Hydrogen-carbon dioxide & .6080 & .6024 & -.0056 & -0.92 & \pm .00013 & \pm .00042 \\
\hline 9 & Nitrogen & .9666 & .9672 & +.0006 & +.06 & \pm .00014 & \pm .00044 \\
\hline 10 & Nitrogen-carbon dioxide & 1. 0982 & 1. 1017 & +.0035 & +.32 & \pm .00016 & \pm .00051 \\
\hline 11 & $\ldots$..._. do & 1. 2792 & 1. 2907 & +.0115 & +.90 & \pm .00012 & \pm .00039 \\
\hline 12 & do & 1. 3984 & 1. 4269 & +.0285 & +2.04 & \pm .00011 & \pm .00033 \\
\hline 13 & Carbon dioxide a & 1. 5268 & & & - n-n & -non & (n) \\
\hline 14 & Propane a & 1. 5461 & 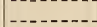 & - & - & - & - \\
\hline 15 & Butane a & 2.0644 & & (-non & - n-n & & \\
\hline & Averages .... & & $\ldots$ & 0.0084 & 0.87 & \pm 0.00016 & \pm 0.00050 \\
\hline
\end{tabular}

a The range of the instrument was such that the specific gravities of these gases could not be determined. 
more than the other, with the result that the apparent center of gravity (the point of application of $m$ ) is shifted, and to bring this point again into vertical alinement with the point of support and thus restore equilibrium, the beam must rotate through a certain angle.

The scale of the balance is graduated so that equal angles are marked with equal increments of specific gravity, and the counterweight and weight for adjusting sensitivity are fixed by the manufacturer so that the reading is correct with air $(S=1)$ and with some other gas of known specific gravity, $S_{1}$.

A somewhat involved consideration of simple mechanical principles leads to the equation

$$
S-R=\frac{m N}{A L}\left(\frac{a}{a_{1}} \tan a_{1}-\tan a\right),
$$

in which $N$ is the distance of the apparent center of gravity below the center of the bearing balls when the beam is in equilibrium, $A$ is the weight of air displaced by the bulb, $L$ is the distance from the center of volume of the beam (nearly the center of the bulb) to its center of gravity (nearly the center of the bearing balls), $a$ is the angle between the equilibrium position of the beam in the gas being tested and the equilibrium position in air, and $a_{1}$ is the corresponding angle between the equilibrium positions in the calibrating gas and in air. $S-R$ is the error in the determination of specific gravity inherent in the mechanics of the system, and would be the same for a balance of any kind in which equal angles are graduated to represent equal increments of specific gravity. Actually, a balance operates to make $S-1$ proportional to the tangent of the angle of displacement from the position of equilibrium in air, not directly to that angle, and this is the source of the error. Unfortunately, the scale cannot be made proportional to the tangents of angles without abandoning the present very convenient micrometer head and worm gear as a reading device.

Each of the quantities on the right-hand side of eq 7 can be determined approximately. $N$, the distance of the center of gravity below the center of the ball, is subject to adjustment and determines the "sensitivity," the angle of displacement corresponding to a given change in specific gravity; it can be computed from the two lastmentioned quantities.

In the Anubis balance, the sensitivity is such that a change of specific gravity of 0.1 causes a deflection of about $2.5^{\circ}$. The calibrating gas was reported to have had a specific gravity of 0.56 . The errors inherent in the scale have been computed and are represented in figure 15 by the curve marked $2.5^{\circ}$ : As a matter of interest, the errors that would have resulted had adjustments been made to give higher sensitivities of $3.5^{\circ}$ and $5.0^{\circ}$ per 0.1 unit of specific gravity have been added to the figure.

The observed errors were much greater than those calculated by eq 9 for a balance of the observed sensitivity, and their plot can be considered to resemble the curves of figure 15 only in a general way. However, the balance beam is supported on balls resting on a plane, and if the plane is tilted the balls tend to roll downhill. This tendency modifies the curve of errors decidedly. In the following dis- 
cussion, the angle between the bearing plane and the horizontal will be represented by $e$ and the radius of the bearing balls by $r$. 'The point of support of the beam is no longer directly below the line connecting the center of the balls, and neither is the apparent center of gravity. The angle between the vertical and a perpendicular from the apparent center of gravity to the line connecting the centers of the balls will be represented by $e^{\prime}$. The other symbols have the same meanings as in eq 7.

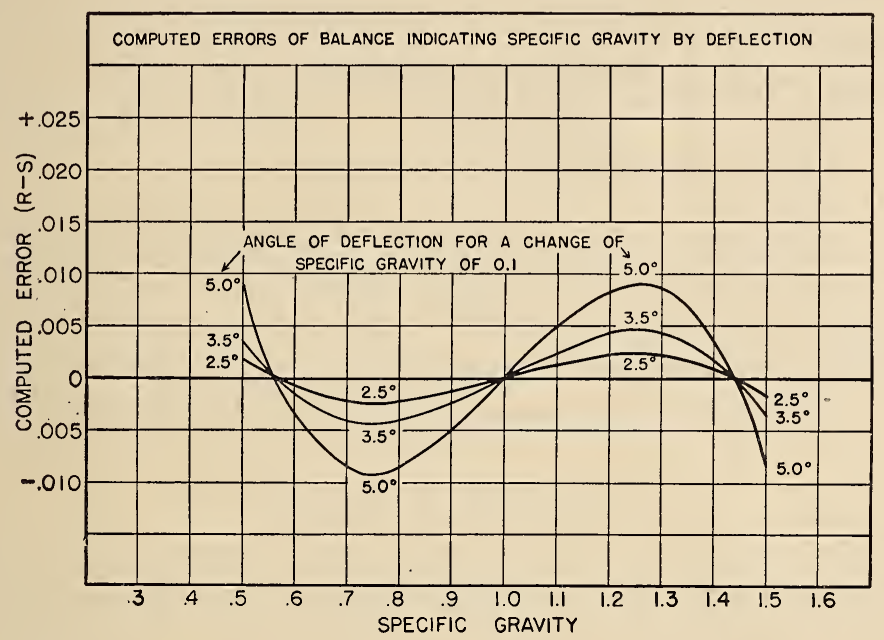

FIGURE 15.-Computed errors of a balance indicating specific gravity by deflection.

Again, by considering simple mechanical principles, it is found that

$$
\sin e^{\prime}=\frac{r}{N} \sin e
$$

and that

$$
\begin{aligned}
& S-R=\frac{a}{a_{1}} \times \frac{m r \sin e}{A L \cos a_{1}}\left[\frac{\sin \left(e^{\prime}+a_{1}\right)}{\sin e^{\prime}}-1\right] \\
& -\frac{m r \sin e}{A L \cos a}\left[\frac{\sin \left(e^{\prime}+a\right)}{\sin e^{\prime}}-1\right] .
\end{aligned}
$$

Again, putting approximate values for the Anubis balance into the equation, the curves shown in figure 16 were obtained for various angles of tilt. The curve marked $0^{\prime}$ is the same as the curve marked $2.5^{\circ}$ in figure 15 . The small circles represent the observed errors previously shown in figure 14 . Figure 16 appears to offer a complete explanation for the general trend of the observed errors if the bearing planes were tilted about $0.5^{\circ}$ with respect to the level on the balance case at the time of calibration. This tilt apparently remained unaltered, as the curve of errors appears to pass through 1.0 and 0.56 , the calibration points, within the limit of experimental error. 


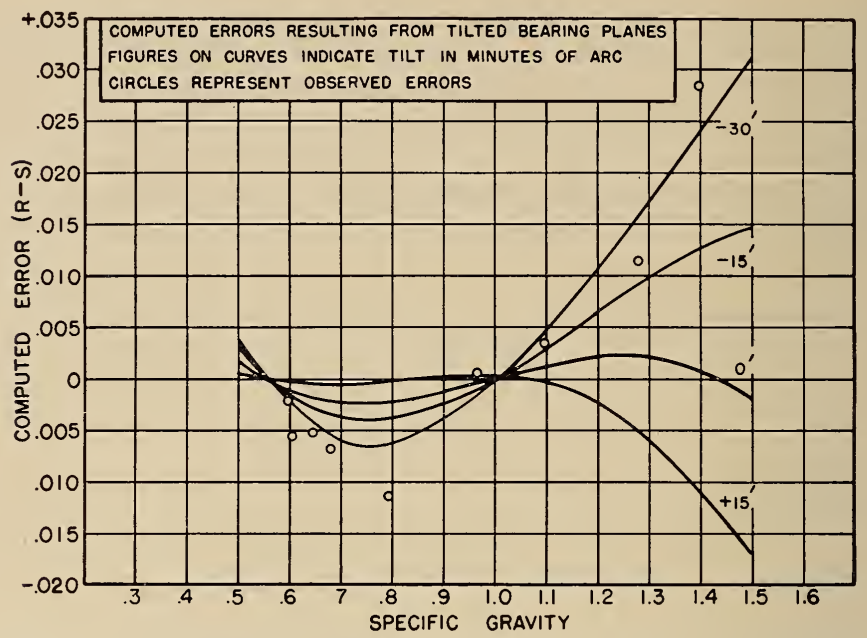

FIGURE 16.-Computed errors resulting from tilted bearing planes.

Figures on curves indicate tilt in minutes of arc. Circles indicate errors observed for Anubis portable gas balance No. 115 .

\section{(f) LEVELING THE BALANCE}

The errors discussed in the preceding section were computed under the assumption that the instrument is used in exactly the position in which it was calibrated; they are inherent in the mechanics of the instrument and have nothing to do with its manipulation. A displacement of the longitudinal level after the air check is made introduces another set of errors that is much greater than that resulting from an inclined support at the time of calibration. The effect can be computed from eq. 8 , in which $e$ is the angle of tilt and $e^{\prime}$ the error (in terms of angle) resulting from it. For the Anubis balance with a sensitivity of $2.5^{\circ}$ per 0.1 unit of specific gravity, it is found that a change of level of $0.1^{\circ}$ after the air check will affect the following measurement of specific gravity by 0.145 .

This extraordinary sensitivity to a change of level makes serious the slightest disturbance between the time of the air check and the reading of the specific gravity of the gas. The most probable cause of such a disturbance is the accidental movement of the balance during connecting or disconnecting from the gas lines or air dryer or during manipulation of the valves. If after the balance has been moved the spirit level is depended on to restore the condition of the last air check; the leveling must be done within an angle of about $0.0007^{\circ}$ if the next reading is to be accurate to even 0.001 specificgravity unit. This is an almost impossible requirement.

During the experiments with the balance, it rested on a heavy stone laboratory table top supported on wooden cabinet work. The effect of inaccuracies of leveling the instrument were studied experimentally by placing a weight of $25 \mathrm{lb}$ on the edge of the stone table top in front of the balance. This caused the bubble in the spirit level to move toward the back of the instrument by about one tenth of a 
division on the scale etched on the level. A series of 10 observations of the balance reading on a single sample of air were made alternately with and without the weight on the table. The average of five observations with the level displaced differed by 0.0018 from the average of the five taken with the instrument level. This means that variations of 0.0002 in specific gravity may result from variations of the level of 0.01 division, which is entirely imperceptible. Perceptible variations result when the arm is rested on the edge of the table while adjusting the micrometer wheel, indicating that care should be taken to see not only that the instrument is level when observed but that it is not displaced from level during the process of making the adjustment to the balance point.

\section{(g) TEMPERATURE COEFFICIENT}

Tests, consisting of 10 determinations of specific gravity with the same test gas (mixture 1 ), were made at $65.0^{\circ}$ and $90.1^{\circ} \mathrm{F}$ in addition to that at $78.2^{\circ} \mathrm{F}$, for which the results have been given in detail.

During these tests at a lower and at a higher temperature than normal, the temperature of the room was maintained substantially

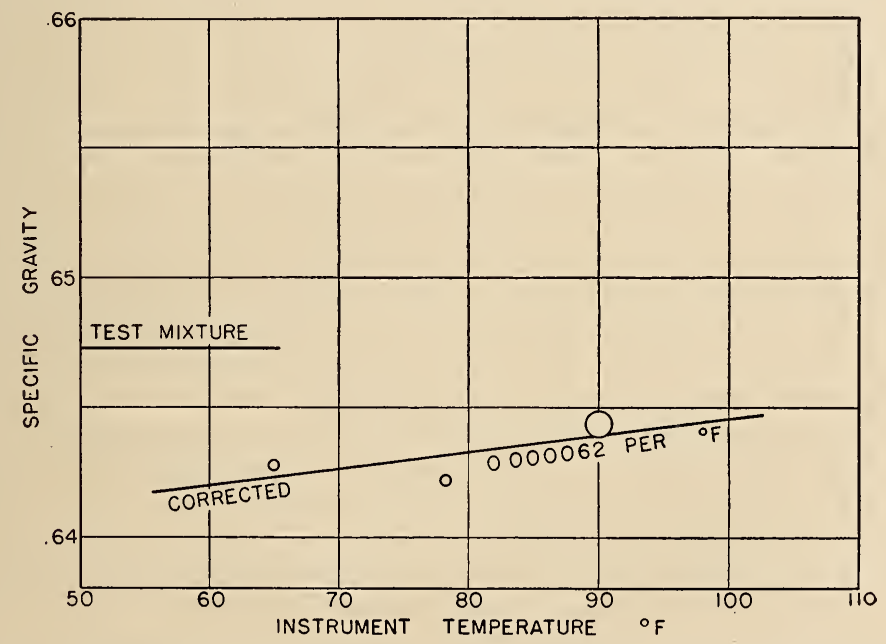

FiguRE 17.-Temperature coefficient of the Anubis portable gas balance No. 115 determined with test mixture 1 , after oorrection for carbon dioxide in the reference air.

constant by automatic control, and several hours were allowed for the balance to come to temperature equilibrium before starting the test. The air check was, of course, made at the same temperature as the test with the gas.

The results have been plotted against temperature in figure 17. A straight line, determined by the method of least squares, has been passed through the three points, and the slope of the line, constituting the temperature coefficient, is indicated thereon. The radius of the circle around each observed point is equal to the probable error of the mean of the 10 determinations which that point represents. The fact 
that the observed differences between the specific gravities at the three temperatures are not greatly in excess of their probable errors and that they vary in a somewhat improbable manner leaves some doubt as to whether the balance has an appreciable temperature coefficient. Any inaccuracy in the construction or use of the correction chart and differences in the deviations of test gas and reference air from the ideal gas laws, as well as changes in dimensions of the balance itself, would appear as part of the "temperature coefficient." As to changes of dimensions within the balance, any change that shifts the center of gravity or the center of volume of the parts attached to the beam horizontally, would produce the same temperature coefficient for all gases. If the changes affected the vertical distance between the center of gravity and the bearing surface, the temperature coefficient would be proportional to the difference between the specific gravity of the gas and 1.0.

\section{(h) OTHER PROBABLE SOURCES OF ERROR}

(1) Air-Check Correction.-If the instrument is so calibrated that its reading on dry carbon dioxide-free air at $30 \mathrm{in}$. and $60^{\circ} \mathrm{F}$ is 1.0000 , it will indicate directly the specific gravity of a gas sample at the same temperature and pressure. It is impracticable to set the reading exactly on 1.0000 under these conditions, or on the exact reading corresponding to this at any other temperature and pressure, after ascertaining the correct reading by use of the gas law factor in the chart supplied with the instrument. The procedure recommended in Bulletin 106 is to determine the reading of the instrument on air, and then to determine the difference between this and the reading which the instrument should give at the temperature and pressure observed, as determined by use of the chart. This difference is then applied as a correction to the observed reading on gas before correction to standard conditions. If the air used were dry and free from carbon dioxide, if temperature and pressure determinations were accurate, if sufficiently precise leveling were possible, and if no mechanical changes were to occur in the balance mechanism, a single determination of the air-check correction would suffice. If accuracy is important, however, the correction should be determined after moving to a new location or support and thereafter at intervals sufficiently frequent to demonstrate the permanence of the correction or insure that it is known to the required limit of uncertainty. It has been suggested that the shift in the air-check correction for balance 115 may have been the result of gradual relief of mechanical strains in the arm carrying the movable index, introduced when it was shaped.

Individual determinations of the air-check correction vary sufficiently to necessitate the use of the average of a series of determinations rather than a single one. In the case of the test used as an illustration above, the probable error of the mean of 10 determinations was 0.00013 , while that of a single determination was 0.00042 .

(2) Calibration.-The instrument is calibrated by the manufacturer, and its accuracy thereafter depends on the accuracy with which the calibration is made and the absence of subsequent changes which may affect it. It is important to follow the instructions in Bulletin 106 with regard to changes of any part of the beam assembly, since 
any vertical change of the center of gravity of the beam with respect to the point of support will change the calibration. Such effects may arise from careless handling, or possibly from the gradual relief of mechanical strains in the invar beam. They may manifest themselves in changes in the air-check correction, if not obscured by larger effects such as those discussed above, but they will be accompanied by changes of calibration which can only be detected by testing the instrument with a gas of accurately known specific gravity. It should be stated, however, that the balance is ruggedly made and that no effects were observed which could be attributed to a change in "calibration."

The accuracy with which the manufacturer knows the specific gravity of the gas used for calibration is important, for an uncertainty of 0.001 at a specific gravity of 0.750 may amount to an error of 0.002 at a specific gravity of 0.500 and 1.500 . At specific gravity 1.000 , calibration errors become unimportant as compared with those resulting from errors in level, pressure, temperature, correction chart, and determination of the balance point.

(3) Purity of Material Tested.-An uncertainty of the composition of the material tested, as a result of incomplete purging, may be a source of error. Purging should be rapid enough to produce some turbulence inside the balance case which will keep the contents stirred up and clean out corners. A filter may be necessary, as suggested in Bulletin 106, if the gas carries dust. Alternate purging and reading until the variations in the readings become random may be required to establish the time required at the rate used. In the case of air, the rate should not be so high that incomplete drying results. Air from a compressed supply may contain vapors or other gases. Air from the laboratory may be similarly objectionable. 'The balance is not provided with means for purging with air from other than a compressed supply, but means for drawing air from the laboratory are not difficult to provide. If the laboratory air is not free from carbon dioxide, as will usually be the case, this should be removed before drying the air during purging, or corrected for, as has been done in the case of the test described above. Air from outside, unless contaminated with measurable amounts of foreign gases, would be preferable. The carbon dioxide content of outdoor air may be as high as 0.04 percent, which would affect the specific gravity by 0.00014 . The 0.10 percent of carbon dioxide found in the air of the laboratory necessitated a correction of 0.0005 in the specific gravity, which is somewhat larger than the probable error of a single determination and may not be negligible.

As long as the balance is operated at atmospheric pressure, contamination of the sample by leaks is eliminated as a source of error, but, to prevent diffusion of air into the balance, care must be taken to close the purge valve as soon as the balance has reached atmospheric pressure after the gas flow is stopped.

(4) Determination of Balance Point of Beam.-The determination of the balance point of the beam, and consequently the reading on the scale, is subject to errors or uncertainties from several sources, most of which are covered or implied in the directions for operation. The reading is lower when the pointer swings five divisions up and five down on the movable index scale, than when it swings four up and four down. The damping also seems to be more rapid and less regular. 
The reading continues to increase as the amplitude decreases. As indicated in Bulletin 106, best results are attained by taking the reading when the amplitude is four divisions up and four down.

The method by which the pointer is determined to be swinging four divisions up and four down makes a difference in the reading. If the reading of the pointer on the movable index scale is observed at the top of its swing and again the next time the pointer reaches the bottom of its swing and the adjustment is made immediately thereafter, the reading on the micrometer wheel will differ by about 0.004 from that obtained if the adjustment follows observations made in the reverse order. The first procedure gives the better results, when the index scale is being adjusted downward, because it permits the observer to follow the highest positions of the pointer downward with the chosen index line until the desired amplitude is reached. This results in fairly accurate adjustments during a larger number of swings and is nearly equivalent to slowing down the rate of damping. In any case, it is necessary to use the same procedure with the gas as with the preceding air check.

The error in reading the scale on the micrometer wheel may be 0.0001 or 0.0002 , since the fourth place is estimated. Of course continuous clockwise motion of the micrometer wheel during the setting of the balance point is essential to avoid errors caused by backlash in the mechanical parts, as has been pointed out in Bulletin 106.

For some reason not fully explained the displacement of the beam produced when it is released by the arresting mechanism depends on temperature. It is about 4.5 divisions at $65^{\circ} \mathrm{F}, 5.5$ divisions at $78^{\circ}$ and beyond the end of the scale at $90^{\circ}$. At the lower temperatures there is not enough time to make a good adjustment of the scale before the oscillation becomes less than the prescribed 8 divisions. When this occurs it is necessary to release the beam several times before a good setting can be obtained.

(5) Pressure Determinations.-An error in determining the barometric pressure, whether as the result of using a faulty instrument, an error in reading, or failure to make needed corrections, makes a proportional error in the specific gravity. For example, an error of 0.1 inch of mercury as the result of failure to correct the barometric column for temperature would make the determination of the specific gravity of test mixture 1 too high by 0.0021 if the air check was based on a correct barometric pressure, and too low by 0.0012 if the air check involved the same barometric error as the gas.

(6) Temperature Determinations.-Uncertainties in reading the thermometer scale, errors in the indication of the thermometer, and lack of equilibrium between thermometer bulb and the gas in the balance case may give rise to errors in the specific gravity. The scale on the thermometer of balance 115 is graduated in intervals of $1 \mathrm{deg} F$, and one may attempt to estimate tenths of a degree. It can probably be read to $\pm 0.2 \operatorname{deg} F$ with certainty.

Thermometers, even when they prove to have no correction on calibration, should be tapped before reading if they are to indicate correctly, and one hesitates to tap sharply a thermometer attached to the balance case. In addition to this, the thermometer may have a calibration correction of a few tenths of a degree. 
Although the bulb of the thermometer does not project entirely into the balance case, it is surrounded by a metal casing in good thermal contact with the heavy-brass case. The gas will not require much time to come to the temperature of the balance, and the thermometer is likely already to be very near the temperature of the balance. Handling, lights, observer, etc. all affect the balance temperature. A varying temperature indicates possible uncertainties.

It seems easily possible that a combination of errors, such as the above, might amount to a total of $0.5 \mathrm{deg} \mathrm{F}$. Assuming everything else correct, however, a thermometer reading that is too high by $0.5 \mathrm{deg}$ $\mathrm{F}$ will result in the value obtained for the specific gravity being too low by only 0.0006 in the case of test mixture 1 if the error was only in the temperature of the gas, and by 0.0003 if the same error occurred during both the measurement of the gas and the air check. Consequently, small uncertainties in the temperature are of little moment.

(7) Gas-Law Corrections.-The chart provided with the instrument appears to be accurately prepared with coordinates that can be read as accurately as it is possible to read the thermometer and barometer. Significant errors resulting from its use are likely only in case the operator makes an error in the interpolation between the steps to which the correction factor is given, which are 0.005 apart.

The Anubis balance is much less affected by deviations from ideality of the gases tested than are balances in which adjustments of pressure are used to produce the same position of balance with different gases, because changes which occur in barometric pressure are relatively small and the Anubis balance is usually operated only at atmospheric pressure.

\section{(i) COMMENTS ON OPERATION AND SOME SUGGESTIONS FOR IMPROVEMENT}

Suggestions made to the manufacturer for the improvement of the instrument, some of which may be incorporated by the user, were as follows:

Suggestion 1: While a three-point support is, in general, preferable to one of four points, in the present case it might improve the stability of the instrument to have a cross support more nearly under the center of mass.

Suggestion 2: For convenience in purging with air, a hose connection and cock in place of the purge valve would permit drawing air from the best source, uncontaminated by passage through pumps, storage tank or pipes, and dried and freed from carbon dioxide.

Suggestion 3: It might be worthwhile, for the peace of mind of the new user, to provide closer correspondence between the tenths on the reference scale and the revolutions of the micrometer wheel. When set to correspond at 1.000, the reference scale is off by 0.03 at 0.600 .

Suggestion $4:$ Reading the position of the beam pointer on the movable index might be made easier if the pointer were made to contrast more sharply with the scale.

Suggestion $5:$ It might be desirable to amplify the printed directions to include the following points: Careful lighting is necessary, and the position of the light is important. The advisability of noting the reading of the beam pointer at the top of its swing and again at 
the bottom and making the adjustment of the micrometer wheel while the pointer is moving upward. The great importance of doing this the same way every time.

Suggestion 6: The greatest improvement could be made by supplying a correction chart for the systematic errors involved in the leveling of the balance planes. If these are level, the fact can be determined by calibrating with gases near both extremes of the range of the instrument. Carbon dioxide would probably be satisfactory for the heaviest gas if the sensitivity of the instrument were reduced a little to accommodate it. The entire calibration curve could be rather easily worked out mathematically from three calibration points, for carbon dioxide, air, and methane, for example, even if it is not practicable to make the bearing planes exactly parallel to the level.

\section{AC-ME RECORDING GRAVITOMETER NO. 271}

\section{(a) DESCRIPTION}

This instrument (fig. 18) is described in the manufacturer's instruction booklet only by means of sectional drawings, with a key to identify the numbered parts. The booklet gives adequate instructions for installation, calibration, maintenance, and care.

The instrument is not portable (weighs $157 \mathrm{lb}$.) and is inclosed in a sheet metal case $44 \mathrm{in}$. high, $25 \mathrm{in}$. wide, and $15.5 \mathrm{in}$. deep, with the top and right side hinged to provide access to the mechanism. It is essentially a balance, the beam (forked at one end) consisting of a cross member forming the base of the fork supported on knife edges at each end of the cross member, and balanced by a rod (corresponding to the handle of a fork), screwed into the cross member on the side opposite the two arms. The float, a cylindrical tank of light sheet aluminum about $27 \mathrm{in}$. high by $10 \mathrm{in}$. in diameter, is supported between the two arms of the beam from hardened steel hooks on knife edges placed on the ends of the arms. The float is counterbalanced by an adjustable balancing weight held in place by a lock nut on the threaded end of the rod that forms the rest of the beam.

The float has a conical top surmounted by a pin to hold the small test weights, and a conical bottom opening into a short cylindrical outlet $2 \mathrm{in}$. in diameter and $5 \mathrm{in}$. long. The outlet tube dips into liquid in an oil-seal cup that is fitted with a large concentric tube to carry the discharged sample outside the case at atmospheric pressure, and a smaller tube in its axis running up nearly to the top of the float carries the sample into the float from the control valve and flow meter mounted on the outside of the case at the top of the left side near the front.

The cross member of the beam carries a vertical rod at one end, near the front of the case, which is attached by means of a link to the pen mechanism. The length of this rod and the relative length of the pen arm as compared to the short rod, to which the link is connected, serve to magnify the motion of the beam.

The circular 24-hour chart is driven by a spring clock located inside the upper front of the case, and is accessible through a glass door on the front.

The chart is $10 \mathrm{in.} \mathrm{in} \mathrm{diameter,} \mathrm{graduated} \mathrm{from} 0.5$ near the center 


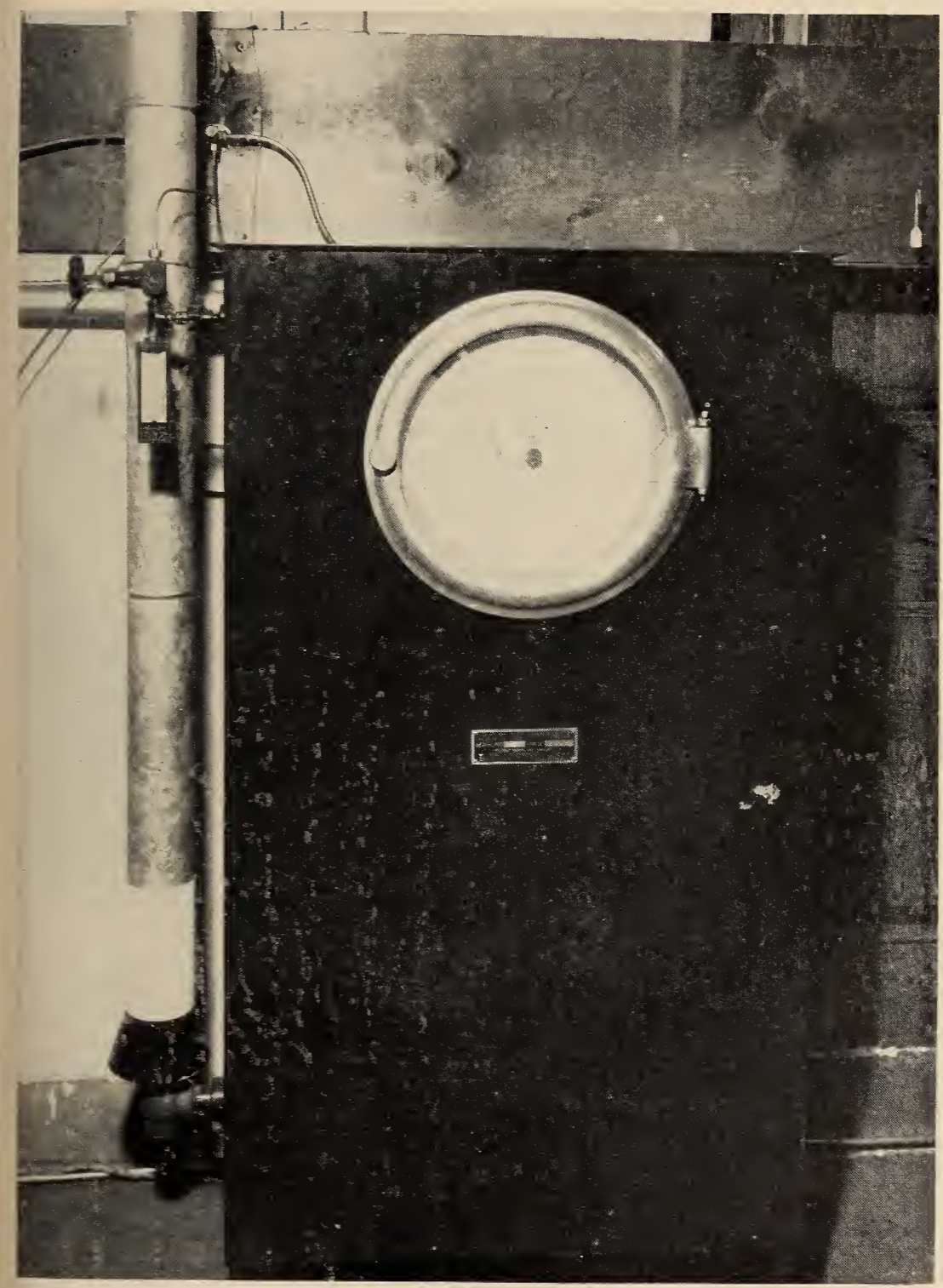

Figtre 18.-Ac-Me recording gravitometer No. $2 \% 1$. 
to 1.0 near the outer edge in intervals of 0.01 . The 0.01 intervals are a little more than one-sixteenth in. wide, and the reading can be estimated to about \pm 0.001 .

The working force which operates the instrument is the difference between the weight of the gas contained in the float and an equal volume of the surrounding air. This working force is opposed by a pendulum which carries an adjustable weight and is attached to the cross member of the beam in a manner which permits the angle between the pendulum rod and the longitudinal axis of the beam to be adjusted.

The instrument is compensated for changes of temperature and atmospheric pressure by the action of a volume of air contained within a coiled metal tube mounted on the back of the case. One end of the coil is closed by means of a valve which permits adjustment of the pressure of the air in the compensator coil.

The other end connects with one side of what is, in effect, a flexible mercury manometer, the other side of which is attached to the balance beam. The flexible link between the two parts is a small rubber tube parallel to but below the bearings of the balance beam. A scale on the arm of the manometer attached to the case assists in adjusting the amount of mercury and the pressure of air in the compensator. The arm of the manometer attached to the beam terminates in a bulb above the bearings of the balance. The action of the compensator is as follows: Changes of temperature or barometric pressure cause changes in the volume (and density) of air in the compensator coil. These changes of volume cause equal changes in the volume of mercury in the bulb attached to the balance beam. Hence, the effect of a change of atmospheric temperature or pressure is to add to an upward extension of the beam a weight of mercury proportional to the effect of the change on the density of air. When the float is filled with air and the pen indicates 1.000 the beam is level and the mass of mercury is directly above the bearing, where it does not affect the balance in either direction. But when gas of another specific gravity fills the float and the beam is not level, the mass of mercury is at one side of the support and tends to tilt the beam farther by an amount proportional to the deflection. Thus there is added a correction to the reading of the balance which is proportional to the effect of atmospheric conditions on the density of gas and at the same time proportional to the difference betwreen the density of the test gas and that of air. This is the relation needed for compensation. The design further involves the provision of a volume of compensating gas and a weight and position of mercury that will make the compensating force not only proportional to but equal to the correction desired.

\section{(b) MODIFICATIONS FOR PURPOSES OF TESTS}

To avoid contamination of the surrounding air, the gas discharged from the instrument at atmospheric pressure at the bottom of the case was collected and discharged from the room by means of the 3-in. exhaust duct with dampers previously mentioned and an adjustable sleeve that fitted closely over but did not make contact with the top of the downdraft diverter on the discharge outlet of the instrument. 
The dampers were so adjusted that stopping or starting the exhaust fan produced no change in the indication of the instrument.

Thermocouples were located inside the case, one mounted adjacent to the thermometer near the top on the left side of the case and another near the center of the compensator coil, so the temperature at these points could be determined while the instrument was in operation without opening the case.

The feet of the instrument were fixed in position on the floor by melting wax around and under the edges of the flanges.

The instructions call for filling the oil seal with "a very light oil, preferably mineral seal oil. If this is not available, kerosine may be used." The oil seal was filled with kerosine of 0.81 specific gravity. This evaporated rapidly and crept freely over the surrounding parts. After evidence was obtained that changes in its level had a marked effect on the indication of the instrument and that its vapor contaminated the reference air inside the closed case, also affecting the indication, the kerosine was replaced by Markol, a sharp petroleum fraction having a specific gravity of 0.846 and a viscosity of 0.245 poise at $25^{\circ} \mathrm{C}$. but a vapor pressure of about $0.0001 \mathrm{~mm}$ of mercury at $25^{\circ} \mathrm{C}$. In addition, it did not creep.

The instructions call for filling the mercury container from the bottle marked "exact amount of mercury for Ac-Me Gravitometer" Serial No. 271, 573.5 grams." When this was done the level of the mercury in the gage glass was not exactly at zero, although the instrument case was level according to the spirit levels. Since it is necessary that the mercury level in the gage be at zero when the compensator ralve is open, the quantity of mercury was adjusted to bring the level to zero.

\section{(c) METHOD OF OPERATION}

The directions supplied for the installation, calibration, and operation of the instrument were followed with a few minor modifications and extensions during the testing with nine of the gases of known specific gravity. It was after some preliminary operation and following the tests with mixture 1 that the kerosine in the seal cup was replaced by Markol to prevent the various adverse effects attending the use of a more volatile oil.

Before admitting the test gases, the instrument was calibrated according to the instructions. Air from the laboratory was drawn through the float in reverse by applying suction at the gas connection. The case of the instrument was open. The room was adjusted as nearly as possible to a relative humidity of 35 percent and a temperature of $7 \tau^{\circ} \mathrm{F}$ for calibration and for each test with a standard mixture, in order that the chart might have the same dimension from test to test as at calibration. The air check was made, as well as the subsequent calibration and tests with the standard mixtures, using the portion of the chart at or near the 6-o'clock axis, the direction in which the chart paper shows the least change of dimensions with changes of relative humidity.

After purging the float with air, the flow was stopped and the case closed. The side door was opened during adjustments of compensator and weights but was kept closed but unlatched during the rest of the time. Great care was taken to avoid 
jars to the case and movement of the knife edges on the supports during adjustments. The beam was held in contact with the limit stop at one end or the other of the gap while adjusting the weights. The compensator gage was set at 0.00 and the counterweight adjusted to bring the pen to 1.000 . The adjustment of the pendulum rod was checked by changing the compensator gage reading to +1.00 and -1.00 successively, without change of indication on the chart. The compensator gage was again set at 0.00 , all the five test weights were removed at the same time, 20 minutes was allowed for drainage, and the pendulum weight was adjusted to bring the pen to 0.500 . When all five test weights were replaced at the same time, the pen again read 1.000. This result was accomplished only after several successive adjustments of the counter- and pendulum weights with varying departures of the pen from the desired readings. When the test weights were replaced one at a time, the record of the pen was never at the correct mark. The following, after setting the pen on $0.500 \pm 0.0005$, is a typical series: $0.5985,0.699,0.799,0.899,0.9975$. Considerable difficulty was encountered in adjusting the counter-and pendulum weights as it was impossible to move the lock nut without some movement of the weight, and this could not be detected because there is no mark on the weight and no reference point to which a mark might be referred. In addition to this trouble, the pendulum weight appeared to be eccentric, so that it was often impossible to predict the direction of the effect of moving it. There were also indications that the rubber tube connecting the mercury reservoir to the compensator gage sometimes slipped slightly on or off the end of the metal tube as a result of stretching when the beam moved from one end to the other of its travel, and this resulted in the failure of the pen to return to 1.000 after having been set at 0.500 . After succeeding in the attempt to get a reading at 1.000 after a return from 0.500 , the barometer and temperature of the instrument thermometer were read, the compensator gage reading was determined from the chart inside the cover, and the compensator gage set at that reading.

Before subsequent tests, the barometer and instrument temperature were read, and the compensator gage was read without jarring the case. The gage was then tapped and again read and both readings recorded, together with the reading from the chart. If correction was required, the gage was reset at the reading from the chart. The level of the oil in the seal cup was checked and adjusted if necessary. The instrument case was opened to be sure that it was filled with room air at 35-percent relative humidity and at $77^{\circ} \mathrm{F}$.

After the calibration which preceded testing with mixture 2, no check of the calibration was made until after testing with mixture 9 (sp gr 0.9666). The range of the instrument was then changed by adjusting the pendulum rod to the vertical position with the pen at 0.500 and checking by adjusting the compensator gage to +1.00 and -1.00 as before. $\mathrm{A}$ single brass weight that had the same weight as the combined five test weights was placed on the float during the above adjustment. The five test weights were then also placed on the float for the adjustment of the pen at 1.000 ( $\mathrm{sp}$ gr 1.500). The instrument was then recalibrated, as previously described, for tests with the mixtures having specific gravities between 1.000 and 1.500. 
Each test of the instrument with a test gas involved purging until the reading and record had been constant for at least 15 minutes. The indication and record were then displaced by removing one of the five test weights, which allowed the float to rise out of the oil. After about 7 minutes the weight was replaced with care to avoid immersing the bell below its former position and so that no displacement of the reading would result from the presence of oil on the float and no time for drainage would be needed. The reading became constant again almost immediately.

During the 13-minute test period, a record was made of the chart reading, the temperature shown by the two thermocouples, the room temperature, the barometric pressure, the relative humidity and drybulb temperature, and the time at which the record was started. This procedure was repeated until 10 records had been made with the test gas. The position of the center of the record line in each case was then measured with an ocular-scale microscope. These 10 values of specific gravity were then averaged for the test. The temperatures, barometric pressure, and relative humidity reported with each test are the averages of the values recorded for the 10 determinations.

\section{(d) CORRECTION FOR EFFECT OF RELATIVE HUMIDITY ON CHART PAPER}

All readings were corrected, for the effect of humidity on the dimensions of the charts, to a relative humidity of 35 percent by the method described for all instruments in section III, 2 (e) (p.20).

\section{(e) REFERENCE AIR}

The air inside the instrument case is used as a standard of reference, and uncertainties as to its composition caused by contamination with the vapor of a volatile seal oil or by variations in the carbon dioxide and water content of the air cause errors in the specific gravity indicated by the instrument. Contamination with the vapor of a volatile seal oil causes a reading that is too low, and the higher the temperature the greater is the error. Leaks of gas in the vicinity, inadequate disposition of the sample discharged from the instrument, as well as carbon dioxide from laboratory burners, power-plant stacks, etc., may cause errors of this kind. Although the case is not gastight, there is little opportunity for interchange with the air outside. Humidity and carbon dioxide determinations for the purpose of applying corrections will result in corrections that may be wrong if the air inside the case is not of the same composition as that outside.

In this case, as the air in the laboratory that surrounded the instrument and filled the case and served as the standard of reference was neither dry nor free from carbon dioxide, corrections to the observed reading were required to place the indication of the instrument on the same basis as the standard specific gravity of the test mixture.

(f) CORRECTION FOR WATER VAPOR AND CARBON DIOXIDE IN REFERENCE AIR

The instrument is mechanically calibrated by the use of weights, each of which has one-tenth the weight of "standard" air (free from water and carbon dioxide) which would fill the float at a temperature of $60^{\circ} \mathrm{F}$ and a pressure of $14.4 \mathrm{lb} \mathrm{in.}^{2}$ (equivalent to a barometric 
pressure of 29.3 in.), which had been taken as standard conditions in the manufacturer's calibration.

The compensator is designed to eliminate the effects of changes of the buoyant force of the "reference" air surrounding the float, caused by changes of temperature and pressure, but it does not compensate for changes of its composition. Neglecting the volume of metal in the thin-walled float, the volume of the outside air is equal to that of the gas being tested. Then, if we take as the unit of force the weight of that volume of gas of specific gravity 1.0000, it is apparent that water vapor and carbon dioxide each affects the buoyant force and the indication of specific gravity by an amount equal to the fraction in the outer air and to the difference between the specific gravity of the contaminant and unity. That is, $S=R-0.378 w+0.529 c$, where $S$ is the specific gravity of the gas being tested, $R$ is the reading of the instrument, $w$ is the fraction of water vapor, and $c$ is the fraction of carbon dioxide in the reference air.

The average of the "observed" determinations of the specific gravity of test gas 2 was 0.6900 . After correction for the changes of dimensions of the chart, it was 0.6901 . The average moisture content of the air was 1.15 percent, and the average carbon dioxide content was about 0.1 percent. Substituting these values in the above equation,

$$
\begin{aligned}
S & =0.6901-0.378 \times 0.0115+0.529 \times 0.001 \\
& =0.6901-0.0043+0.0005 \\
& =0.6863 .
\end{aligned}
$$

\begin{tabular}{|c|c|}
\hline $\begin{array}{l}\text { Correction for effect on chart of departure of relative } \\
\text { humidity from } 35 \text { percent }- \text {--- } \\
\text { Correction for effect of water vapor in air on buoyancy } \\
\text { Correction for effect of carbon dioxide in air on buoyancy }\end{array}$ & \\
\hline $\begin{array}{l}\text { Net correction } \\
\text { "Observed" specific gravity, mean }\end{array}$ & \\
\hline $\begin{array}{l}\text { Indicated specif } \\
\text { Specific gravity }\end{array}$ & $\begin{array}{r}0.6863 \\
.6820\end{array}$ \\
\hline percentage of standar & \\
\hline
\end{tabular}

Summarizing the observations and corrections for mixture 2 :

A summary of the numerical results obtained from the tests of the instrument with the series of test gases (except the tests made to determine temperature and humidity coefficients) is given in table 7 , and the errors of the instrument uncorrected and after corrections for the effect of relative humidity on the chart, and for water vapor and for carbon dioxide in the reference air have been applied, have been plotted for each test gas in figure 19.

\section{(g) SOURCES OF ERROR}

(1) Temperature Coefficient.-If the temperature and pressure compensator operates satisfactorily, the specific gravity indicated by the instrument, after calibration and operation by the methods described above, should be independent of the temperature of the instrument. To determine whether this was the case, a series of tests 
at different temperatures, each consisting of 10 readings of the specific gravity of a single test gas (mixture 2) was made as described under "method of operation." Two of these tests at $77.6^{\circ} \mathrm{F}$ and one at $92.6^{\circ} \mathrm{F}$ were made with substantially the same percentage $(1.15)$ by volume of water vapor in the reference air. In another test, at $67.9^{\circ} \mathrm{F}$, the relative humidity was practically the same as in the tests at $77.6^{\circ} \mathrm{F}$ (36.9 percent), but the percentage of water by volume was different of course. In still another test, at $80.1^{\circ} \mathrm{F}$, neither the relative humidity nor the persentage of water by volume was duplicated. The observed results have all been corrected for the departure of the

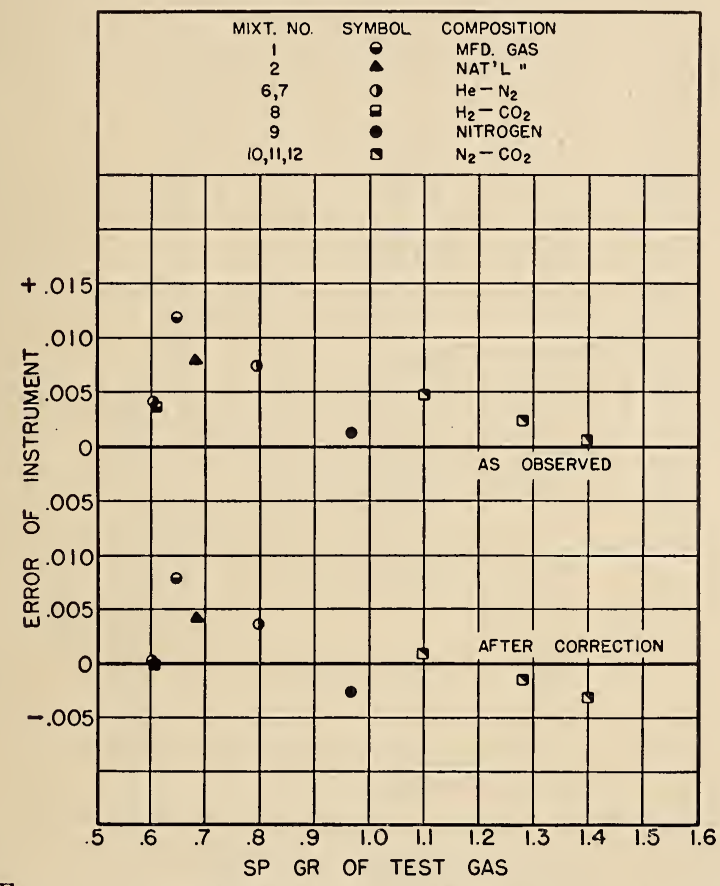

FIGURE 19.-Error of the Ac-Me recording gravitometer No. 271 determined with each test gas, as observed and after the application of corrections for the effect of relative humidity on the chart, and for water vapor and carbon dioxide in the reference air.

chart paper from 35-percent relative humidity and to dry carbon dioxide-free reference air. (The laboratory air was assumed to contain 0.1 percent of carbon dioxide.) The results, as observed and after all corrections have been applied, have been plotted against temperature in figure 20. A straight line, determined by the method of least squares, has been passed through the three points representing tests made with gas containing the same percentage of water, another through the three points representing tests with gas of the same relative humidity, and a third line through all five points after they have been brought to a common basis by the application of the corrections discussed above. The slopes of these lines, constituting the temperature coefficients, are indicated thereon. 


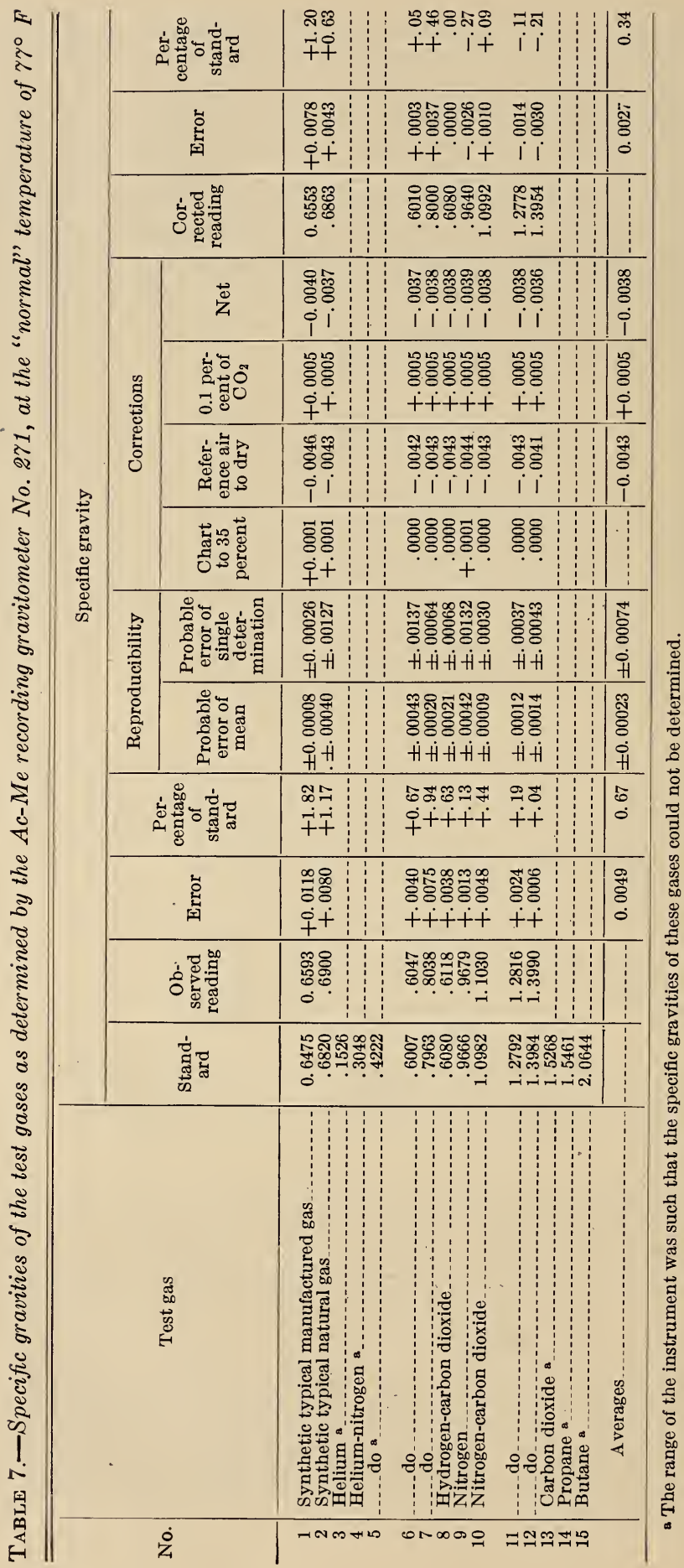


The radius of the circle around each observed point is equal to the probable error of the mean of the 10 determinations which that point represents.

It may be noted that the circles are small as compared with the differences which appear between tests on successive days under nearly the same conditions. Even when all the corrections that have been evaluated have been applied, the difference appears to be approximately 0.0035 in one case. If one considers that the uncertainty of a particular test may be more accurately evaluated by comparing that test with another made under the same conditions than by computing the probable error of the mean of the 10 determinations which constitute the single test, then it is seen that an uncertainty of 0.0035 could suffice to bring all five of the solid points to a straight line at a specific gravity as low as 0.6833 and eliminate any residual temperature coefficient.

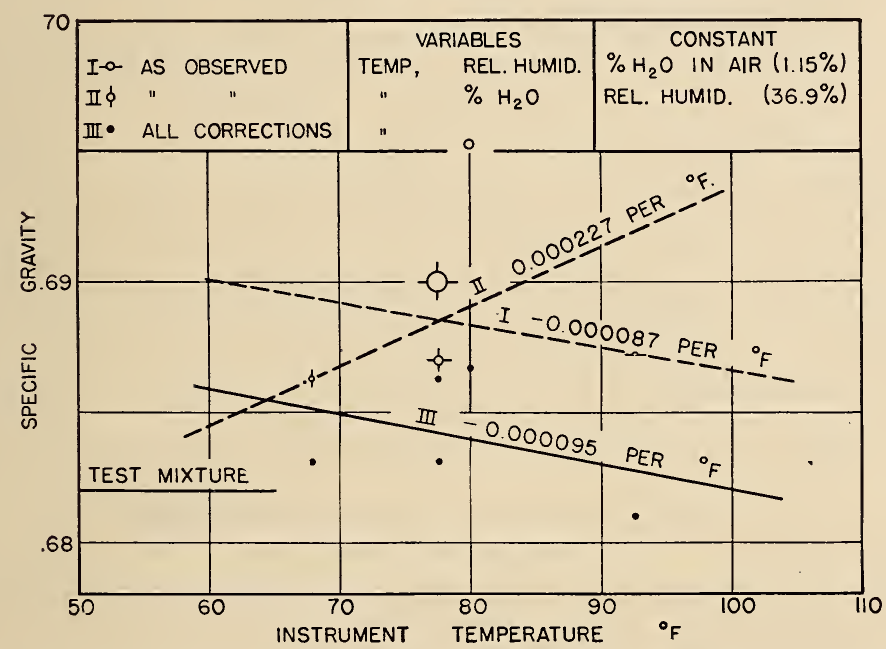

FIGURE 20.-Temperature coefficients of the Ac-Me recording gravitometer No. 271 determined with test mixture 2 , as observed (-0-at constant percentage of water vapor in the reference air (1.15 percent); $\phi$ at constant relative humidity of the reference air (36.9 percent)), and - after the application of all corrections.

Had this temperature coefficient been determined while the seal cup contained kerosine, it could have been attributed to the kerosine, for the contamination of the reference air with kerosine vapor would certainly have been higher at higher temperatures. The gas would probably have been contaminated only slightly, if at all, because the flow of sample would carry the heavier vapor out immediately. The gas, referred to a reference heavier than normal air, would then appear to be lighter than it actually was and thus could account for a residual negative temperature coefficient.

As this explanation can not apply when the seal cup was filled with Markol, it must be concluded either that the temperature compensation of this instrument is inaccurate to the extent of about $0.0001 / \mathrm{deg}$ $\mathrm{F}$, or that its reproducibility is of the order of 0.0035 . 
(2) Humidity Coefficient.-Variations of relative humidity from 10 to 70 percent in the same place at different times of year are easily possible. At a temperature of $77^{\circ} \mathrm{F}$, this range colresponds to a range of water-vapor concentration of from 0.3 to 2.2 percent. The uncorrected reading could be too high by as much as 0.0083 if the water-vapor concentration were 2.2 percent.

In order to determine experimentally the effect on the indicated reading of variations in the water content of the surrounding reference air, a test, consisting of 10 determinations of the reading, was made in the manner previously described, with the reference air containing 2.78 percent in addition to two tests with air containing 1.15 percent and 1.19 percent of water, which correspond nearly to 35 -per-

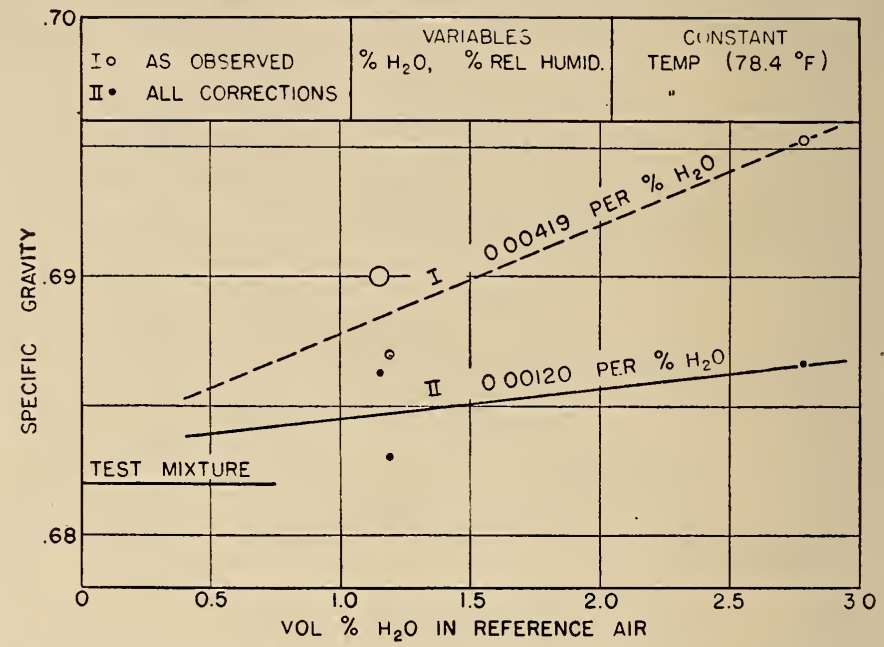

FIgURE 21.-Humidity coefficient of the Ac-Me recording gravitometer No. $2 \% 1$ determined at constant temperature $\left(78.4^{\circ} F\right)$ with test mixture 2 ; $\odot$ as observed, and after the application of all corrections.

cent relative humidity at $77^{\circ} \mathrm{F}$, the conditions chosen as "normal" for the purpose of these tests.

During the tests the instrument was maintained at as near the same temperature as possible. The average temperature was $78.4^{\circ} \mathrm{F}$, and temperatures during individual tests differed from this by $1.7^{\circ} \mathrm{F}$ or less.

The results as observed and after correction to a chart reading at 35 percent relative humidity and to dry carbon dioxide-free reference air have been plotted in figure 21 against percentage of water vapor in the reference air. Straight lines, determined by the method of least squares, have been passed through the three points, and the slopes of the lines, constituting the humidity coefficients, are indicated thereon.

The slope of the line through the solid points is still 29 percent of the slope of the line through the uncorrected points, but it may be noted that, as in the case of the temperature coefficient, an uncertainty of 0.0032 would suffice to bring all the solid points to a horizontal line 
at a specific gravity as low as 0.6835 , and so eliminate any residual slope. In this case the effect of water vapor on the readings is believed to have been eliminated by the corrections. It must therefore be concluded that there is an uncertainty in the individual tests of at least 0.0032 .

(3) Accuracy of Readings.-The position of the record mark on the chart may be read to 0.01 and estimated to 0.001 , which is small as compared with some probable errors from other sources.

(4) Material Tested.- Uncertainty as to the material being tested may be a source of error if insufficient time for purging is allowed. Sereral tests indicated that from 8 to $10 \mathrm{cu} \mathrm{ft}$ of sample were required to purge the float completely. The displacement of a heavier gas by a lighter one is more readily accomplished than the reverse, as the sample enters the float near the top. A heavier gas entering at the top will tend to fall through a lighter one without displacing it so completely. The rate of purging should be kept relatively high to facilitate mixing the entering gas with the contents of the float. This seems feasible, as the rate of purging, from 4 to $12 \mathrm{cu} \mathrm{ft} / \mathrm{hr}$, caused no perceptible change in the reading. Purging appears to approach completeness asymtotically with time, and approximately the same degree of completeness should be reached after a given length of time, regardless of the difference between the specific gravity of the entering gas and that already present. But the smaller the difference in specific gravity, the smaller will be the departure from the reading which would be reached after purging is complete. If the specific gravity of the sample varies, rising and falling, the reading at a particular time will lag behind the specific gravity of the entering gas, and the uncertainty will be larger, the larger the variations and the lower the purge rate.

As the sample flows downward over the oil seal and directly out, there is no likelihood of serious contamination of the sample with vapor from a volatile oil in the seal cup.

(5) Sealing liquid.-In addition to the contamination of air in the case with its vapor, a volatile seal oil can cause an error if its level in the cup is not maintained the same as at calibration. As the level is lowered by evaporation, the buoyant force of the liquid on the immersed neck of the float becomes less, causing the reading to be high. At the same time the volume of the float is increased. With a gas lighter than air this would cause the reading to be low. The effect of the change in weight of seal oil displaced by immersed metal is considerably larger than the change in the difference between the weights of gas and air. With the float filled with air, a change of one-eighth inch in the level of the liquid produced a change of 0.005 in the reading.

(6) Volume of float.-As the float rises, the volume of the float and, consequently, the working force are changed. The instrument is placed in mechanical balance during calibration with the float at both extreme positions. It is filled with air and. no buoyant force is exerted by gas. With the float at its upper limit when filled with a gas of 0.500 specific gravity, the volume of the float will be increased by $1.37 \mathrm{cu}$ in. which is 0.08 percent of the valume of the float $(1,728$ cu in.). This would cause the reading to be too low by 0.0004 . 
(7) Calibration.-As stated in the instructions, the pendulum rod (which carries the mercury reservoir for temperature and pressure compensation) should be exactly vertical when the float is filled with air, so that the quantity of mercury in the reservoir will not affect the reading. Even though this condition is met and the pen reads 1.000 with the test weights on the float and also reads 0.500 without the weights, the readings are slightly low by varying amounts when the weights are added singly and low by from 0.002 to 0.010 when all have been added. The reading always was nearer 1.000 after a return from 0.500 when all the weights were added at once. No reason for this behavior has been discovered other than the possible displacement of the rubber tubing mentioned in the discussion of calibration in section IV, 3 (c). The float is lowered into the seal oil during this process, so no drainage is involved.

(8) Temperature Changes.-The relative lengths and arrangement of lever arms in the beam and linkages connecting it to the pen appear to have been so designed that there will be little residual effect on the reading as a result of the changes in length of metal parts with temperature, although the residual temperature coefficient shown by the lowest curve of figure 20 may have resulted from this cause if the effect is real.

(9) Temperature and.Pressure Compensator.-An error in the location of the compensator gage on the instrument case, in the quantity of mercury contained in the system, or in the volume of the air reservoir could cause an error in the compensation of the instrument for temperature changes. For gases having a specific gravity less than 1.000, overcompensation, causing too low a reading at higher temperatures, would result if the system contained too much mercury, if the gage were set too high, or if the air reservoir were too large. For gases having a specific gravity greater than 1.000 , overcompensation, causing too high a reading at higher temperatures, would result from the same errors. These possibilities are recognized by the manufacturer, and while this instrument appears to be slightly overcompensated, the error, if any, is not larger than the differences observed between readings on the same gas after an interval of 4 days.

However, when the temperature of the air surrounding the instrument was changed at a rate between $5^{\circ}$ and $10^{\circ} \mathrm{F} / \mathrm{hr}$, the temperature of the compensator air reservoir lagged behind the temperature at the location of the mercury thermometer by about $3^{\circ} \mathrm{F}$. This would be expected to result in errors of compensation as well as errors resulting from corresponding differences between the temperature of the gas inside the float and the air surrounding it inside the case of the instrument. The net effect was that the readings rose with rising temperature as much as 0.003 above the reading at constant temperature and fell as much as 0.0025 below with falling temperature.

When the mercury in the compensator system moves up or down gradually as a result of temperature or pressure changes, it tends to hang up in the tubing. Tapping the gage caused the mercury to move an average of 0.03 to 0.04 division or less; 0.03 to 0.04 division could account for an error in specific gravity of about 0.001 . When the gage was tapped before each reading, the reading of the gage corresponded 
satisfactorily over a period of several months with the reading from the chart.

The mercury meniscus in the gage was lubricated with a small drop of $n$-dibutylphthalate, which was effective as long as the mercury was in frequent motion but was not effective for slow changes. .

(10) Mechanical Effects.-Errors may result, of course, from various mechanical sources, mainly friction. The action of the beam appeared to be sluggish with the pen near 1.00. Part of the difficulty encountered during calibration may be from such a source. Sometimes slight tapping of the case will cause a shift in reading. This was noted at the beginning of the tests, and was quite marked during the test with mixture 9, (0.9666). After the displacements mentioned in section IV, 3 (c), the pen was allowed to approach the equilibrium reading from both directions. The readings as a result of approach from above were consistent, as were those resulting from approach from below, but the two sets were about 0.003 apart.

The bearings had been cleaned and oiled, as recommended in the instructions, before calibration about $61 / 2$ months before. During this period the case was kept closed, and there was no indication of dust or dirt inside the case.

The constancy of volume of the rubber tubing connecting the parts of the compensator is doubtful, and the constancy of the forces which the tube exerts on the beam when in the same place at different times is even more doubtful. The magnitude of the possible error from these effects was not determined.

\section{(h) COMMENTS ON OPERATION AND SOME SUGGESTIONS FOR IMPROVEMENT}

The instrument appears to have been well designed and constructed, and the following suggestions made to the manufacturer are in the nature of refinements. Some of them pertain to convenience in calibration and adjustment, which is likely to be relatively infrequent, and in practice may not be worth the trouble involved in incorporating them in the instrument.

1. Comparing the apparent effects of the rubber tubing connecting the compensator gage to the moving parts on the beam, it is suggested that, instead of the tube projecting from the side of the pendulum rod below the line of the knife edges, the pivot bearing of the pendulum assembly be used as the tube. The yoke in the cross member of the beam could be extended, the pendulum bearing could pass through a web across the center of the yoke, and the rubber tube could be placed in the line of the bearings so that no lateral flexing or stretching of the tubing would occur as the beam moves. This might eliminate some of the sluggishness of the action and some uncertainty as to reproducibility.

2. It is suggested that greater care in drilling and tapping the pendulum weight might eliminate the eccentricity that has proved troublesome in the present instrument.

3. The chart paper fits the short cylindrical hub rather snugly, so that the paper must be stretched slightly, and there is a possibility of introducing a slight eccentricity in the position of the chart. It is suggested that the hub be tapered slightly, so that the paper can be started easily and stretching minimized and distributed uniformly. 
4. It might be advantageous to provide for some more definite interchange of air between the inside and outside of the instrument case, so that the composition and temperature of the air surrounding the float will follow more closely that of the room. In some locations, however, where changes may be rapid and considerable, louvres near top and bottom of the case might not be an advantage.

5. A gage outside the seal cup, marked so that the level of the seal oil could be easily observed and adjusted to the mark might be helpful.

6. To avoid inadvertent movements of the knife edges while adjusting weights during calibration, some means of locking the beam or lifting it from the bearings might be an advantage.

7 . If checking the calibration or adjustment of the weights is at all frequent, it would be helpful to substitute for the lock nuts some means of holding the weights against inadvertent movement, but which would permit them to be moved when desired. An index to indicate in which direction and how much a weight had been moved would also be helpful.

8. If checking the position of the pendulum rod or changes of range is at all frequent, a point on the lower end of the pendulum rod, and a corresponding reference point mounted vertically below the knife edge on the back of the case would be helpful in setting the pendulum rod in a vertical position while the beam is clamped with the pen at the desired reading.

\section{ANUBIS RECORDING GAS GRAVITOMETER}

\section{(a) DESCRIPTION}

The Anubis recorder (fig. 22), which weighs $41 \mathrm{lb}$, is adequately described by the manufacturer in "Care and Operation," Bulletin No. 105 , and instructions are given for installation, calibration, maintenance, and care.

The instrument consists of a balance beam with arms of equal length, at the ends of which are suspended two bells in sealing liquid contained in two interconnecting tanks. One bell is open to the air through holes in its crown, the other through a "gas column," a vertical tube connected to the space under the bell. The mechanism of the balance is mounted on the column and protected by a wooden case $25 \mathrm{in}$. high, 183/4 in. wide and $11 \mathrm{in}$. deep, with a glass window in the door. The working force that operates the instrument is the difference in the pressures on the top and on the underside of the crown of the second bell, and is equal to the difference in weight between a column of gas 6 in. in diameter and about $59 \mathrm{in}$. high and a column of the surrounding "reference" air of the same dimensions. This working force is opposed by a pendulum weight mounted on a horizontal arm (with a bimetallic strip to vary its distance below the balance beam and compensate the instrument for temperature changes) and by a difference in buoyant forces equal to the difference in weight of sealing liquid displaced by the submerged metal of the two bells. The motion of the beam is transmitted by a connecting rod to a pen mechanism, and the specific gravity is recorded on a clock-driven circular chart graduated from 0.5 to 1.0 in intervals of 0.01 . The first $1 / 2$ meter of the gas column is contained within the 


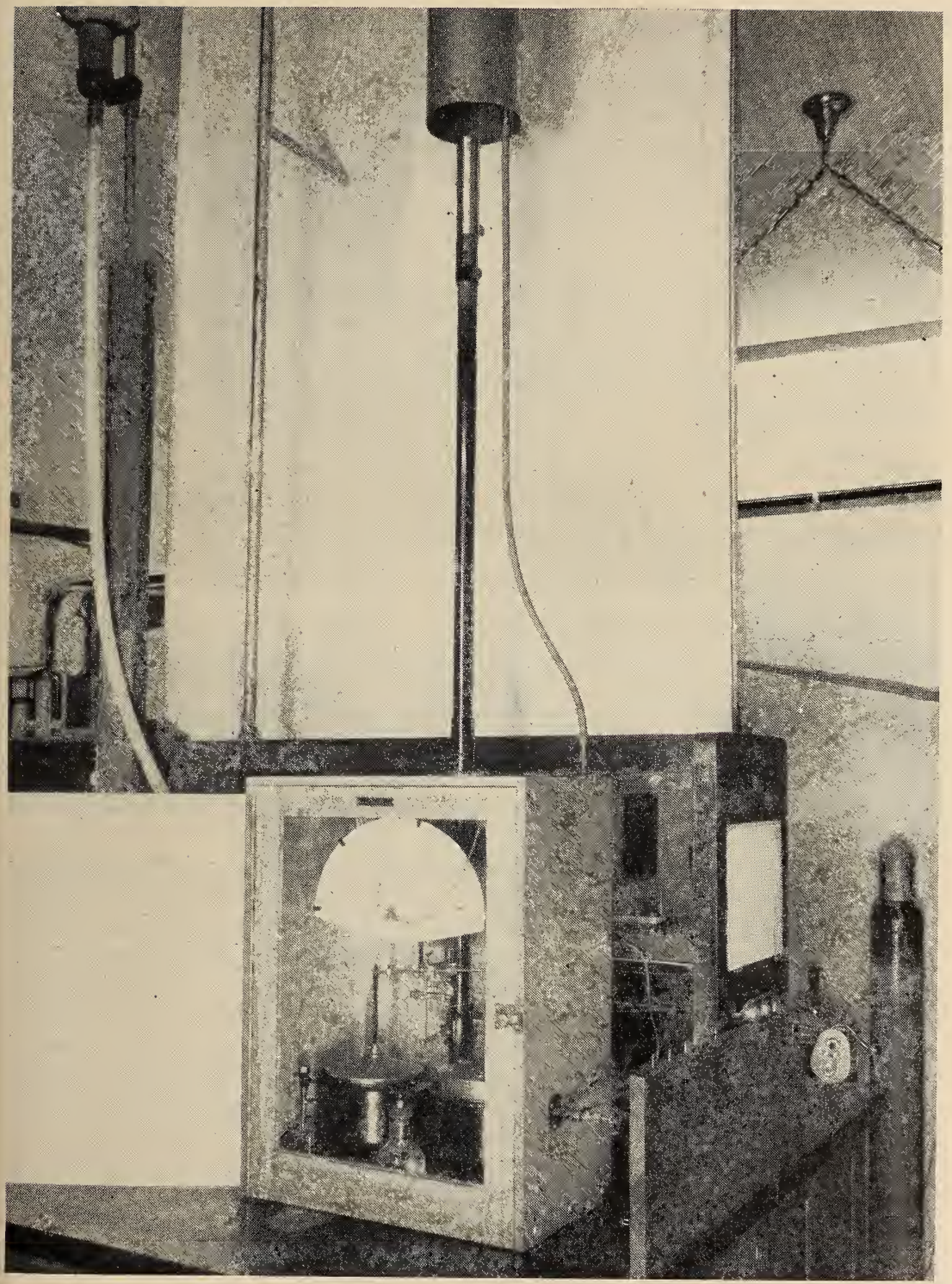

Figuke 22.-Anubis recording gas gravitometer. 
case, the upper section is removable and is attached at the top of the lower section, which projects through the top of the case. At the top of the gas column is a movable cap by means of which the height of the column can be adjusted to compensate for changes in the barometric pressure, or set to the height for the average pressure at the location of the instrument. A scale attached to the cap is marked to correspond to different barometric pressures, and the adjustment for each pressure is made by setting the corresponding scale reading opposite a "barometric index" adjustably attached to the column. The sensitivity of the instrument and its corresponding "calibration" depend on the correct setting of the barometric index in relation to the combined effects of the pendulum weight and the buoyance of the sealing liquid.

The gas sample is admitted to the bell through an orifice at constant pressure. The flow into the apparatus as a whole is approximately controlled by the manual adjustment of a valve, and excess pressure is relieved through a tube dipping into a water seal and vented outside the balance case. Within the bell, the sample is distributed through a T-tube and passes out through the gas column at the rate of about $0.7 \mathrm{cu} \mathrm{ft} / \mathrm{hr}$. The bell that is open to the air serves to balance the weight of the working bell and to compensate for surface tension of the sealing liquid on the working bell.

\section{(b) MODIFICATIONS FOR PURPOSES OF TESTS}

To avoid contamination of the surrounding air, the gas from the gas column was collected and discharged from the room by means of the 6 -inch exhaust duct with dampers previously mentioned and an adjustable sleeve ending a short distance above the gas column. The dampers were so adjusted that stopping or starting the exhaust fan produced no change in the indication of the instrument. The dis: charge of the overflow gas from the seal bottle was inside this duct also.

For convenience in reading the temperature of the instrument during operation, a thermocouple was introduced through one of the vents in the back of the case and the junction located near the bimetallic temperature compensator. The interconnecting tanks were at first filled with kerosine of 0.81 specific gravity. After some preliminary operation and the tests on mixture 1, it was found that $120 \mathrm{ml}$ of kerosine had evaporated from the tanks in 1 month at a temperature of about $77^{\circ} \mathrm{F}$. A distinct odor of kerosine was noticed whenever the door of the case was opened. It was felt that contamination of the reference air and of the flowing sample was probable, and as the tests with mixture 1 showed a small positive residual temperature coefficient, it was considered possible that this resulted from an increased contamination of the sample with kerosine vapor at the higher temperatures. In addition, the kerosine crept over the surfaces of the bells and over the rims of the tanks.

To eliminate probable sources of error from such causes, the kerosine was replaced by Markol, which had a vapor pressure of about $0.0001 \mathrm{~mm}$ of mercury at $25^{\circ} \mathrm{C}$. In addition, it did not creep.

Before further testing, however, a representative of the manufacturer stated that the design of the instrument had been based on the 
use of kerosine of 0.78 specific gravity. Consequently, the Markol was replaced by Varsol, or Stoddard solvent, another readily available petroleum fraction, which had a specific gravity of 0.78 and a minimum flashpoint of $100^{\circ} \mathrm{F}$, as compared with that of $115^{\circ} \mathrm{F}$ for the kerosine originally used. Its vapor pressure was probably about 2 to $3 \mathrm{~mm}$ at $25^{\circ} \mathrm{C}$. Unfortunately, if one chooses a kerosine of a particular specific gravity, the vapor pressure that accompanies it is not subject to choice. They cannot be selected independently. This material also had a tendency to creep.

As the design of the instrument had been based on a specific gravity of 0.78 for the sealing liquid, Varsol was used throughout the remaining tests. It will be noted, however, that when the determination of the temperature coefficient was repeated when testing with mixture 2 (after recalibration), the coefficient which remained (after all corrections had been applied) was $+0.0004 / \mathrm{deg} \mathrm{F}$, while that obtained with mixture 1 and kerosine of 0.81 specific gravity was +0.0003 . The effect of contamination of the sample with kerosine vapor will be discussed further in the section on Sources of Error.

\section{(c) METHOD OF OPERATION}

The directions supplied for the installation and operation of the instrument were followed, with a few minor modifications and extensions during the testing with nine of the gases of known specific gravity.

Before admitting the test gases, the instrument was checked with air according to the instructions, air from the laboratory being drawn through, with the upper section of gas column removed. During the air check, as well as the subsequent tests on the standard mixtures, the portion of the chart at or near the 6-o'clock axis, the direction in which the chart paper showed the least change of dimensions with changes of relative humidity was used.

The room was adjusted as nearly as could be to a relative humidity of 35 percent at a temperature of $77^{\circ} \mathrm{F}$ for calibration and for each test with a standard mixture, in order that the chart might have the same dimension from test to test as at calibration.

After the air check, the upper gas column was replaced and the test mixture introduced. The movable cap of the gas column was adjusted to bring the pen as near as possible to the specific gravity of the test mixture (in this case mixture 2, sp gr 0.6820 ). The corrected barometric pressure was then ascertained, and the barometric index of the gas column set at the point on the cap scale corresponding to this reading.

Before each test of the instrument with a test gas, the oil level was checked and adjusted to the proper level. (About $100 \mathrm{ml}$ of Varsol evaporated per month from the tanks, although gas flowed through the instrument only about 1 percent of the time. The liquid level is not of primary importance in this instrument because the two reservoirs are connected, and a change of level affects both sides of the balance alike.) The case was opened to establish equilibrium of air and chart with room conditions, after which the case was closed, except for the two vents, which were left open at all times. 
Each test of the instrument with a test gas involved purging until the reading and record had been constant for at least 15 minutes. The indication and record were then displaced about 0.03 specific gravity unit by placing a small piece of metal on the balance bell, which lowered it into the oil and raised the working bell an equal distance. After about 7 minutes the displacement weight was removed and the immersion of the bells reversed momentarily so that as nearly as possible the same drainage of oil would occur from both bells. The reading became constant again in about 3 minutes. During the 15 -minute test period, a record was made of the chart reading, instrument temperature, room temperataure, barometric pressure, relative humidity, and dry-bulb temperature, and the time at which the record was started. During the 7 -minute displacement period the gas-column cap was adjusted to the existing barometric pressure.

This procedure was repeated until 10 determinations of the reading of the instrument on the test gas had been made. The position of the center of the record line for each reading and for the calibrating setting (with mixture 2) was measured with respect to printed lines on the chart with the aid of an ocular-scale microscope. The 10 values of specific gravity were then averaged for the test. The temperatures, barometric pressure, and relative humidity reported with each test are the averages of the values recorded for the 10 determinations.

After the calibration with mixture 2, no further calibrations were made until that on mixture 10 , which was made after the range of the instrument was changed for operation with gases having specific gravities from 1.0 to 1.5.

The change of the range of the instrument from 0.5 to 1.0 to the range 1.0 to 1.5 was accomplished in the manner indicated in the instructions. The pendulum clamp screw was loosened, and while the pendulum was still held vertically by the zero stop the balance beam was moved until the pen read 0.5 instead of 1.0. Final adjustment was made by means of the sliding weight on the balance beam as in the case of the previous air checks. Purging with air and the other necessary steps incident to the air check were conducted as previously described. The calibration was attempted with test mixture 10 as described with mixture 2.

The instrument could not, however, be brought to the correct reading with mixture $10(\mathrm{sp} g r=1.0982)$. The reading being too high and the specific gravity greater than 1.0, the reading was decreased by lowering the gas column cap. At its lowest possible position, the reading was still too high, probably because in the process of changing the range (making the pen read 0.5 with air) the working bell had been brought to its lowest position, thus increasing the length of the gas column more than it could be shortened by lowering the gas-column cap.

Various considerations connected with the preparation of the test mixtures made necessary their preparation in the order of increasing specific gravity. Consequently, no mixture of known and higher specific gravity was available for calibration at a point farther from air before testing with mixtures nearer air.

Calibration with mixture $11(\mathrm{sp}$ gr=1.2792) was successful and tests were continued through mixture 13. 
Corrections were applied in all cases for the effect of relative humidity on the dimensions of the chart (as described in section III, 2 (e), p. 20) and for the effects of water vapor on the density of the air of the laboratory, which was considered to be "reference air," because the instrument is not tightly inclosed. No corrections were applied for temperature or pressure because the instrument is designed to compensate for temperature by the action of the bimetallic element on the height of the center of gravity of the pendulum and for barometric pressure by the setting of the cap at the top of the gas column.

The effect of a change in the amount of carbon dioxide and water vapor in the laboratory air on the indications of the instrument are exactly the same as in the case of the Ac-Me gravitometer. That is, if the instrument were set to record the true specific gravity, $S$, in dry, carbon dioxide-free air, the equation

$$
S=R-0.378 w+0.529 c
$$

given for the other instrument would apply. ( $R$ is the reading in contaminated air, $w$ is the fraction of water vapor, and $c$ is the fraction of carbon dioxide by volume in the reference air.) In this case, however, the measurement of specific gravity of the test gas is really based on the difference between the reading with the test gas and that with the calibrating gas of known specific gravity. Hence $C$, the correction to be applied in this instrument, is given by the equation

$$
C=S-R-\left(S_{0}-R_{0}\right)=-0.378\left(w-w_{0}\right)+0.529\left(c-c_{0}\right),
$$

in which $S_{0}$ is the true specific gravity of the calibration gas, $R_{0}$ the scale reading at the time of calibration, and $w_{0}$ and $c_{0}$ the fractions of water vapor and carbon dioxide in reference air at that time.

It was found impracticable, if not impossible, to set the pen exactly at the specific gravity of the standard gas during calibration. The position on the chart of the record made by the pen during calibration was measured with the ocular-scale microscope and compared with the known specific gravity of the calibrating gas to obtain a "calibration correction", which was thereafter applied to the average of tests with each of the other gases. In the calibration with mixture 2 , this correction was -0.0006 .

The corrections for the results obtained with test mixture 2 have then been combined as follows:

Chart correction for departure of relative humidity from

35 percent

Calibration correction

Correction of reference air to 1.10 percent water vapor

Correction of reference air to 0.1 percent carbon dioxide $-\quad .0000$

Net correction to observed specific gravity

Observed specific gravity, mean $\quad .6822$

Net correction

Indicated specific gravity

Specific gravity of test mixture 2 2

Error of instrument

Error, percentage of standard specific gravity 
The data have been treated in the same manner in the case of each of the other test gases which had specific gravities within the range of the instrument, and a summary of the numerical results is presented in table 8. The errors of the results "as observed" and after the corrections noted above have been applied are plotted for the various test gases in figure 23.

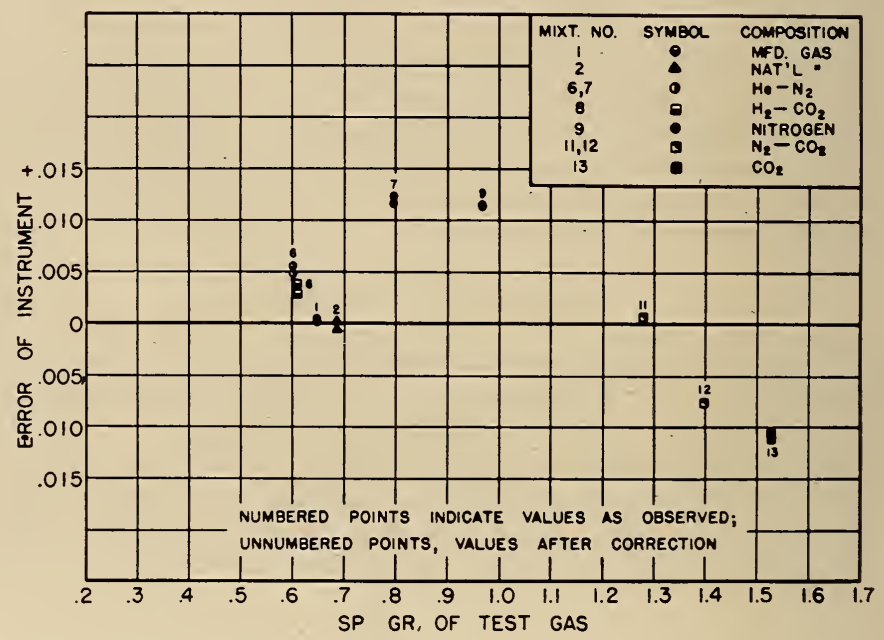

FIGURE 23.-Error of the Anubis recording gas gravitometer determined with each test gas.

The numbered point of each pair indicates the error as obserred and the unnumbered point the error after the application of all corrections.

\section{(d) SOURCES OF ERROR}

(1) Accuracy of Reading.-The position of the record mark on the chart can be read to 0.01 and estimated to 0.001 . A mistake of 0.001 is small as compared with possible errors from some other sources.

(2) Calibration.-Failure to set the pen exactly at the specific gravity of the known gas by the manipulation of the height of the gas column will, of course, introduce an error into the record. The setting is not an easy one to make because the temperature of the column is somewhat altered and the "steady state" otherwise somewhat disturbed, and the instrument must be left to "settle down" for a considerable time before it can be determined how accurately the setting was accomplished.

Any error or uncertainty in the specific gravity of the "known" gas used to calibrate the instrument will result in error in the record with gases of unknown specific gravity, and this fact is perhaps the worst feature of the procedure recommended by the manufacturer of the instrument. Very few laboratories have or can easily obtain a sufficient quantity of gas of known composition or properties, particularly within the range of specific gravity 0.5 to 1.0 , and probably very few have facilities for determining the specific gravity of gas with the accuracy that the excellent qualities of this instrument justify. 
Specific Gravities of Gases

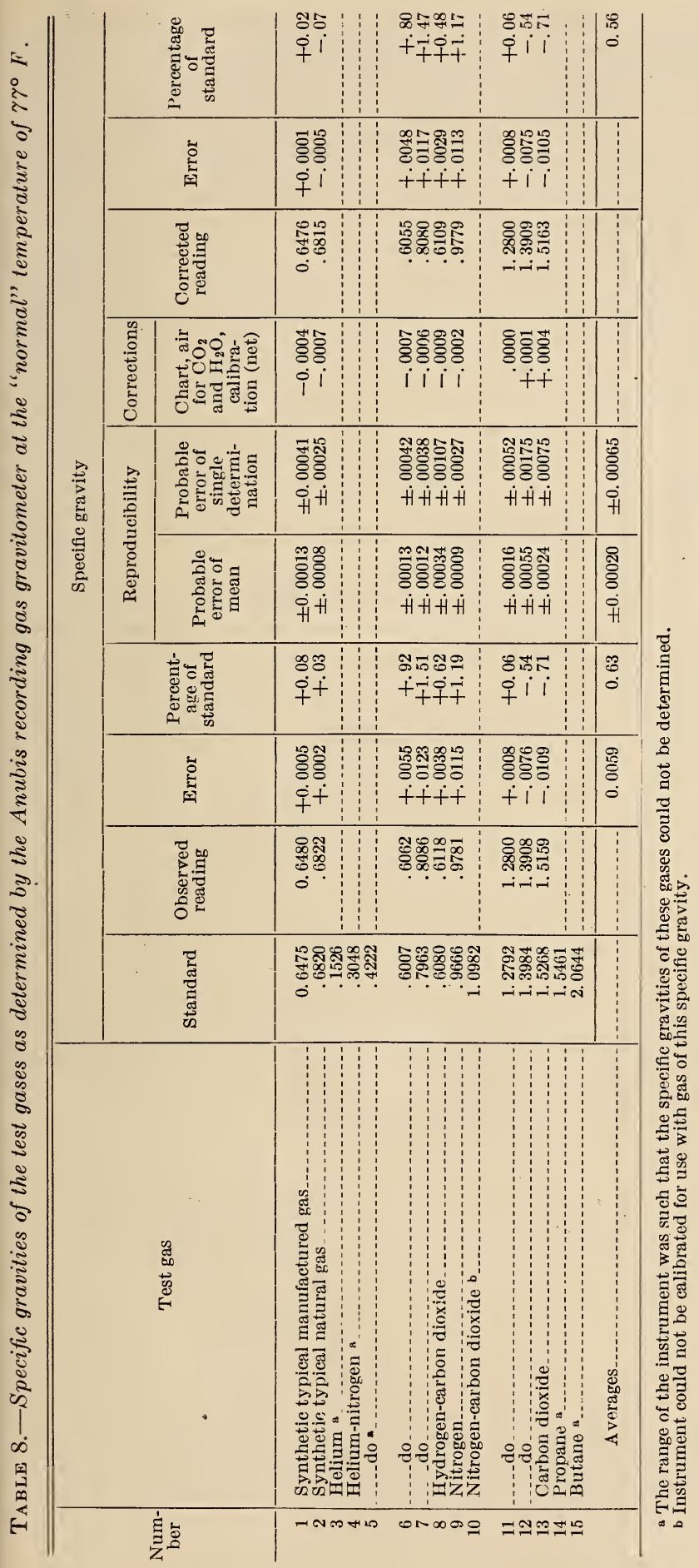


The calibration is essentially an adjustment of relation of the height of the column and the position of the counterweight so that the curve of displacement with respect to specific gravity will have the correct slope. As the slope is determined equally by the two fixed points, any error in the setting of the counterweight to give a zero reading for air is of as much importance as the column height, and if the calibrating gas has a density too close to that of air, the errors in either setting are multiplied for other gases.

(3) Effects of Gravitational Forces That Change With the Position of the Mechanism.-A complete analysis of the moments that tend to deflect the balance beam involves any unbalance of the pen arm and its attachments that is transmitted through the connecting rod, the far from negligible weight of the rod itself, and the forces it produces at its points of attachment to the beam and the pen arm, and the force of gravity on the beam itself. The directions and magnitude of these forces with respect to the axis of the beam are all changing as the beam is deflected, and to determine their magnitude would require that the balance be taken apart and its parts weighed. It seemed better, therefore, to measure directly the forces applied to the bells and the deflections they caused than to calculate them, as was done for the Anubis balance. A hook (made of a large paper clip) was attached to the metal suspension of one of the bells and balanced by a similar clip on the other bell. A large number of small paper clips were then weighed individually to $0.1 \mathrm{mg}$ on an analytical balance and placed one at a time on the improvised support. After each addition of weight, approximately 15 minutes was allowed to permit the sealing fluid to drain and a state steady in other respects to be reached. The record was read under the microscope as before. Plotting the reading with respect to the weight added produced very nearly a straight line. The equations of the straight line and of a curve of the second degree that best fitted the observations were computed by the method of least squares and were adjusted slightly to make them coincide exactly at the assumed calibration points of 1.0 and 0.5 . (This would be done in practice with as much accuracy as possible by shifting the counterweight and the calibration weight.) The curve of the second degree, which undoubtedly agreed with the actual observations more accurately than did the straight line, then showed readings at various parts of the range of specific gravities, which were higher than the straight line by the following amounts:

\begin{tabular}{|c|c|}
\hline Specific gravity & $\begin{array}{c}\text { Reading from sec- } \\
\text { ond-degree curve } \\
\text { minus rea ding } \\
\text { from straight line }\end{array}$ \\
\hline & $s p g r$ \\
0.5 & 0.00000 \\
.6 & .00082 \\
.7 & .00103 \\
.8 & .00094 \\
.9 & .00017 \\
1.0 & .00000 \\
\hline
\end{tabular}


These departures from a straight line, the greatest of which is only one-tenth of a division of the chart, are within the limit of accuracy with which the chart can ordinarily be read with the unaided eye, and the movements of the pen can be considered, for most purposes, to be accurately proportional to the forces applied to the beam.

(4) Gas Column.-The height of the gas column is, of course, the distance from the top of the working bell to the top of the gascolumn cap. (The top of the bell is conical, and the force exerted on it by the inclosed gas is the same as would be exerted on a bell with a flat top located at one-third the distance from the base to the apex of the cone.) When the column cap was adjusted to the index mark of 30 in. the height of the column was $149.7 \mathrm{~cm}$ when the pen was at the top of its range, and the bell moved $2.35 \mathrm{~cm}$ when the pen traveled across the chart, making the column 152.05 cm long when the bell was at its lowest position. As the working bell rises when the specific gravity of the gas increases, the height of the gas column is less than at calibration for gases of greater specific gravity than that of the gas used for calibration (in case the calibrating gas is lighter than air) and the reading is too high. With gases of lower specific gravity than that used for calibration, the height of the gas column will be greater than at calibration and the reading will be too low. If the instrument is calibrated with a gas of 0.500 specific gravity (the instructions state that the calibration should be made with a gas having as low a specific gravity as possible), it is necessary to lower the gas-column cap until the pen reads 0.500 , which process brings the total height of the gas column to $152.05 \mathrm{~cm}$ (assuming a 30-in. barometer, to indicate that the barometric index is set at 30 , the midpoint of the scale, and left there). If gases of specific gravities $0.6,0.7,0.8$, and 0.9 were then successively introduced, the height of the gas column would be progressively decreased by the displacement of the bell, and consequently the difference between the weight of air and gas would be decreased, but at a different rate than it would if the height of the gas column had remained constant.

The errors have been computed for various specific gravities with an instrument calibrated with gas of specific gravity 0.5 and plotted as the upper curve of figure 24. Corresponding errors computed in the same way are shown for calibrations made with gases of other specific gravities. The minimum error within the range 0.5 to 1.0 would occur if the instrument is calibrated with a gas of specific gravity about 0.58 .

Applying the same reasoning to calibrations made for the specific gravity range 1.0 to 1.5 (with air the position of the pen is made to coincide with the lowest line on the chart by keeping the pendulum vertical and shifting the beam and counterweight), it was computed that after calibration with a gas of specific gravity 1.28, gases of specific gravities 1.4 and 1.5 would read low by 0.0015 and 0.0034 , respectively. The computation was made for a calibrating gas of specific gravity 1.28, because that was the gas actually used for the purpose. The error introduced by the changing height of the column accounts for about one-third of the observed error in the case of the other test gases that were heavier than air. 
(5) Leveling of instrument.-A change of level of the instrument has a decided effect on the reading, and there is no provision for determining when the instrument case is level. The principal effect results from the displacement of the supporting and recording mechanism with respect to the vertical position of the "pendulum." This effect is partially counteracted by the flow of oil from one seal pot to the other. The magnitude of the resultant effect was computed and checked experimentally by slipping a 1-mm shim under one edge of the balance case. This change of level (through an angle of about $7^{\prime \prime}$ ) resulted in an apparent change of specific gravity of about 0.02 , which was in good agreement with the calculated value. Probably the manufacturer intended that the effect of placing the instrument on a support not exactly level should be compensated for in the calibration, along with other effects. But without specifying the support, which may be subject to settling, warping, etc, no one can an-

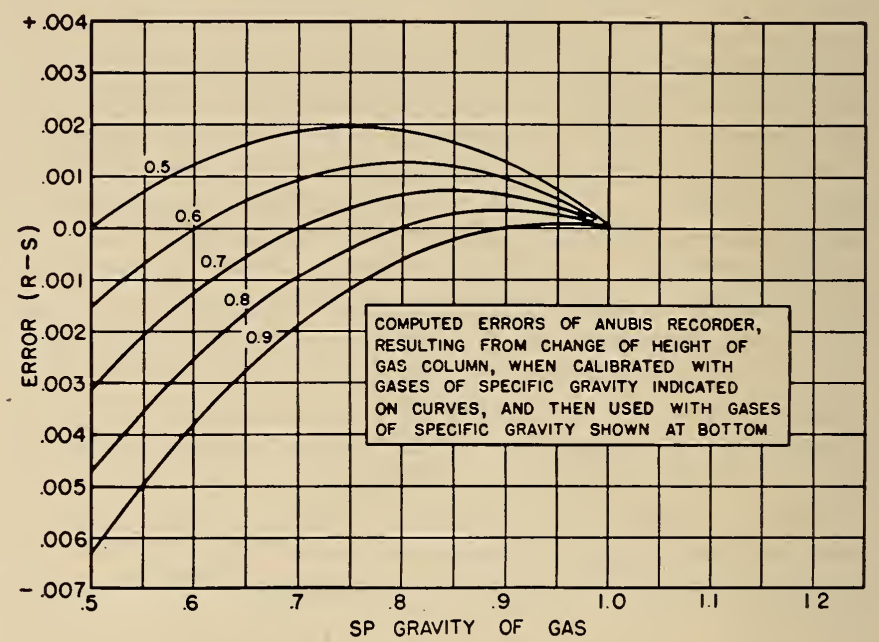

FIgURE 24.-Computed errors of the Anubis recording gas gravitometer resulting from changes in the height of the gas column which accompany deflection.

Numbers on the curves indicate the specific gravity of the gas used for calibration.

ticipate the changes that may take place in its level after the instrument is calibrated. One should not have to make another calibration to check the level.

(6) Weight of Ink in Pen.-When the reading was approximately 1.0 , the ink was removed nearly completely from the pen with the aid of a narrow strip of blotting paper, and the chart was turned under the pen to make a record. The pen was then filled normally with ink and the paper turned in the opposite direction. The distance between the two records was then measured with the aid of the microscope and found to correspond to a difference of 0.004 specific gravity. The same gas in the upper part of the recorder range may, therefore, show differences as great as this at different times, depending on the amount of ink in the pen. In all tests not involving the study of this point, the pen was carefully filled to the same extent as nearly as prac- 
ticable before a critical reading was taken. In spite of this precaution, the amount of ink in the pen may have been one of the factors that caused variations not otherwise accounted for, and it must certainly appreciably affect readings in practice.

(7) Temperature Coefficient.-The specific gravity indicated by the instrument after calibration and operation by the methods previously described should be independent of the temperature of the instrument if the means provided for temperature compensation is satisfactory. A test, consisting of 10 determinations of the specific gravity reading with a single test gas (mixture 2) was made as described in the method of operation at each of the temperatures $67.7^{\circ}$, $78.5^{\circ}, 79.1^{\circ}, 80.1^{\circ}$, and $92.9^{\circ} \mathrm{F}$.

Three of these tests were made at substantially constant water content of the reference air (average 1.15 percent, equivalent to 36.5-percent relative humidity at $77^{\circ} \mathrm{F}$ ), and three were made at substantially

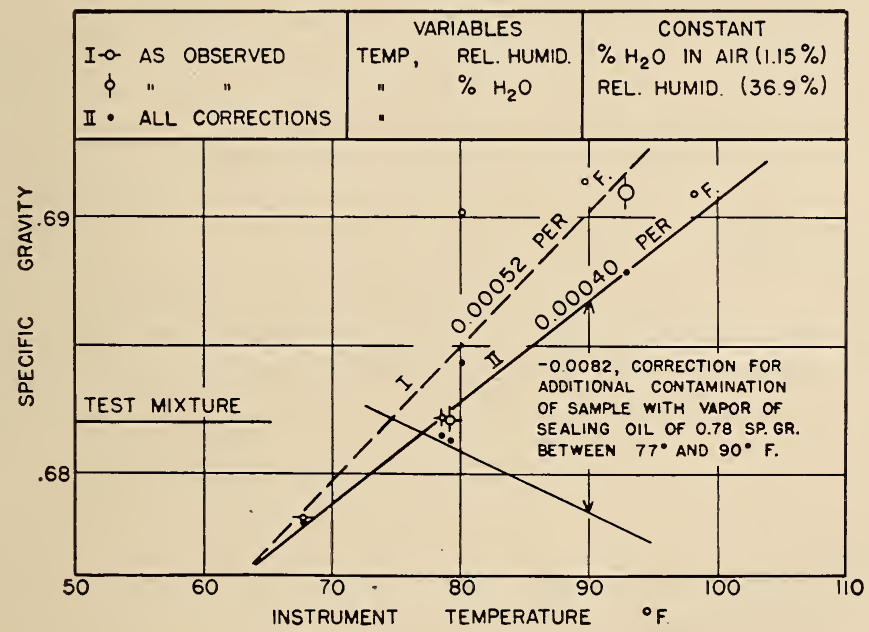

FIGURE 25.-Temperature coefficients of the Anubis recording gas gravitometer determined with test mixture 2, as observed (-๑- at constant percentage of water vapor in the reference air (1.15 percent); $\oint$ at constant relative humidity of the reference air (36.9 percent)), and $\bullet$ after the application of all corrections.

constant relative humidity (average 36.9 percent). The observed results have all been corrected for the departure of the chart paper from 35.0-percent relative humidity, for the calibration error, and to 1.1 percent of water vapor and 0.1 percent of carbon dioxide in the reference air. The results as observed and after the above corrections have been applied, have been plotted against temperature in figure 25. A straight (broken) line determined by the method of least squares has been passed through the five points as observed, and another (solid) line through the five points obtained after having been brought to the same basis by application of the above corrections. The slopes of these lines, constituting the temperature coefficients, are indicated thereon. The radius of the circle around each of the ob- 
served points is equal to the probable error of the mean of the $10 \mathrm{de}$ terminations that point represents.

It may be noted that the circles are small as compared with the differences that appear between tests on successive days at nearly the same temperature. Even when all the corrections that have been evaluated have been applied, the difference in one case is still 0.003 , and a large positive temperature coefficient still remains.

The sealing liquid, of 0.78 specific gravity, had been under suspicion on account of its rapid rate of evaporation. Consequently, approximate values of 4.4 and $5.9 \mathrm{~mm}$ for its vapor pressure at $77^{\circ}$ and $90^{\circ} \mathrm{F}$, respectively, were derived from correlations of its properties. An approximate molecular weight of 138, derived similarly, gave for its vapor a specific gravity of 4.76. These vapor pressures are about onesixth those of water, and assuming that the sample is saturated with the vapor, it would contain 0.58 percent of the vapor at $77^{\circ} \mathrm{F}$ and 0.78 percent at $90^{\circ} \mathrm{F}$. The test gas, 0.6820 specific gravity, mixed with 0.58 percent of solvent vapor, 4.76 specific gravity, then had a specific gravity of 0.7056 , which was made to read 0.6820 by the method of calibration described. At $90^{\circ} \mathrm{F}$, the specific gravity of the mixture of test gas and 0.78 percent of vapor was 0.7138 , or 0.0082 higher than at $77^{\circ}$. If at $90^{\circ} \mathrm{F}$ the correction of -0.0082 is subtracted from the position of the solid line, while it remains in the same place at its calibration temperature of $77^{\circ} \mathrm{F}$, the line representing the positive temperature coefficient is rotated through zero to a negative slope.

Although the values derived in the above computations are obviously rough approximations, it is seen that the degree of contamination of the sample arrived at by this means is ample to account for the large temperature coefficient. Even though the mechanical compensation for temperature changes were perfect, such a residual temperature coefficient could result from the use of a sealing liquid with a vapor pressure as high as that of Varsol or Stoddard solvent (sp gr 0.78). The kerosine (sp gr 0.81) originally used would have been preferable to the Varsol had it been a nearly pure compound, which it probably was not. The Markol (sp gr 0.846) had a vapor pressure of approximately $0.0001 \mathrm{~mm}$ of mercury at $25^{\circ} \mathrm{C}$, which is too low to affect the fourth decimal place in the specific gravity of the sample at any temperature encountered in a laboratory.

The fact that the solvent vapor is more than sufficient to account for the residual temperature coefficient may be explained either on the basis of uncertainties in estimating its vapor pressure or on lack of complete saturation of the test gas with the vapor or partial saturation of the reference air inside the case, or a combination of all three effects.

(8) Temperature Lag.-When the temperature of the air surrounding the instrument was changed at a rate between 5 and $10^{\circ} \mathrm{F} / \mathrm{hr}$, the temperature at a point near the bimetallic compensator lagged behind the room temperature by nearly $2 \mathrm{deg}$ F. This caused errors of compensation, as well as errors resulting from corresponding differences between the temperature of the gas inside the bell and gas column and the air inside the case and surrounding the gas column outside. The net effect was that with rising temperature the readings 
rose as much as 0.014 above the reading at constant temperature, and with falling temperature fell as much as 0.008 below.

(9) Properties and Changes of the Sealing Oil.-The properties of the liquid used for sealing the bells are of great importance. The liquid must be able to "wet" the surface of the metal with certainty and uniformity to prevent irregular errors as the result of surface tension, but it is possible for the oil to be too "good" in this respect. The kerosine in the tanks tends to creep over the surface of the bells and dust may collect on their tops. This can be a source of error only if the weight of the kerosine and dust is greater on one bell than on the other. The equality of dimensions of the two bells reduces to a minimum the probability of significant error from this source but does not eliminate it entirely. The oil should have a low viscosity in order that it may drain promptly from the bell that is raised partly out of the liquid by any change of specific gravity.

Kerosine of specific gravity 0.78 , recommended by the manufacturer, is almost ideal in respect to the properties mentioned. However, a petroleum oil of so low a specific gravity usually has a high vapor pressure and produces a high temperature coefficient, as already described. In addition, a commercial kerosine is never a pure compound and its composition and properties, including vapor pressure, change as the liquid evaporates.

The liquid exerts a buoyant force on each of the bells equal to the product of the volume of submerged metal and the specific gravity of the oil. When the specific gravity changes from 0.5 to 1.0 , the measuring bell rises $2.35 \mathrm{~cm}$ and the other falls a like amount. The thickness of the metal of the bells is about $0.25 \mathrm{~mm}$ and their diameter $15 \mathrm{~cm}$. The buoyant force (in grams) on each bell then changes about

\section{$0.025 \times 2.35 \times 15 \pi \times d=3 d$ grams,}

where $d$ is the density of the oil. As there are two bells and their buoyancies change in opposite directions, the net effect is equal to a change of load produced by the gas column of about $6 d \mathrm{~g}$. If the specific gravity of the oil does not change, these buoyant forces are among the several that are taken into account by the calibration, and therefore introduce no error. At the specific gravity of the gas at which the buoyant forces are equal, that is, when the beam is level, their equality is not affected by a change of specific gravity of the oil. But in other positions an error is introduced which is equal to about

$$
\frac{6}{33.5} \times \frac{\left(S-S_{1}\right)}{0.5} \times \frac{d_{1}-d}{2.35}=0.15\left(S-S_{1}\right)\left(d_{1}-d\right)
$$

where $S$ is the specific gravity of the gas, $S_{1}$ is the specific gravity at which the bells are equally submerged, and $d$ and $d_{1}$ are, respectively, the specific gravities of the liquid when the measurement and the calibration are made. In this instrument, when calibrated for the range of specific gravities 0.5 to $1.0, S_{1}$ is about 0.625 . Assume, for example, that the specific gravity of the liquid at the time of calibra- 
tion was 0.78 and that later it was 0.80 . Then, with a gas of specific gravity 0.80 , the instrument would read low by about

$$
0.15(0.80-0.625)(0.78-0.80)=0.0005 \text {. }
$$

This error is in addition to that caused by the effect of the changing content of vapor on the actual specific gravity of the gas in the column.

If kerosines possessing such characteristics as two samples tested at this Bureau for purchase by the Government are used in the instrument, they will gradually fractionate (more completely even than at higher temperature), and as the residue is replenished from time to time but never drained, the vapor pressure will fluctuate but gradually become less. Differences between the vapor pressure at the time of calibration and later use may easily reach $0.0025 \mathrm{~atm}$ if a commercial kerosine is used as a sealing liquid. For the purpose of computing the approximate errors that may result from fractional distillation of the sealing oil, it was assumed that the average of these two kerosines was used in the instrument. It was also assumed, for the purpose of computing the changes in properties which accompany the change in boiling point, that the oil consisted of a mixture of 67 mole percent of naphthene hydrocarbons and 33 mole percent of paraffin hydrocarbons and that all properties follow the "law of mixtures." Data for the properties of the hydrocarbons were taken from the monograph of the American Chemical Society on this subject. The data derived from these assumptions are stated in table 9 .

TABLE 9.-Properties of kerosine assumed to be used as a sealing oil

\begin{tabular}{|c|c|c|c|}
\hline & $\begin{array}{l}\text { Beginning of } \\
\text { vaporization }\end{array}$ & $\begin{array}{l}10 \text { percent } \\
\text { evaporated }\end{array}$ & $\begin{array}{l}50 \text { percent } \\
\text { evaporated }\end{array}$ \\
\hline $\begin{array}{l}\text { Boiling point } \\
\text { Specific gravity } \\
\text { Molecular weight } \\
\text { Vapor pressure at } 25^{\circ} \mathrm{C}^{\mathrm{C}} \\
\text { Specific gravity of vapor }\end{array}$ & $\begin{array}{l}169 \\
77.3 \\
139 \\
0.0035 \\
4.83\end{array}$ & $\begin{array}{l}199.5 \\
78.5 \\
154 \\
0.0014 \\
5.34\end{array}$ & $\begin{array}{l}223.5 \\
79.6 \\
175 \\
0.0007 \\
5.97\end{array}$ \\
\hline True specific gravity of gas & \multicolumn{3}{|c|}{ Specific gravity of saturated gas } \\
\hline \multirow[t]{2}{*}{1.000} & $\begin{array}{l}0.5152 \\
1.0134 \\
1.5117\end{array}$ & $\begin{array}{l}0.5061 \\
1.0053 \\
1.5046\end{array}$ & $\begin{array}{l}0.5038 \\
1.0034 \\
1.5031\end{array}$ \\
\hline & \multicolumn{3}{|c|}{$\begin{array}{l}\text { Error caused by change of vapor pressure of } \\
\text { sealing fluid }\end{array}$} \\
\hline $\begin{array}{l}0.50-1.00 \\
1.50\end{array}$ & $\begin{array}{r}0.0000 \\
.0000 \\
.0000\end{array}$ & $\begin{array}{r}0.0091 \\
.0081 \\
.0061\end{array}$ & $\begin{array}{r}0.0114 \\
.0100 \\
.0086\end{array}$ \\
\hline
\end{tabular}

The errors listed in the table are derived from the assumption that the calibration will make the reading exactly right at the time the sealing liquid is first added. Subsequent readings will be too low by the amounts indicated.

(10) Humidity Coefficient.-In order to determine experimentally the effect on the indicated reading of variations in the water content 
of the surrounding air, a test consistng of 10 readings of the specific gravity of the same gas was made in the manner previously described, with the water content of the reference air at 2.78 percent in addition to two tests at 1.15 and 1.19 percent, which correspond nearly to 35.0 percent relative humidity at $77^{\circ} \mathrm{F}$, the conditions chosen as "normal" for the purposes of these tests.

During these tests the instrument was maintained as near as possible to the same temperature. The average temperature was $79.2^{\circ}$ $\mathrm{F}$, and temperatures during individual tests differed from this by $0.9 \mathrm{deg} \mathbf{F}$ or less.

The results, as observed and after all the corrections had been applied, have been plotted against "percentage of water in reference air" in figure 26. Straight lines, determined by the method of least squares have been passed through the three points, and the slopes

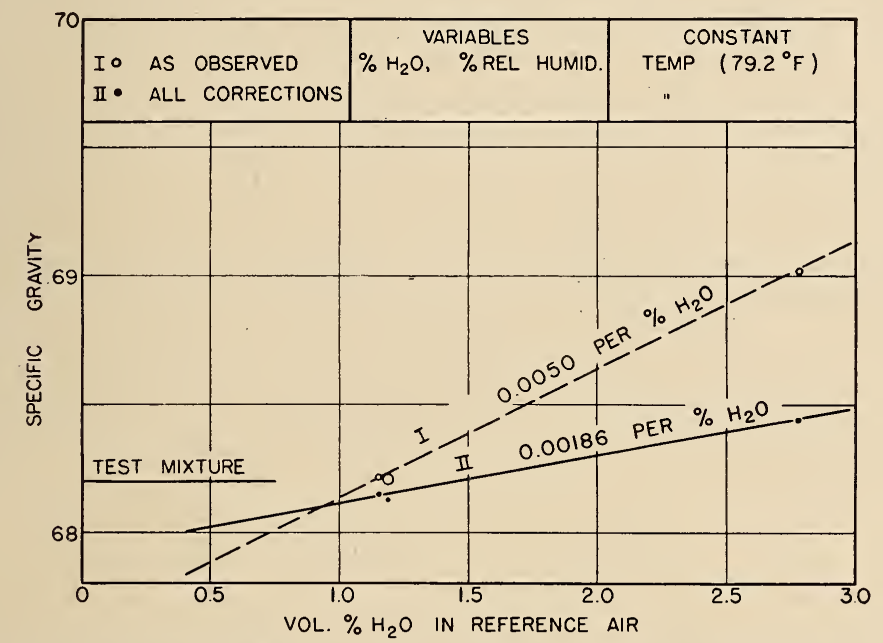

FIGURE 26.-Humidity coefficient of the Anubis recording gas gravitometer determined at constant temperature $\left(79.2^{\circ} \mathrm{F}\right)$ with test mixture $2 ; \bigcirc$ as observed and $\bullet$ after the application of all corrections.

of the lines, constituting the humidity (or percentage of $\mathrm{H}_{2} \mathrm{O}$ ) coefficients, are indicated thereon.

It may be noted that although the effect of variations in the percentage of water in the air has been reduced to about 37 percent of the original effect by applying all the corrections, the coefficient has not been reduced to zero as it should have been.

The correction for the 1.68 percent of water vapor in excess of the 1.1 percent present at calibration amounts to -0.0064 , which is 70 percent of the entire coefficient as observed. The residual coefficient which is still to be accounted for is equivalent to an error of 0.90 percent of water vapor. The uncertainty in the observations of relative humidity is sufficient to account for only about 0.04 percent of water, or 4.4 percent of this amount. However, if one admits the possibility of an uncertainty in the individual tests amounting to 0.003 , as is indicated by the solid points used to determine the tem- 
perature coefficient, this would suffice to bring all the points to a horizontal line. Since any known dependence on water vapor has been eliminated by the application of the corrections, it must be concluded that such an uncertainty actually exists.

(11) Effect of Relative Humidity on Chart.-Tests of the paper used on this instrument show that a change of 80 percent in the relative humidity changes by 0.60 percent the dimension of the paper in the 6-o'clock axis and by the 1.43 percent in the 12-o'clock axis. Readings of the instrument are subject to correction on account of this effect under all conditions except that in which the instrument is calibrated, and the record made with the chart exposed to air of the same relative humidity as that existing at the time the chart was printed.

At any other relative humidity, the circles on the chart are no longer circles and their radii are different. A relative humidity change of 47.4 percent (which is not excessive) from that at calibration resulted in a correction of 0.0012 on the 6-o'clock axis with test mixture 2 ( $\mathrm{sp} \mathrm{gr}$ $0.6820)$. A correction of approximately 0.0028 on the 12 -o'clock axis would have been required with an additional uncertainty in the reading unless it were known that the relative humidity at calibration was the same as that at printing.

(12) Barometric Pressure.-If the calibration is done according to the manufacturer's instructions, the reading is correct at the barometric pressure assumed (when the calibration was made) to be average for the testing station. The reading at any other pressure is in error by an amount that is proportional to the calibrating pressure, to the difference between the actual pressure and the assumed average, and to the difference between the specific gravity of the gas and that of air. That is,

$$
R-S=B_{1}\left(B-B_{1}\right)(1-S)=\left(\frac{B}{B_{1}}-1\right)(1-S),
$$

where $R$ is the reading of the instrument; $S$ is the true specific gravity of the gas; $B$ is the barometric pressure at the time the reading is made, and $B_{1}$ is the barometric pressure at which the correct specific gravity would be recorded. However, a correct reading of specific gravity can be obtained by shifting the cap from the position representing the average barometric pressure to a position representing the actual pressure at the moment. The cap was shifted in this way when making tests with the various standard gas mixtures.

(13) Reference Air.-Uncertainties as to the composition of the surrounding air, used as a standard of reference, caused by contamination from various sources, will cause errors in the specific gravity indicated by the instrument. Leaks of gas from points within the instrument case, especially from loose joints in the stopper of the seal bottle or rubber-tube connections, cracked rubber tubing, permeability of even good rubber to some gases, diffusion through the liquid in the seal tanks, etc., may contaminate that portion of the reference air that is inside the case. Lack of adequate disposition of the gas flowing from the seal-bottle vent and from the top of the gas column, may cause contamination of the reference air outside the case. Such contamination by the sample will result in an indicated specific gravity that is 
nearer 1.000 than it should be, giving a high reading for gases having a specific gravity lower than air and a low reading for gases having a specific gravity higher than air.

The vapor of the liquid in the seal tanks will contaminate the reference air inside the case to an extent, depending on the degree of ventilation of the case. The effect of such vapors has just been discussed in connection with the contamination of the gas sample. In the case of the reference air, the effect will be to give an indicated specific gravity that is too low. The magnitude of the effect will be much more variable in this case because of the variability of concentration of the vapor as a result of variations in ventilation, principally perhaps from opening the door of the case.

The effects of water vapor.and carbon dioxide have been discussed in section III 1 (a) and IV 4 (d) (10). Variations of relative humidity from 10 to 70 percent in the same place at different times of year are easily possible. At a temperature of $77^{\circ} \mathrm{F}$ this range corresponds to a range of water-vapor concentration of from 0.3 to 2.2 percent. Even if the calibration were made with the water content of the air in the middle of this range, the uncorrected reading could be in error by as much as \pm 0.0036 as a result of variations up to 0.95 percent of water vapor from the mean value of 1.25 percent. The effects of carbon dioxide are produced only by variations of the carbon dioxide content of the air from that existing at the time of calibration, and will be negligible except for unusual changes in ventilation or occupancy of the room, or the operation of burners.

(e) COMMENTS ON OPERATION AND SUGGESTIONS FOR IMPROVEMENT

It was found that this instrument could be dismantled to the extent of lifting the bells from the oil and the beam from its bearings and reassembled without readjustment and without change of reading. This fact and the quick and accurate response of the instrument to mechanical loading shows that the action of the instrument as a balance is remarkably free from mechanical trouble. Inaccuracies must arise almost wholly from conditions (of which the vapor of the sealing liquid is an outstanding example) that affect the loads that the gravitometer, as a balance, has to weigh.

Such an instrument deserves much more careful consideration in the matter of calibration and sealing liquid than was provided for in the recommendation of the manufacturer. The major changes needed, therefore, had to do with the manufacturer's provisions for these two most important items, and not with the construction of the balance itself.

1. Instead of vaguely specifying (by density only) an extremely variable commercial product as the sealing liquid, the manufacturer should purchase and supply with the instrument a sealing fluid of satisfactorily low vapor pressure and viscosity. This should be a nearly pure compound, so that its properties do not change appreciably. An oil such as that sold under the name Markol (specific gravity 0.846 ) has a negligible vapor pressure and appears to be suitable in other respects.

2. Instead of leaving the fundamental relation of column height and the position of the center of gravity of the instrument to determi- 
nation by the user by a difficult and uncertain method as is done at present, the manufacturer should take the full responsibility for this and should fix the index by which the column height is judged. Then the cap can be graduated and numbered so that the reading of the index will be 30 when the height is actually $30 \mathrm{in}$.; then other graduations should be made and marked as a reciprocal scale. Then the user will simply set the cap to the mark reading his average barometer. Checking of the calibration can be done, with much greater accuracy than by the present method, with no trouble, and without the need of using a gas of known specific gravity by adding a weight supplied by the manufacturer to one side of the balance following an air check. This check will not involve the height of the gas column. The weight can be made conveniently in the form of a thumbscrew to be inserted into a threaded hole in the strip by which the bell is suspended, and adjusted in the company's laboratory with the aid of an analytical balance.

3. The range of the instrument can be changed with accuracy and ease by the same method, that is, by adding to one side or the other of the balance a predetermined weight after shifting the position of the beam. Again the thumbscrew in the suspension strip is suggested. This would probably be preferable to a shifting of the counterweight, as at present practiced.

4. If the final setting of the pen on 1.000 with air is to be left to the user, as it probably should be, a more accurate means than the sliding of the counterweight should be provided. It is difficult to move this heavy weight by the necessary small amounts. A fine adjustment in the form of a screw entering the end of the counterweight, which would probably be differently shaped than at present, would be satisfactory and would involve a minimum of change in the present instrument. A sleeve nut threaded directly on the balance beam, together with a fixed counterweight providing most of the compensation for the pen-arm connections might be equally satisfactory.

5. A simple means of correcting for the effect, on the chart, of relative humidity changes that occur subsequent to calibration would be to mount a fixed pen, adjusted to read 1.000 on the chart (or to follow a line outside the regular chart by perhaps the same space as that between lines of the chart) at the time of calibration and left there until the next calibration. The readings could then be corrected by the amount of the departure of the record of this pen from 1.000 , multiplied by the proportionate distance of the reading of the movable pen from the center of the chart.

6. Leaks inside the balance case from the seal bottle and its connections might be made less likely by using a bottle with a metal screw cap and gasket. The metal tubes could then be soldered through the cap and the rubber tubing replaced by metal tubing.

7. It has been suggested that the instrument might be made independent of changes of the water vapor and carbon dioxide content of the surrounding air, which occur subsequent to calibration, by closing the balance bell and fitting it with a reference air column opening through a replaceable cartridge containing Ascarite and calcium chloride. The column could be purged at calibration and maintain 
a standard of reference that would be dry and free from carbon dioxide.

8. A humidity-correction chart could be supplied with the instrument for the use of those interested in momentary readings. Automatic correction for humidity does not appear practicable except by the means suggested in the preceding paragraph.

9. It would be worthwhile to attach a spirit level or at least a plumb bob to the column inside the case to make it possible to level the balance easily and accurately.

10. The wooden case has shown some signs of warping and loosening at the joints at the bottom. It might be desirable to use a metal case with louvres for ventilation. A metal case would provide better conduction of heat and consequently reduce differences in temperature between inside and outside that occur during changes of the temperature of the surroundings.

\section{SIGMA RECORDER NO. 7 FOR SPECIFIC GRAVITY}

(a) DESCRIPTION

The Sigma recorder (fig. 27) is approximately 14 in. wide, 131/2 in. deep, and $19 \mathrm{in}$. high. The burner at the top of the gas column is $6 \mathrm{ft} 71 / 2$ in. above the table. The entire instrument weighs $68 \mathrm{lb}$.

This instrument (described very briefly in the three pages of description and instructions which accompany it) is nonportable and consists of a heavy cast-iron reservoir and a housing, mounted on four short legs. In the reservoir, filled with mineral seal oil, a bell float 10 in. in diameter and about $2 \mathrm{in}$. high is suspended from one end of a balance beam by a link passing through the cover. The bell is counterbalanced by an adjustable weight at the other end of the beam. The clock, chart mechanism, pen linkage, and bell float for compensating for temperature and pressure are mounted inside a cast-iron housing that forms a part of the cover of the reservoir. An air reservoir for the compensating device is mounted outside on the back of the housing and connects with the compensator bell float inside.

The large bell float is connected by a magnifying lever linkage to a cam, marked with the gas volume factors from 0.90 to 1.10 in the intervals of 0.01 . The cam follower magnifies and transmits the motion of the bell to the pen arm, and the position of the rider on the cam is adjusted automatically through linkages, by the motion of the compensator bell float, which rises and falls as the air in the compensating air reservoir expands or contracts with changes of atmospheric temperature and pressure. The sample is introduced under the 10-in. bell float through a valve, and passes out through the gas column, where according to directions, it is to be disposed of by burning. A rubber hose connects the bell float to a burner, the port of which is adjusted to be $6 \mathrm{ft}$ above the top of the bell. The burner and its connections thus comprise a pressure column similar to that of the Anubis gravitometer, and the force which actuates the instrument is equal to the buoyancy of a column of gas $6 \mathrm{ft} \mathrm{high}$ and $10 \mathrm{in}$. 
in diameter. The burner is shielded to prerent extinction by drafts.

The chart is calibrated in specific gravity from 0.40 to 0.65 in intervals of 0.01 , which are five-thirty-seconds in. wide, permitting visual estimation of the reading to 0.001 or a little better. The 14-day chart

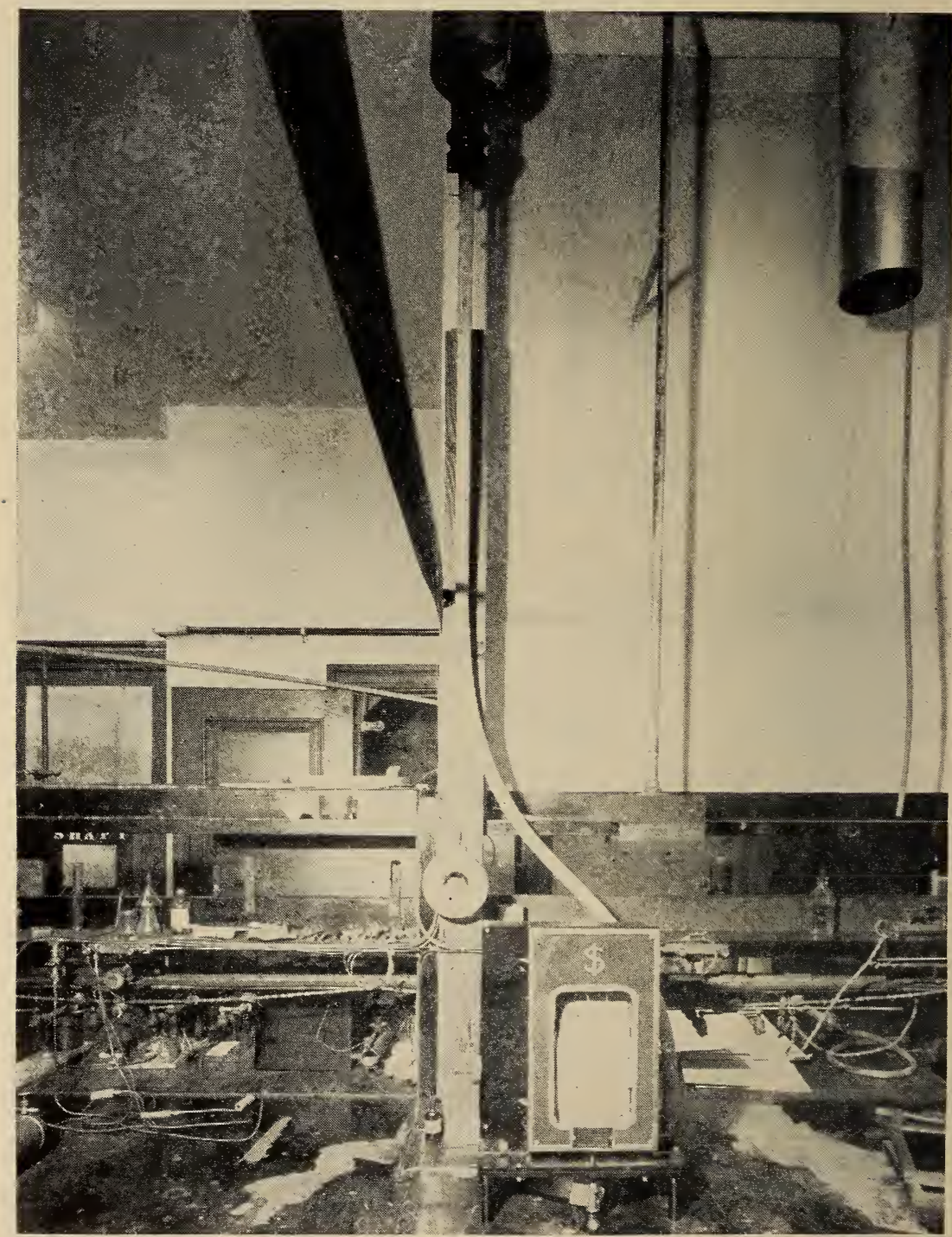

FIgURe 27.-Sigma recorder No. 7 for specific gravity.

is driven at the rate of $1 / 2 \mathrm{in}$./hr by a 14 -day clock and is marked at hourly intervals.

The range of specific gravities over which the instrument operates. although adequate for an English gas works, is too narrow to find wide application among the diverse gases of the United States. 


\section{(b) MODIFICATIONS FOR TESTING}

The burner, instead of being fastened to a wall, was mounted on a clamp sliding on a rod. A collar was adjusted on the rod under the clamp so that the burner. was located at the specified height shown in the blueprint. This permitted the determination of the effect of the flame in terms of height of gas column.

A hood, consisting of 6-in. galvanized iron smoke pipe, was mounted orer the burner and connected to the exhaust fan. An adjustable sleeve orer the burner and dampers were provided so that the discharged gases could be removed from the room without affecting the indication of the instrument. This permitted operation of the instrument with or without a flame on the burner and prevented contamination of the air of the room (which was used as a reference) with products of combustion or unburned or noncombustible gases.

\section{(c) METHOD OF OPERATION}

The directions supplied for the installation and operation of the instrument were followed, with a few minor modifications and extensions, during the testing with four of the gases of known specific grarity.

According to the directions, the large reservoir was to be filled with an oil of "low viscosity." "Paraffin" was said to be suitable, but should it eraporate. "a very thin oil" was to be used. "Spindle oil" and "gas oil" were said to be suitable. The small compensator reserroir was to be filled with "spindle oil or common machine oil."

Kerosine of specific gravity 0.81 first was used, but this evaporated and crept over the rim of the small reservoir and over the adjacent morable parts. Its level was difficult to maintain. its rapor probably contaminated the gas sample, and the creeping liquid may have affected the reading of the instrument. It was therefore replaced in both reservoirs with Markol ( $\mathrm{sp}$ gr 0.846 and viscosity 0.245 poise at $25^{\circ} \mathrm{C}$ ), as was done in other cases previously mentioned.

Before admitting the test gases to the instrument it was calibrated according to the instructions. The burner having been set at the specified height, the instrument was purged with air from the laboratory (adjusted to 35-percent relative humidity) by drawing it down through the gas column. through the bell, and out through the inlet valve. The compensator air reservoir was opened to the air and the cam follower raised until it was above the 1.00 mark on the cam. and the valve closed. By cracking the valve, air was allowed to escape until the cam follower read 1.000 ; then the valve was closed tightly. The cover disk over the large bell was removed, and the test weight placed on the pin. The flow of purge air was stopped, the chart adjusted with the left edge touching its guide, and the pen marle to read 0.500 on the chart by adjusting the counterweight on the balance beam. The test weight was then remored from the large bell and the small corer disk replaced. The temperature of the instrument was determined by means of a thermocouple located near the compensating air reservoir, and the barometer was read and corrected. The gasrolume factor, representing the volume at the measured temperature and pressure of a unit volume at $60^{\circ} \mathrm{F}$ and 30 in., was determined from a table or computed by means of the gas laws. The valve to 
the compensating air reservoir was again opened and the cam follower raised somewhat above the reading desired, the reading of the follower on the cam adjusted to the gas volume factor just computed by allowing air to escape as before, and the valve was again tightly closed.

Before each test of the instrument with a test gas the oil levels were checked, and if necessary adjusted, the temperature and pressure were determined, the correct gas volume factor computed, and if necessary the cam follower was reset to that reading on the cam, and the reading of the cam follower recorded before and after readjustment, as a test of the ability of the compensating mechanism to maintain a correct reading. The test gas was then admitted at a rate of $0.33 \mathrm{cu} \mathrm{ft} / \mathrm{hr}$, resulting in a velocity of flow from the burner of $0.5 \mathrm{in} . / \mathrm{sec}$, and a flame about $5 / 8$ in. high. (This rate had been determined by trial to be about that at which the indication of the instrument was least affected by small changes of rate of flow. The directions state: "The smaller the flame at the burner, the more accurate will the reading be, as a large flame causes a suction at the outlet of the burner which will suck the bell down and give a reading of specific gravity which is too low." Accordingly, the instrument was tested with no flame on the burner, but the effect of the flame was determined and will be discussed under sources of error.)

Each test of the instrument with a test gas involved purging the instrument until the reading and record had been constant for approximately 15 minutes. The indication and record were then displaced by placing a wire rider over the counterweight, moving the pen by about 0.04 specific gravity. This displacement raised the bell out of the oil slightly, so that when the rider was removed after about 5 minutes, the bell returned to its former position in the oil. and no drainage of oil from the bell interfered with the prompt resumption of the equilibrium of the parts. While making the 15-minute record, the chart reading, instrument temperature, room temperature, barometric pressure, relative humidity, and dry-bulb temperature, and the time at which the record was started were all noted. After the displacement period of 5 minutes, another 15 -minute record was made as before, until 10 determinations of the reading of the instrument on the test gas had been made.

The reading on the chart of the center of each of the 10 record lines was then determined with an ocular-scale microscope. These 10 values of specific gravity were averaged for the test. The temperatures, barometric pressure, and relative humidity reported with each test are the averages of the values recorded for the 10 determinations.

(d) CORRECTION FOR COMPOSITION OF REFERENCE AIR

The air surrounding the balance is again the reference air, and its composition affects the reading of the instrument to the same extent as the reference air in the Ac-Me and Anubis recorders, that is, the equation

$$
S=R-0.378 w+0.529 c
$$

again applies, $S$ being the true specific gravity, $R$ the reading of the instrument, and $w$ and $c$, respectively, the fractions of water vapor and carbon dioxide in the air. 


\section{(e) CORRECTION FOR EFFECT OF HUMIDITY ON CHART}

In the case of the paper used on this instrument, tests indicated that a change of 80 percent in the relative humidity changes any horizontal dimension by 1.66 percent, or, for a change of each 1.0 percent in relative humidity, the paper changes its horizontal dimension by 0.021 percent.

The record is made on a continuous strip of paper between guides that are too far apart to prevent all lateral movement. If the specific gravity indicated happened to be near one side of the paper and the fixed chart guide on the other side, and if the relative humidity changed by 30 percent, as it might from day to day, it would be possible to have a difference from this cause as large as 0.0017 .

The mean of the 10 determinations constituting a test has in each case been corrected to obtain the reading that would have been indicated had the relative humidity been exactly 35.0 percent, by the method employed for other charts. (See section III, 2 (e).) The only difference is that the distance from a fixed point to the recorded line is measured from the guided edge instead of from a center.

Summarizing the observations and corrections of mixture 5:

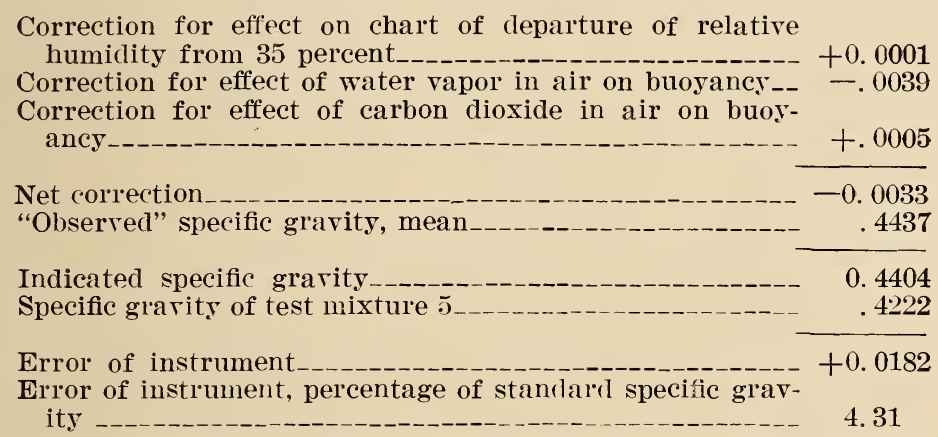

The data have been treated in the same manner in the case of the other test gases whose specific gravity was within the range of the instrument, and a summary of the numerical results is presented in table 10. The errors of the results "as observed" and after the corrections noted above have been applied are plotted in figure 28.

\section{(f) TEMPERATURE COEFFICIENT}

A test consisting of 10 determinations of the specific-gravity reading with a single test gas (mixture 2) was made as described in the method of operation at each of the temperatures $66.9^{\circ}, 77.5^{\circ}, 78.8^{\circ}$, $79.8^{\circ}$, and $92.6^{\circ} \mathrm{F}$ to determine whether the temperature and pressure compensator operates satisfactorily.

Three of these tests were made at substantially constant water content of the reference air (average 1.15 percent, equivalent to 36.5 percent relative humidity at $77^{\circ} \mathrm{F}$ ) and three were made at substantially constant relative humidity (average 36.9 percent). The observed results have all been corrected for the departure of the chart paper from 35-percent relative humidity and to dry carbon dioxidefree reference air. The results as observed and after all corrections 


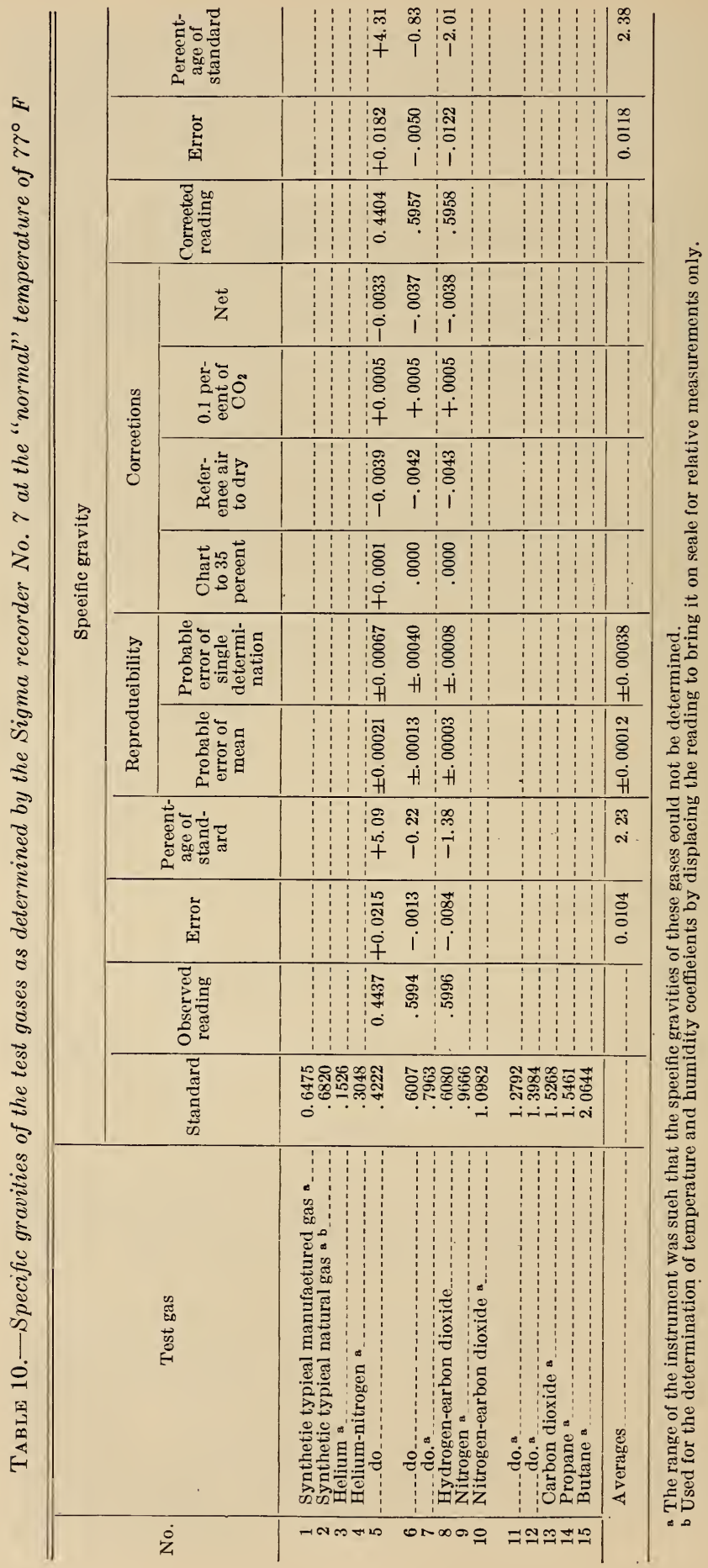




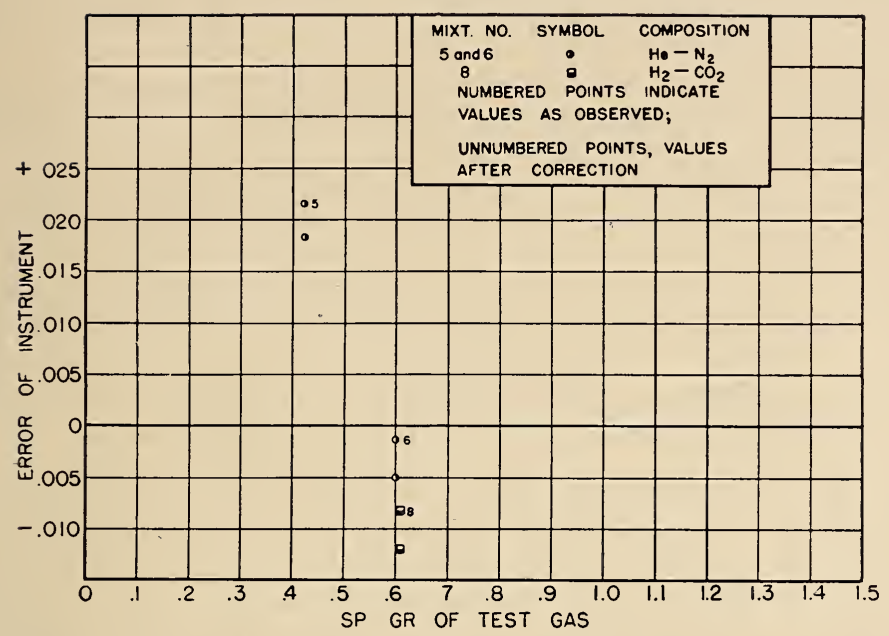

FIgLRE 28.-Error of the Sigma recorder No. 7 determined with each test gas. The numbered point of each pair indicates the error as observed, and the unnumbered point, the error after the application of all corrections.

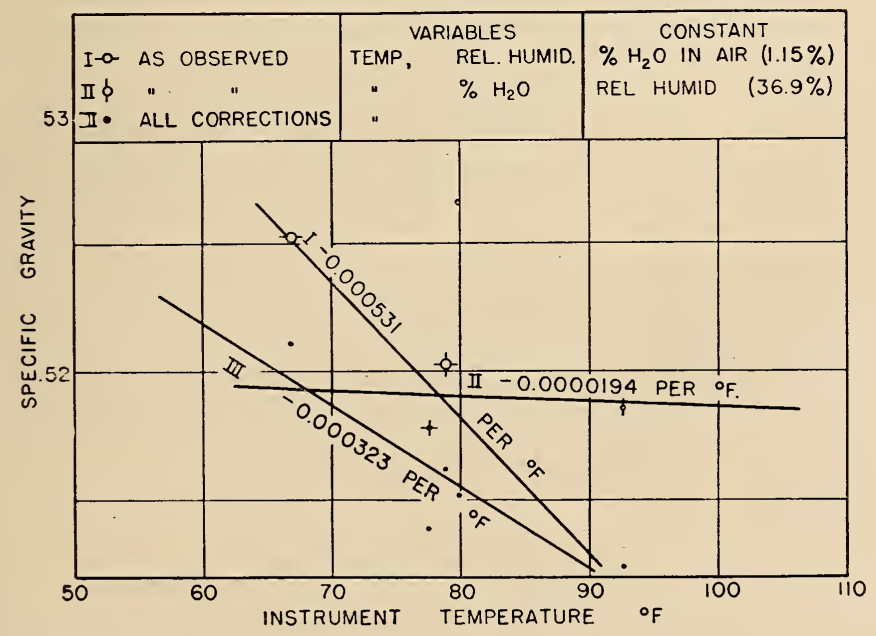

FigtRe 29.-Temperature coefficients of the Sigma recorder No. 7 determined with test mixture 2, as observed (-O- at constant percentage of water vapor in the reefrence air (1.15 percent); O at constant relative humidity of the reference air (36.9 percent)), and - after the application of all corrections. 
were applied have been plotted against temperature in figure 29. A straight line, determined by the method of least squares, has been passed through the three points of each of the two groups mentioned above and another through all five points after they have been brought to a common basis by the application of the corrections discussed above. The slopes of these lines, constituting the temperature coefficients, are indicated thereon.

The radius of the circle around each observed point is equal to the probable error of the mean of the 10 determinations that point represents.

It may be noted that the circles are small as compared with the differences that appear between tests on successive days under nearly the same conditions. Even when all the corrections that have been evaluated have been applied, the differences are still very large and a large negative temperature coefficient still remains.

The variations may in part be caused by failure to reproduce exactly the rate of flow of the test gas and consequently the size of the flame on the burner. These had been adjusted to a minimum at the outset, when it had been determined that extinguishing the flame could be compensated by raising the burner $80 \mathrm{~mm}$ higher. An attempt was made to set the same rate for each test, using the height of the flame as an indicator, and it is believed that this was accomplished to a far greater extent than the instructions indicate is required.

The variations do not appear to result from malfunction of the actuating portion of the compensating mechanism, because, while temperature and pressure varied, the reading indicated by the cam follower on the scale differed from the correct factor for that temperature and pressure by less than four-tenths division, whereas the factor changed nearly five divisions. A fraction, about 5.2 percent of the apparent residual negative temperature coefficient, may be accounted for by expansion of the mechanical members of the mechanism.

If one considers that the uncertainty of a particular test may be more accurately evaluated by comparing that test with another made under the same conditions than by computing the probable error of the mean of the 10 determinations that constitute the single test, then it is seen that an uncertainty of 0.0023 would suffice to bring all five of the solid points of figure 29 to a straight line having a slope of about $-0.000154 /{ }^{\circ} \mathrm{F}$. This is still about 47.5 percent of the slope -0.00032 which was found. It appears, therefore, that the instrument is overcompensated as a result of setting the center of curvature of the cam too far from the pin by which the cam follower link is attached to the pen mechanism.

\section{(g) HUMIDITY COEFFICIENT}

To determine experimentally the effect on the indicated reading of variations in the water content of the surrounding air, which is used as a reference, a test consisting of 10 determinations of the reading was made in the manner previously described, with the water content of the reference air at 2.78 percent in addition to two tests at 1.15 and 1.19 percent, which correspond nearly to 35.0 -percent relative humidity at $77^{\circ} \mathrm{F}$, the conditions chosen as "normal" for the purposes of these tests. 
During these tests the instrument was maintained at as near the same temperature as possible. The average temperature was $78.7^{\circ} \mathrm{F}$, and the temperatures during individual tests difiered from this by $1.2^{\circ} \mathrm{F}$ or less.

The results as observed, and after correction to a chart reading at 35 -percent relative humidity, for 0.1 percent of $\mathrm{CO}_{2}$ in the air, and to dry reference air, have been plotted against "water vapor in the reference air," in figure 30 . Straight lines, determined by the method of least squares, have been passed through the three points, and the slopes of the lines, constituting the humidity (or percentage of water) coefficients, are indicated thereon.

It may be noted that the effect of variations in the percentage of

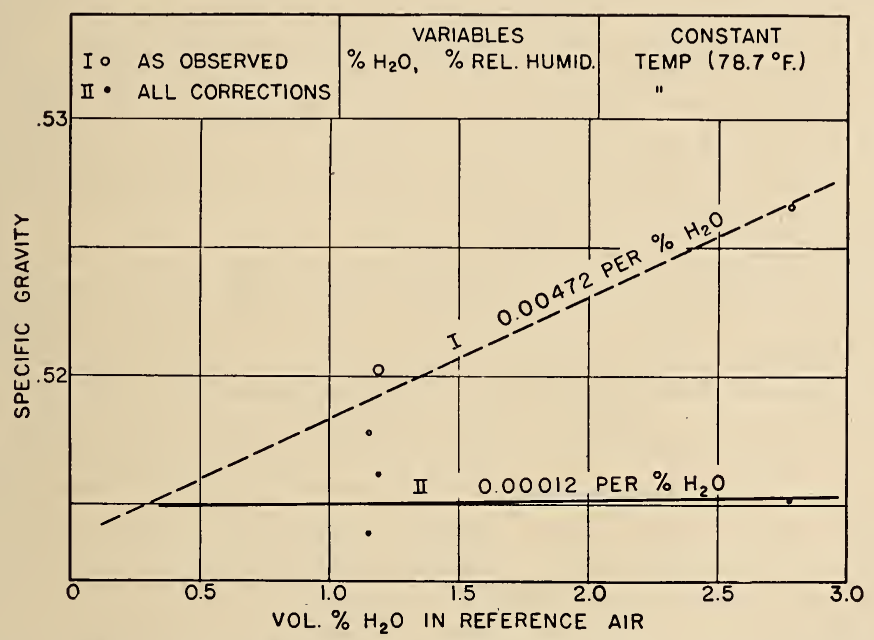

FIGURE 30.-Humidity coefficient of the Sigma recorder No. 7 determined at constant temperature $\left(78.7^{\circ} \mathrm{F}\right)$ with test mixture 2 ; $\bigcirc$ as observed, and after the application of all corrections.

water in the air has been reduced practically to zero by applying all the corrections, the slight residual coefficient being easily accounted for by the uncertainty in the individual tests. The results, when corrected for water vapor in the reference air, are independent of the concentration of that water vapor.

\section{(h) OTHER SOURCES OF ERROR}

(1) Accuracy of Readings.-The position of the record mark on the chart can be read to 0.01 and estimated to 0.001 , in some cases perhaps to \pm 0.0005 , which is small compared with errors from other sources.

(2) Position of Chart.-The guides for the chart paper are farther apart than the width of the chart by about $1.1 \mathrm{~mm}$, and consequently, movement of the chart from contact on one side to contact on the other would correspond to an uncertainty of 0.0027 in specific gravity.

(3) Material Tested.-With continuous purging, contamination of the sample with air is unlikely unless there is a bad leak at some point between the throttling valve and the lower end of the hose leading to 
the burner. Samples with specific gravities less than air cause the pressure between those points and in the hose to be below atmospheric, but by too small an amount to result in contamination with air unless the opening is large.

A possible source of contamination of the gas sample is the seal oil used in the reservoir to seal the bell float. The use of oil having an appreciable vapor pressure will result in the contamination of the sample with oil vapor. For example, a kerosine of specific gravity 0.81 (molecular wt about 180) such as that originally used in the instrument would have a vapor of specific gravity about 6.2. Its vapor pressure at $77^{\circ} \mathrm{F}$ is approximately $2 \mathrm{~mm}$. If one assumes that it would evaporate into the sample at a rate which would bring the proportion of vapor in the sample to about one-half that at saturation, the proportion present would be about 0.13 percent vapor. 0.13 percent of vapor of specific gravity 6.2 mixed with 99.87 percent sample of specific gravity 0.5000 would yield a mixture of specific gravity 0.5074 , and thus cause an error of +0.0074 in the specific gravity of the sample. If one assumes that the sample is saturated with kerosine vapor, the error is twice as great.

The Markol, which has been used as a seal liquid in all the tests with this instrument, will not affect the fourth decimal place of the specific gravity even though its vapor saturates the gas sample.

(4) Effect of Flame.-A statement in the directions that "The smaller the flame at the burner, the more accurate will the reading be, as a large flame causes a suction at the outlet of the burner which will suck the bell down and give a reading of specific gravity which is too low", indicates that the flame is recognized as a source of error. The magnitude of the error was determined by adjusting the sampling rate with the flame burning, noting the indicated specific gravity, and then extinguishing the flame. After the burner had cooled to room temperature, the reading had increased by 0.014 . Raising the burner $80 \mathrm{~mm}$ restored the indication to the original reading by increasing the height and consequently the buoyancy of the gas column. Another determination, however, indicated that an increase in height of $100 \mathrm{~mm}$ was necessary to compensate for the absence of the flame. The determination is obviously not of high accuracy.

The tests of the instrument with nonflammable gases made the presence of a flame impossible, but when the test was completed in each case, the burner was raised $80 \mathrm{~mm}$ and an additional determination made. The effect produced on the indicated specific gravity was to decrease the reading in all cases, but the amount was found to vary from 0.014 to 0.022 .

It is obvious that the flame, or its equivalent, is a source of a considerable and quite variable error, one that is several times that required to account for the behavior with respect to temperature and humidity coefficients. The desirability of eliminating the flame is distinctly indicated.

(5) Height of Gas Column.-The height of the gas column is the distance between the top of the bell and the rim of the burner. When gases of different specific gravity are introduced the bell moves upward or downward and thus changes the height of the gas column 
by $0.1 \mathrm{in}$. for each 0.1 of specific gravity. The reading will thus be in error by a corresponding amount at specific gravities other than 0.5 , the calibration point. At 0.65 the error from this source would be about -0.2 percent, and at 0.4 the error would be about -0.13 percent.

(6) Rate of Sampling.- The indication is affected by the rate of sampling, as might be expected. The optimum rate is the lowest that will keep the bell and gas column purged. If the rate is decreased below this, air tends to spill into the top of the column and a higher reading results. If the rate is increased above the optimum, the pressure required to produce the increased flow through column and burner increases the reading. At the optimum rate, the indication is affected little or not at all by small changes in rate. The optimum rate was determined by measurement to be $0.33 \mathrm{cu} \mathrm{ft} / \mathrm{hr}$ for this instrument, and when the gas is combustible results in a flame of the size used in the determinations of temperature and humidity coefficients.

(7) Temperature Lag.-When the temperature of the room was changed at a rate between 5 and $10 \operatorname{deg~} \mathrm{F} / \mathrm{hr}$, the temperature at a point beside the compensator air reservoir lagged behind the room temperature by between 3 and $4 \operatorname{deg} \mathrm{F}$. This would result in errors of compensation, as well as errors resulting from corresponding differences between the temperature of the gas inside the bell and gas column and the air surrounding them. The net effect was that with rising temperature the readings rose as much as 0.0075 above the reading at constant temperature, and with falling temperature, fell as much as 0.0100 below.

(8) The Test Weight.-Any inaccuracy in the determination and adjustment of the proper mass of the test weight used in the calibration would result in an error of displacement at specific gravity 0.5 , which appears to be constant over the entire range. The proper weight is 0.5 times the weight of air (dry and free from $\mathrm{CO}_{2}$ and at $60^{\circ} \mathrm{F}$ and $30 \mathrm{in} . \mathrm{Hg}$ ) in a column having the height of the gas column and the diameter of the inside of the bell. Error's in the estimation of these dimensions are involved in the determination of the proper weight. If the dimensions given by the manufacturer are correct, the weight should weigh $56.47 \mathrm{~g}$. It was found to weigh $56.72 \mathrm{~g}$. which is 0.5022 times the weight of the air. The pen being set to read 0.5000 , the indicated specific gravity is 0.0022 too low in the case of this particular test weight.

(9) Sealing Oil.-Unless an oil of low viscosity and specific gravity is used (which carries with it a vapor pressure higher than desirable), an appreciable weight of oil may be held upon the sides of the bell after a change in specific gravity causes the bell to be immersed and then withdrawn from the oil. About the same proportion of the weight held up will drain off in a given length of time, regardless of viscosity or specific gravity of the oil. That which remains tends to give a low reading, but should cause no serious lag or inaccuracy unless the changes are marked and rapid. If the sealing-oil creeps, the weight of the film formed tends to give a still lower reading, and no counterbalancing bell offers hope that the effect will be 
canceled. As Markol has little tendency to creep, the tests were not much affected, but some kerosines might cause serious error by creeping.

(10) Oil Level.-The level of the oil in the reservoirs should be carefully and regularly inspected and adjusted, especially if an oil of appreciable vapor pressure is being used. At calibration a portion of the bell is immersed in the oil, and subsequent readings are subject to an error to the extent that the immersion of the bell changes thereafter. There is no counterpoise bell to cancel the immersion effect; therefore, the reading becomes lower as the oil level drops.

(11) Immersion Error.-At calibration the reading is set at 0.5. Consequently, the immersion error is zero at specific gravity 0.5000 . At lower specific gravity the bell will be immersed more deeply, the buoyant force will be greater, and the reading will tend to be too high on this account. At higher specific gravities the reading will tend to be too low.

(12) Pendulum Weight.-A pendulum weight attached to the fulcrum rod of the balance beam, its position adjustable by loosening a setscrew, produces an effect opposite to that required for compensation of the immersion of the bell. Neither its purpose, its correct position, nor its existence are mentioned in the instructions. Its weight is about $60 \mathrm{~g}$, and it is suspended about $5 \mathrm{~cm}$ below the fulcrum, so that an incorrect position might account for an appreciable systematic error.

(13) Oil in Pneumatic Compensator.-Accidental movement of the small balance beam carrying the compensator bell and counterweight may result in the oil in the reservoir being raised to the rim of the inner cylinder of the annular reservoir and some of it finding its way into the air reservoir. Some may collect in and partially close the tube connecting the reservoir to the bell and thus cause faulty operation of the compensator. This small balance beam is not adequately protected from accidental contact when replacing or adjusting the chart roll, which is located immediately in front of it. The oil level in the compensator reservoir must be kept at the same point $(1 / 4$ in. from rim) in order to maintain the correct reading on the compensator cam corresponding to a given temperature and pressure.

(i) COMMENTS ON OPERATION AND SUGGESTIONS FOR IMPROVEMENT

While the instrument is, as described by its manufacturer, rugged and sensitive, it is believed that its reproducibility, accuracy, and susceptibility to derangement would be improved by the following modifications.

(1) Some sort of flow indicator should be provided, by means of which the flow of the gas sample could be maintained at the same rate.

(2) The error introduced by the presence of the flame on a burner is much greater than that which might be caused by contamination of the reference air by the effluent gas sample in a reasonably well ventilated laboratory. Means should be provided for the elimination of the discharged sample, and the burner and flame should also be eliminated.

(3) The adjustable valve with the notch in the plug, as provided on the instrument tested, leaked badly to the outside unless closed as 
tightly as possible. As a leak here contaminates the reference air, a better type of gas inlet valve is desirable.

(4) The directions for installation, calibration, and care are incomplete and do not assure the user that he has performed certain adjustments as the manufacturer intended.

(5) An adjustable guide at one side of the chart paper would be desirable to keep the paper from wandering back and forth between guides too far apart.

(6) The main balance beam and counterweight should be inclosed in a housing to protect them from dirt and accidental contact, which can change the adjustment and impair accuracy.

(7) Some sort of beam-arresting device to hold the beam while adjusting the counterweight would be a help during calibration.

(8) If it is impossible to make a permanent adjustment of the eccentricity of the cam to accomplish the proper compensation for temperature and pressure changes, a thumbscrew (or screw and lock nut) and hinge, or the equivalent, might be provided to make it possible for the user to eliminate temperature coefficients found to remain after corrections for effects dependent on temperature have been applied. This would not be worthwhile unless other equally serious sources of error are also eliminated.

(9) Some means of compensation for variations in the buoyant force resulting from immersion of the bell to different depths at different specific gravities should be provided.

(10) The rubber hose might be replaced by a metal tube that could be attached rigidly to the base of the instrument.

\section{METRIC INDICATING GRAVITOMETER}

\section{(a) DESCRIPTION}

The Metric indicating gravitometer (fig. 31) (described in Bulletin E-21, of the American Meter Co.) consists of a motor, or turbine, driven by compressed gas or air, and two centrifugal blowers mounted directly on the shaft, one on each side of the motor. Each blower is connected to a vertical water manometer that indicates the static pressure produced by the blower to which it is connected. The inlet of one blower is permanently open to the surrounding air, and its case is provided with an orifice that allows air to escape at a rate to insure that the case is continuously purged with fresh air. This blower and manometer serve as a speed indicator for the motor and the other blower. The inlet to the other blower is connected through a valve to the supply of gas to be tested. When the gas is shut off, the surrounding air is admitted automatically to the blower casing through a small orifice. The casing is provided with an orifice to allow the air or gas to escape and keep the blower casing purged with a fresh sample. The manometer, which indicates the pressure developed in the casing, will be referred to as the "test manometer." When gas is admitted, the pressure on a third manometer at the inlet orifice is kept slightly above $(+0.15 \mathrm{in}$. or less) atmospheric pressure to prevent the entrance of air; air enters if the pressure falls below atmospheric. 
108 Miscellaneous Publications, National Bureau of Standards

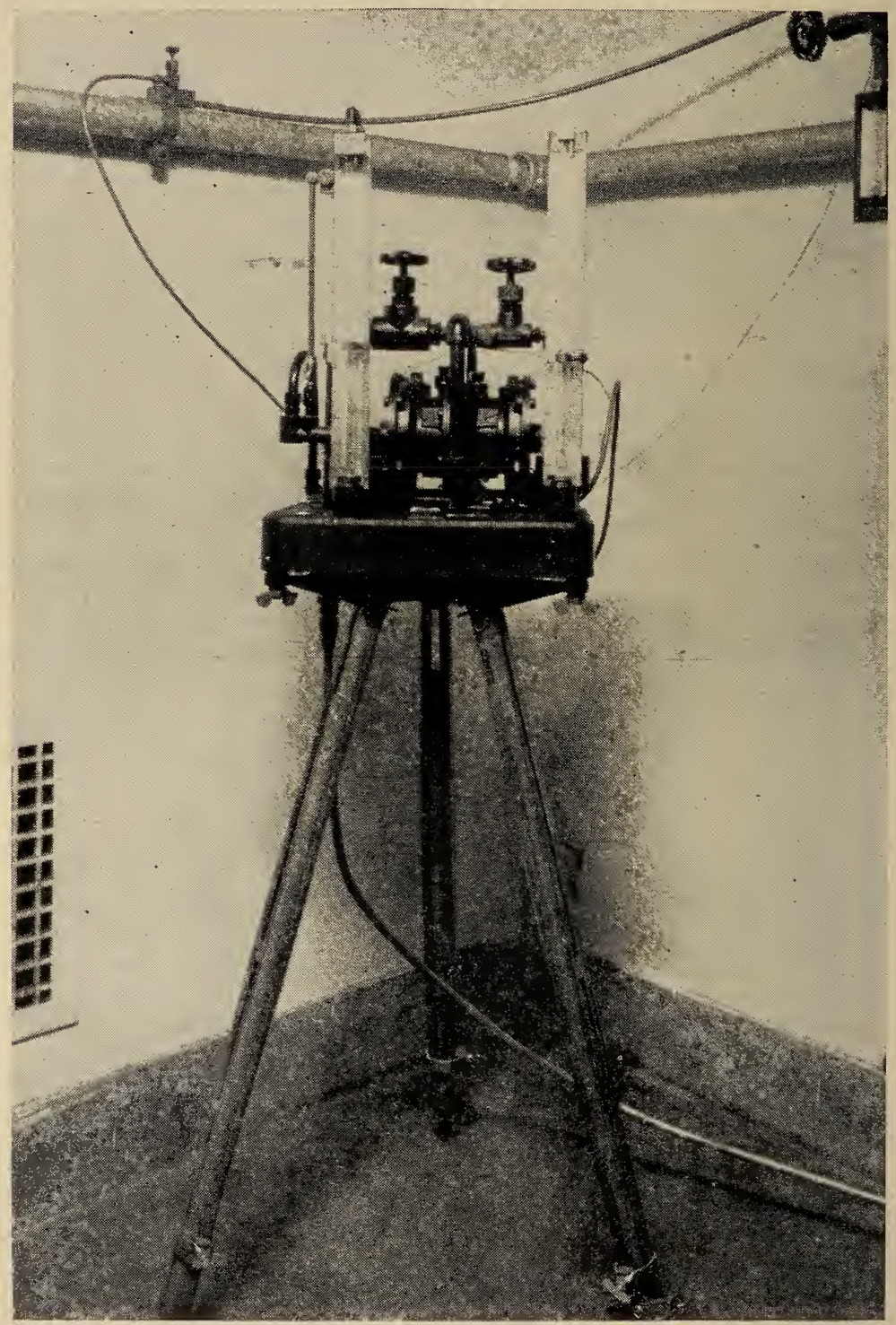

Figure 31.-Metric indicating gravitometer. 
The instrument is supplied with two diaphragm regulators in series to reduce the gas pressure nearly to atmospheric, as the instrument was designed to be driven by the gas supply that is being tested. In the case of the instrument supplied for test, the regulators would accommodate pressures between 25 and $100 \mathrm{lb} / \mathrm{in}^{2}{ }^{2}$

In making a test, the motor speed is increased (with gas shut off) until the test manometer indicates approximately $10 \mathrm{in}$. of static pressure, the position of the meniscus in the speed-indicating manometer is marked by moving the adjustable marker, and the test manometer read. Gas is then admitted and the speed regulated to bring the meniscus of the speed-indicating manometer to the marked pressure and the test manometer again read. The gas pressure divided by the air pressure (both indicated on the test manometer) is the specific gravity.

The Metric indicating gravitometer, although rather heavy, may be classed as a portable instrument. The mechanism, mounted on a metal base is inclosed in a wooden case (with handle) $191 / 2 \mathrm{in}$. high, $14 \mathrm{in}$. wide, and $12 \mathrm{in}$. deep. The case has a door at the front hinged at the bottom and supported by chains for use as a shelf. The whole is mounted on a detachable tripod stand with extensible wooden legs having a minimum length of $30 \mathrm{in.} \mathrm{A} \mathrm{length} \mathrm{of} \mathrm{armored} \mathrm{high-pres-}$ sure rubber hose is supplied for connection to the gas line. The three pieces combined weigh $51 \mathrm{lb}$.

\section{(b) MODIFICATIONS FOR TESTING}

For the purpose of these tests some modifications in the gas connections were necessary. The supply of test gas was limited, so the motor was driven by a supply of compressed air at about $75 \mathrm{lb} . /$ in. $^{2}$, the cock at the motor controlling the gas supply to the inlet of the first gas-pressure regulator was closed permanently, and the line disconnected from the regulator. As the pressure of the test gas was often above 100 lb./in. ${ }^{2}$, a high-pressure diaphragm regulat or was installed with a gage, from which the test gas was supplied to the inlet of the gas regulator on the instrument.

The wooden case was removed from the instrument to make the parts more accessible and insure adequate ventilation so that the test gas discharged into the surrounding air would be less likely to contaminate the reference air.

A thermocouple was located near the test blower with which to measure the temperature of the instrument during operation.

\section{(c) METHOD OF OPERATION}

In making a single determination, the motor speed was adjusted until the test manometer read exactly $10 \mathrm{in}$., and the position of the meniscus in the speed-indlicating manometer was marked by adjusting the slide. Gas was then admitted by adjusting the outlet pressure on the high-pressure regulator to give a positive pressure of from 0.05 to $0.10 \mathrm{in}$. on the manometer at the air-inlet orifice of the test blower. The motor speed was then readjusted to bring the speed-indicating manometer to the mark previously set, and the specific gravity read off directly on the test manometer by multiplying the reading in 
inches by 0.1. During these operations another observer read and recorded the temperature of the room, the instrument temperature, the barometric pressure, and the relative humidity, as well as the time when the specific-gravity reading was taken.

A test of the instrument with a given test gas, at a given temperature and relative humidity, consisted of a continuous series of 10 determinations of the specific gravity, as described above. The 10 values obtained were then averaged. The temperature, barometric pressure, and relative humidity reported with each test are each the average of the observed readings recorded during the 10 determinations. The temperature and relative humidity of the air of the room were controlled, so that the effects of these variables on the indication. of the instrument might be determined.

When the specific gravity of the test gas reached 1.3, the motor speed was adjusted until the test manometer read exactly 5 in. with air instead of $10 \mathrm{in.}$, and the manometer readings with gas were multiplied by 0.2 to obtain the specific gravity.

\section{(d) CORRECTION FOR COMPOSITION OF REFERENCE AIR}

As the reference air that enter's the blower when the speed is determined is neither dried nor freed from carbon dioxide, the observed readings change with changes in the content of water and carbon dioxide in the reference air. The specific gravity, $S$, is the product of the reading $R$ and the true specific gravity (referred to standard air) of the reference air. That is, if water and carbon dioxide are the only impurities,

$$
S=R(1-0.378 w+0.529 c),
$$

where $w$ and $c$ are the fractions of water vapor and carbon dioxide respectively, in the reference air. Each observation of specific gravity was corrected for the presence of these substances in the air of the room, as indicated by the equation.

The corrections for the results obtained with test mixture 1 have then been combined as follows:

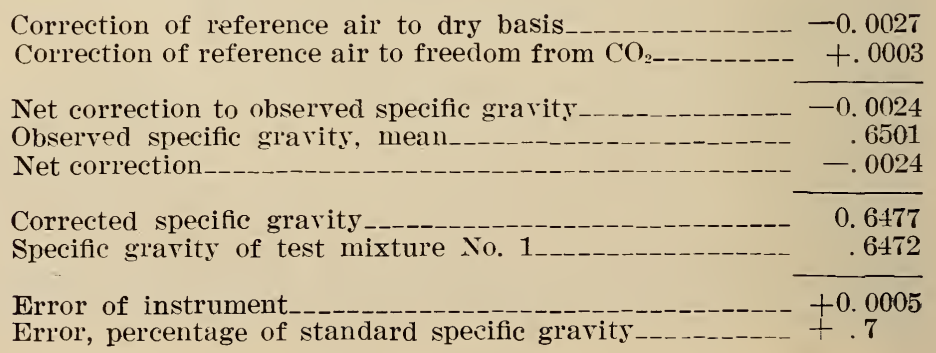

The data have been treated in the above manner for each of a variety of test gases and test conditions, and a summary of the numerical results is presented in table 11 .

The errors of the results "as observed" and after the corrections noted above have been applied are plotted in figure 32 . 
Specific Gravities of Gases

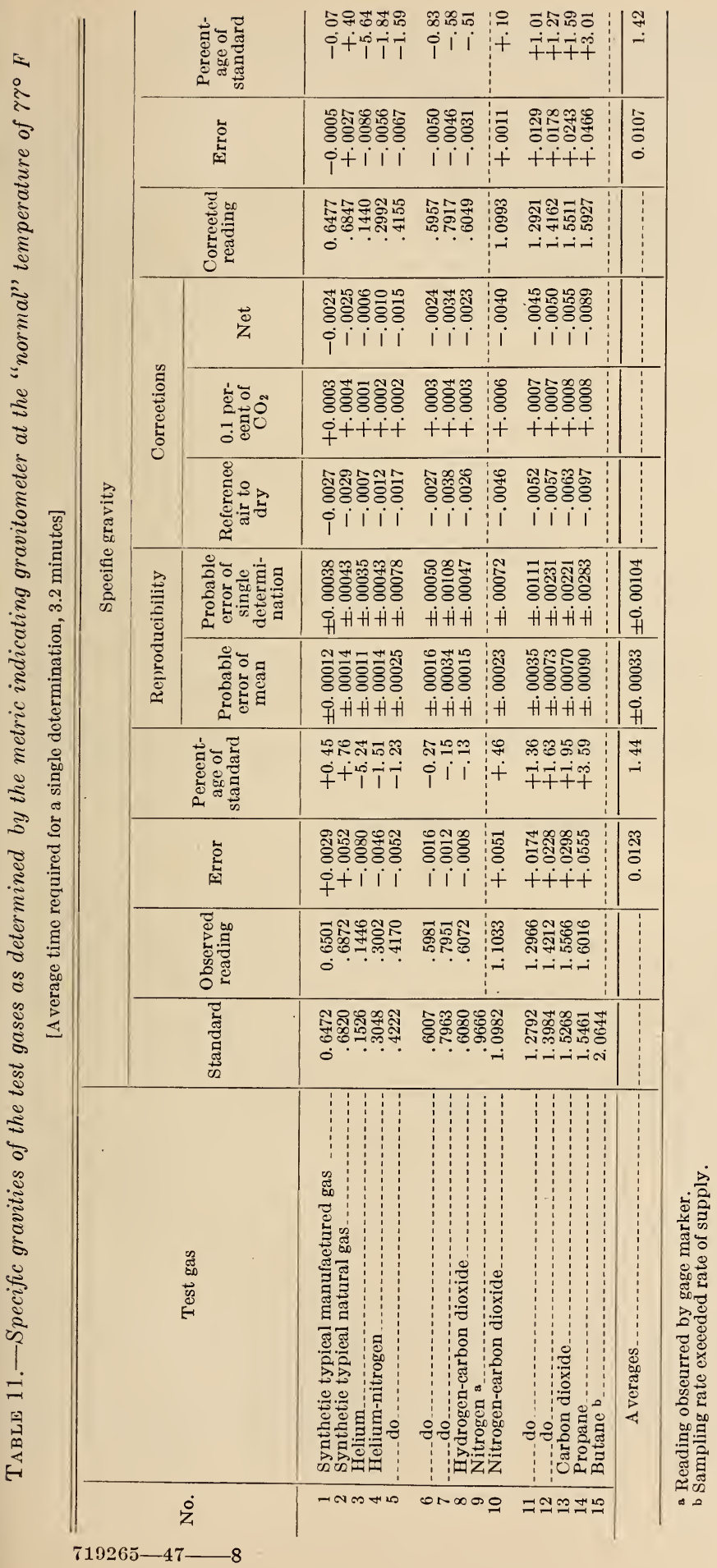




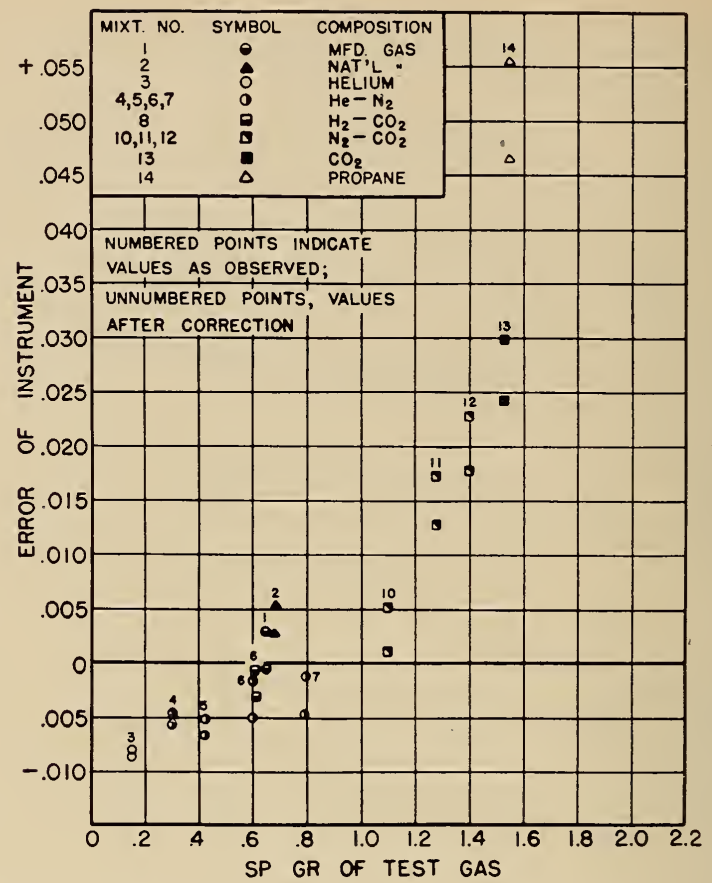

FIGURE 32.-Error of the Metric indicating gravitometer determined with each test gas.

The numbered point of each pair indicates the error as observed and the unnumbered point the error after the application of all corrections.

\section{(e) TEMPERATURE COEFFICIENT}

To determine whether the numerical result obtained by following the method of operation described above was independent of the temperature of the instrument, a test consisting of 10 determinations of "specific gravity", using the same test gas (mixture 1), was made at $72.2^{\circ}$ and at $96.2^{\circ} \mathrm{F}$, in addition to that at $82.1^{\circ} \mathrm{F}$ described in the illustration discussed previously, and one at $83.5^{\circ} \mathrm{F}$, which was made as a check at normal conditions after the other tests.

During these tests at a lower and a higher temperature than normal, the water content of the reference air was maintained as nearly constant as possible. The average water content was 1.1 percent (35percent relative humidity at $77^{\circ} \mathrm{F}$ ) and the water content during individual tests deviated from this by 0.07 percent or less.

The results, as observed and after correction to the basis of dry reference air, have been plotted against temperature in figure 33 . Straight lines, determined by the method of least squares, have been passed through the four points, and the slopes of the lines, constituting the temperature coefficients, are indicated thereon.

The radius of the circle around each observed point is equal to the probable error of the mean of the 10 determinations that point represents. 


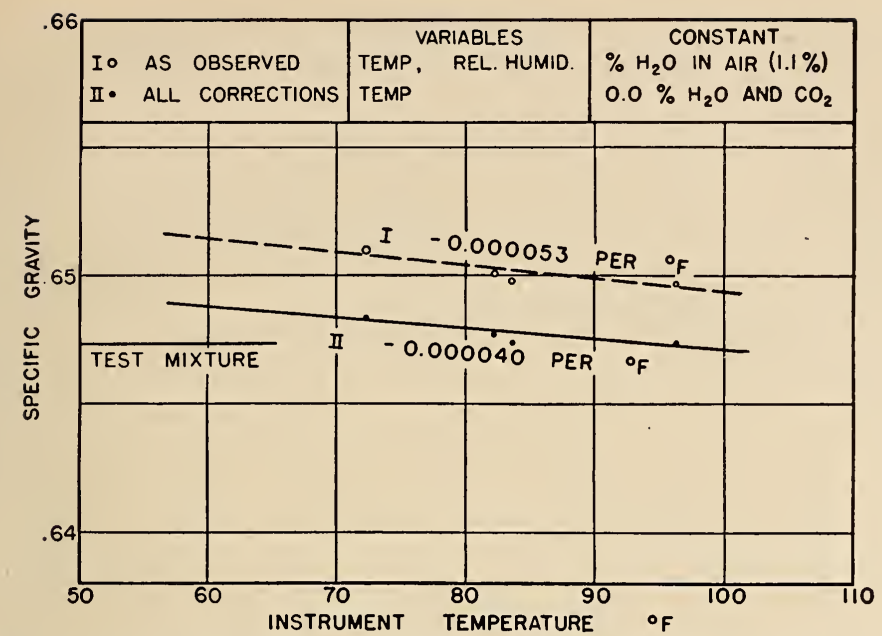

FIGURE 33.-Temperature coefficient of the Metric indicating gravitometer determined with test mixture 1: $O$ as observed at constant percentage of water vapor in the reference air (1.1 percent) and $\bullet$ after the application of all corrections.

It may be noted that the temperature coefficient shown by the corrected values is only three-quarters of that shown by the values as observed, and that the error of the instrument has been greatly decreased by correcting the observed values to the basis of dry reference air and 0.0 percent carbon dioxide.

\section{(f) HUMIDITY COEFFICIENT}

To determine experimentally the effect on the numerical result of variations in the water content of the surrounding air, which is used as a reference, a test consisting of 10 determinations of "specific gravity" was made with the water content of the reference air at 0.52 percent and at 2.29 percent in addition to two at 1.09 percent, which corresponds nearly to 35 -percent relative humidity at $77^{\circ} \mathrm{F}$, the conditions chosen as normal for the purposes of these tests. During these tests at a lower and higher water content than normal, the instrument was maintained at as near the same temperature as possible. The arerage temperature was $82.4^{\circ} \mathrm{F}$, and the temperatures during individual tests deviated from this by $1.1^{\circ} \mathrm{F}$ or less.

The results, as observed and after correction to the basis of dry reference air and for 0.1 percent $\mathrm{CO}_{2}$, have been plotted in figure 34 against the percentage of water vapor in the reference air. Straight lines, determined by the method of least squares, have been passed through the four points, and the slopes of the lines, constituting the humidity (or percentage of water) coefficients, are indicated thereon.

It will be noted that the application of the corrections has slightly more than accounted for the effect of the water shown in the results as observed. However, all the corrected values now fall within 0.001 of the specific gravity of mixture 1. 


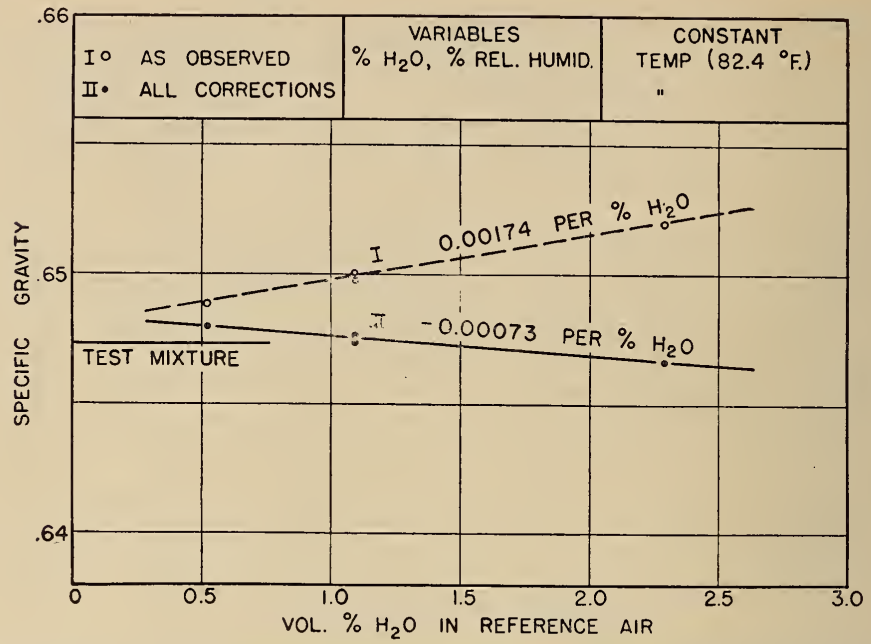

FIGURE 34.-Humidity coefficient of the Metric indicating gravitometer determined at constant temperature $\left(82.4^{\circ} F\right)$ with test mixture 1; $\bigcirc$ as observed, and after the application of all corrections.

As may be seen from a study of figure 34, reference air containing 0.5 percent of water vapor by volume gives an indicated specific gravity that is less by 0.0035 than reference air containing 2.5 percent of water vapor." These variations correspond to a range of variation of the relative humidity of from 13 to 67 percent at $82.4^{\circ} \mathrm{F}$, a variation not unlikely to be encountered.

At a relative humidity of 35 percent and at $77^{\circ} \mathrm{F}$ (chosen as normal conditions) the indicated specific gravity of 0.6500 is higher by 0.0028 than it would be if the reference air were dry.

The magnitude and sign of the errors from this source are, of course, dependent on the specific gravity of the gas being tested.

\section{(g) OTHER SOURCES OF ERROR}

(1) Readings.-The position of the meniscus in the manometers can be estimated to \pm 0.01 in., which would correspond to an uncertainty of \pm 0.001 in the specific gravity, if there were no other sources of error.

As it is necessary in making a determination to set one meniscus to a mark and to read the position of the other as nearly simultaneously as practicable, equal errors of opposite sign are possible, producing an uncertainty of \pm 0.002 . As the test also depends on a preliminary setting with air, which involves the same chance of error in reading, the total error that may be made is again doubled to 0.004 .

Although it is highly desirable that the test manometer be read at the time the reference meniscus is set on the mark, this is impossible because the two manometers are too far apart and the menisci are usually at different levels. Relatively rapid variations in the positions 
of the menisci and the irregularity of the interval between changes add to the uncertainty that the readings of the two manometers correspond to exactly the same speed.

The difficulty just mentioned may appear as a source of constant error, rather than as a random one, in the process of setting the reference marker to the meniscus while the test manometer reads $10.00 \mathrm{in}$. It is difficult to estimate the magnitude of errors of this kind, but it appears possible that they might be larger than 0.004 .

(2) Water Level in Manometers.-As the right-hand manometer is used only as a reference and speed indicator, the water in the reservoir need not be set at zero on the scale with the motor stationary. In the case of the test manometer, however, if the water level is not so adjusted that the meniscus reads zero when the motor is not running, a small error may be introduced. For example, suppose the meniscus read -0.1 in. instead of zero and apparent readings on air and gas were 10.00 and 6.80 , respectively. The specific gravity would be supposed to be 0.680 . The actual pressures would be 10.10 and 6.90 , and the corresponding specific gravity would be 0.683 . The error of -0.003 is the result of an easily noticeable maladjustment of the water level and is not likely to occur unless its possibility is not recognized.

(3) Material Tested.-Errors of several types may arise from uncertainties as to the material being tested, either gas or air.

After setting the speed-reference marker with the test meniscus at 10.00 in., if insufficient time is allowed for the test blower to be purged with gas, or if the pressure indicated by the gage on the gas manifold is not greater than atmospheric, the material tested may be a mixture of gas and air instead of gas, and the indicated specific gravity will be nearer that of air than would be the case if purging was complete.

During a test of gas, purging of the test blower results in a continuous discharge of gas through the purge orifice, and also through the larger orifice in the gas manifold. The discharge through this orifice serves to relieve any excess of pressure at the entrance to the blower and at the same time to prevent the entrance of air. This gas is discharged into the air that surrounds the instrument, a portion of which is drawn into the air blower, which indicates the motor speed. If the air is contaminated with gas, the motor speed will be set faster to bring the meniscus to the mark, and the indicated specific gravity will again be nearer to air than it would be without contamination. Errors from this cause may be minimized by keeping the manifold manometer pressure positive but small and by making sure of good positive ventilation of the instrument.

During a test of air with the motor running on gas or a test of gas with the motor running on air, the pressure inside the motor casing is greater than atmospheric and will tend to cause gas or air to flow along the bearings from the motor case into the blowers. If, and to the extent to which such a flow takes place, contamination of the material in the test blower and the speed-reference blower may be the source of errors, causing the indicated specific gravity to be nearer air than it should be. 
Several suggestions for the improvement of the instrument have been made to the manufacturer.

(1) A more positive means of insuring good ventilation of the instrument case might be provided to minimize contamination of air by gas discharged through purge and manifold orifices. (1.0 percent of water vapor (specific gravity 0.6221 ) in the reference air produces an error of 0.0025 when testing a gas of 0.647 specific gravity. Contamination to the same extent with a gas of specific gravity near 0.622 would have a like effect.)

(2) Unless the pressure of the line from which the motor is driven is quite steady, it is difficult to adjust and hold the motor speed constant long enough to read the test manometer. Perhaps a little more inertia in the form of a flywheel on the motor shaft might help.

(3) It would seem to be possible, and very desirable, to bring the two glass tubes close enough together so that the eye could observe both at once. With an adjustable marker, there is no real need for a scale behind the gage on the speed-indicating blower, and the tube could be placed ailongside the scale of the test blower. There appears to be no simple mechanical way to bring the two menisci to the same level, except when both blowers operate on air. It might be done optically by means of two small plane mirrors mounted on light frames arranged with spring clamps to slide on the reference-gage tube and form a periscope of variable length. The meniscus in the test gage tube could then be read while observing the other meniscus at the marker of the reference gage.

(4) In the case of mixture 9, the reading was obscured by the metal marker on the test gage glass. Markers of transparent plastic might be used to prevent such a difficulty.

(5) The legs of the tripod are hinged independently at their juncture with the head, and there is no bracing between the legs. The weight of the instrument combined with these factors makes initial leveling difficult and sometimes precarious. A somewhat more rigid tripod would be advantageous.

\section{RANAREX SPECIFIC GRAVITY RECORDER NO. A2360 AND PORTABLE SPECIFIC GRAVITY INDICATOR NO. P1284}

\section{(a) DESCRIPTION}

The Ranarex specific gravity recorder (fig. 35) is designed to be hung on a wall or mounted flush on a panel in a permanent location. It is rugged, compact, inclosed in a metal case occupying a space approximately $261 / 2$ by $111 / 2$ by $103 / 4$ in. and weighs about $903 / 4 \mathrm{lb}$. The Ranarex indicator (fig. 36) is portable, rugged, and compact. It is inclosed also in a metal case, occupies a space approximately 9 by 9 by $17 \mathrm{in}$., and weighs about $32 \mathrm{lb}$. Both instruments operate on 110-volt alternating current, but instruments are supplied for other voltages and types of current when desired, including 6- and 12-volt direct (storage battery) current. The charts of alternating-current instruments are driven by Telechron motors; those of direct-current instruments by spring-wound movements. 


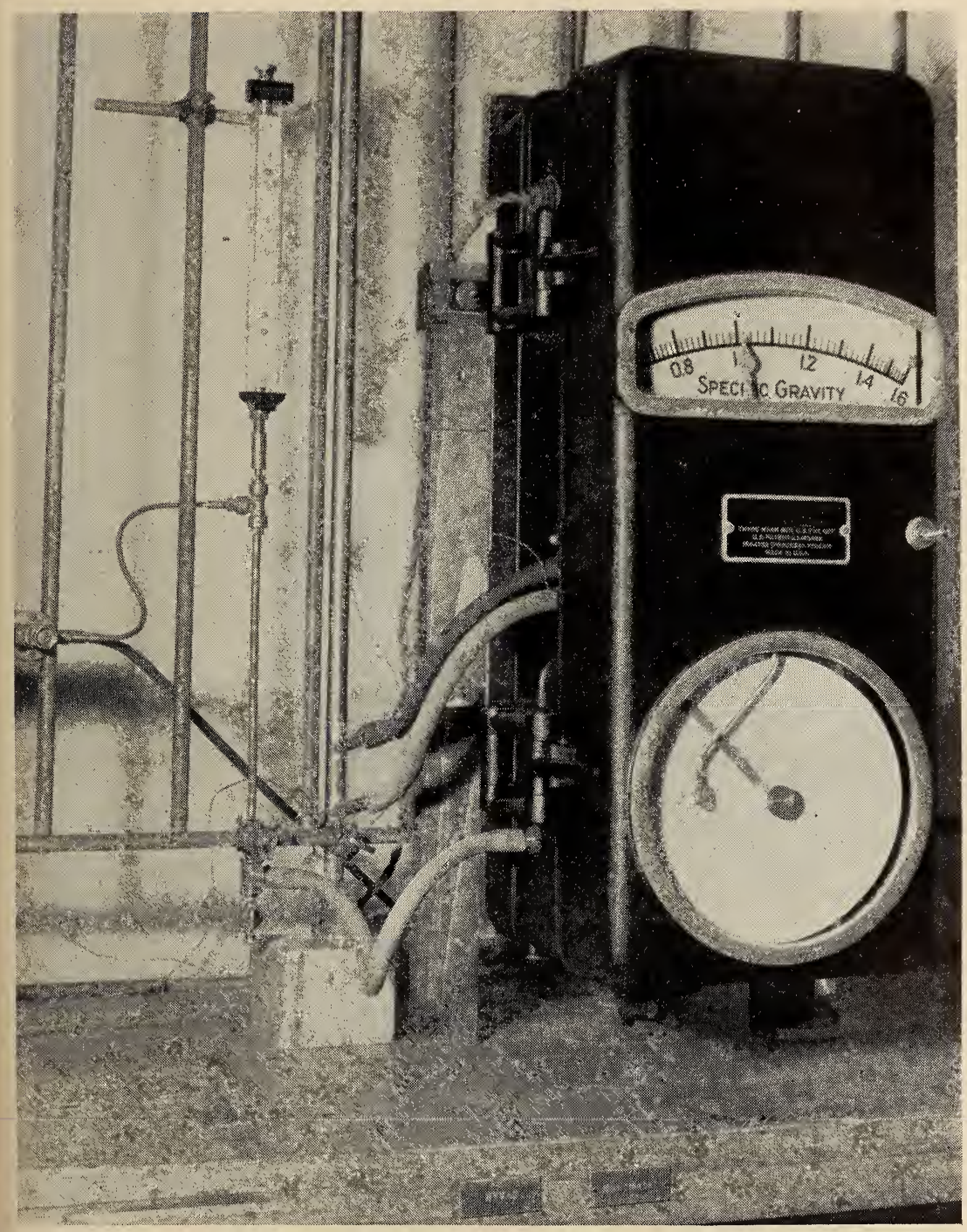

FIGURE 35.-Ranarex specific gravity recorder No. A2360. 
118 Miscellaneous Publications, National Bureau of Standards

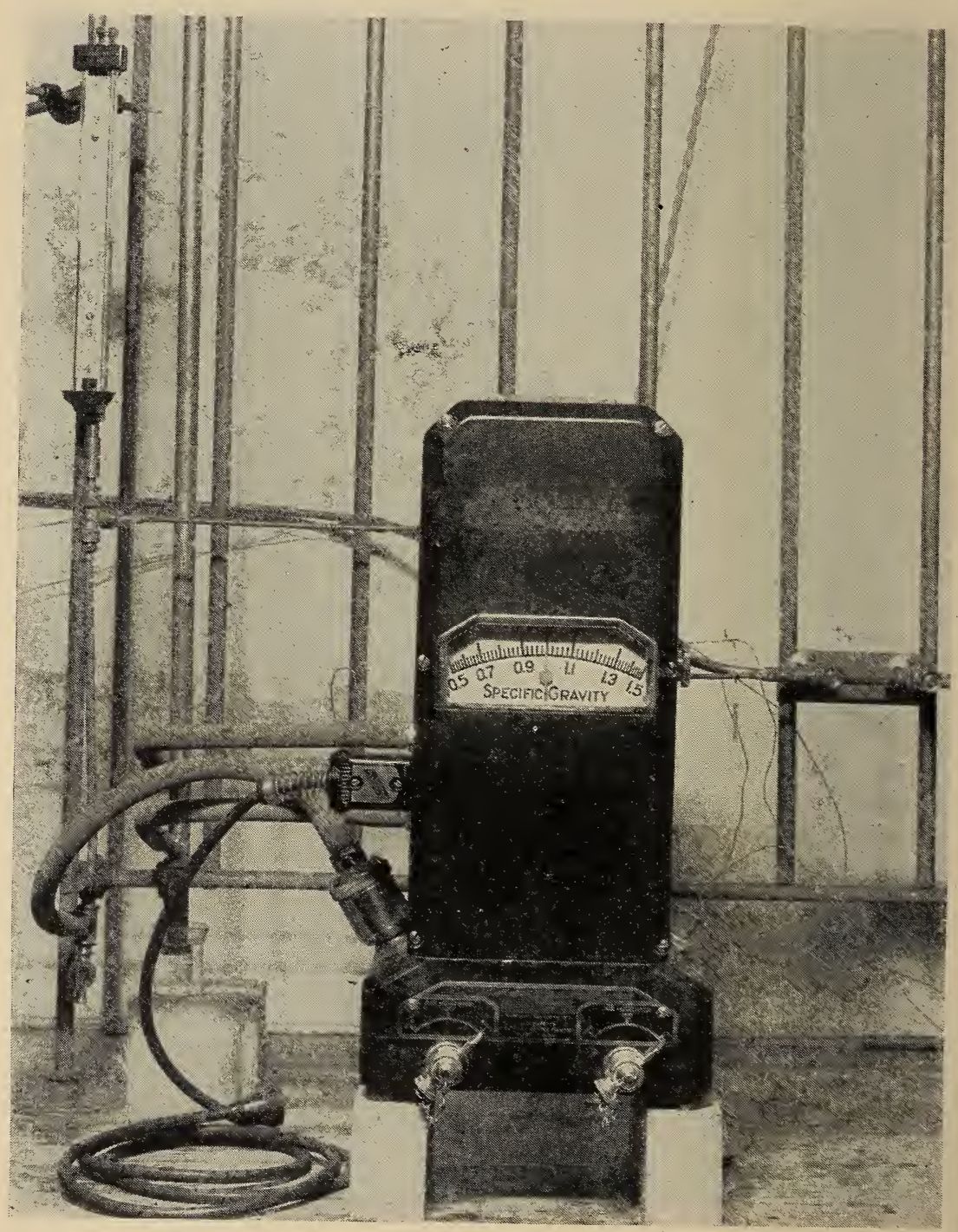

Fial RE :3i-Línarex portable specific gravity indicator No. P1284. 
They are made and sold by the Permutit Co., 330 West $42 \mathrm{~d}$ St., New York, N. Y., and a description and directions for installation and operation are given in booklets supplied with the instruments.

The two instruments are identical in principle. A rotating motion is imparted to the gas by means of a motor-driven fan running in a chamber. The fan drives the gas against the blades of a similar fan (or impulse wheel) located opposite the fan in the same chamber and thus produces a torque on the shaft of that impulse wheel, the torque being assumed to be proportional to the specific gravity of the gas. In order to eliminate the influence of changes in fan speed, temperature, humidity, and atmospheric pressure, a comparing torque is produced by air on another impulse wheel to which a similar motion is imparted by means of a second fan driven by the same motor and a single belt rotating in the opposite direction in a second chamber. The instruments are designed to saturate both gas and air with water vapor before whirling them. "The shafts of the two impulse wheels are coupled together by means of a lever on each and a connecting link. The coupling system prevents complete rotation of the impulse wheels, but the difference between the two opposing torques causes a limited movement of the system that is transmitted to a pointer mounted on the shaft of the impulse wheel operating in gas. The pointer indicates the ratio of the gas torque to air torque, in terms of specific gravity, on a scale reading from 0.2 to 1.0 in the case of the lower range, which was tested with mixtures 1 to 9 , inclusive. The higher range of the recorder extended from 0.6 to 1.6 and was tested with mixtures 10 to 14 , inclusive. The higher range of the indicator was from 0.5 to 1.5 , and test mixture 14 was not used.

In the recorder the pointer shaft is extended on the opposite side of its hub and is fitted with a hinge on which is mounted a pen shaft that records the indication on a chart driven by a Telechron motor. The scales of both instruments and the recorder chart are graduated in intervals of 0.02 , and the reading may be estimated to about \pm 0.002 at midrange and to about \pm 0.004 at the ends, where the divisions are about half as far apart. (The manufacturer states that the instruments may be furnished with a variety of shorter ranges for specific purposes and that the shorter ranges are capable of being calibrated and read more accurately than the longer ones.)

The case of the recorder is hinged in two places so that access may be had to the front and back of the center portion containing the mechanism.

Tests indicated that the reading of the recorder will reach a constant value in about 2 minutes after admitting the gas and return in about 1 minute to a constant reading on air. The indicator is somewhat faster-constant readings are obtained in about 30 seconds after admitting gas or air to the measuring chamber.

The instructions call for operating the instrument with the gas inlet valve adjusted so that the driving fan in sampling gas reduces the gas pressure to between $1 / 4$ in. and $1 / 2$ in. of water below atmospheric pressure as indicated by a manometer at the gas inlet. At $1 / 2$ in. below atmospheric, the instruments sample gas at about $6 \mathrm{cu} \mathrm{ft} / \mathrm{hr}$. At 1/4 in., the rate is about $10 \mathrm{cu} \mathrm{ft} / \mathrm{hr}$. 


\section{(b) MODIFICATIONS FOR TESTING}

Thermocouples were used to measure temperatures. One couple was immersed in the water of the air saturator, inserted through a rubber stopper, which was used to close the water filler opening in place of the screw plug. Another couple was inserted through a puncture in the rubber hose at the outlet of both the gas and air chambers.

\section{(c) METHOD OF OPERATION}

During the testing with 13 gases of known specific gravity (12 only were used with the indicator), the directions for the installation and operation of the instruments have been followed with only a few minor modifications and extensions.

The rates of flow of gas and air through the instruments were such as to give readings on the inlet gages of about minus one-quarter inch or a little more, as recommended by the manufacturer. They were first observed by connecting a laboratory gas meter to the outlet. However, the meter restricts the flow; hence, in the tests of the action of the saturators, the outlet of the meter was connected to vacuum and the suction adjusted to make the flow the same, as indicated by gage reading, as it was before the meter was connected. As first measured, with the meter driven by the pressure from the blowers, the rates of flow were 6 to $10 \mathrm{cu} \mathrm{ft} / \mathrm{hr}$. When the resistence of the meter was eliminated by applying suction, rates of 16.5 and 12.6 $\mathrm{cu} \mathrm{ft}$ per hour were obtained for the recorder and the portable instruments, respectively.

The instruments were tested in a room adjusted to a "normal" temperature of $77^{\circ} \mathrm{F}$, except during the determination of the effect of temperature, when one test was made at a lower and one at a higher temperature than this. Before each test of the instrument with a test gas, the water level in the two saturator reservoirs was adjusted to the full mark, and the instrument was then operated on air for from 3 to 4 hours so that it reached temperature equilibrium. Tests showed that the temperature was still rising slightly at the end of 4 hours. The reading of the recorder on air required slight readjustment to 1.0 during the first part of this period. When the air reading was set to 1.0 before each test with gas, the gas reading rose by 0.002 during the first hour but showed no change with temperature thereafter. No change of reading of the indicator could be detected during the period of heating up.

Each test of each instrument with a test gas involved observing the reading on air for several minutes and, if necessary, setting the pointer to 1.000 by means of the adjusting nut. The instrument was then purged with the gas for approximately 10 minutes, during which time the reading of the pointer was observed and recorded. A record was made of the temperatures of the room, of the water in the air saturator, and of the gas and air at the respective outlets. The barometric pressure, relative humidity, and the time of day were also recorded. This entire process was repeated until 10 determinations had been made. The 10 readings of specific gravity read on the scale of the indicator were averaged for the test of that instrument. In the case of the recorder, the reading on the chart of the 
middle of each recorded line while operating on gas and on air was determined with an ocular-scale microscope. These 10 values of specific gravity after correction of each for the displacement of the preceding air reading from 1.000, were then averaged for the test. The temperatures and other data reported with each test are the averages of the values recorded for the 10 determinations.

After the completion of the testing with gases having specific gravities less than 1.000, the recorder was cleaned, fitted with an indicating mechanism designed for the range from 0.6 to 1.6 , and its calibration checked by a representative of the manufacturer, so that tests could be made with gases having specific gravities greater than 1.000. The indicating instrument was sent to the factory, where it was cleaned and fitted with an indicating mechanism designed for the range from 0.5 to 1.5 , and returned. In all cases the instruments were adjusted to indicate directly the specific gravity of the dry gas with respect to dry air, and consequently no corrections should be required to place the reading on the same basis as that of the test gas if the calibration was carried out at a room temperature of $77^{\circ} \mathrm{F}$. As the temperature of the room during the original factory calibrations is not known, no attempt to compute corrections has been made, and the results are reported as observed so far as the water-vapor contents of the gas and air are concerned.

The data have been treated in the manner described in Section III, 1, under "Treatment of results" in each case. A summary of the numerical results obtained with the recorder is presented in table 12.

TABLE 12.-Specific gravities of the test gases as determined by the Ranarex specific gravity recorder No. A2360 at the "normal" room temperature of $77^{\circ} F$.

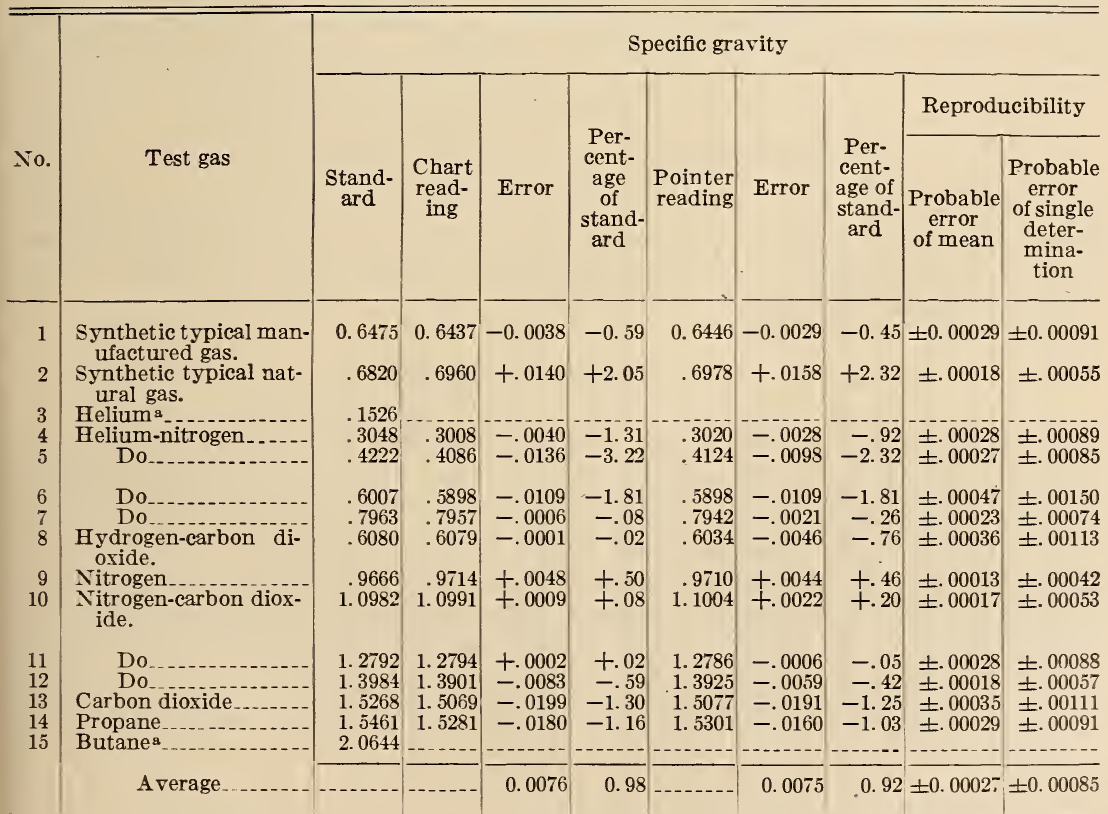

- The range of the instrument was such that the specific gravities of these gases could not be determined. 
The figures given for reproducibility apply only to the readings from the chart. The value of specific gravity and error given for the pointer is in each case the mean of the 10 pointer readings with that test gas. The errors of the instrument, for the chart and for the pointer, have been plotted for each test gas in figure 37.

The readings of the indicating instrument have been treated in the same way. They are recorded in table 13 and plotted in figure 38.

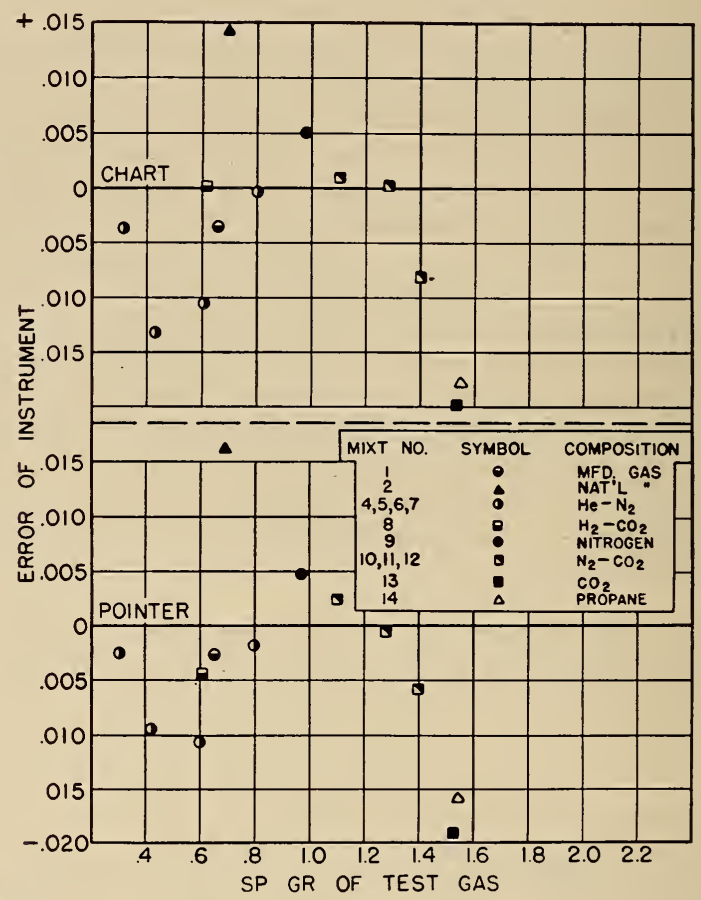

Figure 37.-Errors of the Ranarex specific gravity recorder No. A2360 determined with each test gas as found for the churt and the pointer.

No corrections are applicable.

(d) SOURCES OF ERROR

(1) Temperature Coefficent.-In order to determine whether the indications of the instruments, obtained by following the methods of operation previously described were independent of the temperature of the room, tests, consisting of 10 readings, were made with the same test gas (mixture 1) after adjusting and maintaining the temperature of the room at various constant temperatures. The recorder was tested at $55.2^{\circ}, 67.3^{\circ}$, twice at $91.8^{\circ} \mathrm{F}$, and a check test was made at $77.3^{\circ} \mathrm{F}$ in addition to that at $77.2^{\circ} \mathrm{F}$ previously described. The indicator was tested at $67.4^{\circ}$ and $91.8^{\circ} \mathrm{F}$ in addition to the tests made at $77.2^{\circ} \mathrm{F}$. 


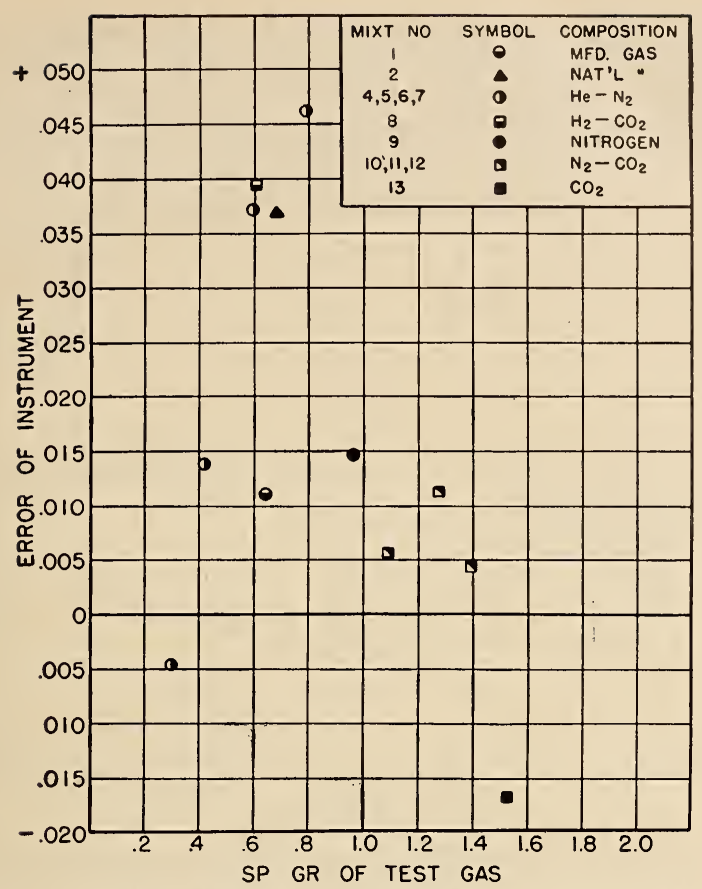

FIGURE 38.-Errors of the Ranarex portable specific gravity indicator No. P1284 determined with each test gas. No corrections are applicable.

TABLE 13.-Specific gravities of the test gases, as determined by the Ranarex portable specific gravity indicator at the "normal" room temperature of $7 \gamma^{\circ} \mathbf{F}$.

\begin{tabular}{|c|c|c|c|c|c|c|c|}
\hline \multirow{3}{*}{ No. } & \multirow{3}{*}{ Test gas } & \multicolumn{6}{|c|}{ Specific gravity } \\
\hline & & \multirow[b]{2}{*}{$\begin{array}{l}\text { Stand- } \\
\text { ard }\end{array}$} & \multirow[b]{2}{*}{$\begin{array}{c}\text { Observed } \\
\text { reading }\end{array}$} & \multirow[b]{2}{*}{ Error } & \multirow[b]{2}{*}{$\begin{array}{l}\text { Percent- } \\
\text { age of } \\
\text { standard }\end{array}$} & \multicolumn{2}{|c|}{ Reproducibility } \\
\hline & & & & & & $\begin{array}{c}\text { Probable } \\
\text { error of } \\
\text { mean }\end{array}$ & $\begin{array}{l}\text { Probable } \\
\text { error of } \\
\text { single de- } \\
\text { termina- } \\
\text { tion }\end{array}$ \\
\hline 1 & Synthetic typical manufactured & 0.6475 & 0.6585 & +0.0110 & +170 & +0.00011 & +0.0003 \\
\hline 2 & Synthetic typical natural gas & .6820 & .7189 & +.0369 & +5.41 & \pm .00057 & 土.00181 \\
\hline 3 & Heliuma ${ }^{a}$ & .1526 & & & & & \\
\hline 4 & Helium-nitrogen & .3048 & .3002 & -.0046 & -1.51 & \pm .00013 & \pm .00043 \\
\hline 5 & 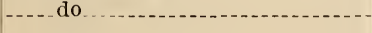 & .4222 & .4360 & +.0138 & +3.27 & \pm .00014 & \pm .00045 \\
\hline 6 & -... do do..... & .6007 & .6379 & +.0372 & +6.20 & \pm .00029 & \pm .00092 \\
\hline 7 & - do do & .7963 & .8425 & +.0462 & +5.80 & \pm .00021 & \pm .00066 \\
\hline 8 & Hydrogen-carbon dioxide & 6080 & .6473 & +.0393 & +6.46 & 土. 00018 & \pm .00056 \\
\hline 9 & Nitrogen & .9666 & .9812 & +.0146 & +1.51 & \pm .00009 & \pm .00028 \\
\hline 10 & Nitrogen-carbon dioxide & 1. 0982 & 1. 1040 & +.0058 & +.53 & \pm .00000 & \pm .00000 \\
\hline 11 & - do do & 1. 2792 & 1. 2905 & +.0113 & +.96 & \pm .00023 & \pm .00073 \\
\hline 12 & do & 1. 3984 & 1. 4028 & +.0044 & +.31 & 土. 00009 & \pm .00028 \\
\hline 13 & Carbon dioxide & 1. 5268 & 1. 5100 & -.0168 & -1.10 & \pm .00000 & \pm .00000 \\
\hline 14 & Propane a & 1. 5461 & . ......... & - & - & - & -.......... \\
\hline \multirow[t]{2}{*}{15} & Butane a & 2. 0644 & - - n- & $-1-2-1$ & - & - & - \\
\hline & A verage & & & 0.0202 & 2.90 & \pm 0.00017 & \pm 0.00054 \\
\hline
\end{tabular}

a The range of the instrument was such that the specific gravities of these gases could not be determined. 
The results from the chart readings of the recorder have been plotted against temperature in figure 39 . The readings of the indicator are plotted in figure 40 . In each case, a straight line, determined by the method of least squares, has been passed through the six points, and the slope of the line constituting the temperature coefficient is

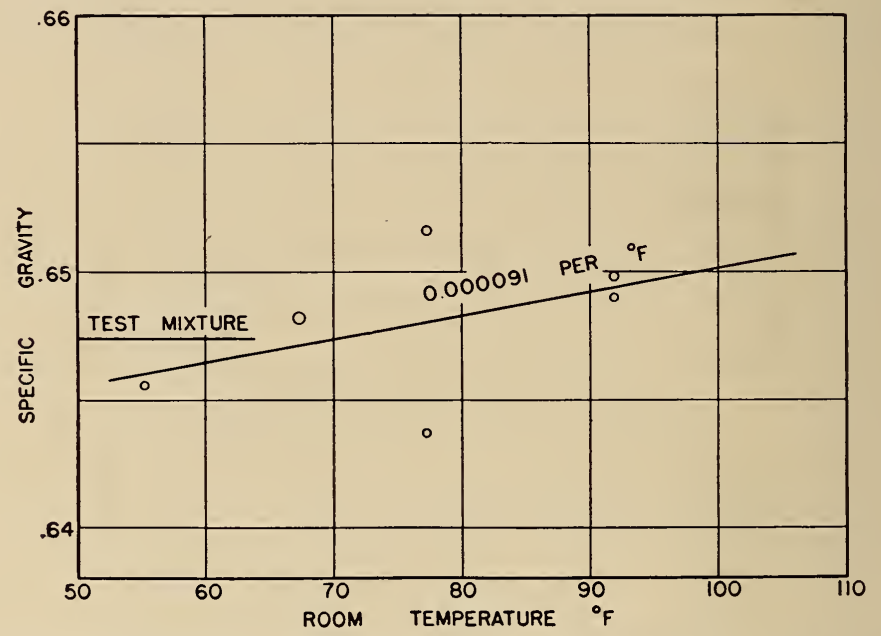

FiguRE 39.-Temperature coefficient of the Ranarex specific gravity. recorder determined with test mixture 1.

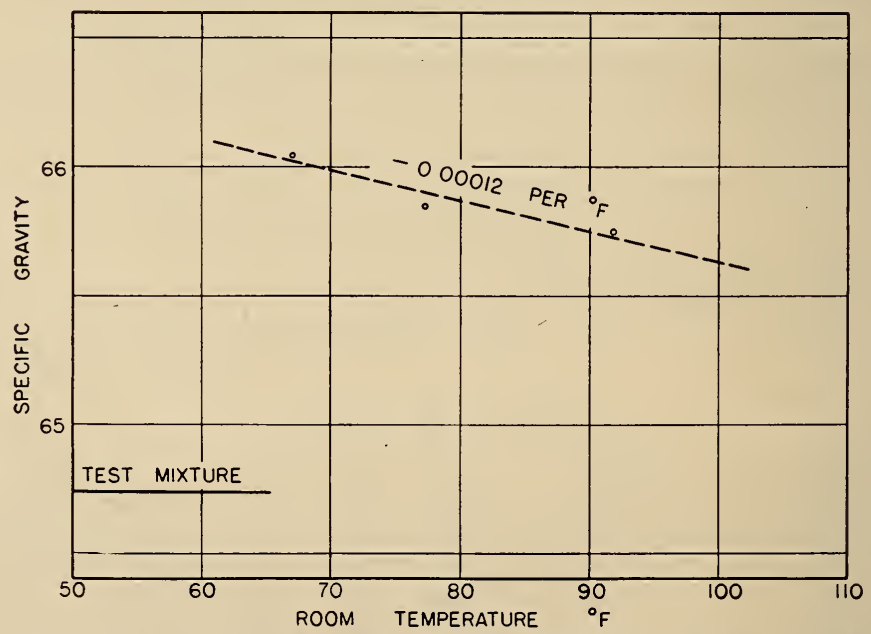

FIGURE 40.-Temperature coefficient of the Ranarex portable specific gravity indicator determined with test mixture 1.

indicated thereon. The radius of the circle around each point is equal to the probable error of the mean of the 10 readings which that point represents.

The heat generated during the operation of the instruments, primarily by the electric motors, raises their temperatures above that of 
the room. The temperature of the water in the air saturator and of the gas and air at their respective outlets was determined after steady conditions had been reached at the various room temperatures employed in the tests. The results have been plotted in figures 41 and 42 . Supplementary tests indicated that the temperature of the water in the gas saturator was practically the same as that in the air saturator in each instrument.

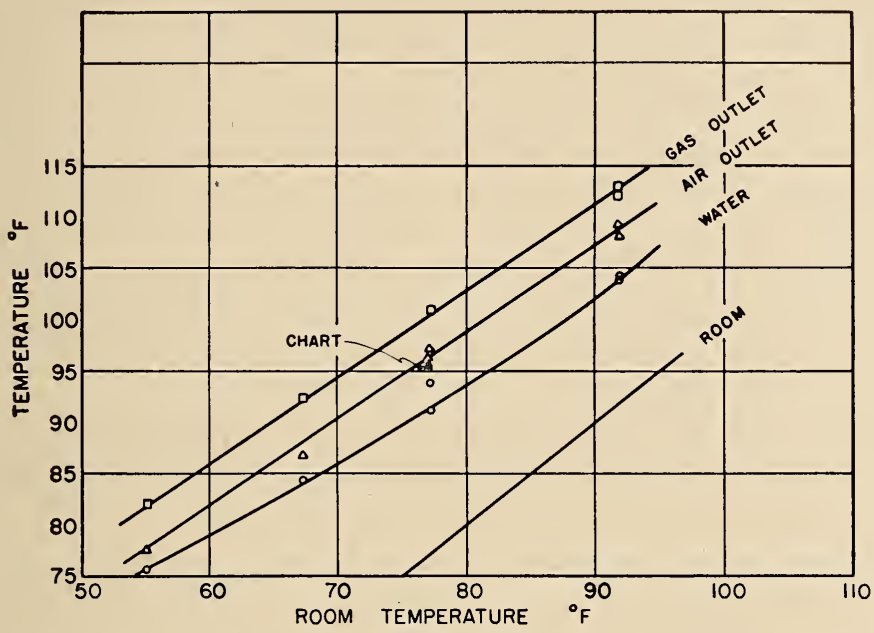

FIGURE 41.-Equilibrium temperatures in the Ranarex specific gravity recorder No. A2360 at the gas outlet, air outlet and of the water in the air saturator as related to the temperature of the room.

The temperature of the chart is indicated by the solid circle.

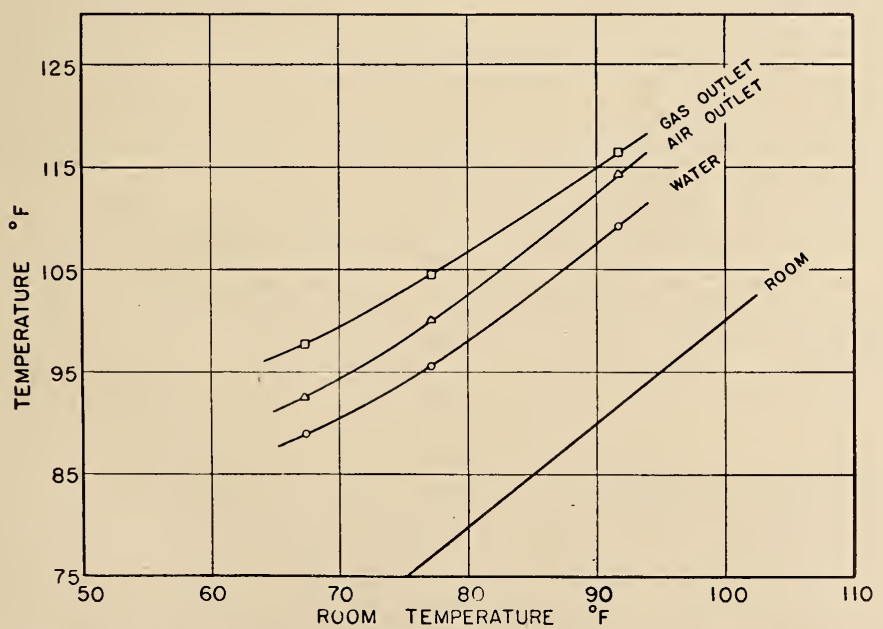

FIGURE 42.-Equilibrium temperatures in the Ranarex portable specific gravity indicator No. P1284 at the gas outlet, air outlet, and of the water in the air saturator, as related to the temperature of the room. 
The manufacturer has stated that the temperature of the room at calibration might have been as low as $70^{\circ}$ or as high as $80^{\circ}$, and was probably about $75^{\circ} \mathrm{F}$, which differs so little from the $77^{\circ}$ chosen as "normal" for these tests that no great error will result from assuming calibration at $77^{\circ}$ for the purpose of the following discussion.

It may be seen from figure 41 that when the room was at $77^{\circ}$, the water in the recording instrument was at $91^{\circ}$, at which temperature its vapor pressure is $37.2 \mathrm{~mm}$. The barometric pressure averaged $750 \mathrm{~mm}$, and if saturated at this temperature, both air and gas would contain 4.96 percent of water vapor. However, tests showed that the instrument sampled gas at the rate of $16.5 \mathrm{cu} \mathrm{ft} / \mathrm{hr}$ as compared to $4.34 \mathrm{cu} \mathrm{ft} / \mathrm{hr}$ for the air, and that the gas was only 65 -percent saturated with water as compared to 96-percent saturation of the air. Consequently, gas containing $0.65 \times 4.96$, or 3.22 percent, of water vapor was compared with air containing $0.96 \times 4.96$, or 4.76 percent. of water vapor, and the adjustment of the instrument made it read the specific gravity of the dry gas compared with dry air.

When the room temperature was changed to $55^{\circ}$, the temperature of the water was $75.7^{\circ} \mathrm{F}$. If we assume the same degrees of saturation as at calibration, the gas contained 1.98 percent of water vapor and the air 2.92 percent. Similarly, at a room temperature of $92^{\circ}$, the water was at $104^{\circ}$ and the gas, if saturated to the same degree as before, would contain 4.8 percent of water vapor and the air 7.08 percent.

When a dry gas of specific gravity 0.6475 with respect to dry air is mixed with 3.22 percent of water vapor of specific gravity 0.6221 , the ratio of its density to that of dry air is 0.6467 . If it is referred to air containing 4.76 percent of water vapor, the ratio is 0.6589 . If the instrument was calibrated with this gas at $77^{\circ}$, it must have been made to read 0.6475 , less than the ratio of the density of the gas to that of the air actually in the instrument by 0.0114 .

When the gas contains 1.98 percent of water vapor and the air contains 2.92 percent, the ratio of density of the wet gas to that of the wet air is 0.6542 , but as the instrument has been set to read 0.0114 less than the ratio of the actual densities, the reading should be $0.6542-0.0114=0.6428$, which is less than the specific gravity of the dry gas referred to dry air by 0.0047 .

When the gas contains 4.8 percent of water vapor and the air contains 7.08 percent, the ratio of density of the wet gas to that of the wet air is 0.6640 . Deducting the 0.0114 introduced in calibration, the instrument should read 0.6526 , which is too high by 0.0051 .

Likewise, it may be seen from figure 41 that when the room was at $77^{\circ}$, the air at its outlet was at $96.3^{\circ}$, and the gas at its outlet was at $100.4^{\circ} \mathrm{F}$. By definition, the specific gravity is the ratio of the densities of gas and air at the same temperature and pressure. Taking into account the direct effects of the differences of temperature at calibration and during the experiments at different temperatures in the same way that vapor pressures were taken into account, it was found that, within the temperature range investigated, the maximum error that can result directly from temperature differences will be of the order of 0.001 , which is a small fraction of the effect caused by differences in water vapor content. 
As has been noted, certain assumptions were made in the computations of the effect of water vapor when the temperature of the room in which the instrument operates is different from that at the time of (alibration. In many cases, perhaps in most, the gas will be partially saturated before reaching the instrument, and a higher degree of saturation during the measurement will result. There was some uncertainty whether in making corrections at one temperature with the aid of data observed at another the corrections should be assumed to be a constant additive or a constant proportional quantity. Actually, it makes little difference which is assumed. The available observations seemed to be in a little better agreement when a constant correction was added. Although the errors computed are not exact, they indicate that the temperature coefficient shown in figure 39 is less than might have been expected and may be accounted for on this basis alone.

The observed data relating to moisture content and temperature of gas and air at the temperature of calibration of the indicating instrument and during subsequent tests were considered in the same way. When the room was at $7^{\circ}$, the water in this instrument was at $95.6^{\circ}$. Gas was sampled at the rate of $12.6 \mathrm{cu} \mathrm{ft} / \mathrm{hr}$; air at 4.1 $\mathrm{cu} \mathrm{ft} / \mathrm{hr}$. The gas was 75 -percent saturated and contained 4.29 percent of water vapor; the air was 98-percent saturated and contained 5.6 percent of water vapor. If these had represented the actual conditions of calibration, the ratio of density of the gas to that of the air in the instrument would have been 0.6604 , but the instrument would have been made to read 0.6475 , the specific gravity of dry gas referred to dry air, less than 0.6604 by 0.0129 . Assuming, as in the case of the other instrument, that the degrees of saturation of gas and air remained unchanged at other temperatures, the actual ratio of density of gas to air in the instrument should have been 0.6580 when the room temperature was $67^{\circ}$ and 0.6671 when room temperature was $91.8^{\circ}$. Subtracting 0.0129 in each case, we should expect readings of 0.6451 and 0.6542 at the two temperatures for the specific gravity of the gas. The first of these figures is less than the specific gravity of dry gas referred to dry air by 0.0024 , and the second is too high by $0.006 \bar{T}$. From the computations made, therefore, we should have expected the reading of specific gravity to increase with an increase of room temperature. The observed effect was a decrease, which has not been accounted for. It may be that the conditions of calibration and of saturation assumed in the discussion did not correspond closely enough to the fact, or that some factor that has not been considered affected the result. When the disagreement between observed and computed temperature effect was discovered, it was too late to supplement the original observations with more complete data.

(2) Pressure Differences.-The operator adjusts the pressure of the gas in the gas chamber, according to the directions supplied by the manufacturer, by opening the valve on the sample line until the gage at the gas inlet shows from one-fourth to one-half in. in negative water pressure. The pressure of the air in the air chamber depends on the suction produced by the impeller and on the size of the orifice 
that limits its flow into the saturator. The difference between the pressure of the gas and that of the air usually will not be more than one-fourth in. of water, which would introduce an error of about 0.06 percent, which is negligible in comparison with other sources of error.

(3) Purging.-If the gas chamber is incompletely purged, the sample may be contaminated by air, which will cause the specific gravity indicated to be nearer 1.00 than it should be. It was found necessary to purge at a higher rate than the directions called for in the case of gases of very low specific gravity. The negative pressure at the gas inlet was reduced to near zero to obtain a minimum steady reading.

(4) Leaks.-Leaks of any sort will cause the indicated specific gravity to be nearer 1.00 than it should be. Directions are given by the manufacturer for testing for leaks, and periodic tests should be made.

A leak, which had escaped attention in the laboratory, was discovered in the indicating instrument by the manufacturer when it was returned for readjustment to the higher range. Larger errors were found with the indicating than the recording instrument; generally, they were in the direction that would have been caused by leakage, and they were greater before than after the readjustment. It is probable that the errors of this instrument resulted, in part at least, from this undiscovered leak. Unfortunately, it was not possible to repeat the tests with the gases of low specific gravity after the leak was discovered, and it is impossible to say definitely how many tests were affected, or to what extent.

Regarding the cause of the leak, the manufacturer stated that it "probably developed during the testing and was probably caused by the fact that the instruments were shipped so long before being tested, during which interval the gaskets lost their resilience."

(5) Calibration.-Any uncertainty as to the specific gravity of the gases with which the instrument is calibrated will cause corresponding errors in the subsequent indications of the instrument.

(6) Viscosity.-In order to determine whether the indication of the instrument was dependent on the viscosity of the gas, two of the test mixtures were prepared with specific gravities as nearly the same as practicable, but with viscosities that differed as much as possible. Mixture 6 consisted of 44.5 percent of helium and 55.5 percent of nitrogen, with a specific gravity of 0.6007 . Mixture 8 consisted of 63.1 percent of hydrogen and 36.9 percent of carbon dioxide, with a specific gravity of 0.6080 . Although the relative viscosities of these mixtures are not known, the viscosities of both helium and nitrogen are relatively high, and those of both hydrogen and carbon dioxide are relatively low.

The numerical results, given in tables 12 and 13 , show that in the recording instrument the error was -0.0109 with mixture 6 and -0.0001 with mixture 8 . With the indicator, the errors were +0.0372 and +0.0393 , respectively. On the face of these results alone it might be concluded that viscosity appreciably affects the recorder but not the indicator. 
However, there are three reasons for doubting the validity of such a conclusion: (1) The mechanisms of the two instruments are so nearly identical that such a difference seems decidedly improbable, (2) the apparent effect on the recorder judged from these two mixtures is in a direction opposite to that anticipated, and (3) there is, in the case of test gases 9 to 13 with the recorder, a consistent trend of error in the direction we should expect from the differences in riscosity which is opposite to that observed with test gases 6 and 8 . Probably the observed difference between the errors in the last two cases was caused by something other than viscosity, in which case the trend in mixtures 9 to 13 may be significant. With one exception, the trend with the same mixtures in the indicator was in the same direction, but in view of the observations with test gases 6 and 8 , the trend cannot be ascribed with certainty to the effect of viscosity.

(7) Readings.-The positions of the pointers and the recording pen on the scales are in continuous fluctuation, the range of which, at the middle of the scale, was initially about 0.015 specific gravity unit in the recorder and about 0.003 in the indicator. After the range of the recorder was changed for tests with the gases of specific gravities greater than 1.0, the fluctuation in the recorder, as shown by the width of the line on the chart was nearly 0.025 . Because of the smaller width of the scale intervals, all the above figures, in terms of scale units, are approximately doubled near the ends of the scale.

Errors in the recorder may also result from lack of correspondence of the readings of pen and pointer. These were adjusted as nearly as possible to correspond at the beginning of the tests, and after changing the range of the instrument. Although the readings did not remain identical, there was no consistent difference that could be ascribed to a mechanical displacement.

The width of the pointer and of the marks on the scale make the estimation of the third decimal difficult.

(8) Effect of Relative Humidity on the Chart.-Tests of the chart paper used on the recorder showed that a change of 80 percent in the relative humidity will change the dimension of the paper by 0.72 percent in the 6-o'clock axis, and by 1.66 percent in the 12 -o'clock axis. Small errors, under 0.001 , for a range of relative humidity from 25 to 55 percent, will result on this account if the instrument is calibrated or used at relative humidities other than that existing when the chart was printed. At other relative humidities the circles on the chart will no longer be exact circles, and their radii will be different.

\section{(e) COMMENTS ON OPERATION AND SUGGESTIONS FOR IMPROVEMENT}

The following suggestions for improvement were made to the manufacturer.

1. The temperature coefficient might be reduced by the use of driers instead of saturators, but resistance to flow through a drier might be a problem as the pressure differences are low, and rapid purging is necessary. If the flow is not through a drier but over its surface (as in the case of the saturator), drying might be as uncertain as is the saturation. There is also the trouble and expense of constantly renewing the drying agent. If complete saturation is desired, a more 
effective saturator might be devised, without introducing much more resistance to flow.

2. It might be an improvement to open up the orifice controlling the entrance of air so that the flow of air would be approximately the same as that of the gas. Although saturation would be less complete, it would be more nearly the same in the two cases.

3. In the indicating instrument, the knob of the zero adjustment gets very hot after several hours of operation, especially if the temperature of the room is high. Although this knob is octagonal in shape, it is smooth and is difficult to turn. A deep knurl might be better than the smooth octagonal shape.

4. In the recorder, the spring bar over the chart, which raises the pen off the paper, should be located far enough from the chart that the paper cannot touch it and smear the record. This was accomplished by bending in the present case.

\section{FISHER DENSIMETER (EXPERIMENTAL MODEL)}

(a) INTRODUCTION

The apparatus called a densimeter by its manufacturer (fig. 43) is of the type also called an effusiometer, but is more commonly referred to as a "Schilling apparatus". The intervals of time required for identical volumes of gas and air to flow through a small orifice are observed, and the square of their ratio is the approximate specific gravity of the gas. The method was developed nearly a century ago by Bunsen and Schilling. It has been studied at the Bureau of Standards by Edwards ${ }^{4}$ and by Buckingham and Edwards ${ }^{5}$ much more completely than has been possible in connection with the present investigation and was found to be inherently incapable of giving very accurate determinations of specific gravities of gases of all compositions. A variety of physical effects are involved, which may, in a given case, lead to compensating errors so that a highly accurate result is obtained. but the same apparatus may not give good measurements with another gas or under slightly changed conditions. The conditions that cause error include changes in the orifice by minute dust particules or condensed films of liquid, usually water, but the most important effects involve thermal changes in the gas stream through expansion, friction, and turbulence, and these are greatly influenced by microscopic variations in the small orifices used.

It was found that the inherent accuracy of the method is improved by increasing the difference of pressure on the two sides of the orifice and by increasing the size of the orifice, but both changes decrease the time required for the efflux of a given volume of gas or air, and the impracticability of accurately measuring short intervals of time becomes the limiting factor in determining specific gravity unless the volume of gas is correspondingly increased.

This fact supplies the answer to a natural question. A knowledge of the specific gravity of gas is useful principally in connection with the measurement of the flow of gas through orifices; then why is not the rate of flow through an orifice the best measure of the property

${ }^{4}$ J. D. Edwards, Effusion method of determining gas density, BS Tech. Pap. T94 (1917).

5 Edgar Buckingham and J. D. Edwards, Effux of gases through small orifices, BS Sci. Pap. 15, $573(1920)$, S359. 
with which we are concerned in metering? The reason is that orifice meters are used almost exclusively for the measurement of very large rates of flow; the orifices are many thousand times the area of those in the effusion apparatus, and they are usually under considerably

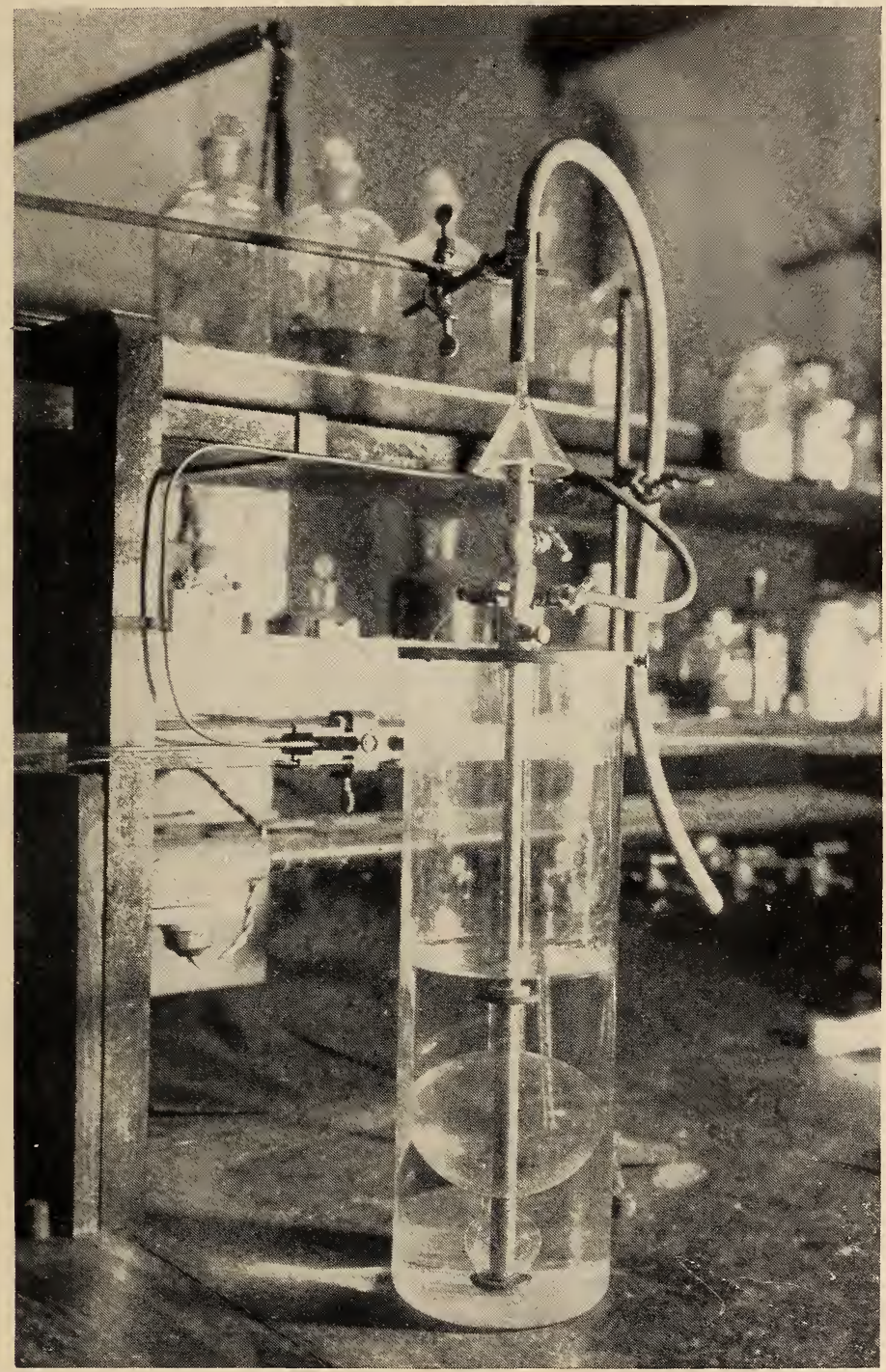

FIGURE 43.-Fisher densimeter (experimental model).

greater pressure. If slightly increasing the size of orifice and the driving pressure in an effusion apparatus decidedly improves the accuracy of determinations of specific gravity. it is evident that the relative rates of flow of different gases through commercial orifice 
meters must correspond much more closely to their true specific gravities than to the erroneous specific gravities deduced from the rate of flow through the tiny orifice of an effusion apparatus.

In comparison with other instruments of its type, the Fisher Densimeter employs unusually large reservoirs and, for a water-sealed apparatus, an unusually high pressure, which certainly contribute to its accuracy. It also incorporates improvements of mechanical construction that add to its ruggedness and convenience. The accuracy of the determinations made with this apparatus have been surprisingly high. In the light of previous experience with instruments of the effusion type, judgment must be reserved as to whether duplication of the equipment (particularly the orifice) and conditions of testing will be practicable to the extent of insuring equally good results with all "densimeters" of this model.

(b) DESCRIPTION

The Fisher densimeter consists of a tall cylindrical Pyrex jar with a flat disk of Bakelite for a cover. The under side is grooved to fit over the rim of the jar, and thumbscrews are set through the edge to clamp against the outside of the glass to hold the cover in place. A metal tube is arranged to slide through a smooth bushing fixed in the center of the Bakelite cover, and passes through a glass globe attached to the lower end of the tube by compression between rubber gaskets at the top and bottom. The upper end of the tube is fitted with a cross to which are connected three Hoke needle valves for controlling air, sample, and flow to the orifice, which is mounted, inclosed in a fitting, above the upper needle valve. Stops are provided to limit the motion of the tube. which is raised to allow water to drain out and air to flow into the reservoir, and lowered to a fixed position to provide a reproducible head of water to expel air or sample through the orifice. The jar is marked to indicate the height of water in it when the reservoir is lowered against the stop and filled with water. Blackened etch marks run entirely around the tubes above and below the reservoir to serve as markers in timing the flow of gas through the orifice. A small accessory reservoir below the lower mark provides space for partial compression of the gas when the filled reserroir is lowered into the water. The water flows in and out of the reservoir through holes around the lower rim of this accessory reservoir. A thumbscrew is provided in the side of the smooth bushing on the cover to hold the movable tube and reservoir at the raised position if desired. Gas flows in and out of the reservoir through a hole in the metal tube placed close enough to the upper rubber gasket so that no gas is trapped when the reservoir and tube fills with water. The portion of metal tube below this hole is drained by a similar hole in the tube below the lower reference mark, and a small hole in the bottom cap. which holds the lower rubber gasket. The glass tubes carrying the reference marks above and below the reservoir are of approximately the same size. and slightly larger than the concentric metal tube, so that the moving water surface passing the mark is about the same size in both cases.

The jar contains about $8 \mathrm{lb}$ of water, which jackets the reservoir 
and serves to minimize fluctuations of temperature and to make any changes in temperature slow and reasonably uniform.

No provision had been made for a thermometer, so a hole was drilled in the cover, through which a thermometer could be inserted between the reservoir and the jar to about the level of the center of the reservoir.

\section{(c) METHOD OF OPERATION}

The directions for the operation of the instrument supplied with it were followed, with various extensions, during the testing with 15 mixtures of known specific gravity.

In purging the instrument in preparation for a determination of effusion time, the reservoir was filled three times, and the determination made after the third filling. The volume of gas in the metal tube not displaced by water was estimated to be about $14 \mathrm{ml}$, which is 2.64 percent of the total estimated volume of $530 \mathrm{ml}$ when filled to the lower mark. The specimen to be measured would contain this proportion of the previous contents if the determination were made without purging. If the determination were made on the second filling, the specimen would still contain 0.07 percent of the original contents, which was not considered negligible for the purposes of these tests. The determinations were made after the third filling when the specimen timed contained only a negligible proportion (0.002 percent) of the original contents.

Before starting the flow, about 30 seconds was allowed for water to drain from the walls of the bulb, and for the gas to become saturated with water vapor. When the flow was started as soon as practicable, about 15 seconds, after all water had drained from the bulb, the effusion time was between 0.2 and 0.3 second shorter than when 1 minute had elapsed after the water had drained out before starting the flow. Longer delay in starting the flow, up to 10 minutes, showed no further increase in effusion time. It was concluded that drainage and saturation were complete, at least as far as any measurable effect on the effusion time is concerned, within 45 seconds after the last water drained out, or 30 seconds after it would have been possible to start the flow.

During the manipulation of the instrument care was taken to avoid ummecessary contact of the hands with the metal parts above the cover, so that the temperature of the water might represent as nearly as possible the temperature of the orifice as well as that of the gas in the glass bulb.

A single determination of specific gravity consisted of three successive determinations of the time of effusion of the air of the laboratory, followed immediately by purging the instrument with the test gas and three successive determinations of the time of effusion, again followed immediately by purging with air and three more determinations of the effusion time of air. The average of each set of three effusion times was computed, and the mean of the averages for air was used with the average for the gas in computing the specific gravity.

Observations of the temperature of the water and of the corrected barometric pressure were made during each determination of effusion 
time. The temperature of the room was automatically controlled. Consequently, changes in temperature were very small, and as the times for air were taken before and after those for the gas, the necessity for any correction for temperature changes during a determination are obviated. In the absence of relatively sudden reversals of direction in barometric changes, corrections for changes in barometric pressure likewise are obviated.

In making a test of the instrument at a given temperature, with a given test mixture, two observers each made a series of five determinations of specific gravity by taking the effusion times of air and gas alternately, finishing with air, and using the effusion times of air obtained before and after each of the five effusion times for gas for the computation of the five values of specific gravity. The 10 values of specific gravity obtained by the two observers were then averaged. The temperature and barometric pressure reported with each test is the average of all the observations of water temperature and of barometric pressure recorded during the test.

In this apparatus both gas and air are saturated with water vapor during the observations. The quantities directly observed are the time, $T_{\mathrm{g}}$, of efflux of gas and the time, $T_{\mathrm{a}}$, of efflux of air. If we let

$$
R=\frac{T^{2}}{T_{a}^{2}}
$$

$R$ is the "observed" ratio of the density of saturated gas to that of saturated air.

The ratio, $R$, is not the specific gravity of the gas, which is the ratio of the density of the gas as sampled (dry, in this case) to the density of dry air. (See sec. I, 2 , for definitions.) The ratio, $R$, can be converted to the specific gravity, $S$, by the use of equation 4 , given in section III, 2 (b), under the heading "adjustment of observations of gas density for humidity and carbon dioxide." The equation is

$$
S=R+\frac{0.622 w(R-1)}{b+h-w}
$$

in which $b$ is the barometric pressure, $h$ is the head of water, and $w$ the vapor pressure of water at the temperature of observation, all in millimeters of mercury.

Substituting the observed value of $R$, the average values of the barometric pressure $(753.6 \mathrm{~mm} \mathrm{Hg})$, the average head of water $(9.4$ $\mathrm{mm} \mathrm{Hg}$ ) and water-vapor pressure under the conditions of observation (24.75 $\mathrm{mm} \mathrm{Hg})$,

$$
\begin{aligned}
& S=0.6542+\frac{0.622 \times 24.75(0.6542-1)}{753.6+9.4-24.75}=0.6542-0.0072 \\
& S=0.6470 .
\end{aligned}
$$

Corrected specific gravity $=0.6470$ Specific gravity of test mixture 1.- $\quad=0.6474$ Error of instrument Error, percentage of standard specific gravity------ $=-0.06$

As the accuracy and reproducibility of the instrument might be expected to differ with different conditions of temperature and with test gases of different specific gravity and different chemical constitution, the data have been treated in the above manner for each of the test gases, and a summary of the results is presented in table 14. 


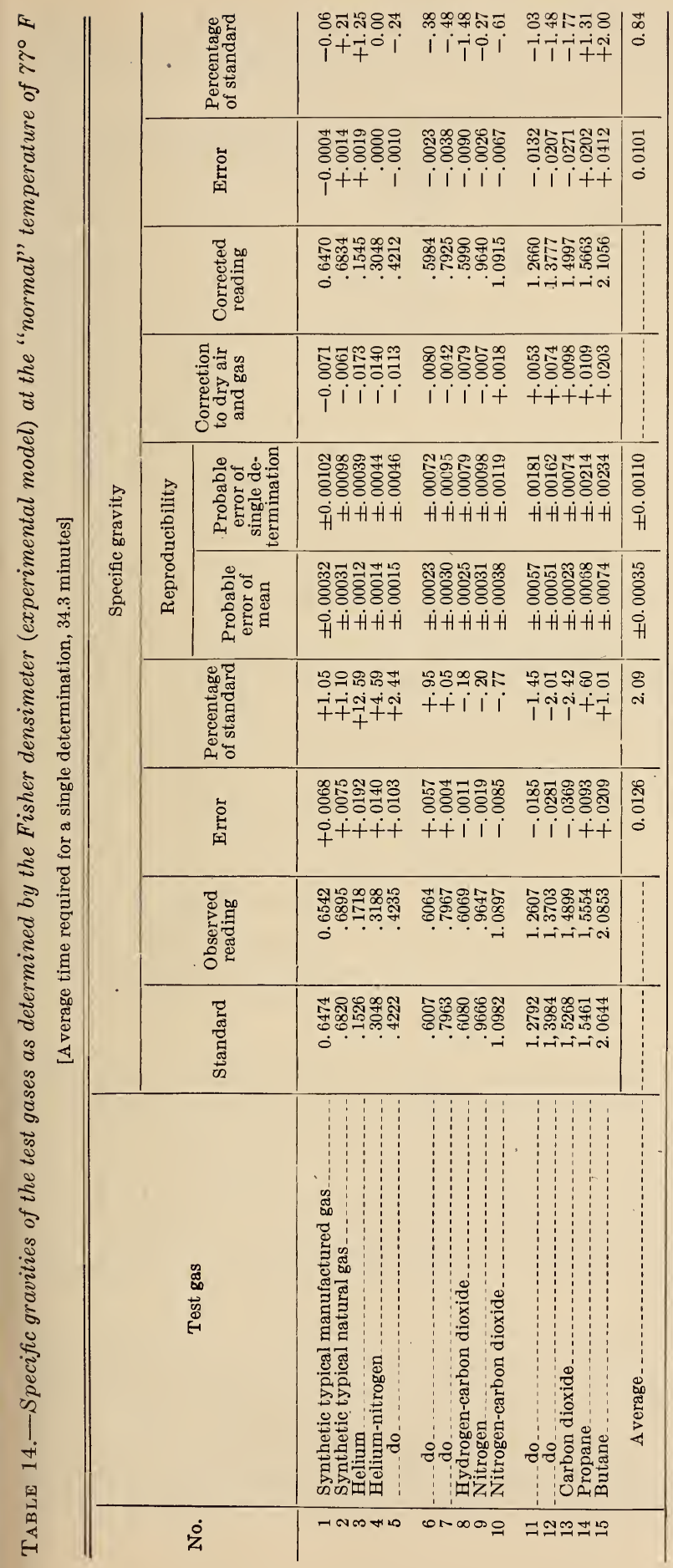


The errors of the instrument, as observed, and after corrections for the water vapor in both gas and air have been applied, are plotted in figure 44 .

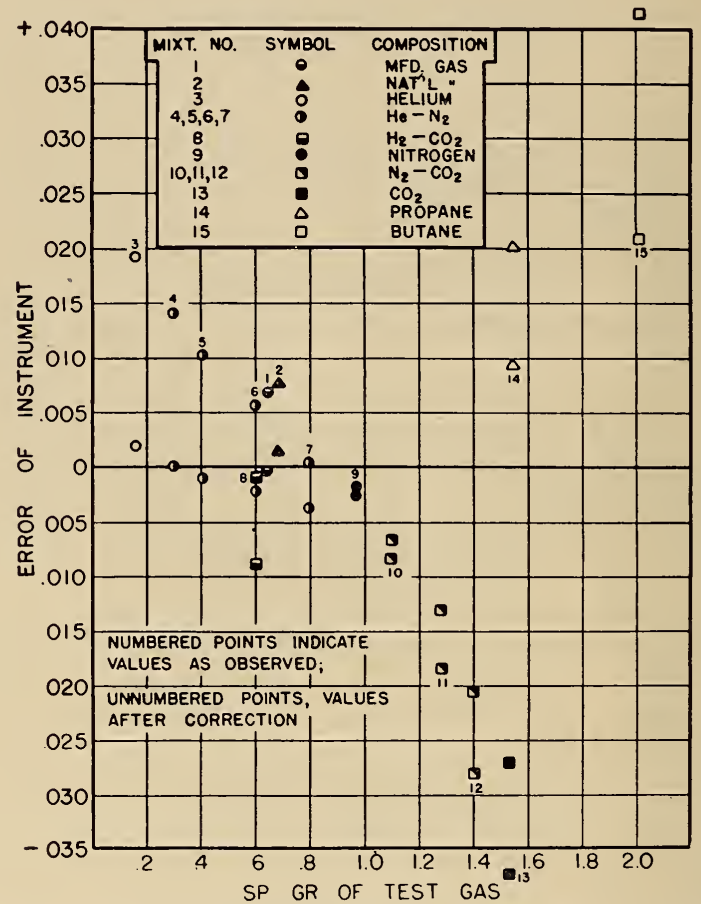

FIGURE 44.-Error of the Fisher densimeter (experimental model) determined with each test gas,

The numbered point of each pair indicates the error as observed, and the unnumbered point the error after the application of corrections for the water vapor in both gas and air.

\section{(d) SOURCES OF ERROR}

The various data that should be recorded during any determination of specific gravity with the effusiometer are all potential sources of error, as errors in the determination of any variable will affect the final result. Variables are barometric pressure, temperature, material tested, effusion time, and the observer, in addition to more constant sources of error, such as the characteristics of the orifice, which may differ from one to another. Figure 45 shows an enlarged outline of the orifice supplied in the densimeter, with a scale from which its size may be estimated.

(1) Temperature Coefficient.-A test consisting of 10 determinations of "specific gravity" by two observer's using the same test mixture, No. 1 , was made at $67.2^{\circ} \mathrm{F}$ and another at $91.8^{\circ} \mathrm{F}$, in addition to that at $78.2^{\circ} \mathrm{F}$ described in the illustration discussed previously. The results, as observed, and after correction to the dry basis, have been plotted against temperature in figure 46. Straight lines, determined by the method of least squares, have been passed through the three 
points, and the slopes of the lines, constituting the temperature coefficients, are indicated thereon.

It will be noted that the correction of the observed results to the basis of dry air and gas have practically eliminated the large temperature coefficient, as well as the error of the instrument, which increased rapidly with increasing temperature.

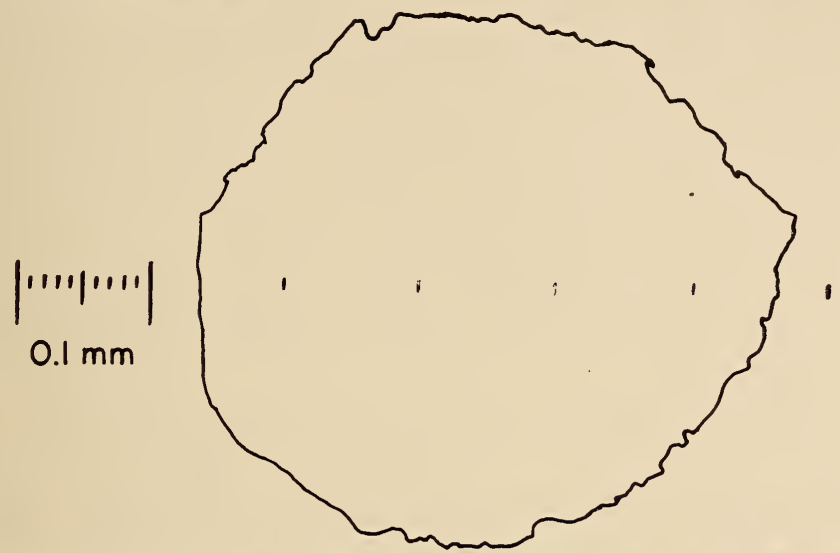

FIGURE 45.-Enlarged outline of the orifice supplied with the Fisher densimeter (experimental model).

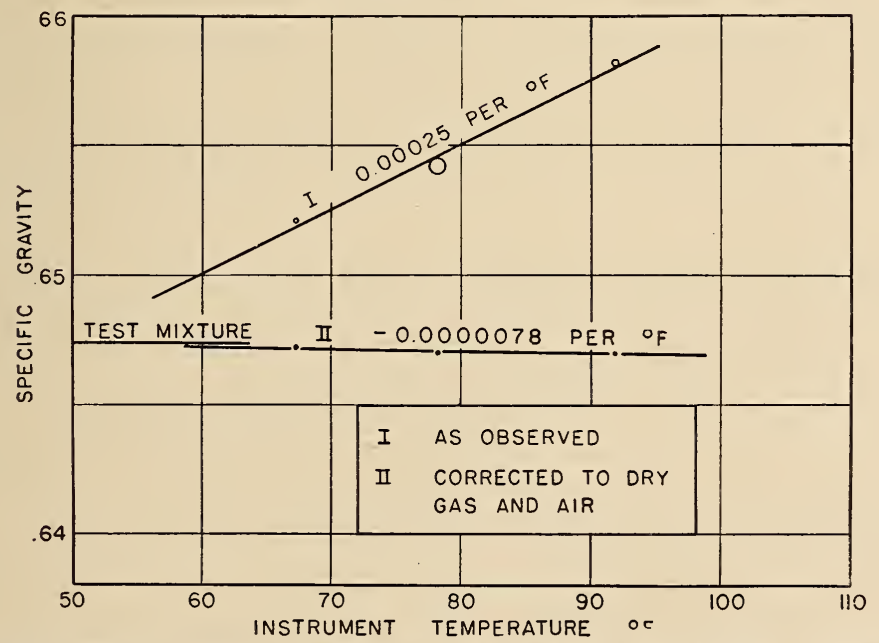

FIGURE 46.-Temperature coefficient of the Fisher densimeter (experimental model) determined with test mixture $1, \bigcirc$ as observed, and - after correction to the dry basis.

The radius of the circle around each observed point is equal to the probable error of the mean of the 10 determinations which that point represents.

(2) Pressure Changes.-Barometric pressure errors will produce small and usually negligible effects on the numerical result. The effects of uniform pressure changes that take place during a determination are 
eliminated by taking an air time before and after the gas time, and using the average. However, a significant error may occur if the change is of the order of $1 \mathrm{~mm}$ and is not uniform ; for example, a case in which the barometric pressure varies as follows: During first air 760, during gas 760, during second air 759, the average barometric pressure during the two air times would differ by $0.5 \mathrm{~mm}$ from the pressure during the gas time. This is $1 / 1520$, or 0.66 percent. The effect of a change of pressure would be to change the density of the reference air by 0.066 percent, and cause a difference in the observed specific gravity of 0.0004 , with a gas of approximately 0.65 specific gravity.

(3) Absolute Pressure.-An equal error in the determination of the barometric pressure has less effect because it affects gas and air almost alike. Specific gravity is independent of pressure, as long as the pressure of gas and air are the same, but the barometric pressure affects the proportion of water vapor and so enters the formula for correcting observed results to the dry basis. An error of $10 \mathrm{~mm}$ in the barometric pressure would affect the correction of a gas of 0.65 specific gravity by only about 0.00007 .

(4) Changes of Water Temperature.-Temperature errors, as in the case of barometric pressure, are significant largely in the form of temperature changes that occur during a determination. The effects on the numerical result of uniform temperature changes are eliminated by timing the air both before and after the gas.

Nonuniform changes of temperature of the water are unlikely in an instrument containing as much water as this one does, except when hot gas is introduced, when excessive time elapses between timing the two air samples, or when the temperature of the room is changing very rapidly. If, as in the case of the barometric change illustrated above, the first air and the gas are timed at the same temperature $\left(77.0^{\circ} \mathrm{F}\right)$ and the second air at a water temperature $1^{\circ} \mathrm{F}$ lower, two effects will result. The average air temperature will be $0.5^{\circ}$ lower than the gas temperature, which will increase the average air density by $0.5 / 460$, or 0.11 percent, which will make the observed specific gravity lower than it should have been by 0.0007 . The average vapor pressure of the water in the air will be lower by $0.38 \mathrm{~mm}$ than its vapor pressure in the gas. The effect of this is in the opposite direction to the first and amounts to 0.0001 . Both effects together would yield a specific gravity, corrected to the dry basis, which would be too low by 0.0006 .

Absolute errors in measuring the water temperature affect only the correction to the dry basis, if the temperature is constant during a complete determination of specific gravity. If the thermometer reads $77.0^{\circ} \mathrm{F}$ when the temperature is actually $76^{\circ} \mathrm{F}$, the vapor pressure of the water in both gas and air will be less than supposed by $0.78 \mathrm{~mm}$. This will make the actual specific gravity greater than supposed by 0.0002 .

As temperature affects the density, and consequently the time of effusion, it is important that the temperature of the orifice be constant, as well as the temperature of the water, during a determination of specific gravity. It is necessary during the raising and lowering of the bulb and the manipulation of the needle valves to handle the metal parts to which the orifice is attached. No attempt has been made in this study to measure the temperature of the orifice, 
but care has been taken to make contact only with the handle of the valves, and to keep the time of contact between the hands and the metal parts as short and as uniform as possible so as to minimize temperature variations from this source.

It is likewise important that the orifice should never be at a lower temperature than the water, and that such adiabatic cooling as takes place as the sample flows through the orifice never reduces the temperature of the sample below the water temperature. Otherwise, condensation of water in the orifice may change the time of effusion in the same way that dust adhering to the orifice would change it.

(5) Material Tested.-An uncertainty as to the material being tested, either air or gas, may arise through incomplete purging of the instrument before effusion. If the apparatus is purged only twice, with either gas or air, 0.07 percent of the previous contents remain. In the case of a gas of 0.6500 specific gravity, the effect of the lack of complete purging is that the air actually used for comparison has a specific gravity of 0.99975 instead of 1.0000 and the gas has an actual specific gravity (referred to pure air as unity) of 1.00025 . When the impure air is compared with the impure gas the observed specific gravity is $0.6 \check{5} 05$.

Another possible source of error in material is the possibility of starting the effusion of the sample before allowing sufficient time to insure equilibrium with water vapor. At $77^{\circ} \mathrm{F}$ and $30 \mathrm{in.} \mathrm{Hg}$ the sample, when saturated, is composed of 3.1 percent water vapor and 96.9 percent of gas or air. Correction of the observed result to the dry basis assumes complete saturation. Tests have indicated that if effusion is started as soon as possible after filling the bulb, the time of effusion is shorter, in the case of air, by 0.2 second than the time obtained if effusion is started 30 seconds or more later. This is the limit to which many stopwatches may be read, and perhaps as close as many observers may be expected to repeat.

It should be noted that with all other instruments tested, except the Ranarex indicator and recorder, the specific gravity obtained is that of the gas as sampled, including the water vapor contained in it. In the "effusiometer" and the Ranarex instruments the gas is saturated or nearly saturated with water vapor before testing and its specific gravity subsequently computed to a dry basis. No information is available as to the specific gravity of the gas containing water, unless an independent determination of its water content is made and a correction applied. This fact did not affect the results of tests in this study, since all test gases were dry to begin with.

The material tested is a source of more serious errors, however, in that physical properties, other than specific gravity, have various effects upon the flow of the gases through the orifice. These properties include compressibility, thermal conductivity, and viscosity, and have been discussed, along with the effects of the individual orifice, by Edwards and Buckingham in Scientific Paper S359 issued by the National Bureau of Standards in 1920. The effects of these variables may be seen by an examination of the errors observed when the present series of 15 gases were tested with the single orifice in the instrument supplied (fig. 44). 
The following comment on errors from solubility and condensation was submitted by the manufacturer of the instrument:

"It would appear that the errors of corrected values up to a specific gravity of 0.9 are very small indeed. However, almost immediately after the specific gravity rises above 0.9 , the errors are progressively greater. I believe we can explain this readily on the basis of solubility or compressibility of the gases. For instance, the greatest negative error is that of pure carbon dioxide, while various concentrations of carbon dioxide in nitrogen produce negative errors of lesser magnitudes. I believe the propane and butane values are in error probably because of compressibility or condensation. It has always been said that diffusion methods should not be used on the more imperfect gases, and I presume we can almost call propane and butane vapors, rather than gases."

(6) Errors in Timing.-Such errors include lack of reproducibility of the reaction time of the observer and various possible defects of the stop watch.

In order to minimize the former, in this study, three successive times have been averaged, before changing from gas to air or the reverse.

The stop watch may be an unsuspected source of error in several ways. The hand may fail to return accurately to zero sometimes, but not always. The watch may run fast on one side of the dial and slow on the other, usually on account of the eccentricity of the dial. The magnitude and sign of the error would thus depend on the portion of the dial at which the hand was stopped. As this is almost always different as between the time for air and for the gas being tested, this will usually cause an error in the specific gravity. The watch may tend to stick or hesitate at some point or points during a revolution, sometimes but not always, and a number of times this happens during the timing of a sample, and its severity will vary and introduce errors. The hand may jump at the start, always or only at times, with its consequent effect on the result.

The effect on the specific gravity of errors in timing are magnified by reason of the fact that the times of effusion of air and gas are squared before taking the ratio. The effect may be illustrated by the following assumed case of two consecutive determinations consisting of three effusion times for air alternating with two for gas, with the temperatures and pressures constant throughout.

\begin{tabular}{|c|c|c|c|c|}
\hline Effusion time for & $\begin{array}{l}\text { Average effu- } \\
\text { sion time for } \\
\text { air }\end{array}$ & Time $^{2}$ for air & Time $^{2}$ for gas & 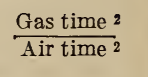 \\
\hline $\begin{array}{l}\text { Air } 120.0-- \\
\text { Gas } 97.0\end{array}$ & 120. 0 & 14400. 0 & 9409. 0 & 0. 6534 \\
\hline $\begin{array}{l}\text { Gas } 97.2 \\
\text { Air } 119.8\end{array}$ & 119. 9 & 14376. 0 & 9447.8 & 6572 \\
\hline
\end{tabular}


Although the two average times for air are within 0.1 second of each other, and the two times for gas are within 0.2 second of each other, the resulting difference in the specific gravity in the two cases is 0.0038 .

Of course, the assumption that the time for air fell 0.2 second and that for gas rose 0.2 second in the second determination accentuated the effect, but the situation is entirely possible with random errors of 0.2 second. Such large differences between the two gas times and between the two arerage times for air may be decreased by substituting for each individual time the average of two or more times taken successively. If the individual times show an extreme variation of 0.2 second, as they well may, the differences between their averages will decrease as the number of observations increases, with a corresponding reduction in the variation of the resulting specific gravity.

Even when three observations are areraged, as was the case in this study, the variations in the resulting specific gravity may be large, as can be seen in the table illustrating the method of treating the data in an earlier portion of this report.

It may be mentioned that the watch used in obtaining the data in this study was compared over a complete revolution with an audible signal from a standard clock and that none of the various defects mentioned above was detected.

(7) Errors of the Observer.-In the absence of defects in the watch, the variations in time observed at constant temperature and pressure with successive determinations on the same material may be ascribed to either or both of tro causes. They may be the result of actual differences in time of effusion between the marks. they may be the result of differences in the reaction time of the observer, or they may be the result of both. In all probability the observer carries the most of the burden.

During three tests, of 10 determinations each, a total of 70 sets of three consecutive effusion times each were involved. The differences between the longest and shortest time in each set are tabulated to show the number of times each difference occurred in the 70 sets.

$\begin{array}{llllllll}\text { Difference (sec) } & 0.0 & 0.1 & 0.2 & 0.3 & 0.4 & 0.5 & \\ \text { Number of times found---- } 14 & 16 & 27 & 6 & 6 & 1 & \text { Total, 70 } \\ \text { Percentage of } 70 \text { - } & 20 & 23 & 38.6 & 8.6 & 8.6 & 1.4 & \end{array}$

It will be noted that 81.6 percent of the 70 differences were 0.2 second or less. The observations were divided equally between two observers.

The observer may decrease the variations in the time observed also by practice, or "education", as illustrated by the same data. In the following table the three tests have been separated to show the decrease in frequency of the larger variations.

\begin{tabular}{|c|c|c|c|c|c|c|c|}
\hline Difference $(\mathrm{sec})_{--}$ & 0.0 & 0.1 & 0.2 & 0.3 & 0.4 & 0.5 & Total \\
\hline No. of times found & $\begin{array}{l}\text { 1st test__-_- } 6 \\
\text { 2nd test_-_- } 6\end{array}$ & $\begin{array}{l}5 \\
5 \\
5\end{array}$ & $\begin{array}{l}3 \\
8\end{array}$ & $\begin{array}{l}4 \\
2\end{array}$ & 5 & 1 & 24 \\
\hline & 3rd test__-__- 2 & 6 & 16 & 0 & 0 & 0 & 24 \\
\hline
\end{tabular}


(e) COMMENTS ON THE OPERATION AND SOME SUGGESTIONS FOR IMPROVEMENT

The following suggestions for the improvement of the Fisher densimeter, which was an experimental model, were transmitted to the manufacturer.

If the instrument is used in a place where changes of temperature of several degrees may occur, or if the screws are turned up too tight, the screws bearing directly on the glass rim may start cracks in the jar. Such a crack occurred in the model tested after the temperature had been changed over a range of about $30 \mathrm{deg} \mathrm{F}$.

(1) An opening in the cover for a thermometer would be desirable since for accurate work it is necessary to know that the temperature is constant or that it is drifting at a uniform rate. In addition it is necessary to know accurately what the temperature is during a determination if the result is to be corrected to a dry basis. For accurate work this correction cannot be neglected, for at $77^{\circ} \mathrm{F}$ the correction to a dry basis changes the specific gravity by approximately 0.007 .

(2) The clearance between the metal tube and the glass tube at the upper mark might be increased sufficiently so that all water will drain out when the reservoir is filled with gas. Water is sometimes held up by capillary attraction unless the gas is admitted very slowly at first. No difference in effusion time has been definitely traced to this variable in the volume of gas, but the presence of the water at this point produces an irregular surface as the water surface passes the upper mark and may decrease the precision of timing the flow.

(3) When filling with air, the water level rises in the overflow bulb to a point so near the mark that disturbance of the water surface incident to opening the needle valve sometimes persists as the water passes the lower mark. Also the time which elapses between opening the needle valve and starting the watch is so short that starting the watch at exactly the right time is made more difficult than is desirable. These difficulties might be more or less completely overcome by lengthening the lower tube between reservoir and overflow bulb about an inch.

(4) A rim of metal or other suitable material might be cemented to the rim of the glass jar, against which the thumb screws holding the cover in place could bear. A groove or depressions might be ground in the glass near the rim to key the cement to the glass if necessary.

(5) Access to the thumbscrew that holds the bulb and tube secure seems somewhat obstructed by the handles of the gas and air needle valves when in the lowered position. 'There is no certainty that anything can be done about this to advantage for it probably would not be wise to lengthen the tube until the valves are above the screw, or to change the orientation of the valves. Locating the thumb screw on the back of the collar by rotating the cover $180^{\circ}$ does not seem to be much less inconvenient.

(6) The metal tube frequently binds in the collar in the cover while being raised. No lubricant would seem desirable on account of contamination of the water, and it is doubtful whether it would be desirable to make the fit any looser. No simple unobjectionable substitute has suggested itself. 
(7) The rubber gasket at the top of the bulb swelled gradually, so that after immersion in water for about 2 years it trapped a bubble, and failed to fill completely with water at the exit hole as gas is displaced. The rubber might be replaced by some plastic material which would not swell after prolonged immersion in water.

\section{DISCUSSION}

\section{INTERPRETATION OF THE RESULTS OF TESTS}

The instruments submitted for test are all supposedly stock instruments as sold to the industry, with the exception of the Fisher densimeter, which is an experimental model. One instrument might be expected to exhibit the same kind of behavior and give the same kind of results as another that is apparently identical. But it is obviously impossible to make two instruments that are exactly alike and that will give identical results under the same conditions.

It should be kept in mind, then, that although one may expect the results of the tests described above to give a valid indication of the performance in general of other instruments of the same kind, the results of the tests apply quantitatively only to the one instrument of each kind on which the tests were performed.

It should also be kept in mind that these tests were performed under optimum conditions, designed to determine the best of which each instrument was capable. Variations in the conditions of use, especially in the field, as well as less care in manipulation on the part of the operator may be expected to result in less accurate and less reproducible measurements than those indicated in this report.

The instruments vary widely in the character of service and functions they are designed to perform. Some are designed for permanent installations, some for portability, some for quick results, some for the highest accuracy, some for recording, some for indicating, and others for measurements from which the results are computed.

It seemed best, in this report, to express no opinions regarding the relative merits of the instruments but to present all the facts observed during their testing so that the characteristics of each may be considered in connection with the individual requirements of a particular user.

It is to be expected that in the long time that has elapsed since the various instruments were manufactured numerous improvements have been made. Some of these may be the result of "suggestions for improvement," which were made to the manufacturers after this investigation and which have been recorded in this paper because some of them are known to have been adopted, whereas others probably indicate the direction, at least, in which improvement is to be anticipated. It is not to be expected that everything suggested will be found practicable or even desirable or that improvements will be limited to them.

Washington, October 9, 1944. 


